\title{
PROJETOS ESTRUTURAIS DE RESERVATÓRIOS PARALELEPIPÉDICOS DE CONCRETO ARMADO MOLDADOS IN LOCO
}

\section{FLÁVIO DE OLIVEIRA COSTA}

Dissertação apresentada à Escola de Engenharia de São Carlos, da Universidade de São Paulo, como parte dos requisitos necessários para a obtenção do Título de "Mestre em Engenharia de Estruturas".

ORIENTADOR: Prof. Dr. Libânio Miranda Pinheiro

São Carlos

1998 
Class.

Cutt.

Tombo

Costa, Flávio de Oliveira

C823p Projetos estruturais de reservatórios paralelepipédicos de concreto armado moldados in loco. / Flávio de Oliveira Costa.--São Carlos, 1998.

Dissertação (Mestrado) - Escola de Engenharia de São Carlos - Universidade de São Paulo, 1998.

Área: Engenharia de Estruturas.

Orientador: Prof. Dr. Libânio Miranda Pinheiro

1. Reservatórios - Projeto estrutural. 2. Concreto armado. 3. Engenharia de estruturas. 4. Otimização estrutural. I. Título. 
Candidato: Engenheiro FLAVIO DE OLIVEIRA COSTA

Dissertação defendida e aprovada em 08-06-1998 pela Comissão Julgadora:

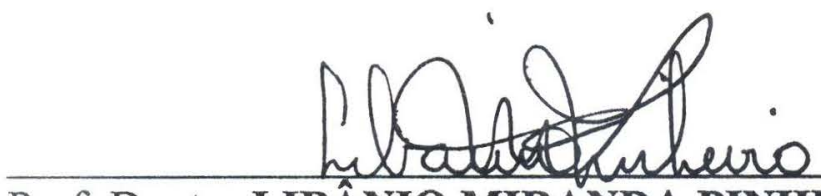

Prof. Doutor LIBÂNIO MIRANDA PINHEIRO (Orientador)

(Escola de Engenharia de São Carlos - Universidade de São Paulo)

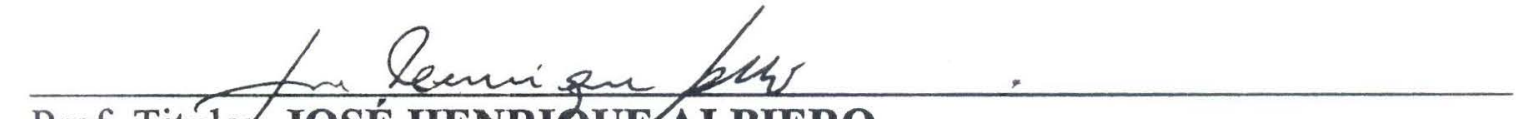

Prof. Titular JOSÉ HENRIQUE ALBIERO

(Escolade Engenharia de São Carlos - Universidade de São Paulo)

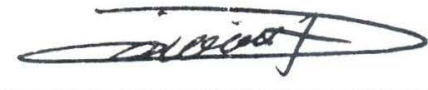

Prof. Associado ROBERTO LUIZ DE ARRUDA BARBATO

(Escola de Engenharia de São Carlos - Universidade de São Paulo)

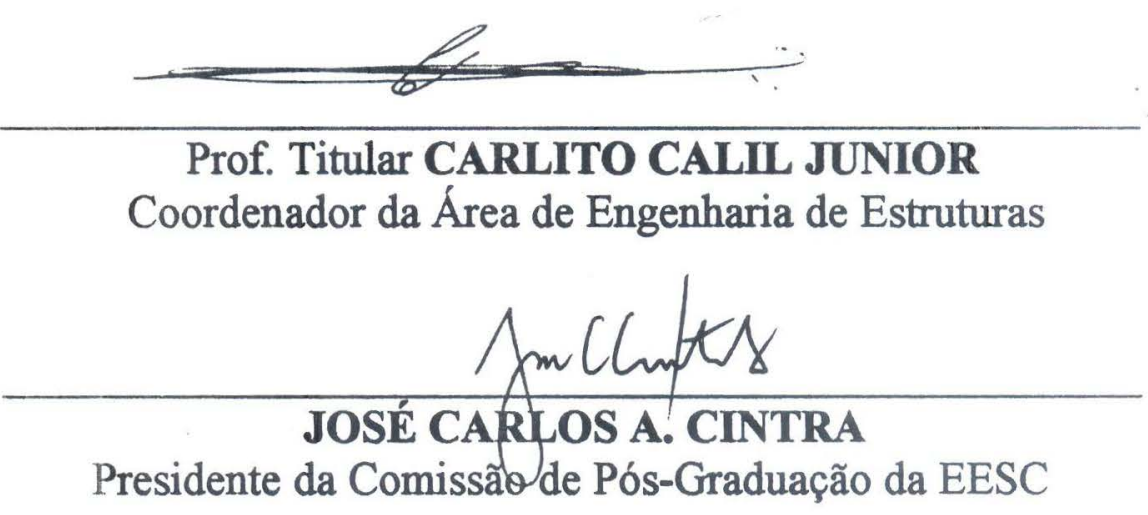


LISTA DE FIGURAS ............................................................... i

LISTA DE TABELAS .............................................................

1. INTRODUÇÃ

2. GENERALIDADES

2.1. DEFINIÇÕES E RESTRIÇÕES.................................................................

2.2. PROPRIEDADE ESPECIAL DOS RESERVATÓRIOS.............................. $\mathbf{0 6}$

2.3. CONCEITOS COMPLEMENTARES DE ÁREAS DA CONSTRUÇÃO CIVIL NECESSÁRIOS À EXECUÇÃO DOS PROJETOS ESTRUTURAIS.........................................................

2.3.1. Mecânica dos Solos..............................................................................

a) Não considerar a coesão dos solos.......................................................... $\quad 08$

b) O solo atuando como ação nas paredes........................................................ 09

c) $O$ solo atuando como elemento resistente..................................................... 11

2.3.2. Materiais e Técnica das Construções........................................................ 21

a) Juntas de concretagens............................................................................ 22

b) Detalhes que favorecem a concretagem...................................................... 25

2.3.3. Aspectos Arquitetônicos...................................................................... $\quad 27$

2.4. CLASSIFICAÇÃO ESTRUTURAL E CONSTRUTIVA DOS RESERVATÓRIOS............................................................................ 35

2.4.1. Quanto à posição das cubas em relação ao solo............................................. 35

a) Reservatórios elevados........................................................................... 35

b) Reservatórios térreos.................................................................................. $\quad 36$ 
2.4.2. Quanto à forma das superfícies médias das cubas

a) Reservatórios em cascas......................................................................... 37

b) Reservatórios piramidais........................................................................ 37

c) Reservatórios prismáticos..................................................................... 38

2.4.3. Quanto ao tipo da fundação................................................................. 39

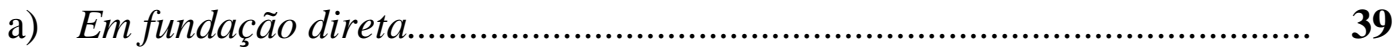

b) Sobre estacas e/ou tubulöes...................................................................... 39

2.4.4. Quanto ao processo construtivo............................................................. 40

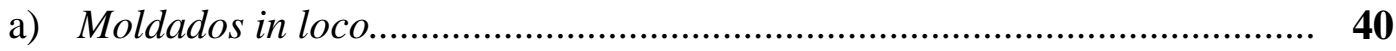

b) Pós-elevados...................................................................................... 41

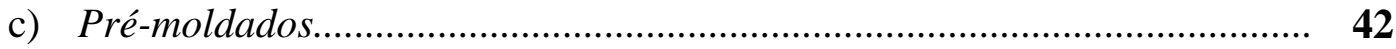

2.4.5. Quanto ao volume de água armazenada.............................................. 44

2.4.6. Resumo das classificações.................................................................. 45

2.4.7. Tipos de reservatórios paralelepipédicos.................................................. 46

3. CONSIDERAÇÕES SOBRE OS PROJETOS DE RESERVATÓRIOS PARALELEPIPÉDICOS ......................... 47

3.1. MATERIAIS, FORMAS E ELEMENTOS ESTRUTURAIS

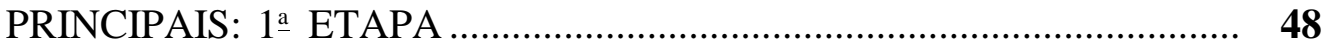

3.2. AÇÕES E CARREGAMENTOS: 2a ETAPA …..................................... 49

3.2.1. Conceitos e definições........................................................................ 49

a) Ações que podem atuar nos reservatórios.................................................. 49

b) Carregamentos dos reservatórios...................................................... $\quad \mathbf{6 0}$

3.2.2. Carregamentos dos reservatórios térreos................................................... $\mathbf{6 1}$

a) Reservatórios achatados sobre estacas, com cobertura............................ $\mathbf{6 1}$

b) Reservatórios achatados sobre estacas, sem cobertura.............................. 62 
c) Reservatórios achatados em fundação direta, com cobertura...................... 63

d) Reservatórios achatados em fundação direta, sem cobertura..................... 64

e) Reservatórios alongados sobre estacas, com cobertura.............................. 64

f) Reservatórios alongados sobre estacas, sem cobertura............................ 67

g) Reservatórios alongados em fundação direta, com cobertura.................... 67

h) Reservatórios alongados sem fundação direta, sem cobertura.................... $\mathbf{6 8}$

i) Reservatórios cúbicos sobre estacas, com cobertura................................. 69

j) Reservatórios cúbicos sobre estacas, sem cobertura.............................. 71

k) Reservatórios cúbicos em fundação direta, com cobertura......................... 72

1) Reservatórios cúbicos em fundação direta, sem cobertura......................... $\mathbf{7 5}$

3.2.3. Carregamentos dos reservatórios elevados............................................. 76

a) Reservatórios elevados com fuste, sobre estacas...................................... 77

b) Reservatórios elevados com fuste, em fundação direta.............................. $\mathbf{7 8}$

c) Reservatórios elevados com pilares, sobre estacas................................... 79

d) Reservatórios elevados com pilares, em fundação direta............................ 80

\subsection{ESQUEMAS ESTÁTICOS DAS CUBAS E CÁLCULO DOS} ESFORÇOS: 3ㄹ ETAPA

3.3.1. Grupos estruturais de um reservatório e trechos estruturais de uma cuba.

3.3.2. Reservatórios achatados

a) Ocorrência.

b) Grupos estruturais.

c) Trechos estruturais das cubas.

d) Esquemas estáticos dos trechos estruturais das cubas.

3.3.3. Reservatórios "alongados",

a) Ocorrência.

b) Grupos estruturais..... 
c) Trechos estruturais das cubas.............................................................. 94

d) Esquemas estáticos dos trechos I e II ..................................................... 94

e) Considerações sobre as torres e as fundações dos reservatórios elevados

3.3.4. Reservatórios "cúbicos" ........................................................................... 95

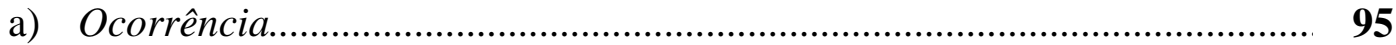

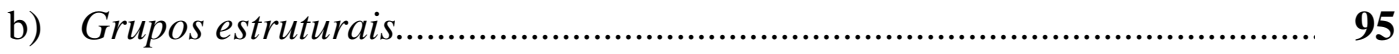

c) Trechos estruturais das cubas................................................................. 96

d) Esquemas estáticos das lajes e paredes, no funcionamento como placas............................................................. 96

3.4. DIMENSIONAMENTO E DETALHAMENTO: 4ㄹ ETAPA …................ 99

3.4.1. Tabelas inéditas A1 a A4 para dimensionamento de lajes e paredes

3.4.2. Fissuração, simplificação e tabela inédita A11 para pré-dimensionamento com fissuração embutida.

3.4.3. Tabelas inéditas A5 a A11 para dimensionamento de seções retangulares: $\mathrm{k}_{6}$, $\rho$ e $\beta_{\mathrm{x}}$, e processo simplificado para dimensionamento à flexo tração.

3.4.4. Tabelas inéditas A12 e A13 para a obtenção dos momentos e normais longitudinais de paredes de comprimento infinito, sob carregamentos hidrostáticos e uniformemente distribuidos.

3.4.5. Critérios para dimensionamento das paredes de cada tipo de reservatório

3.4.6. Detalhes das armações entre uniões de laje e de lajes com paredes

3.4.7. Detalhes típicos dos principais elementos estruturais dos reservatórios........ 
ANEXO A

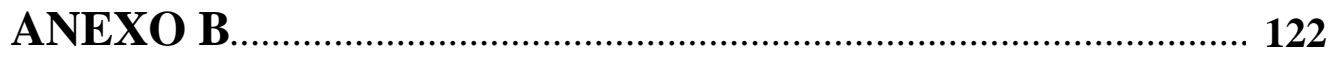

REFERÊNCIAS BIBLIOGRÁFICAS...................................... 161 


\section{LISTA DE FIGURAS}

Figura 2.1 - Diagramas de empuxos em repouso sobre paredes de reservatórios apoiadas pelas lajes.

Figura 2.2 - Relação entre os deslocamentos dos Muros de Arrimo e os respectivos empuxos.

Figura 2.3 - Situação crítica de estabilidade ao escorregamento devido aos empuxos desequilibrados.

Figura 2.4 - Seção transversal de um reservatório térreo em fundação direta a serem consideradas na verificação da sua estabilidade ao escorregamento.

Figura 2.5 - Seção transversal de um reservatório elevado em fundação direta, considerada na verificação da sua estabilidade ao escorregamento.

Figura 2.6 - Tensões normais resistentes atuando sob sapatas de reservatório em fundação direta e respectivas tensões limites para solicitações centradas e excêntricas.

Figura 2.7 - Esquema estático do fundo de uma piscina considerada apoiada em meio elástico (fundação direta) submetido às cargas da parede $\mathrm{N}(\mathrm{tf} / \mathrm{m})$ e $\mathrm{M}(\mathrm{tf} \mathrm{m} / \mathrm{m})$

Figura 2.8 - Trecho contínuo de solo de comprimento a sob a estrutura em estudo e a barra de concreto fictícia equivalente.

Figura 2.9 - Estrutura apoiadas em meio elástico com divisões menores na região das cargas aplicadas

Figura 2.10- Grandes reservatórios em fundação direta.

Figura 2.11- Grandes reservatórios em fundações sobre estacas.

Figura 2.12- Grandes reservatórios com juntas.

Figura 2.13- Pequenos reservatórios.

Figura 2.14- Reservatórios elevados sobre estacas. 
Figura 2.15- Piscinas, tanques e canais............................................................ 20

Figura 2.16- Ábacos para o cálculo dos coeficientes de reação elástica do solo. NAVFAC D4-7 (1971), Mar.

Figura 2.17- Planta e corte de um reservatório em fundação direta, reação com indicação das juntas de concretagem horizontais e verticais.

Figura 2.18- Reservatório de pressão constante: $4 \mathrm{~m}^{3}-$ D.H.S. da Faculdade de Engenharia Civil da Unicamp.

Figura 2.19- Vista inferior lateral do reservatório do D.H.S.

Figura 2.20- Reservatório elevado: $250 \mathrm{~m}^{3}$ - Santa Rita do Passa

Quatro - SP.

Figura 2.21- Cortes A e B do reservatório elevado de Santa Rita do Passa Quatro.

Figura 2.22- Reservatórios elevados sobre fuste, mais comuns.

Figura 2.23- Reservatórios elevados sobre pilares, mais comuns.

Figura 2.24- Seção transversal de um reservatório em fundação direta com cobertura em laje-cogumelo com ábacos.

Figura 2.25- Reservatórios elevados com as cubas em cascas..... 37

Figura 2.26- Cubas tronco-piramidais

Figura 2.27- Exemplos de reservatórios paralelepipédicos.

Figura 2.28- Reservatórios executados mais freqüentemente com fôrmas deslizantes

Figura 2.29- Indicação do uso de fôrmas trepantes em um reservatório.

Figura 2.30- Ilustração do início da suspensão via macacos hidráulicos, posicionados no topo do fuste, da cuba executada no chão com uso de fôrmas tradicionais.

Figura 2.31- Ilustração do início da concretagem do fuste sob a cuba

Figura 2.32- Reservatório cilíndrico executado com elementos pré-fabricados

Figura 2.33- Reservatório elevado e pré-fabricado para a Faculdade de Engenharia Civil da Unicamp. 
Figura 2.34- Caixa d'água de 1000 1, executada em propriedade rural...............

Figura 3.1 - Corte vertical de um trecho de uma parede de um reservatório.

Figura 3.2 - Corte A da figura 3.1 com armadura de retração inferior à mínima.....

Figura 3.3 - Dois tipos de trinca, I e II, possíveis de ocorrer em coberturas de reservatórios, devidas às cargas de uso (água e terra), agravadas com as variações de temperatura

Figura 3.4 - Esquema estático simplificado d região central do reservatório com indicação de todas as ações dos carregamentos 1a, 1b, 2a e 2b

Figura 3.5 - Esforços máximos de uma faixa central unitária de um reservatório achatado sobre estacas, devidos às ações dos pesos próprios permanentes (G), água (A), empuxo de terra $(\mathrm{T})$ e variação da temperatura $( \pm \Delta \mathrm{t})$.

Figura 3.6 - Trecho principal de um reservatório achatado com indicação das ações dos carregamentos $1 \mathrm{a}$ e $1 \mathrm{~b}$ e das suas seções críticas para dimensionamento

Figura 3.7 - Trecho principal de um reservatório achatado com indicação das ações dos carregamentos $2 \mathrm{a}$ e $2 \mathrm{~b}$ e das suas seções críticas para dimensionamento

Figura 3.8 - Trecho principal de um reservatório achatado com indicação das ações do carregamento 3 e das suas seções críticas para dimensionamento

Figura 3.9 - Trecho principal de um reservatório achatado com indicação das ações dos carregamentos $1 \mathrm{a}$ e $1 \mathrm{~b}$ e das suas seções críticas para dimensionamento

Figura 3.10- Trecho principal de um reservatório achatado com indicação das ações dos carregamentos $2 \mathrm{a}$ e $2 \mathrm{~b}$ e das suas seções críticas para dimensionamento

Figura 3.11- Trecho principal de um reservatório alongado, com indicação das ações do carregamento 1 e das suas seções críticas para dimensionamento 
Figura 3.12- Trecho principal de um reservatório alongado, com indicação das ações do carregamento 2 e das suas seções críticas para dimensionamento.

Figura 3.13- Trecho principal de um reservatório alongado com indicação das ações do carregamento 3 e da sua seção crítica para dimensionamento.

Figura 3.14- Indicação de soluções para reservatórios térreos sob a ação de lençol freático

Figura 3.15- Trecho principal de um reservatório alongado com indicação das ações do carregamento 4 da sua seção crítica para dimensionamento

Figura 3.16- Trecho principal de um reservatório alongado com indicação das ações do carregamento 1 e das suas seções críticas para dimensionamento

Figura 3.17- Trecho principal de um reservatório alongado com indicação das ações do carregamento 2 e das suas seções críticas para dimensionamento

Figura 3.18- Seção de um reservatório cúbico, com indicação das ações do carregamento 1 e das suas seções críticas para dimensionamento

Figura 3.19- Seção de um reservatório cúbico, com indicação das ações dos carregamentos $2 \mathrm{a}, 2 \mathrm{~b}$ e $2 \mathrm{c}$ e das suas seções críticas para dimensionamento

Figura 3.20- Seções de um reservatório cúbico, com indicação das ações dos carregamentos $3 a$ e $3 b$ e das suas seções críticas para dimensionamento

Figura 3.21- Trecho principal de um reservatório cúbico com indicações das ações do carregamento 4 e das suas seções críticas para dimensionamento

Figura 3.22- Seção de um reservatório cúbico, com indicação das ações do carregamento 1 e das suas seções críticas para dimensionamento 
Figura 3.23- Seção de um reservatório cúbico, com indicação das ações dos carregamentos $2 \mathrm{a}, 2 \mathrm{~b}$ e $2 \mathrm{c}$ das suas seções críticas para dimensionamento

Figura 3.24- Seção de um reservatório cúbico, com indicação das ações do carregamento 3 e da sua seção crítica para dimensionamento.

Figura 3.25- Seção de um reservatório cúbico, com indicação das ações do carregamento 4 e suas seções críticas para dimensionamento.

Figura 3.26- Carregamentos para a verificação das fundações de reservatórios com fuste, sobre estacas.

Figura 3.27- Carregamentos para a verificação das fundações de reservatórios com fuste, em fundação direta.

Figura 3.28- Carregamentos para a verificação das fundações, para dimensionamento dos pilares e para se obter o coeficiente de instabilidade $\alpha$.

Figura 3.29- Carregamentos para o dimensionamento dos pilares, verificação das fundações e para se obter o coeficiente de instabilidade $\alpha$

Figura 3.30- Indicação dos trechos PRINCIPAIS I e COMPLEMENTARES II de um reservatório.

Figura 3.31- Trecho estrutural principal I de um reservatório achatado, em fundação direta e sem cobertura, com indicações para pré-dimensionamento.

Figura 3.32- Esquema estático do trecho principal de um reservatório achatado, em fundação direta e sem cobertura, para uso de programas de pórticos planos que substituem o solo por molas.....

Figura 3.33- Esquema estático do trecho principal de um reservatório achatado, em fundação direta e sem cobertura, para uso de programas de pórticos planos comuns.

Figura 3.34- Trecho estrutural principal I de um reservatório achatado, em fundação direta e com cobertura, com indicações para pré-dimensionamento. 
Figura 3.35- Esquema estático do trecho principal de um reservatório achatado, em fundação direta e com cobertura, para uso de programas de pórticos planos

Figura 3.36- Indicação dos trechos I e II de um reservatório achatado sem cobertura, carregamentos e esquemas estáticos correspondentes.

Figura 3.37- Carregamentos e esquemas estáticos correspondentes para o cálculo dos momentos longitudinais máximos de paredes infinitas travadas pela cobertura na parte superior.........

Figura 3.38- Esquemas estáticos principais, com e sem cobertura. 93

Figura 3.39- Esquemas estáticos complementares, com e sem cobertura.

Figura 3.40- Esquemas estáticos principais e complementares dos reservatórios elevados

Figura 3.41- Tipos de reservatórios cúbicos usuais

Figura A.1 - Variação dos coeficientes k dos momentos, em função das relações $h / h_{o}$ e $\ell / \ell_{0}$

Figura A.2 - Variação dos coeficientes k dos momentos, em função das relações $h / h_{o}$ e $\ell / \ell_{0}$

Figura A.3 - Variação dos coeficientes k dos momentos, em função das relações $\mathrm{h} / \mathrm{h}_{\mathrm{o}}$ e $\ell / \ell_{\mathrm{o}}$

Figura A.4 - Variação dos coeficientes k dos momentos, em função das relações $h / h_{o}$ e $\ell / \ell_{0}$

Figura B.1 - Casos comuns de estribos dobrados encontrados nas construções

Figura B.2 - Valores normalizados para pontas retas, raios mínimos de dobramentos e trechos circulares.

Figura B.3 - Curvas e raios mínimos de uma dobra de estribos e barras

Figura B.4 - Exemplos de dobras comumente encontradas.

Figura B.5 - Exemplos de três tipos de armaduras como usualmente são desenhadas, com seus tamanhos e seus comprimentos totais 
Figura B.6 - Armadura usada em blocos sobre estacas, em vigas, em

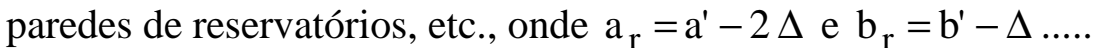

Figura B.7 - Exemplos de alguns gabaritos à esquerda, mais comuns, de trechos de armaduras dobradas.

Figura B.8 - Exemplos de alguns gabaritos à direita mais comuns de trechos de armaduras dobradas.

Figura B.9 - Seqüência das operações para dobrar um estribo, adotada pelos armadores

Figura B.10- Orientação para o dobramento de estribos em uma só operação....

Figura B.11- Dobramento de $90^{\circ}$ de uma barra de $1 \mathrm{~cm}$ de diâmetro, com indicação das posições iniciais e finais da chave durante a operação de dobramento

Figura B.12- Dobramento a $90^{\circ}$, com raio mínimo e em duas etapas de uma barra de $\phi 12,5$

Figura B.13- Exemplo de uma armadura dobrada, desenhada no SISTEMA SIMPLIFICADO.

Figura B.14- Etapas de dobramento de uma curva.

Figura B.15- Armaduras das ligações PAREDES x LAJES de reservatórios......

Figura B.16- Exemplos de representação de estribos e barras no sistema simplificado.

Figura B.17- Valores mínimos de $\mathrm{p}_{\alpha}, \Delta, \mathrm{C}_{\alpha}$ e $\mathrm{g}_{\alpha}$ dos ganchos e das curvas das dobras dos estribos.

Figura B.18- Estribo retangular com ganchos de $45^{\circ}$

Figura B.19- Exemplos de estribos com larguras e alturas, respectivamente, diferentes e a fórmula generalizada para o cálculo do comprimento, $\mathrm{C}$.

Figura B.20- Estribo em forma de "U" com ganchos de $45^{\circ}$ e o cálculo de seu comprimento, C

Figura B.21- Estribo de um só ramo com ganchos de $45^{\circ}$ e o cálculo de seu comprimento, $\mathrm{C}$ 
Figura B.22- Estribo retangular com ganchos de $90^{\circ}$ e o cálculo de seu comprimento, $\mathrm{C}$

Figura B.23- Estribo em forma de "U" com ganchos de $90^{\circ}$ e o cálculo de seu comprimento, $\mathrm{C}$

Figura B.24- Estribo de um só ramo com ganchos de $90^{\circ}$ e o cálculo de seu comprimento, $\mathrm{C}$

Figura B.25- Estribo retangular com ganchos semicirculares e o cálculo de seu comprimento, $\mathrm{C}$

Figura B.26- Estribo em forma de "U" com ganchos semicirculares e o cálculo de seu comprimento, $\mathrm{C}$

Figura B.27- Estribo de um só ramo com ganchos semicirculares e o cálculo de seu comprimento, $\mathrm{C}$

Figura B.28- Estribos de quatro lados com ganchos de $45^{\circ}$ e $90^{\circ}$ e o cálculo de seu comprimento, $\mathrm{C}$

Figura B.29- "Estribo" em forma de "U" sem ganchos e o cálculo de seu comprimento, $\mathrm{C}$

Figura B.30- Valores mínimos de $\mathrm{p}_{\alpha}, \Delta, \mathrm{C}_{\alpha}$ e $\mathrm{g}_{\alpha}$ dos ganchos e das curvas das dobras das barras.

Figura B.31- Barra reta com um gancho de $90^{\circ}$ e o cálculo de seu comprimento, $\mathrm{C}$.

Figura B.32- Barra reta com dois ganchos de $90^{\circ}$ e o cálculo de seu comprimento, $\mathrm{C}$.

Figura B.33- Barra reta com um gancho de $45^{\circ}$ e o cálculo de seu comprimento, $\mathrm{C}$.

Figura B.34- Barra reta com dois ganchos de $45^{\circ}$ e o cálculo de seu comprimento, $\mathrm{C}$.

Figura B.35- Barra reta com um gancho semicircular e o cálculo de seu comprimento, $\mathrm{C}$.

Figura B.36- Barra reta com dois ganchos semicirculares e o cálculo de seu comprimento, $\mathrm{C}$.

Figura B.37- Barra sem gancho com uma dobra e o cálculo de seu comprimento, $\mathrm{C}$ 
Figura B.38- Barra sem gancho com duas dobras e o cálculo de seu comprimento, $\mathrm{C}$

Figura B.39- Barra sem gancho com três dobras e o cálculo de seu comprimento, $\mathrm{C}$

Figura B.40- Barra com uma dobra e um gancho a $45^{\circ}$ e o cálculo de seu comprimento, $\mathrm{C}$

Figura B.41- Barras com duas dobras e dois ganchos a $45^{\circ}$ e o cálculo de seu comprimento, $\mathrm{C}$. 
Tabela 2.1 - Tipos de reservatórios paralelepipédicos em concreto armado......

Tabela 3.1 - Ilustra os aumentos dos principais esforços de um reservatório achatado, devido à variação de temperatura na cobertura

Tabela 3.2 - Valores de $\mathrm{h}_{1}$ da aba, em função do $\phi_{\mathrm{SAP}}$

Tabela A.1 - Momentos máximos: $\mathrm{M}=\frac{\mathrm{k}}{10^{4}} \mathrm{q} \ell^{2}$

Tabela A.2 - Momentos máximos: $\mathrm{M}=\frac{\mathrm{k}}{10^{4}} \mathrm{q} \ell^{2}$

Tabela A.3 - Momentos máximos: $\mathrm{M}=\frac{\mathrm{k}}{10^{4}} \mathrm{q} \ell^{2}$

Tabela A.4 - Momentos máximos: $\mathrm{M}=\frac{\mathrm{k}}{10^{4}} \mathrm{q} \ell^{2}$

Tabela A.5 - Para dimensionamento no Estado Limite Último de seções retangulares à flexão simples com diagrama parábola-retângulo e coeficientes $\gamma_{\mathrm{f}}=\gamma_{\mathrm{c}}=1,4$ e $\gamma_{\mathrm{s}}=1,15$ : C15

Tabela A.6 - Para dimensionamento no Estado Limite Último de seções retangulares à flexão simples com diagrama parábola-retângulo e coeficientes $\gamma_{\mathrm{f}}=\gamma_{\mathrm{c}}=1,4$ e $\gamma_{\mathrm{s}}=1,15$ : C 20

Tabela A.7 - Para dimensionamento no Estado Limite Último de seções retangulares à flexão simples com diagrama parábola-retângulo e coeficientes $\gamma_{\mathrm{f}}=\gamma_{\mathrm{c}}=1,4$ e $\gamma_{\mathrm{s}}=1,15$ : C 25 .

Tabela A.8 - Para dimensionamento no Estado Limite Último de seções retangulares à flexão simples com diagrama parábola-retângulo e coeficientes $\gamma_{\mathrm{f}}=\gamma_{\mathrm{c}}=1,4$ e $\gamma_{\mathrm{s}}=1,15:$ C 30 .

Tabela A.9 - Para dimensionamento no Estado Limite Último de seções retangulares à flexão simples com diagrama parábola-retângulo e coeficientes $\gamma_{\mathrm{c}}=1,4, \gamma_{\mathrm{f}}=1,3$ e $\gamma_{\mathrm{s}}=1,15$ : C25....... 
Tabela A.10- Para dimensionamento no Estado Limite Último de seções retangulares à flexão simples com diagrama parábola-retângulo e coeficientes $\gamma_{\mathrm{c}}=1,4, \gamma_{\mathrm{f}}=1,3$ e $\gamma_{\mathrm{s}}=1,15$ : C 30 .

Tabela A.11- Pré-dimensionamento de Lajes Paredes de Reservatórios

Tabela A.12- Paredes de comprimento infinito, inércia constante com carregamento triangular e retangular, apoiadas na borda superior. Momentos longitudinais no pontos indicados e normais longitudinais apenas nos pontos $1,10,28$ e 37

Tabela A.13- Paredes de comprimento infinito, inércia constante, com carregamento triangular e retangular, livres na borda superior. Momentos longitudinais nos pontos indicados

Tabela B.1 - Bitolas, áreas e pesos. 157

Tabela B.2 - Valores de $\Delta \mathrm{C}(\mathrm{cm})$ para ESTRIBOS 158

Tabela B.3 - Valores de $\Delta \mathrm{C}(\mathrm{cm})$ para ESTRIBOS

Tabela B.4 - Valores de $\mathrm{r}_{\min }, \mathrm{p}_{\alpha}, \mathrm{C}_{\alpha}$ e $\Delta$ (em cm) para DOBRAR ESTRIBOS.

Tabela B.5 - Valores de $\mathrm{r}_{\min }, \mathrm{p}_{\alpha}, \mathrm{C}_{\alpha}$ e $\Delta$ (em cm) para DOBRAR BARRAS 


\section{RESUMO}

COSTA, F. O. (1998). Projetos estruturais de reservatórios paralelepipédicos de concreto armado moldados in loco. 160p. Dissertação (Mestrado) - Escola de Engenharia de São Carlos, Universidade de São Paulo.

Neste trabalho estuda-se a elaboração dos projetos estruturais dos reservatórios paralelepipédicos de concreto armado, comumente usados no armazenamento de água. Para facilitar as análises, estes reservatórios são separados segundo as formas de suas cubas em três grupos, denominados reservatórios achatados, alongados e cúbicos. Para cada um destes grupos apresentam-se indicações para a escolha dos arranjos estruturais bem como dos prováveis carregamentos que devem ser considerados na obtenção dos esforços máximos. Fornecem-se também critérios para a determinação dos esquemas estáticos, correspondentes a cada um destes carregamentos. Incluem-se ainda critérios práticos para o dimensionamento dos elementos estruturais com verificações de fissuração e de estabilidade da estrutura. Sugerem-se, no final, os arranjos das armaduras mais adequados para toda a estrutura e em particular para as ligações das lajes com as paredes e destas entre si.

Palavras Chaves: reservatórios; concreto armado; projeto estrutural. 
COSTA, F. O. (1998). Structural designs of parallelepiped form of reinforced concrete water reservoirs, cast in place. 160p. Dissertação (Mestrado) - Escola de Engenharia de São Carlos, Universidade de São Paulo.

In this work, the elaboration of structural designs of parallelepiped form water reservoirs is studied. To facilitate the analysis, these reservoirs are separated into three groups according to their tank forms, namely flat, elongated and almost cubic. For each one of these groups, adequate structural arrangements are indicated as well as probable loads that must be considered in order to obtain maximum efforts. Criteria are proposed to specify static schemes in agreement with each one of the loads. Practical criteria for the design of structural elements, verification of cracking, and the study of the stability of structures have also been included. Finally, suggestions for the most adequate reinforcement arrangements for the whole structure and in particular for the slab-wall and wall-wall connections.

Key words: reservoirs; tanks; reinforced concrete, structural design 


\section{CAPÍtULOO 1}

\section{INTRODUÇÃO}

O objetivo deste trabalho é a elaboração de um texto básico, que forneça orientação para a execução dos projetos estruturais de todos os tipos de reservatórios paralelepipédicos de concreto armado moldados in loco, para ser utilizado por estudantes e engenheiros calculistas que se iniciam ou tenham alguma experiência nesta área de projetos.

Quando em 1972 o autor foi contratado pelo D.A.E. da cidade de Jundiaí, para a execução do projeto estrutural de um reservatório enterrado com capacidade para $10000 \mathrm{~m}^{3}$ e com altura d'água de 5,80 m, viveu sua primeira experiência como responsável direto pelo projeto de uma grande obra.

Assim, extremamente preocupado com aquela responsabilidade, e não tendo encontrado nenhuma bibliografia específica de apoio, levou alguns meses para definir o arranjo estrutural ideal e só então iniciar os cálculos dos esforços necessários aos dimensionamentos e respectivos detalhes.

Duas foram as dificuldades surgidas e responsáveis por aquela excessiva demora. A primeira foi quanto ao tipo de fundação a ser adotada, tendo em vista ser o solo argiloso e portanto impróprio para a fundação direta. Muitas consultas foram feitas a especialistas em fundações bem como a calculistas experientes, até optar-se pelas 
estacas moldadas in loco, descartando-se as tentadoras sugestões em favor da econômica fundação direta, acompanhadas do frágil argumento de que "a troca de terra por água aliviaria o solo e conseqüentemente não provocaria recalques significativos".

A segunda dificuldade surgiu logo em seguida, na escolha do arranjo estrutural que deveria conduzir as cargas das lajes para as estacas. Graças à experiência do autor em lajes-cogumelo, adquirida nessa mesma época, quando da elaboração do projeto estrutural da Estação Vila Mariana do Metrô de São Paulo, pôde-se encontrar a melhor solução para o fundo daquele reservatório.

Estava lançado assim o uso de lajes-cogumelo em fundos de reservatórios, que nos edifícios eram projetadas, a contragosto dos calculistas, por imposições arquitetônicas.

A partir dessa obra os próprios órgãos governamentais responsáveis pelos reservatórios deste Estado encarregaram-se da divulgação da nova solução.

Entretanto, duas outras inovações, introduzidas pelo autor naquele mesmo projeto, com certeza nunca mais foram utilizadas. Uma delas por ser relativa ao cálculo dos esforços, registrada apenas na memória de cálculo, não fez parte dos desenhos enviados àquela obra. A outra, uma solução muito prática e econômica para a execução das fôrmas dos capitéis troncônicos, transmitida verbalmente aos construtores, também não constou naqueles desenhos.

Em suma, esta história de 25 anos atrás mostra bem as dificuldades e os eventuais prejuízos que se vêm tendo, já há muito tempo, com a falta de uma publicação sobre a elaboração de projetos estruturais de reservatórios de concreto armado.

Muitos trabalhos foram feitos sobre projetos de reservatórios, porém tratando de casos particulares e sem uma discussão global de otimização dos seus elementos e respectivos arranjos.

Outros utilizaram materiais diferentes do concreto armado, como argamassa armada e alvenaria estrutural.

Há também várias publicações sobre reservatórios com paredes protendidas e/ou com formas mais complexas do que a paralelepipedal, onde os esforços são en- 
contrados com um grau maior de dificuldade.

Paradoxalmente, sobre os reservatórios paralelepipédicos de concreto armado, que constituem a grande maioria dos reservatórios executados no país, não se tem qualquer publicação que efetivamente oriente e facilite a elaboração dos seus projetos estruturais.

Assim sendo, este trabalho tem a pretensão de contribuir para cobrir esta lacuna, seguindo as indicações das nossas normas técnicas pertinentes, utilizando os resultados já consagrados de algumas pesquisas que se aplicam também às estruturas dos reservatórios e, principalmente, orientando-se na experiência do autor em projetos de concreto armado.

Ainda, como não se consegue elaborar um bom projeto estrutural sem o conhecimento de conceitos importantes de outras áreas da construção civil, bem como não se deve otimizar um projeto estrutural sem se ter em vista a sua CONSTRUTIBILIDADE e também a FUNCIONALIDADE da obra, serão fornecidas resumidamente algumas informações de MECÂNICA DOS SOLOS, de MATERIAIS e TÉCNICAS DE CONSTRUÇÃO e de ARQUITETURA.

Finalmente, por falta de tempo, não foi possível complementar este trabalho com a apresentação de alguns exemplos. Assim, como sugestão para três trabalhos de iniciação científica ou até mesmo para uma nova dissertação, pode-se executar os projetos estruturais completos de cada um dos seguintes reservatórios paralelepipédicos:

Reservatório achatado, térreo e sobre estacas;

Reservatório cúbico, térreo e em fundação direta;

Reservatório alongado, elevado, com fuste e sobre estacas. 


\section{CAPÍTULO 2}

\section{GENERALIDADES}

\subsection{DEFINIÇÕES E RESTRIÇÕES}

Por reservatórios, do ponto de vista estrutural, denominar-se-ão todas as estruturas que tenham a função de armazenar líquidos.

Em face de sua predominância, e sem nenhuma perda de generalidade, tratarse-ão aqui apenas dos "Reservatórios para Armazenagem de Água" ou, simplificadamente, dos "Reservatórios de Água".

Subdividem-se em dois grandes grupos: o dos Reservatórios Térreos ${ }^{1}$, que descarregam as cargas da água armazenada diretamente para o solo ou para as fundações, e o grupo dos Reservatórios Elevados, que já se utilizam de um elemento ou até mesmo de toda uma estrutura para descarregar o peso da água para as fundações.

Ainda, os reservatórios são compostos das seguintes partes:

\footnotetext{
${ }^{1}$ Embora o termo "enterrado" esteja consagrado pelo uso como denominação dos reservatórios deste grupo, o nome térreo é melhor porque, não particularizando a posição deles em relação ao solo, representa ao mesmo tempo os reservatórios enterrados, semi-enterrados e ao nível do solo, não justificando assim novas classificações em subgrupos só porque apresentam empuxos de terra diferentes. Também é mais fácil de falar e escrever e, até por isto mesmo, não é difícil de se acostumar com essa denominação mais adequada.
} 
CUBA Parte formada por elementos estruturais de superfície com a finalidade principal de armazenar água.

FUNDAÇÕES... ... Elementos estruturais em contato com o solo, com o objetivo de obter deste as reações necessárias ao equilíbrio de toda a estrutura do reservatório. Podem ser:

DIRETAS: $\quad$ Quando o solo da superfície ou próximo dela fornecem, de acordo com as recomendações da Mecânica dos Solos, as reações acima referidas;

Sobre ESTACAS: Quando, não sendo indicada a fundação (ou TUBULÕES) direta acima, é possível obter-se as reações de equilíbrio por meio de estacas ou tubulões.

TORRE Parte estrutural projetada com a finalidade principal de transferir as cargas das cubas e as forças de vento para as fundações. Só existem nos reservatórios elevados e são de dois tipos:

com PILARES: $\quad$ Composta de pilares, em geral, contraventados com vigas;

com FUSTE: $\quad$ Composta de paredes maciças de concreto armado de seção vazada, fechada e constante.

Após estas definições, são considerados aqui como Reservatórios Térreos todos os reservatórios propriamente ditos, piscinas, tanques, canais, etc., cujas cubas estejam em contato direto com o solo da superfície do terreno onde estão construídos.

Já, são elevados os reservatórios construídos sobre as coberturas das residên- 
cias e dos edifícios ${ }^{2}$ bem como todos aqueles cujas cubas são construídas sobre torres.

Finalmente, nesta dissertação tratar-se-á apenas dos reservatórios de concreto armado moldados in loco, cujas cubas tenham formas paralelepipedais, isto é, sejam formadas por lajes e paredes perpendiculares entre si, já conhecidos com o nome de RESERVATÓRIOS PARALELEPIPÉDICOS ${ }^{3}$.

Entretanto, muitas das indicações fornecidas ao longo deste trabalho poderão ser aproveitadas na execução dos projetos de outros reservatórios, mesmo que as suas cubas não tenham esta forma particular.

\subsection{PROPRIEDADES ESPECIAIS DOS RESERVATÓRIOS}

Uma estrutura ou qualquer parte dela não deve atingir os ESTADOS LIMITES de RUÍNA ou de SERVIÇO, ou seja, tem que apresentar ao longo de toda a sua vida útil as seguintes qualidades:

Relativas ao estado limite de ruína:

- Não romper

- Não perder estabilidade

Relativas ao estado limite de serviço:

- Não ter deslocamentos prejudiciais à utilização da obra

- Não ter fissuras prejudiciais ao uso da obra ou à durabilidade da estrutura

Geralmente na elaboração do projeto estrutural de um edifício comum dá-se mais importância às duas propriedades do estado limite de ruína. Em face das dimensões necessárias para não se ter rupturas, normalmente as suas vigas verificam facilmente as propriedades do estado limite de serviço.

2 Estes reservatórios são usualmente denominados de Caixas d'água. Adotaremos para eles bem como para as piscinas, tanques, canais, etc., quando conveniente, o nome genérico de RESERVATÓRIOS, objetivando uma maior simplificação na exposição dos assuntos.

3 Ver citações em HANAI, J.B. (1977). Reservatórios com parede ondulada. Dissertação (Mestrado) - EESC-USP. E também em GUERRIN, A.; LAVAUR, R. Tratado de concreto armado. v.5. 
Já quanto às lajes, dependendo da arrojo do calculista, corre-se o risco de ultrapassar os limites máximos das flechas, porém dificilmente ultrapassar-se-ão os limites máximos fixados para as aberturas de fissuras, tendo em vista os pequenos diâmetros utilizados na armação das mesmas.

Por outro lado, na elaboração dos projetos estruturais de reservatórios, dificilmente haverá problemas com as flechas, em face das maiores dimensões das suas lajes de fundo e das suas paredes. Porém, com certeza, uma ou mais seções de lajes e paredes, com as armaduras encontradas no dimensionamento, não verificarão as aberturas limites das fissuras, pela necessidade de se usar aqui diâmetros maiores do que os diâmetros das lajes do edifício.

Ainda, se estes limites não forem respeitados, certamente haverá problemas com a durabilidade da estrutura e com a principal função dos reservatórios, que é a sua ESTANQUEIDADE.

De nada adianta um reservatório seguro e estável que não armazene água.

Assim, esta qualidade impõe um rigor maior na definição dos arranjos estruturais e dos seus esquemas estáticos para cada um dos carregamentos da cuba, como também se deve ter um rigor maior na execução da sua concretagem e na execução das suas respectivas juntas de concretagens.

Os arranjos estruturais são tomados em função de vários fatores, tais como dimensões dos reservatórios, tipos de fundação, valor da obra (durabilidade), função social, função estética, sistema construtivo etc., ou seja, requer uma experiência profissional mais ampla nos vários aspectos técnicos: arquitetônico, estrutural, hidráulico e construtivo.

Também, os esquemas estáticos adotados no cálculo dos esforços de um carregamento devem ser os mais reais possíveis, em todas as suas regiões. Isto quase sempre leva a se utilizarem dois ou mais esquemas estáticos, para um mesmo carregamento . 


\subsection{CONCEITOS COMPLEMENTARES DE ÁREAS DA CONS- TRUÇÃO CIVIL NECESSÁRIOS À EXECUÇÃO DOS PRO- JETOS ESTRUTURAIS}

À exceção de pequenos reservatórios, um engenheiro projetista de estruturas ou um CALCULISTA, como simplificadamente são chamados estes profissionais no ramo da construção civil, não podem elaborar um bom projeto estrutural de um reservatório sem os conhecimentos básicos de MECÂNICA dos SOLOS, de MATERIAIS e TÉCNICAS DE CONSTRUÇÃO e, mais nos casos de reservatórios elevados, de ARQUITETURA.

A seguir apresentar-se-á para cada uma destas áreas, critérios para os principais conceitos que normalmente são utilizados no projeto estrutural e também para aqueles que não são, mas que deveriam ser utilizados pelos calculistas na elaboração dos seus projetos.

Também serão vistos alguns conceitos de arquitetura que, embora não tenham ligações diretas com os projetos estruturais, devam ser do conhecimento dos calculistas e assim poderem alertar os responsáveis pela obra para eventuais defeitos funcionais.

\subsubsection{Mecânica dos Solos}

Serão abordados alguns aspectos como: não considerar a coesão dos solos, o solo atuando como ação nas paredes e o solo atuando como elemento resistente.

\section{a) Não considerar a coesão dos solos}

Em primeiro lugar, salvo situações muito especiais e devidamente justificadas por especialistas em Mecânica dos Solos, não se deve considerar nenhuma ajuda da coesão do solo, ou seja, adotar sempre $\mathrm{c}=0$.

As justificativas desta hipótese são as seguintes: para argilas muito coesivas, onde se podem ter as melhores colaborações da coesão, a possibilidade real dos taludes serem inundados por ruptura das tubulações neles existentes, e até mesmo por 
vazamentos do próprio reservatório, inviabiliza quaisquer considerações desta ajuda, uma vez que pelo alto grau de colapsibilidade destes solos, as coesões nestes casos caem a zero! Para solos não colapsíveis, a colaboração da coesão já não vale a pena. Portanto, $\mathrm{c}=0$ é a hipótese indicada para todos os solos.

\section{b) O solo atuando como ação nas paredes}

A consideração do solo atuando como ação nas paredes é feita através das aplicações dos seus diagramas de empuxo, de acordo com a teoria clássica da Mecânica dos Solos.

\section{$\underline{\text { Paredes de reservatórios com lajes de cobertura }}$}

Para estes reservatórios adotam-se os diagramas de empuxo em repouso, uma vez que, devido às lajes da cobertura, as paredes têm esquemas estáticos com rigidez suficiente para não possibilitar a mobilização do empuxo ativo do solo.

Estes diagramas são facilmente obtidos com o Coeficiente de Empuxo em repouso dado por $\mathrm{k}_{\mathrm{o}}=1-\operatorname{sen} \phi$, onde $\phi$ é o ângulo de atrito interno do solo. Assim, pela teoria clássica dos empuxos tem-se , para um terrapleno horizontal (Figura 2.1):

$$
\mathrm{p}_{1}=\mathrm{k}_{\mathrm{o}}\left(\mathrm{q}+\gamma_{\mathrm{s}} \mathrm{H}_{1}\right) \quad \text { e } \quad \mathrm{p}_{2}=\mathrm{k}_{\mathrm{o}}\left(\mathrm{q}+\gamma_{\mathrm{s}} \mathrm{H}_{2}\right)
$$

onde :

$\mathrm{q}=$ sobrecarga na superfície do terrapleno $\left(\mathrm{tf} / \mathrm{m}^{2}\right)$;

$\gamma_{\mathrm{s}}=$ peso específico aparente do solo $\left(\mathrm{tf} / \mathrm{m}^{3}\right)$;

$\mathrm{H}_{1}=$ altura de terra acima do apoio superior da parede $(\mathrm{m})$;

$\mathrm{H}_{2}=$ altura de terra acima do apoio inferior da parede $(\mathrm{m})$;

$\mathrm{p}_{1}=$ pressão no apoio superior da parede ou no nível do solo $\left(\mathrm{tf} / \mathrm{m}^{2}\right)$;

$\mathrm{p}_{2}=$ pressão no apoio inferior da parede $\left(\mathrm{tf} / \mathrm{m}^{2}\right)$. 

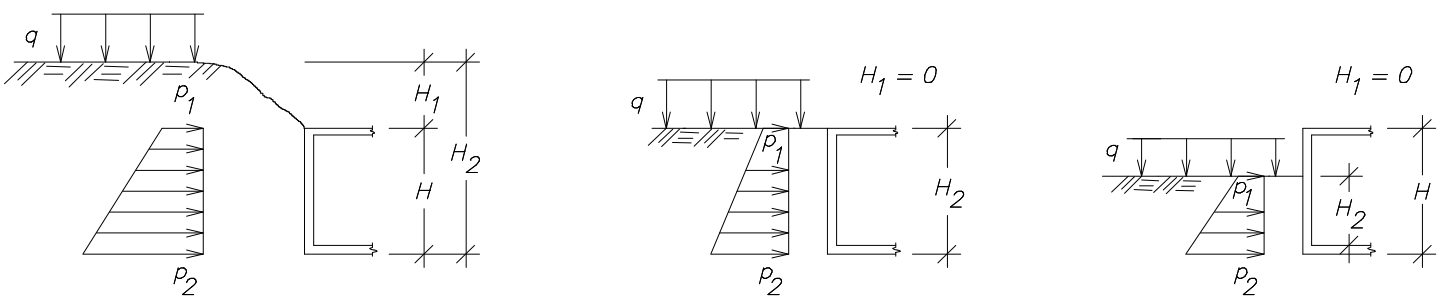

Figura 2.1 - Diagramas de empuxos em repouso sobre paredes de reservatórios apoiadas pelas lajes.

\section{$\underline{\text { Paredes de reservatórios sem lajes de cobertura }}$}

Estes reservatórios em geral apresentam paredes com comprimentos bem maiores do que as alturas. É o caso das piscinas, tanques e canais. Nos cantos ou nas extremidades, quando houver, as paredes absorvem os empuxos de terra com um esquema estático ainda bastante rígido, uma vez que elas trabalham nas duas direções. Os deslocamentos encontrados são insuficientes para se poder considerar, com certeza, a mobilização dos empuxos ativos.

Já nos trechos centrais as paredes funcionam com um esquema estático bem mais flexível (parede em balanço) e com maiores chances de mobilizar os empuxos ativos.

Entretanto, calculando os deslocamentos máximos nestes trechos mais flexíveis, com as dimensões e resistências usuais do concreto armado, encontram-se valores em torno de $\frac{\mathrm{H}}{1100}$.

Como para a mobilização total do empuxo ativo, de acordo com os conhecidos ensaios da Mecânica dos Solos, são necessários deslocamentos do terrapleno em torno de $\frac{\mathrm{H}}{2500}$ a $\frac{\mathrm{H}}{400}$, e considerando a pior hipótese $\left(\frac{\mathrm{H}}{400}\right)$, percebe-se a pouca chance que se tem de utilizar os empuxos ativos (Figura 2.2).

Conclui-se, então, que também para as paredes sem apoio superior e longe dos cantos deve-se adotar o empuxo em repouso. 


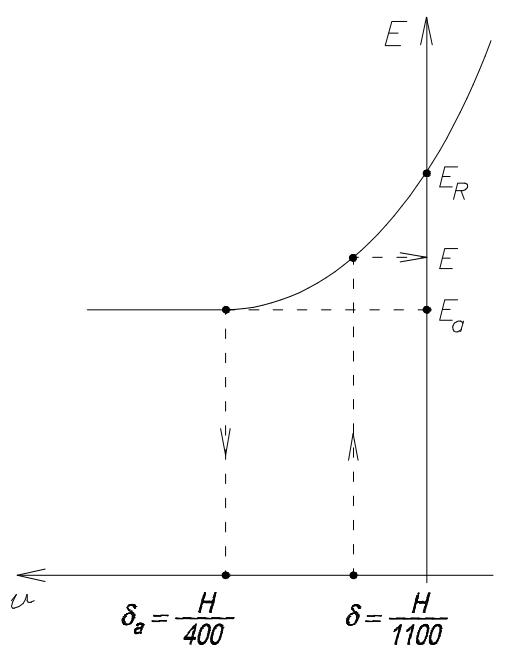

Figura 2.2 - Relação entre os deslocamentos dos Muros de Arrimo e os respectivos empuxos.

Finalmente, para reforçar o acerto desta decisão, citam-se mais os seguintes argumentos:

- Para as piscinas e certos tanques são inadmissíveis deslocamentos no topo das paredes.

- Os empuxos de terra nas paredes dos reservatórios em geral não são o seu pior carregamento. Quase sempre as paredes são pré-dimensionadas considerando os empuxos da água e sem a consideração dos empuxos de terra.

- Como visto no início deste item, nos cantos e nas extremidades das paredes já se tem que considerar o empuxo em repouso. A aplicação também deste empuxo para os trechos centrais das paredes não só fica do lado da segurança com também uniformiza e simplifica os projetos destes reservatórios.

\section{c) $O$ solo atuando como elemento resistente}

O solo será considerado atuando como força de atrito e com tensões normais.

\section{$\underline{\text { Atuando como força de atrito }}$}

Apenas nos reservatórios em fundação direta pode-se e deve-se contar com a força de atrito estático $\mathrm{A}=\mu \cdot \mathrm{N}$ como reação aos esforços horizontais não equili- 
brados, sendo $\mu=\operatorname{tg} \phi$ e $\mathrm{N}=0,9 \mathrm{G}$ para o reservatório vazio, onde:

$\phi$ = ângulo de atrito interno do solo;

$\mathrm{G}=$ soma de todas as cargas permanentes de cálculo, de acordo com 5.4.2.1 da NBR 6118.

Obs.:

$1^{\circ}$ ) Em geral, os reservatórios apresentam boa segurança quanto à estabilidade e ao escorregamento, cujas verificações acabam sendo esquecidas ou ignoradas na prática. Entretanto, como sempre podem aparecer situações especiais, ver caso da Figura 2.3, com grandes empuxos desequilibrados, deve-se estar atento para as verificações destas situações.

Assim sendo, pode-se aplicar o mesmo critério para os muros de arrimo, dos quais se exige uma segurança de 50\% (prevendo água no terrapleno, sobrecargas não previstas, etc.), impondo que $\mathrm{A} \geq 1,5 \mathrm{E}$, onde $\mathrm{E}$ é a força horizontal não equilibrada.

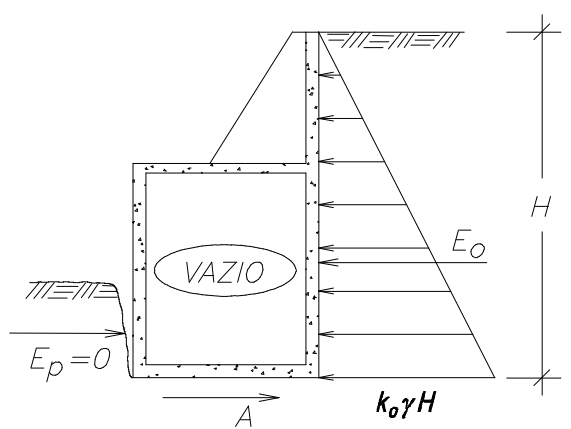

Figura 2.3 - Situação crítica de estabilidade ao escorregamento devido aos empuxos desequilibrados.

$2^{\circ}$ ) Como é fácil de se constatar, a pior situação para se verificar o escorregamento é com o reservatório vazio. Quando se usam juntas de dilatação FUNGENBAND ou similar, pode-se ter empuxos desequilibrados maiores nas paredes dos reservatórios cheios (com $\mathrm{E}_{\mathrm{o}}=0$ ), porém como nestes casos o peso vertical é muito alto, não existe posssibilidade de se ter escorregamento. Assim sendo para os reservatórios térreos (figura 2.4), tem-se: 


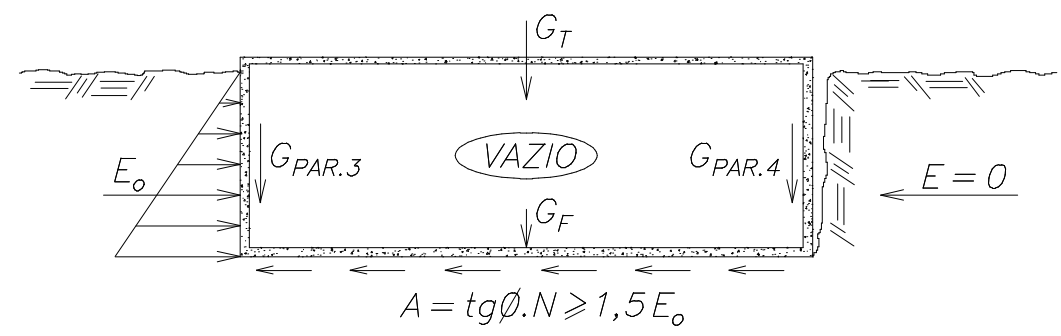

Figura 2.4 - Seção transversal de um reservatório térreo em fundação direta a serem consideradas na verificação da sua estabilidade ao escorregamento.

$A=\operatorname{tg} \phi \cdot N \geq 1,5 E_{0}$

onde:

$\mathrm{N}=0,9\left(\mathrm{G}_{\mathrm{T}}+\mathrm{G}_{\mathrm{F}}+\sum_{\mathrm{i}=1}^{4} \mathrm{G}_{\mathrm{PAR} .}\right)$

$\mathrm{E}_{\mathrm{o}}=$ resultante do empuxo em repouso;

$\mathrm{A}=$ força de atrito resultante sob o fundo.

Já para os reservatórios elevados (Figura 2.5):

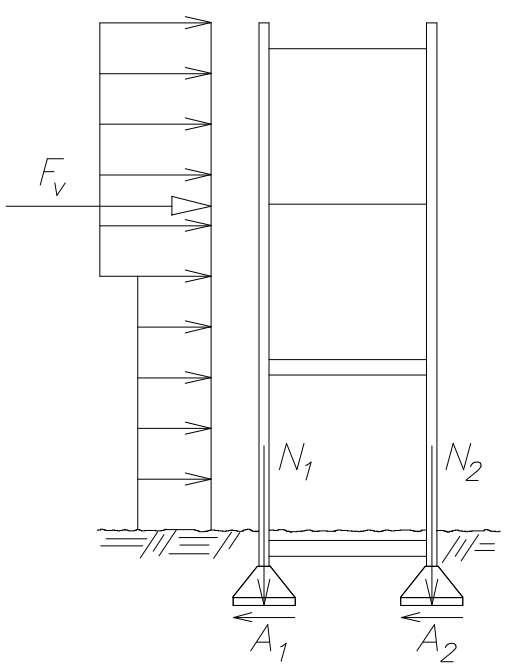

$\mathrm{A}_{1}+\mathrm{A}_{2}=\operatorname{tg} \phi \cdot \mathrm{N} \geq 1,5 \mathrm{~F}_{\mathrm{v}}$

onde:

$$
\begin{aligned}
& \mathrm{N}=0,9 \mathrm{G}_{\text {VAZIO }} ; \\
& \mathrm{N}=\underset{\text { VAZIA }}{\mathrm{G}_{\text {CUBA }}}+\mathrm{G}_{\text {PAR }}+\mathrm{G}_{\text {VIGAS }}+\mathrm{G}_{\text {SAP }}=\mathrm{N}_{1}+\mathrm{N}_{2} ;
\end{aligned}
$$

$F_{V}=$ força resultante do vento;

$A_{1}=A_{2}=$ forças de atrito nas sapatas.

Figura 2.5 - Seção transversal de um reservatório elevado em fundação direta, considerada na verificação da sua estabilidade ao escorregamento. 


\section{$\underline{\text { Atuando como tensões normais }}$}

\section{- Em elementos de fundações rígidos}

Ocorrem nos casos de reservatórios projetados em fundação direta, quando esta ou parte dela é composta de elementos estruturais rígidos suficientes para provocar no solo deformações uniformes ou linearmente variáveis.

Como exemplo, pode-se citar as sapatas dos pilares de reservatórios elevados ou de radiers rígidos como também as sapatas dos pilares internos dos reservatórios térreos (Figura 2.6).
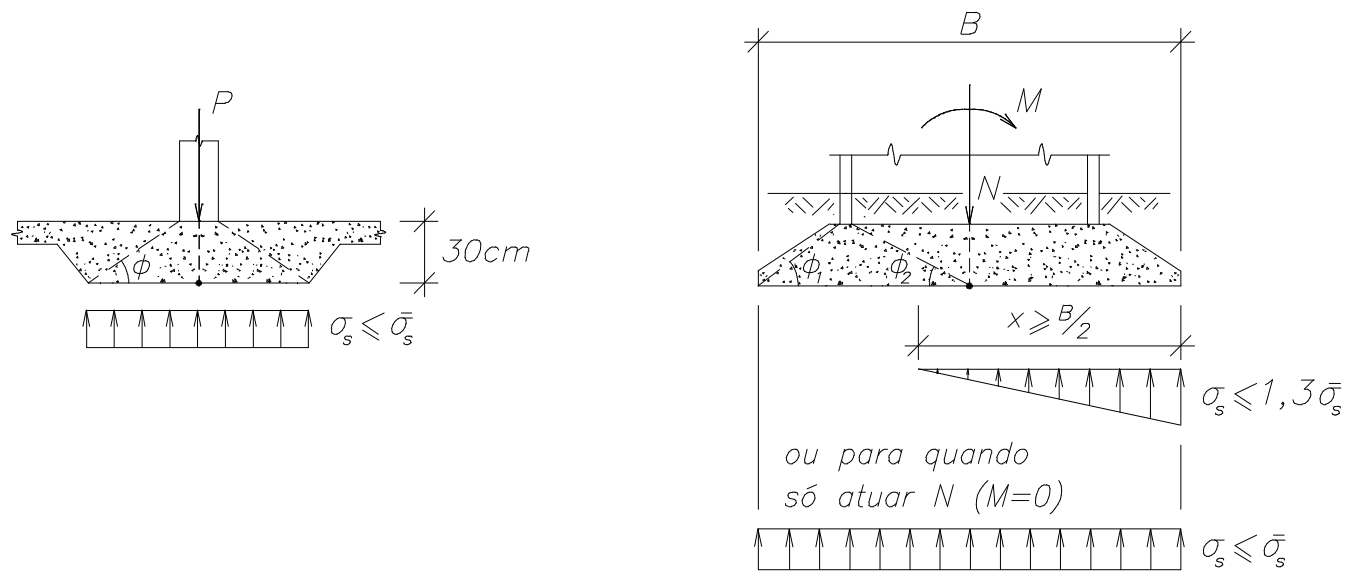

Sapata para o fuste de um reservatório elevado

Figura 2.6 - Tensões normais resistentes atuando sob sapatas de reservatório em fundação direta e respectivas tensões limites para solicitações centradas e excêntricas.

Este é o funcionamento do solo mais conhecido, cabendo ao calculista projetar as sapatas rígidas com dimensões em planta tais que respeitem as tensões admissíveis fornecidas pelo Engenheiro de Fundações, distribuindo uniformemente as cargas centradas e, linearmente variáveis, aquelas que forem excêntricas. Neste último caso pode-se obter as tensões máximas usando-se o ábaco do MONTOYA ${ }^{4}$ para sapatas retangulares rígidas com carga excêntrica nas duas direções.

\footnotetext{
${ }^{4}$ Ver parágrafo 21.2 - 6 ${ }^{\text {, fig. }} 21.9$ de MONTOYA, P. J. et al. Hormigón Armado.
} 
Obs.:

$1^{\circ}$ ) Consideram-se como rígidas as sapatas com $\phi_{\mathrm{i}} \geq \operatorname{arctg} 1 / 2$.

$2^{\circ}$ ) Para os reservatórios elevados o autor considera muito arrojado aplicar o especificado no item 6.2.1.2 da NBR-6122, em relação ao trecho mínimo das tensões de compressão sob as sapatas com cargas excêntricas, ou seja, $x \geq B / 2$. Manter toda a sapata sob compressão não só é mais adequado para um reservatório elevado como não é difícil de se conseguir.

\section{- Em elementos de fundacões flexíveis}

Ocorre em reservatórios térreos projetados em fundação direta, sempre quando esta ou parte dela recebe as reações verticais do solo através de elementos estruturais flexíveis e, também, em reservatórios térreos ou elevados em fundações sobre estacas, que também devem absorver os empuxos desequilibrados de terra ou de água ou, ainda, no caso dos elevados, a força do vento.

Nestes casos, de mais complexidade, não basta apenas calcular a tensão máxima que atua no solo. Como os elementos estruturais das fundações são flexíveis, ao transferirem os esforços dos reservatórios para o solo, eles acabam tendo deformações diferentes ao longo dos seus eixos e, conseqüentemente, provocam tensões diferentes no solo.

Felizmente, devido ao comportamento elástico do solo dado por $\mathrm{k}=\frac{\mathrm{q}}{\mathrm{y}}\left(\mathrm{kgf} / \mathrm{cm}^{2} / \mathrm{cm}\right.$ ou em $\left.\mathrm{MPa} / \mathrm{cm}\right)$, onde $\underline{\mathrm{k}}$ é, em geral, uma característica constante para cada solo, pode-se calcular a tensão máxima que atuará no solo e comparála com a admissível, bem como pode-se obter todos os esforços nos elementos das fundações para que possam ser dimensionados corretamente.

A grandeza $\underline{k}$ é denominada Coeficiente de Reação Elástica do Solo $^{5}$ e é a base da teoria das VIGAS FLEXÍVEIS APOIADAS EM MEIOS ELÁSTICOS.

Por muitos anos os calculistas sofreram com a aplicação prática desta teoria

\footnotetext{
5 Apenas para registro, esta grandeza $\mathrm{k}$ é conhecida na literatura espanhola como coeficiente de Balasto, uma homenagem ao seu criador, segundo os espanhóis.
} 
usando tabelas como por exemplo as de WÖLFER, que os obrigava a dividir uma viga em 15, 20 ou mais partes e calcular para cada uma delas os esforços M, V e q.

Felizmente, hoje existem muitos programas para microcomputadores que calculam com facilidade os esforços destas vigas. Alguns exigem do usuário apenas a subdivisão da viga em $\mathrm{n}$ trechos de comprimento a e a colocação no centro de cada trecho de um nó que estará apoiado sobre uma mola com coeficiente igual a k·a .

Considerando aqueles programas mais simples, ou seja, qualquer programa de pórtico plano, para a consideração do meio elástico $\underline{\mathrm{k}}$ basta seguir as seguintes etapas:

- Divide-se o elemento estrutural flexível da fundação, que se está querendo calcular, em várias barras de no máximo $\mathrm{a}=0,50 \mathrm{~m}$ de comprimento e, para simplificar, com $b_{\mathrm{w}}=1,00 \mathrm{~m}$ (Figura 2.7).

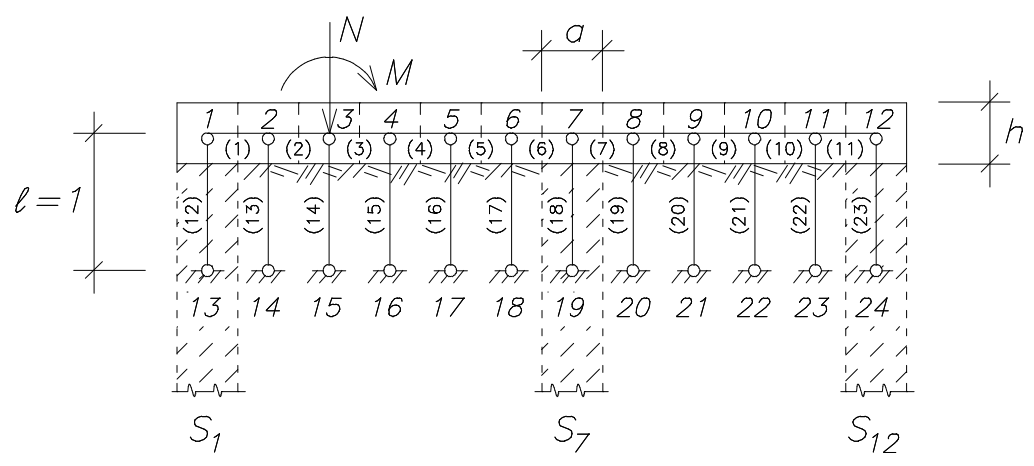

Figura 2.7 - Esquema estático do fundo de uma piscina considerada apoiada em meio elástico (fundação direta) submetido às cargas da parede $\mathrm{N}(\mathrm{tf} / \mathrm{m}) \mathrm{e} \mathrm{M}(\mathrm{tf} \mathrm{m} / \mathrm{m})$.

- A cada nó dessa divisão, se associa um trecho de solo também de comprimento a e largura também $b_{\mathrm{w}}=1,00 \mathrm{~m}$ e profundidade qualquer.

- Trocam-se todos os elementos de solo de comprimento a $\left(S_{1}\right.$ a $\left.S_{12}\right)$ por barras fictícias de concreto (12 a 23) equivalentes, articuladas nas extremidades, com comprimentos unitários e área calculada com $\mathrm{S}=\frac{\mathrm{k}}{\mathrm{E}_{\mathrm{c}}} \mathrm{a}$, onde $\underline{\mathrm{k}}$ é o coeficiente de reação elástica do solo, $\mathrm{E}_{\mathrm{c}}$ é o módulo de deformação longitudinal do elemento 
estrutural que se está calculando e a é o comprimento dos trechos em que foi subdividido o solo.

- Carrega-se o programa do pórtico que se está usando com as áreas S recém calculadas, não esquecendo de liberar à rotação os nós das barras fictícias junto ao elemento de fundação e roda-se o programa, obtendo-se os valores de $\mathrm{M}$ e V, nos diversos nós do elemento, bem como, obtendo-se os deslocamentos dos nós das barras fictícias junto aos elementos que representam os recalques da fundação e ainda também obtendo-se as reações $\mathrm{R}$ dos nós das barras fictícias que fornecem as tensões no solo com $q=\frac{R}{a}$.

Obs.:

$1^{\circ}$ ) Para as barras 12 a 23 serem equivalentes aos trechos de solo $S_{1}$ a $S_{12}$ bastam apresentar as mesmas deformações que sofrem $S_{1}$ a $S_{12}$ quando submetidas a uma mesma carga. Basta então calcular $\underline{S}$ para que se tenha $\Delta \ell=\mathrm{v}$ :

elemento de solo $\left(b_{w}=1,00 \mathrm{~m}\right)$

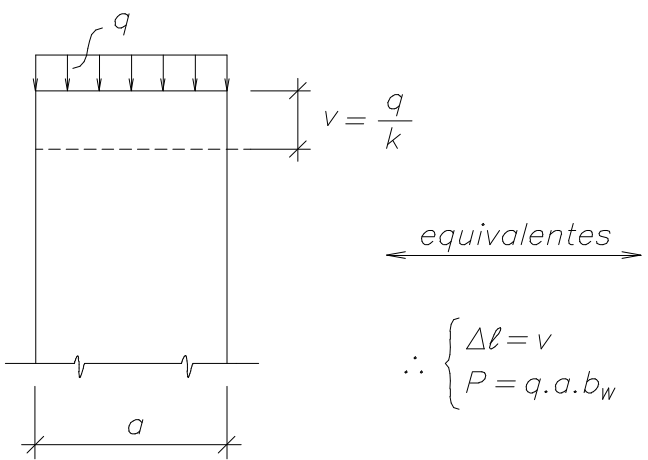

barra ficticia ( $E_{c}$ e $S=$ ?)

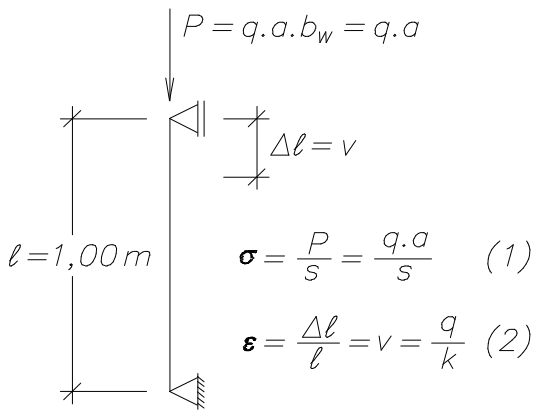

Figura 2.8 - Trecho contínuo de solo de comprimento a sob a estrutura em estudo e a barra de concreto fictícia equivalente.

Aplicando a lei de Hooke na barra fictícia (Figura 2.8), tem-se:

$\sigma=\varepsilon \cdot \mathrm{E}_{\mathrm{c}}$ e substituindo $\underline{\sigma}$ e $\underline{\varepsilon}$ por (1) e (2), obtém-se $\frac{\mathrm{qa}}{\mathrm{S}}=\frac{\mathrm{q}}{\mathrm{k}} \mathrm{E}_{\mathrm{c}} \therefore$

$\therefore \mathrm{S}=\frac{\mathrm{k}}{\mathrm{E}_{\mathrm{c}}} \mathrm{a}$ 
$2^{\circ}$ ) Pode ser interessante dividir o elemento da fundação em trechos menores, próximos às cargas e momentos aplicados. Isto é possível desde que se calculem corretamente as áreas das barras fictícias dos vários trechos. Por exemplo, para dois espaçamentos a e a' (Figura 2.9) calcula-se com a expressão (3):

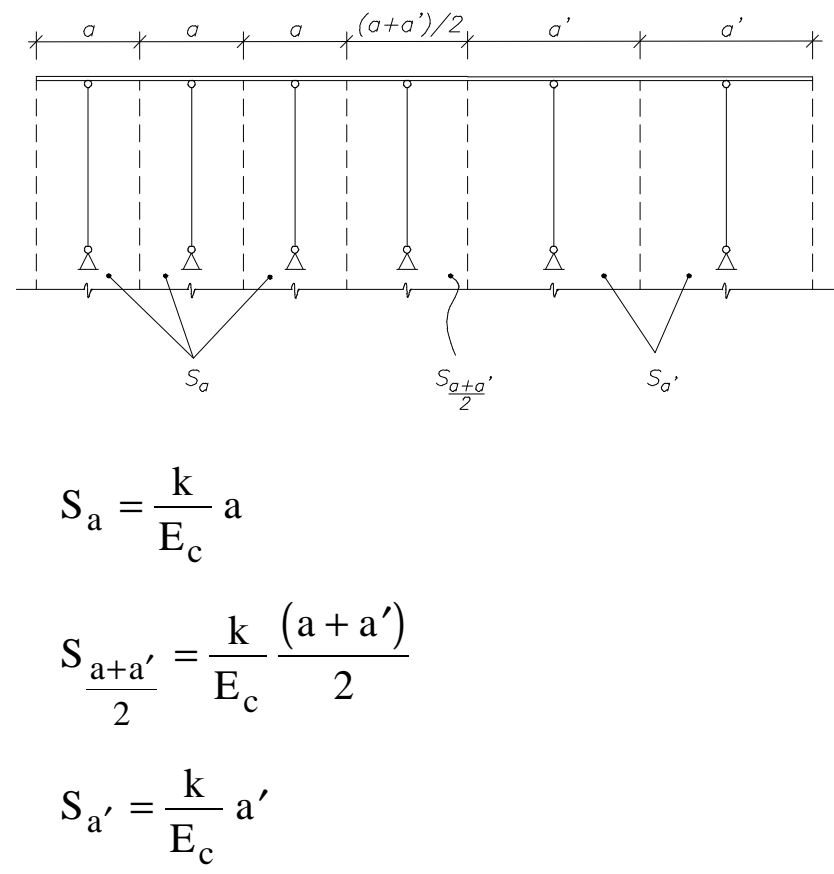

Figura 2.9 - Estrutura apoiadas em meio elástico com divisões menores na região das cargas aplicadas.

$3^{\circ}$ ) Como em Mecânica dos Solos as incertezas dos parâmetros assumidos são bem maiores do que as do concreto armado, é comum, para as estruturas cujos esforços e deslocamentos sejam muito sensíveis às variações de um destes parâmetros, trabalhar com dois valores extremos. Obtém-se assim uma espécie de "envoltória das envoltórias", cercando definitivamente todas as situações críticas da estrutura.

Para o coeficiente de reação elástica do solo $\underline{\mathrm{k}}$, os maiores valores fornecem as máximas pressões no solo e os valores menores fornecem os máximos esforços nas fundações.

Felizmente os elementos estruturais usualmente empregados nas fundações não são muito sensíveis às variações de $\underline{\mathrm{k}}$, podendo-se projetar com um único valor. 
$4^{\circ}$ ) São dados nas figuras 2.10 a 2.15 alguns exemplos de reservatórios onde se deve considerar o efeito do meio elástico nas fundações.
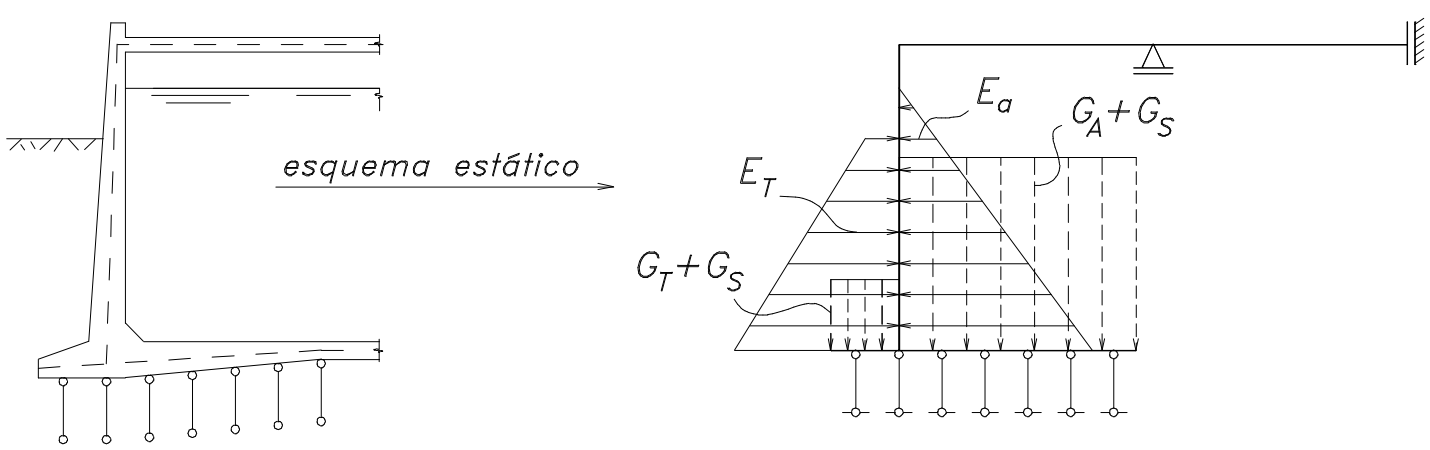

Figura 2.10 - Grandes reservatórios em fundação direta.
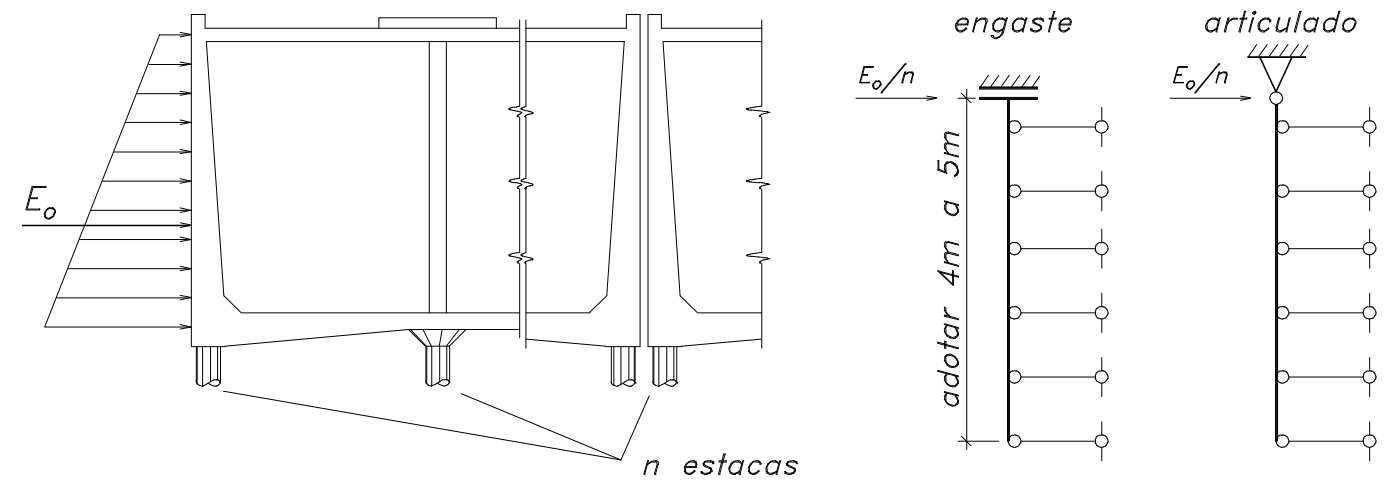

Obs.: A hipótese mais realista é a com engaste, mas é conveniente adotar também a articulada e se obter a envoltória dos esforços das estacas.

Figura 2.11 - Grandes reservatórios em fundações sobre estacas
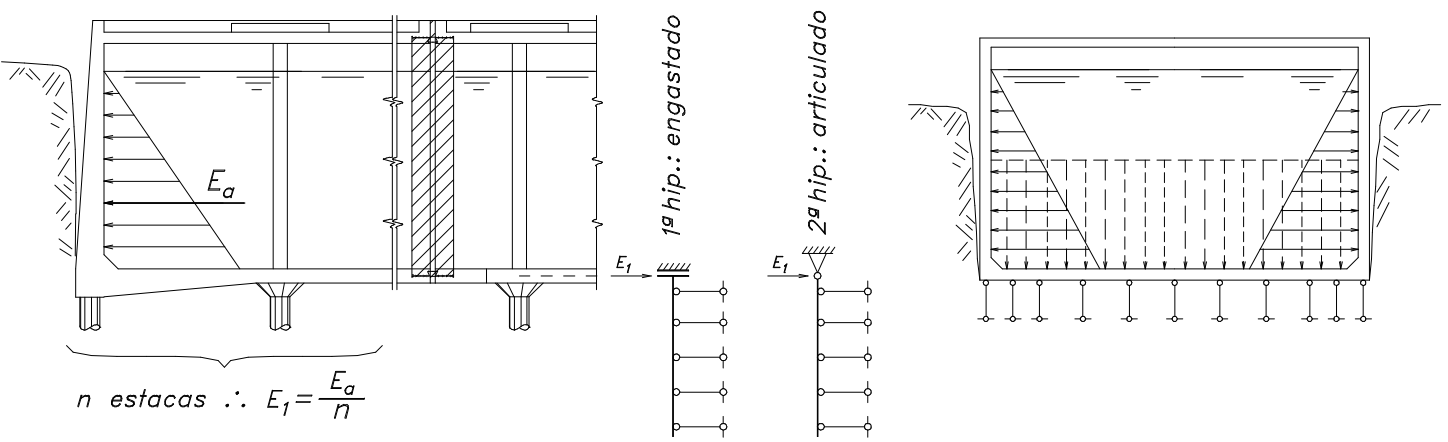

obs.: calcular com as duas hipóteses de vinculação

Figura 2.12 - Grandes reservatórios com juntas

Figura 2.13 - Pequenos reservatórios 


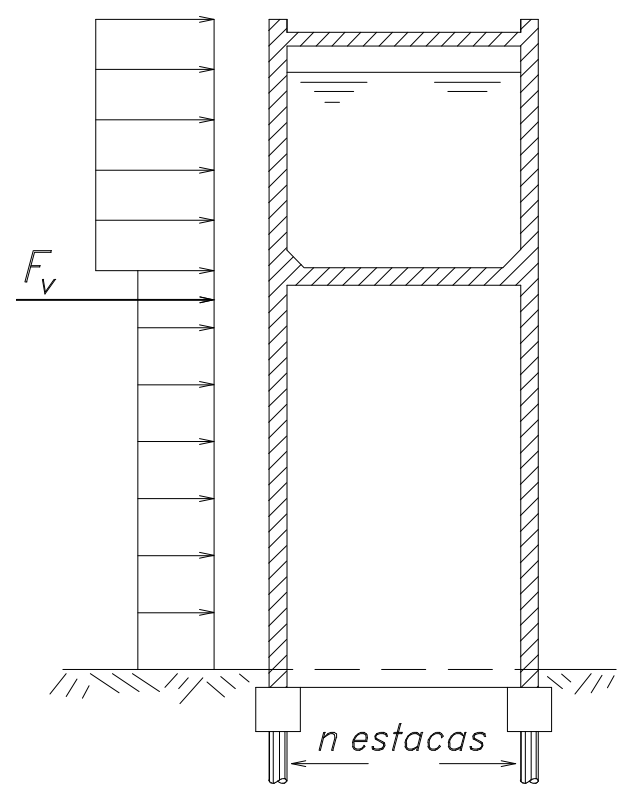

(a) Estrutura e esforços solicitantes (vento)

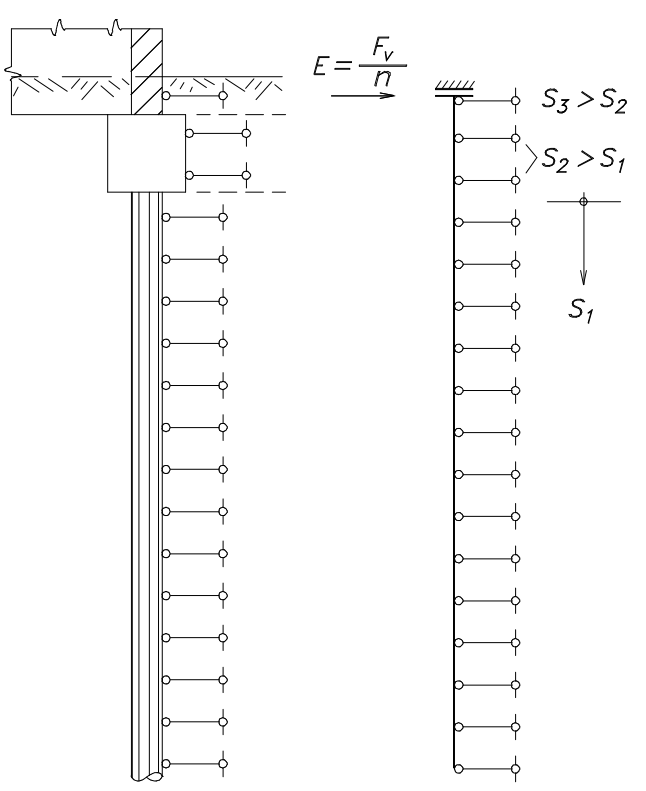

(b) Detalhamento para o cálculo das áreas das barras equivalentes (c) Esquema estático final, pronto para o cálculo

Figura 2.14 - Reservatórios elevados sobre estacas
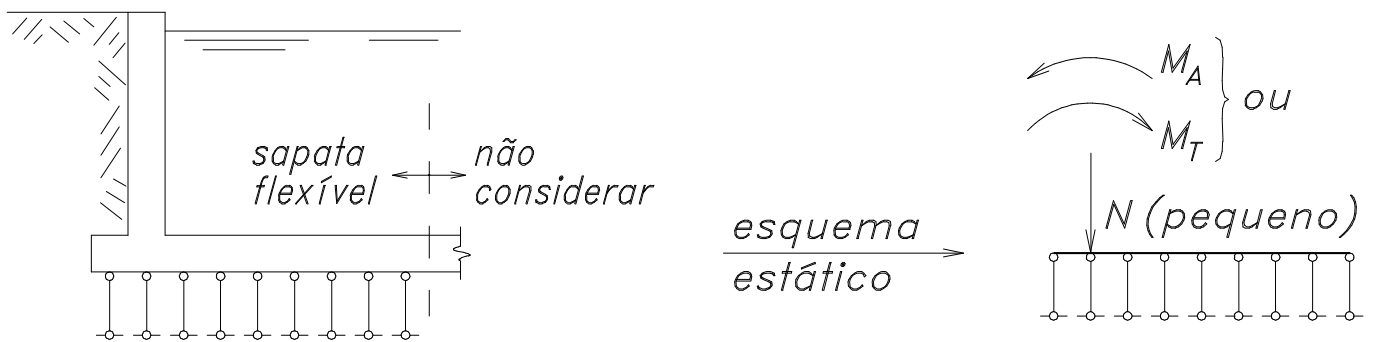

Figura 2.15 - Piscinas, tanques e canais

$5^{\circ}$ ) Apresentam-se na Figura 2.16 ábacos gerais aplicáveis em elementos estruturais horizontais (sapatas e lajes) e também ábacos aplicáveis em elementos verticais (estacas e tubulões) que fornecem os valores dos coeficientes de reação elástica do solo, $\underline{\mathrm{k}}$, em função da resistência à compressão das argilas e das densidades relativas das areias.

Solo Argiloso: $\mathrm{k}=\frac{\mathrm{k}_{\mathrm{v} 1}}{\mathrm{~b}} \quad$ Solo arenoso: $\mathrm{k}=\mathrm{k}_{\mathrm{v} 1}\left(\frac{\mathrm{b}+1}{2 \mathrm{~b}}\right)^{2}$ 

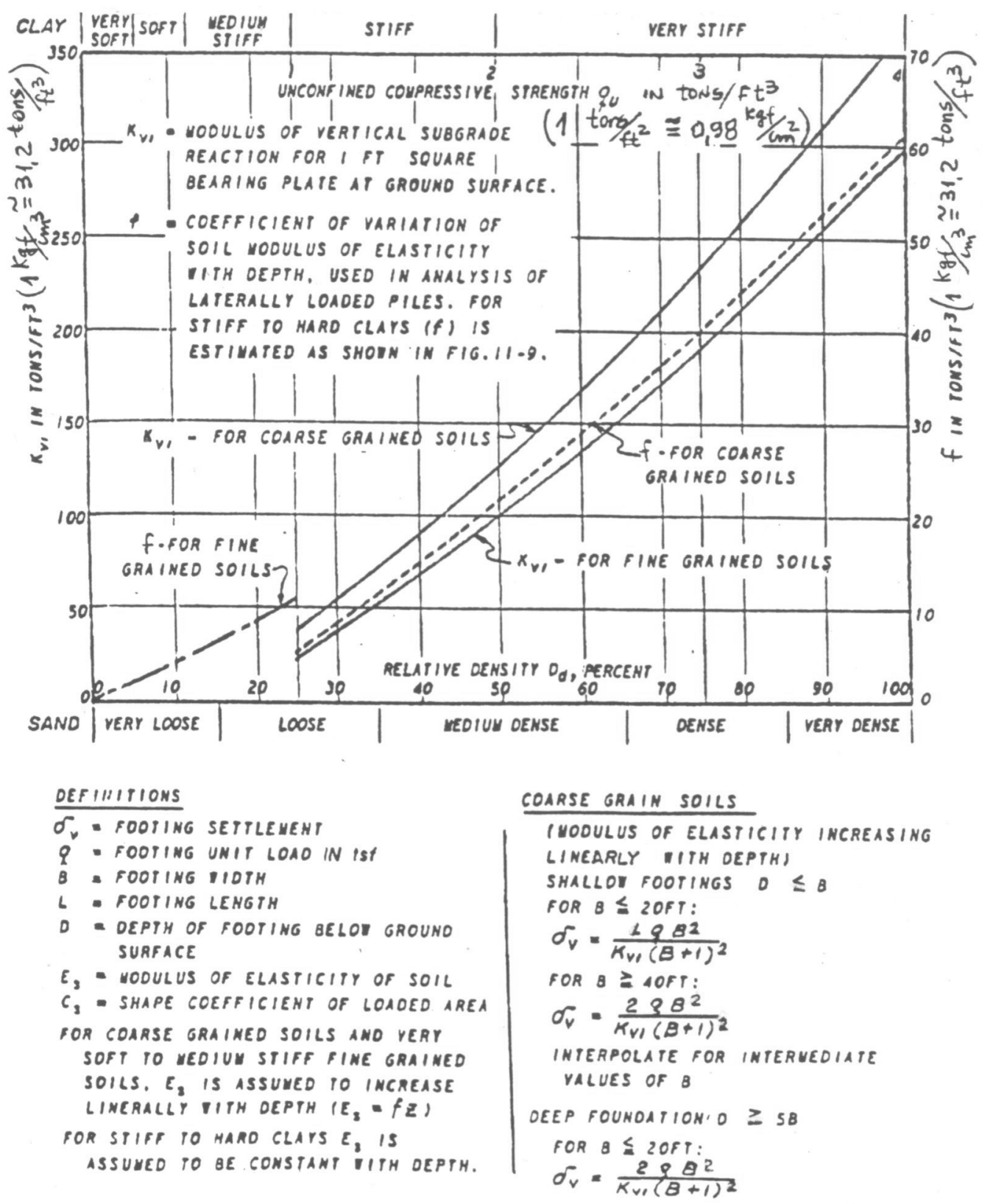

Figura 2.16 - Ábacos para o cálculo dos coeficientes de reação elástica do solo. NAVFAC D4-7 (1971), Mar.

\subsubsection{Materiais e Técnicas de Construções}

Devido à estanqueidade, qualidade especial dos reservatórios conforme visto no parágrafo 2.2 deste capítulo, a concretagem das lajes e paredes da cuba de um reservatório requer um cuidado maior em relação às concretagens das estruturas das outras obras.

Assim, é necessário planejá-la bem, principalmente quanto às juntas de concre- 
tagens, que é por onde vem ocorrendo a grande maioria dos vazamentos dos reservatórios.

Ainda, a execução da estrutura deve ser feita amparada em um bom controle tecnológico, com a aplicação de todas as técnicas, antes, durante e depois da concretagem dos reservatórios.

\section{a) Juntas de concretagens}

Quando possível, o fundo dos reservatórios deve ser executado de uma só vez, concretando-se até um pequeno trecho das paredes. Este tipo de concretagem apresenta dois ou três aspectos favoráveis à qualidade da estrutura.

Primeiro porque não apresenta juntas de concretagens na laje do fundo, local difícil de se constatar vazamentos.

Segundo porque os pequenos trechos de paredes concretados facilitam o represamento de uma pequena lâmina d'água, propiciando assim uma cura ideal para a laje do fundo.

Terceiro porque a junta na parede se afasta da posição onde os esforços são máximos, podendo-se até, para as paredes de reservatórios cobertos, executar a junta nas proximidades do ponto onde os momentos são nulos.

Quando não for possível executar toda a laje do fundo de uma só vez, por limitação operacional, deve-se planejar uma concretagem em etapas compatível com essas limitações e que tenha o menor comprimento de junta possível. Essas juntas deverão receber um tratamento adequado para garantir uma perfeita ligação entre as etapas e conseqüentemente evitar vazamentos através delas.

Ainda, não há razão nenhuma para se preocupar com possíveis escoamentos de armaduras, ou com a possibilidade de se ter fissuras grandes nas junções de "panos de lajes" maiores. Os encurtamentos devidos à retração por ocorrerem em todas as direções não são acumulativos. Para exemplificar estes argumentos, apresenta-se a seguir como sugestão um plano de concretagem para um reservatório térreo com dimensões em planta de $30 \mathrm{~m} \times 30 \mathrm{~m}$, com lâmina d'água de 4,80m e em fundação direta (Figura 17). 
FORMAS DAS FUNDAÇOES

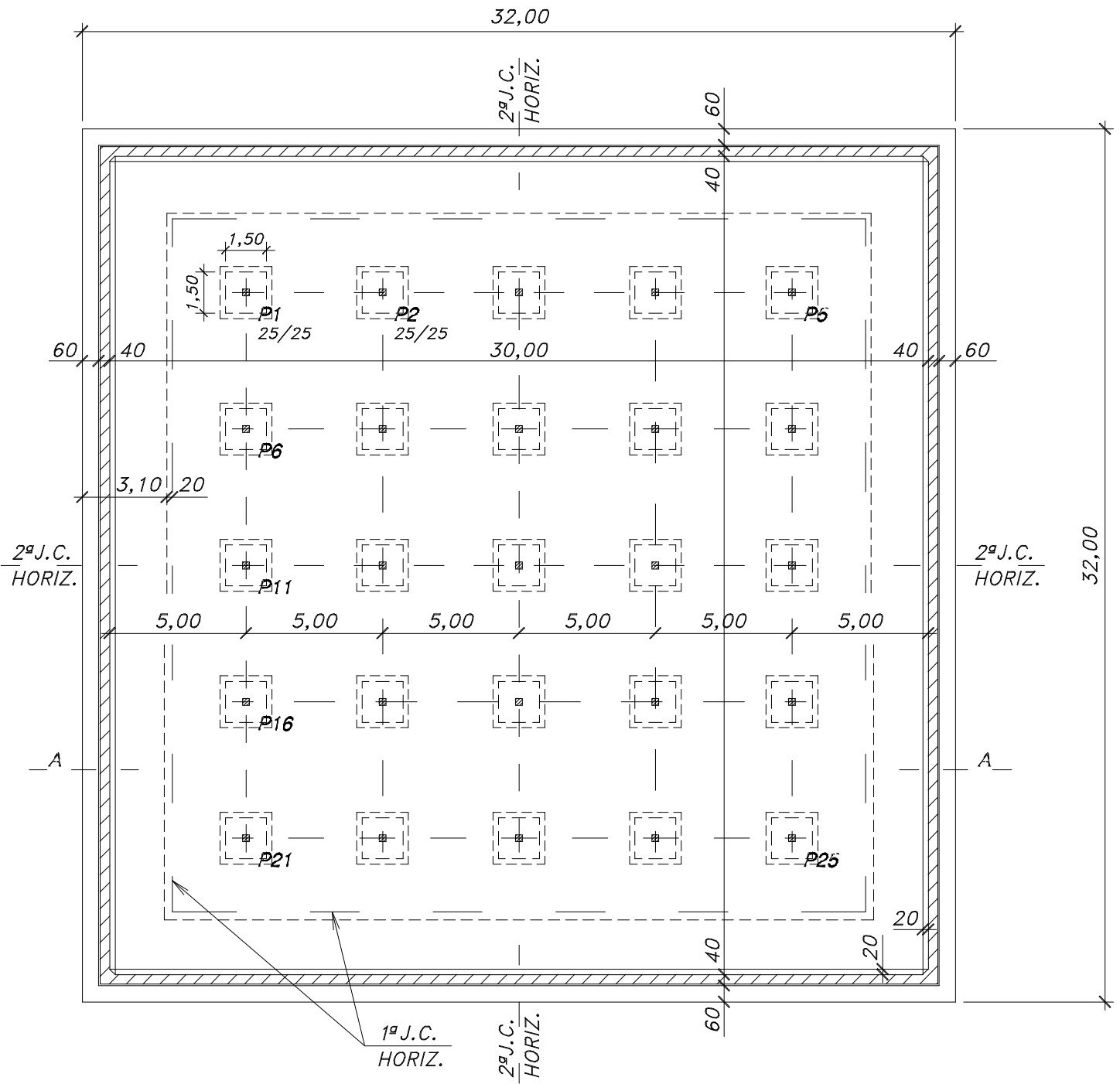

a) Fôrmas da laje do fundo de um reservatório achatado em fundação direta, com indicações das juntas de concretagem horizontais. 


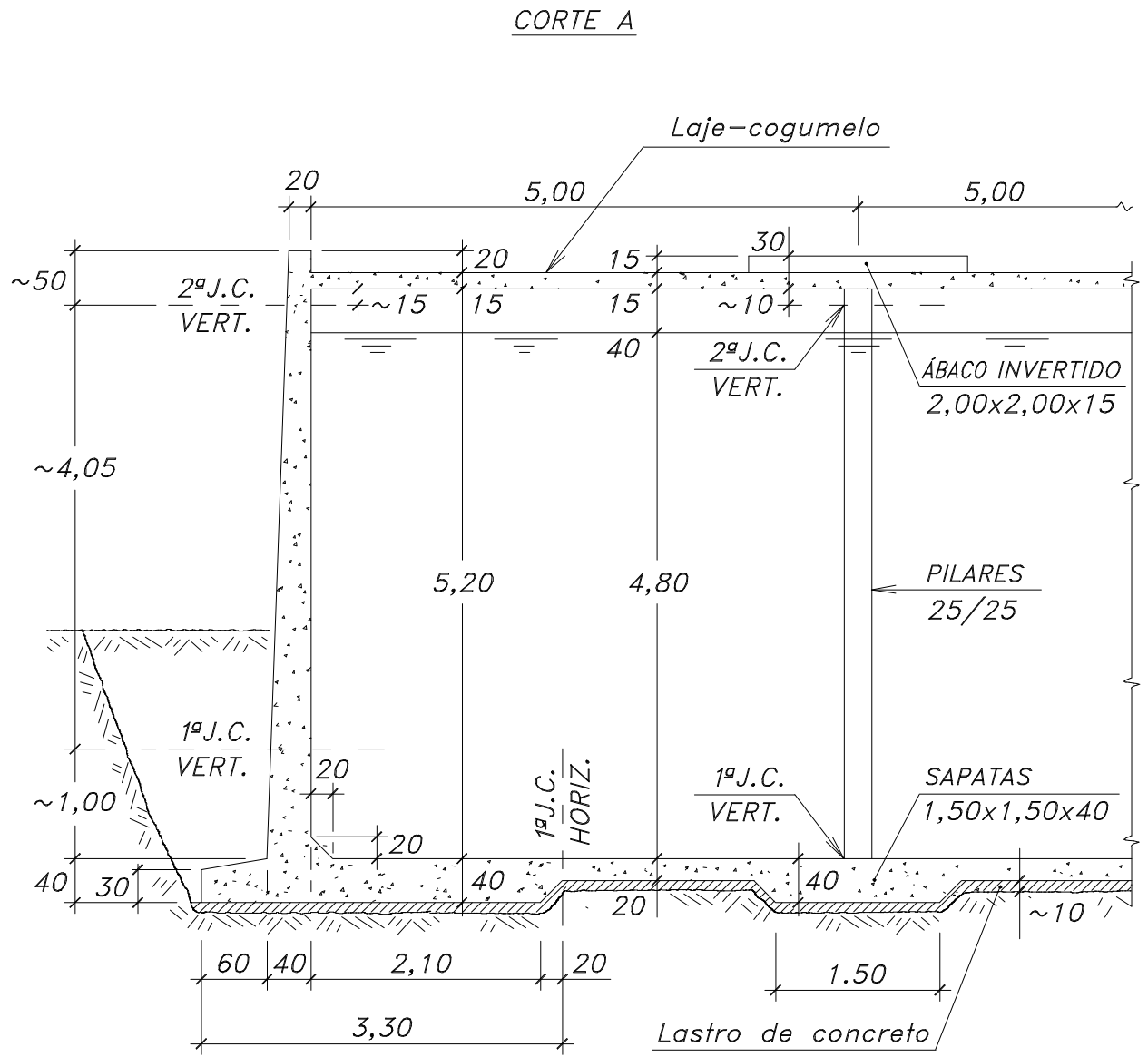

b) Corte A do mesmo reservatório com indicações das juntas de concretagem verticais.

Figura 17 - Planta e corte de um reservatório em fundação direta, com indicação das juntas de concretagem horizontais e verticais.

\section{ETAPAS E JUNTAS DE CONCRETAGEM DE UM RESERVATÓRIO TÉRREO EM FUNDAÇÃO DIRETA}

\section{1a ETAPA: Concretagem (horizontal) da laje do fundo}

Quando não for possível concretar a laje do fundo de uma só vez, deve-se tentar executá-la em duas partes separadas pela primeira junta de concretagem (1 ${ }^{\mathrm{a}}$ J.C.) horizontal (ver corte A), que separa a base das paredes do restante da laje do fundo, sem função estrutural importante.

Se ainda não for possível executar a base das paredes de um só vez pode-se apelar por uma segunda junta de concretagem ( $2^{\mathrm{a}}$ J.C.) horizontal, duas ou quatro vezes, conforme as posições indicadas no desenho de fôrmas das fundações. 


\section{$2^{\text {a }}$ ETAPA: Concretagem (vertical) das paredes e dos pilares}

Esta etapa corresponde à concretagem entre a primeira e a segunda junta de concretagem vertical. São independentes entre si, porém as paredes costumam ser executadas antes dos pilares pois estes são mais fáceis de concretar após a execução das fôrmas da cobertura.

Se nesta etapa não se conseguir executar as paredes de uma só vez, as interrupções deverão ser feitas com juntas verticais e nas mesmas posições das segundas juntas de concretagem horizontais, especificadas para a primeira etapa.

$3^{\text {a }}$ ETAPA: Como agora a estanqueidade não é mais exigida, as condições são as mesmas da coberturas dos edifícios comuns em concreto armado. Ao contrário das paredes e da laje do fundo, pode-se aqui evitar concretagens de panos muito grandes, executando as lajes em duas ou mais etapas, sempre com as juntas faceando os ábacos na face oposta aos painéis concretados.

\section{b) Detalhes que favorecem a concretagem}

Já foi dito que a boa execução das estruturas dos reservatórios só se consegue com um bom controle tecnológico. Ou seja, deverão ser sempre especificados traços para o concreto que, além de fornecerem boas resistências, deverão ter relações água/cimento adequadas à durabilidade da estrutura bem como à trabalhabilidade do concreto, levando-se sempre em conta o método construtivo empregado.

Assim é que serão projetados traços para o concreto que, além da resistência, certamente terão também a relação água/cimento adequada à concretagem e principalmente à durabilidade da estrutura.

Ainda, estes traços deverão ter quantidades de argamassa suficientes para evitar o surgimento de falhas no concreto, fatais à estanqueidade dos reservatórios.

Entretanto, nada poderão fazer os engenheiros construtores e os de controle tecnológico do concreto para evitar estas falhas, se o projeto estrutural não obedecer as duas regras básicas seguintes: 


\section{$\underline{\text { Projetar com dimensões folgadas }}$}

Enfoque diferente ao dos edifícios, deve ser dado às estruturas dos reservatórios.

Nos reservatórios, não se deve ter a preocupação de diminuir as dimensões das lajes e paredes da cuba.

As espessuras menores são mais vulneráveis a vazamentos provocados por falhas de concretagens impossíveis de se evitar, como por exemplo a concentração de armaduras em um ponto, juntas de concretagens em locais inadequados, etc.

Por exemplo, o projeto de contrafortes nas paredes dos reservatórios com a intenção de reduzir a espessura das mesmas, procurando economia, é um critério de concepção totalmente equivocado, uma vez que favorece as falhas de concretagem com a concentração das cargas em elementos estruturais lineares. E mesmo assim, acabam aumentando o custo final do concreto armado, em face do custo alto das fôrmas.

Outro bom exemplo é o projeto de vigas no fundo de um reservatório com fundação sobre estacas. Apresentam os mesmos inconvenientes do caso anterior.

\section{$\underline{\text { Não concentrar as armaduras }}$}

Como já referido no item anterior, deve-se evitar o projeto de vigas e contrafortes, dando preferência ao uso de lajes. Isto evita, entre outros defeitos, a concentração de armaduras.

Ainda, quando do cálculo de lajes deve-se procurar trabalhar com dimensões folgadas, de maneira a não se obter muita armadura, cuidando-se para que estas tenham espaçamentos e bitolas adequadas tais que e $\geq 15 \mathrm{~cm}$ e $\phi \leq \frac{\mathrm{h}}{10}$.

Finalmente, a idéia de economizar ainda pode incomodar o calculista quando da verificação das fissuras e levá-lo a concentrar armaduras. Ou seja, por exemplo, se foi encontrada uma área $\mathrm{a}_{\mathrm{s}}=10,00 \mathrm{~cm}^{2} / \mathrm{m}$ no dimensionamento de uma laje de fundo de um reservatório e, se para se respeitarem os limites de fissuração sejam necessários: 


$$
\begin{aligned}
& \mathrm{a}_{\mathrm{s}_{\mathrm{e}}}=10,00 \mathrm{~cm}^{2} / \mathrm{m}(\phi 10.0 \mathrm{c} / 8 \text { com } 0 \% \text { a mais }) \\
& \mathrm{a}_{\mathrm{s}_{\mathrm{e}}}=11,00 \mathrm{~cm}^{2} / \mathrm{m}(\phi 12.5 \mathrm{c} / 11 \text { com } 10 \% \text { a mais }) \\
& \mathrm{a}_{\mathrm{s}_{\mathrm{e}}}=13,00 \mathrm{~cm}^{2} / \mathrm{m}(\phi 16.0 \mathrm{c} / 15 \text { com } 30 \% \text { a mais })
\end{aligned}
$$

Deve-se escolher a terceira opção.

\subsubsection{Aspectos arquitetônicos}

Qualquer edificação ou parte dela deve apresentar pelo menos as quatro qualidades básicas, as quais, na ordem de importância, são:

- Verificar os estados limites estruturais;

- Ter funcionalidade;

- Ser econômica;

- Ter aspecto agradável.

É opinião geral que as edificações devam sempre apresentar as duas primeiras qualidades, embora em muitos casos elas não aconteçam, por falta de experiência ou por engano ou, ainda, no caso da funcionalidade, por falta de informação ou de conhecimento específico.

Já quanto às duas últimas qualidades, no caso de reservatórios, não são feitas avaliações corretas de suas importâncias.

Infelizmente nestas obras o aspecto estético é, via de regra, sempre colocado num segundo plano em relação ao econômico, até mesmo quando os reservatórios são construídos em regiões nobres e estrategicamente visíveis.

Nestes casos, a beleza pode ser considerada como qualidade funcional, podendo-se até gastar um pouco mais com ela.

Também, um componente dos reservatórios que via de regra não recebe a devida importância são as escadas. Muitos reservatórios têm dupla função, como por exemplo os que funcionam como mirantes, como torre de controle de presídios, como para alimentar experiências de laboratórios, etc. 
Em todos estes reservatórios ocorre acesso diário, semanal ou mensal de pessoas que às vezes não têm boas condições físicas para subir pelas escadas do tipo marinheiro. Nestes casos, as escadas são funcionais, independentemente de serem ou não os reservatórios.

Assim é necessária a divulgação destes dois aspectos funcionais não hidráulicos, muitas vezes prejudicados pelo modus operandi inadequado, já bastante arraigado no setor de projetos da construção civil, quer seja, de primeiro serem feitos os projetos hidráulicos e só depois os enviarem aos calculistas. Em geral, há pouco ou quase nenhum contato inicial entre os especialistas envolvidos na obra, ou seja, entre os arquitetos, os projetistas hidráulicos, os calculistas e os construtores.

Deste modo, sendo os reservatórios uma espécie de CLONES dos projetos hidráulicos, fica mais difícil introduzir inovações arquitetônicas, estruturais e/ou construtivas. Priorizando apenas a funcionalidade hidráulica, corre-se o risco de se conceber um projeto hidráulico com defeitos de CONSTRUTIBILIDADE $^{6}$ e/ou de FUNCIONALIDADE ${ }^{7}$, que se a ele for fornecido um projeto estrutural, o reservatório pode ser executado e estes defeitos tornarem-se irreversíveis.

Não é difícil encontrar exemplos reais que ilustrem, e bem, esta lamentável realidade. Só para confirmar estes argumentos, entre os vários casos reais de projetos com a patologia acima exposta, cita-se o seguinte.

Recentemente foi feito um projeto hidráulico de um reservatório elevado para o Laboratório de Hidráulica da Faculdade de Engenharia Civil da Unicamp. O reservatório foi concebido em concreto armado na forma cilíndrica, abrigando 3 cubas de $4 \mathrm{~m}^{3}$ de água cada uma, com alturas piezométricas respectivas de 12, 24 e 36m.

É claro que os assessores do reitor daquela Universidade não aprovaram a construção, em face do projeto não ter CONSTRUTIBILIDADE.

Ainda, para o acesso às cubas foi projetada uma escada externa do tipo MARINHEIRO, absolutamente inadequada para o tipo de uso da mesma: as visitas às

${ }^{6}$ Por CONSTRUTIBILIDADE entende-se a qualidade que tem um projeto estrutural de fornecer estruturas econômicas e fáceis de se construir.

7 Por FUNCIONALIDADE entende-se a qualidade que tem uma obra ou parte dela de atender bem a todos os objetivos para os quais ela foi construída, sem prejuízo das suas atividades normais, como por exemplo de uso, de operação, de manutenção, etc. 
cubas deveriam ser feitas pelos professores e/ou técnicos do laboratório pelo menos uma vez antes de cada experiência. Esta escada, com certeza, iria dificultar a utilização do reservatório e, conseqüentemente, não seria FUNCIONAL.

Também, o reservatório sendo construído num local alto e visível, entre 2 edifícios pré-fabricados de bom aspecto, a sua forma e respectivo efeito estético teria importância FUNCIONAL. Entretanto, indiferente a estes fatores, foi projetada mais uma torre cilíndrica, já bastante banalizada naquele CAMPUS.

Como acabaram liberando só o primeiro reservatório de $12 \mathrm{~m}$ de altura e sendo este autor convidado para executar o correspondente projeto estrutural, pôde-se corrigir os dois defeitos do projeto original, ou seja, projetou-se um reservatório com aspecto mais agradável do que o cilindro, melhorou-se muito a funcionalidade da escada como também a construtibilidade do reservatório, projetando-o pré-fabricado (Figuras 2.18 e 2.19).

A seguir é apresentado um outro projeto executado pelo autor em 1980, para uma praça do município de Santa Rita do Passa Quatro - SP, onde as qualidades funcionais, construtivas e estruturais foram bem otimizadas, podendo-se destacar:

- Em face dos 22 metros de altura deste reservatório e com possibilidade de funcionar como mirante, projetou-se a escada SANTOS DUMONT ${ }^{8}$, que possibilita uma descida confortável mesmo para uma inclinação de $52,1^{\circ}$, conforme se pode ver na Figura 2.20.

- Os pórticos, parcialmente visíveis externamente, são compostos de oito vigas Vierendell com grande capacidade de resistência à flexão e que comprimem um anel poligonal na ligação fuste/cuba.

- Para facilitar a execução das fôrmas escolheu-se a forma prismática para o fuste e piramidal para a cuba.

- Ainda, procurando um melhor aspecto para o fuste e melhor resistência para a cuba, optou-se pela seção ortogonal.

${ }^{8}$ Entre muitas das suas invenções, SANTOS DUMONT contemplou a CONSTRUÇÃO CIVIL com esta escada. Em NEUFERT, E. (1965). Arte de Projetar em arquitetura, ela é citada como escada de BALANÇO ou de SAMBA, numa sutil e carinhosa referência a seu autor. 
- Finalmente, projetando-se os octógonos do fuste e da base da cuba com as diagonais desencontradas, dá-se uma variação bastante agradável à forma deste reservatório.

- Um observador que o contornar em movimentos circulares terá, a cada $22,5^{\circ}$, sensações bem distintas. A forma da vista 1 , conforme a figura 2.20, dá uma sensação de esbeltez, pois tanto o fuste como a cuba aparecem mais delgados do que a da vista 2 , que já dá a sensação de robustez.

Complementando a exposição sobre estes dois reservatórios, apresentam-se desenhos que destacam os aspectos funcionais mais importantes aqui analisados (Ver também Figura 2.21).

Finalizando, no Brasil e mesmo em países do Primeiro Mundo, talvez não seja possível elaborar os projetos dos reservatórios com a participação de todos os especialistas neles envolvidos, uma vez que não é fácil numa empresa manter estes profissionais em seus quadros de funcionários.

Nestas condições, e sendo o projeto estrutural o último a ser elaborado, o calculista tem a sua responsabilidade aumentada visto que, após a sua entrega, a obra será executada.

Assim, resta a ele a única e incômoda opção que é de entrar em contato com os demais projetistas para alertar e discutir sobre possíveis defeitos funcionais e/ou construtivos. Espera-se que qualquer sugestão, feita apenas com a intenção de melhorar o desempenho da obra como um todo, seja sempre bem recebida pelos seus responsáveis diretos e/ou pelos demais projetistas do reservatório.

Esta é a postura que devem ter todos os profissionais eticamente íntegros e tecnicamente preparados, quando da elaboração dos seus projetos estruturais. 

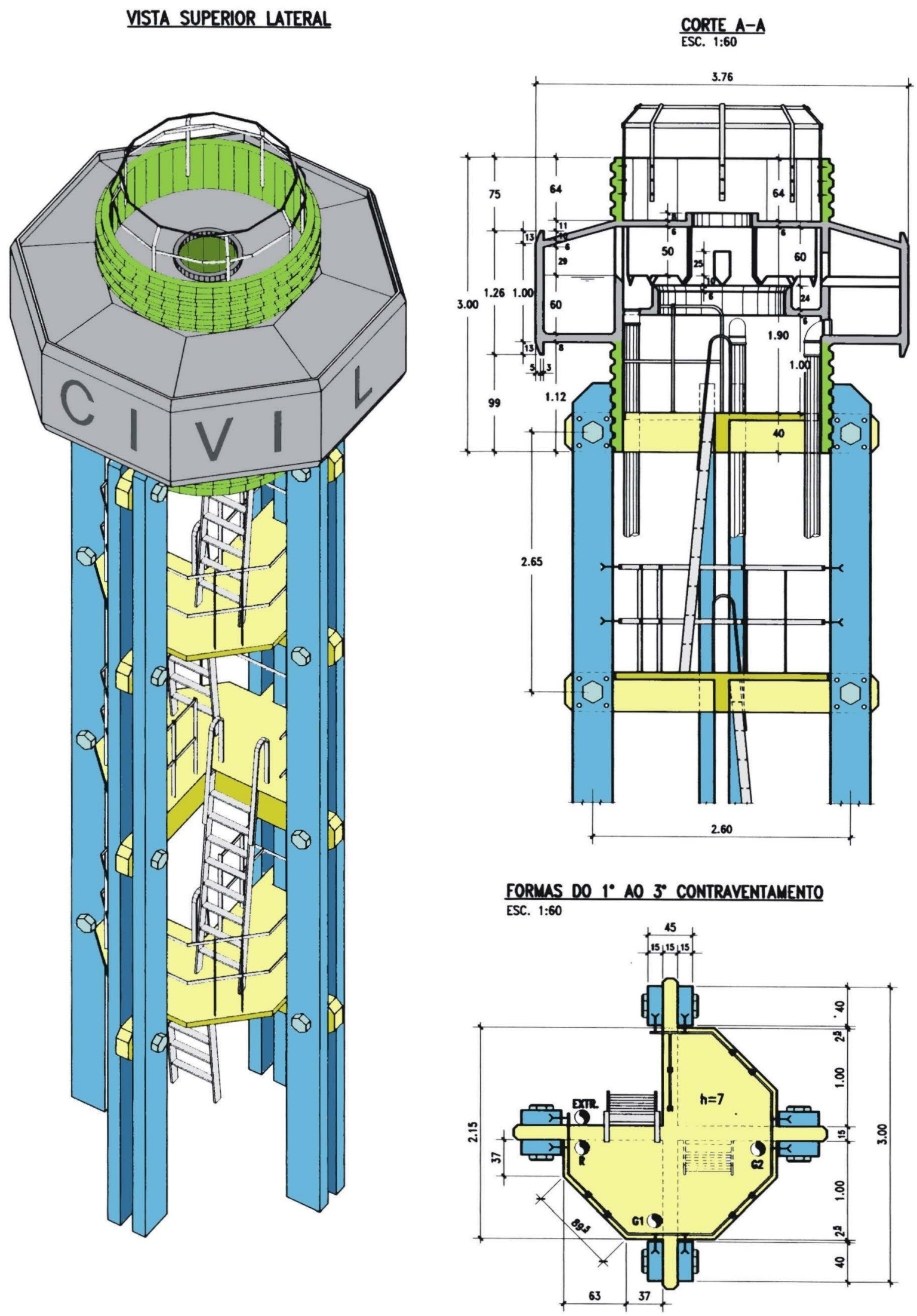

Figura 2.18 - Reservatório de pressão constante: $4 \mathrm{~m}^{3}$ - D.H.S. da Faculdade de Engenharia Civil da Unicamp 


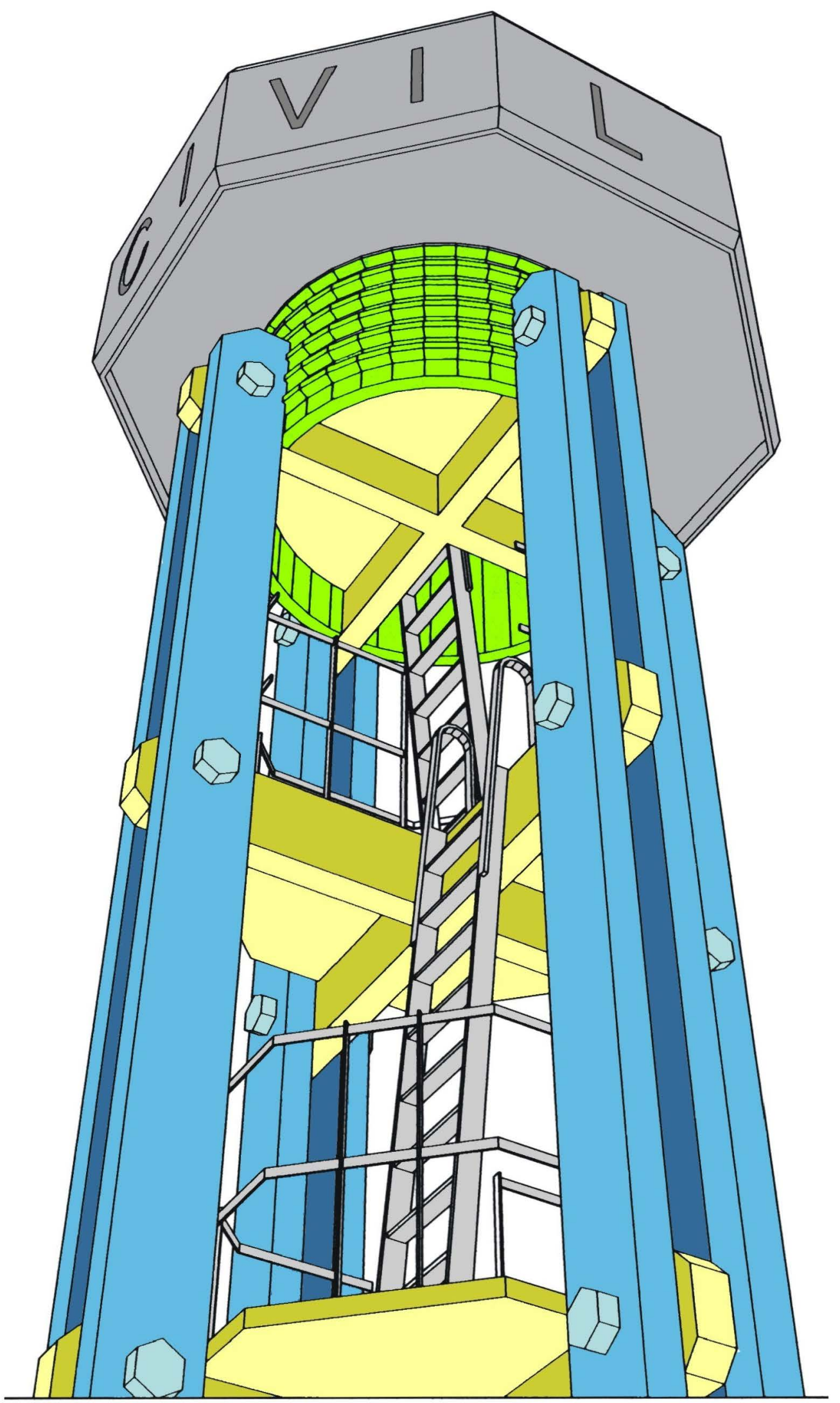

Figura 2.19 - Vista lateral inferior do reservatório do D.H.S 
VISTA 1 ESC. 1:300

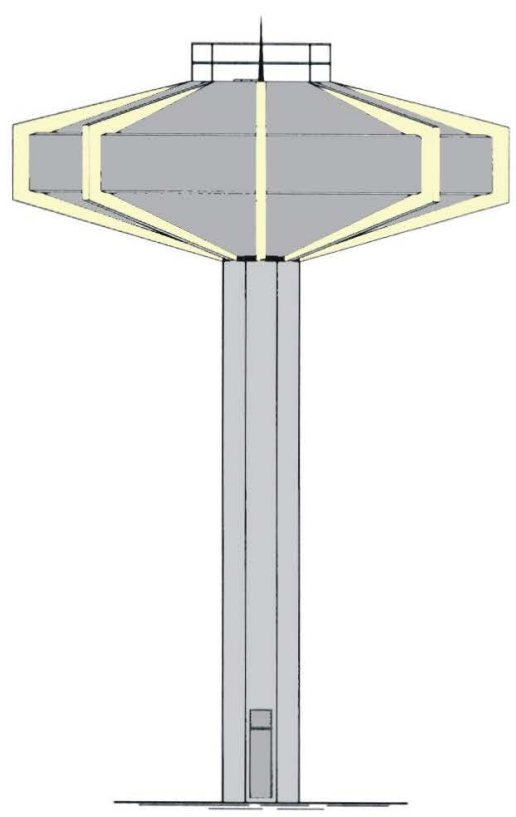

CORTE A-A ESC. 1:50

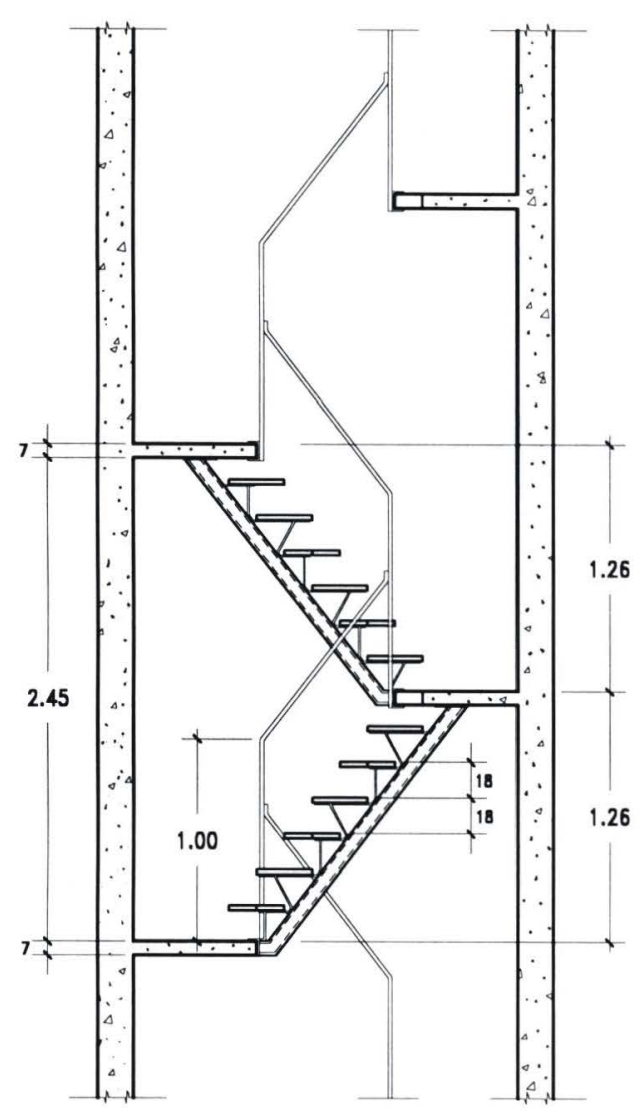

VISTA 2 ESC. 1:300

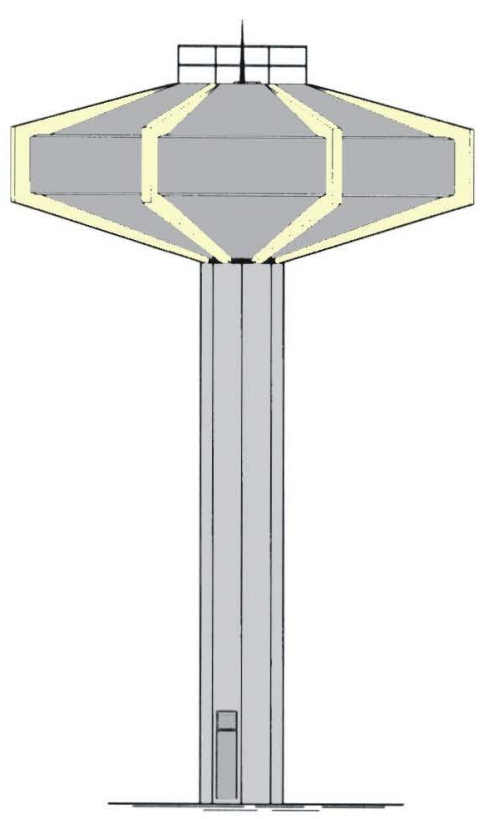

PLANTA ESC. 1:50

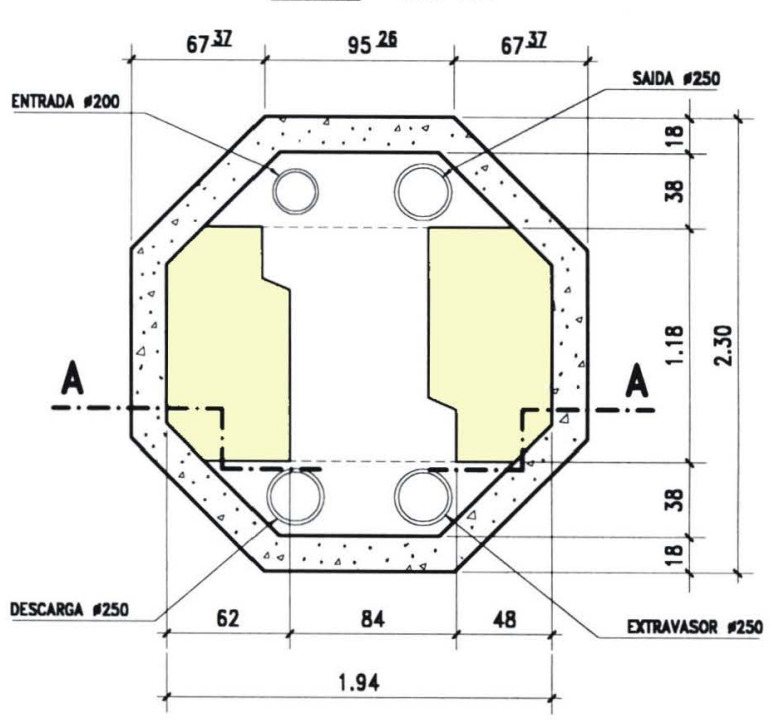

DETALHE TIPICO DOS DEGRAUS ESC. 1:25

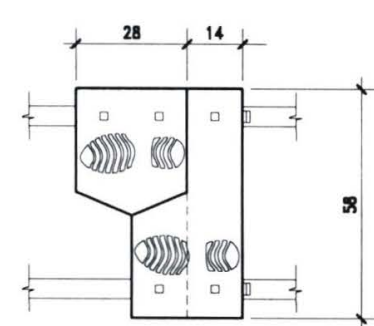

Figura 2.20 - Reservatório elevado: $250 \mathrm{~m}^{3}$ - Santa Rita do Passa Quatro - SP 

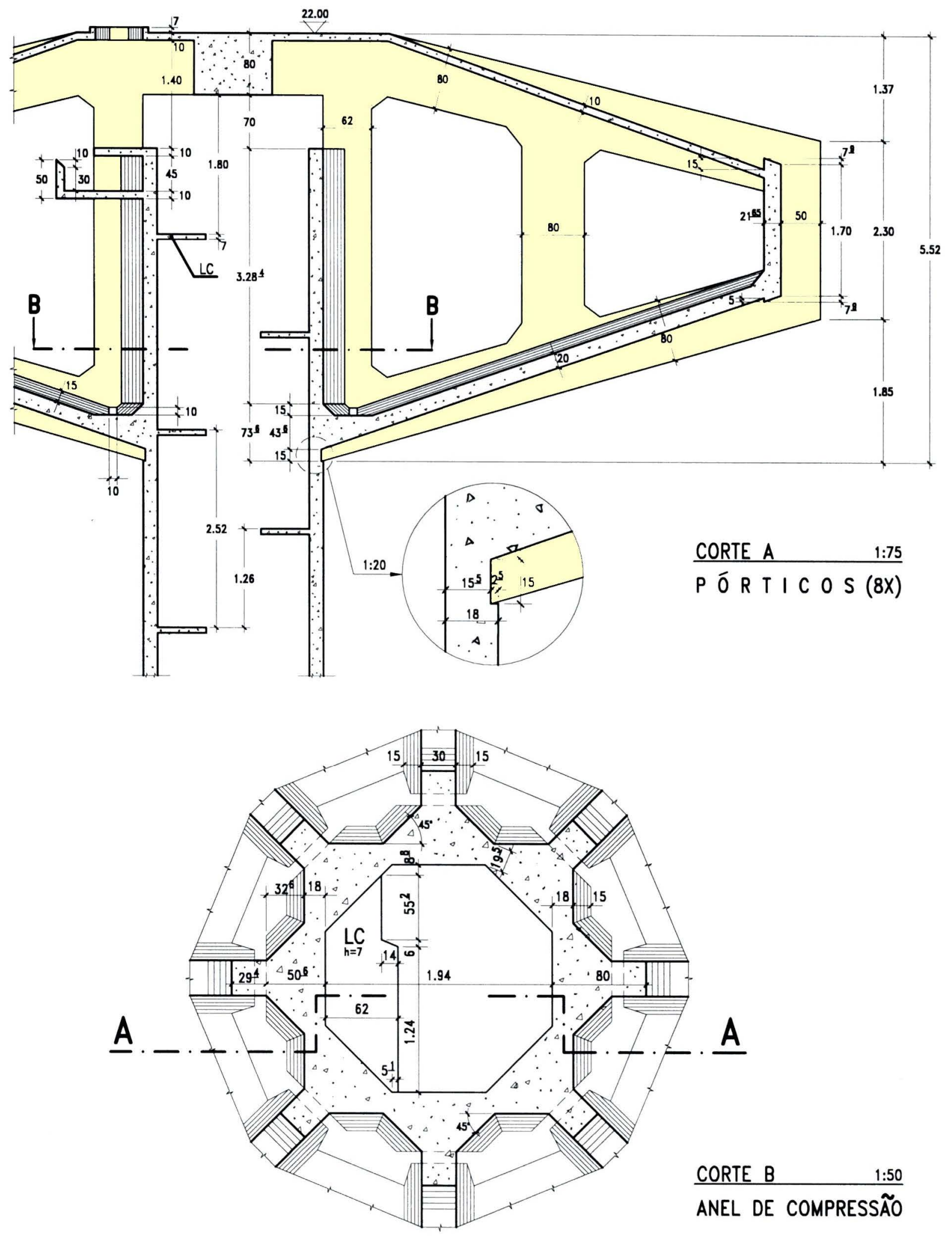

Figura 2.21 - Cortes A e B do reservatório elevado de Santa Rita do Passa Quatro 


\subsection{CLASSIFICAÇÃO ESTRUTURAL E CONSTRUTIVA DOS RESERVATÓRIOS}

Os reservatórios podem ser classificados sob vários aspectos. Porém serão apresentadas aqui apenas as classificações relativas aos aspectos estruturais e construtivos.

\subsubsection{Quanto à posição das cubas em relação ao solo}

a) Reservatórios elevados

$\underline{\text { Torres com fuste }}$

Reservatórios pequenos a grandes (Figura 2.22):

$\phi_{\text {fuste }}<\phi_{\text {cuba }} \rightarrow$ reservatórios grandes e médios

$\phi_{\text {fuste }}=\phi_{\text {cuba }} \rightarrow$ reservatórios médios e pequenos

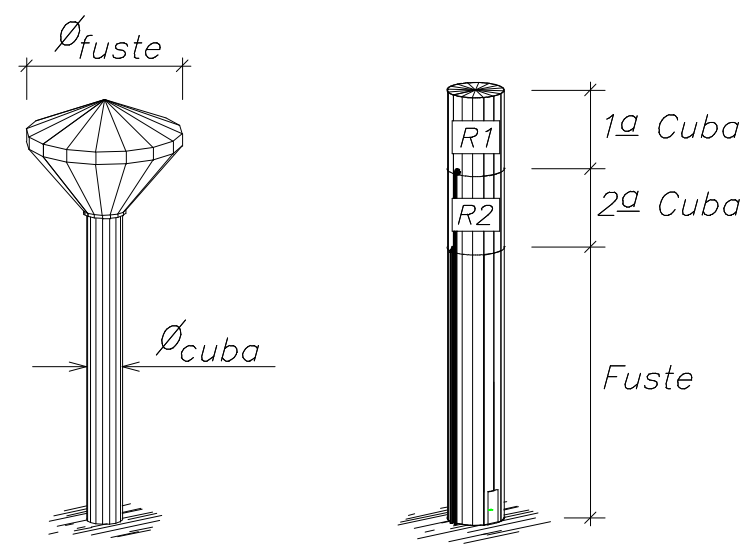

Figura 2.22 - Reservatórios elevados sobre fuste, mais comuns.

$\underline{\text { Torres com pilares }}$

Reservatórios pequenos (escolas, indústrias, residências e edifícios)

(Figura 2.23). 


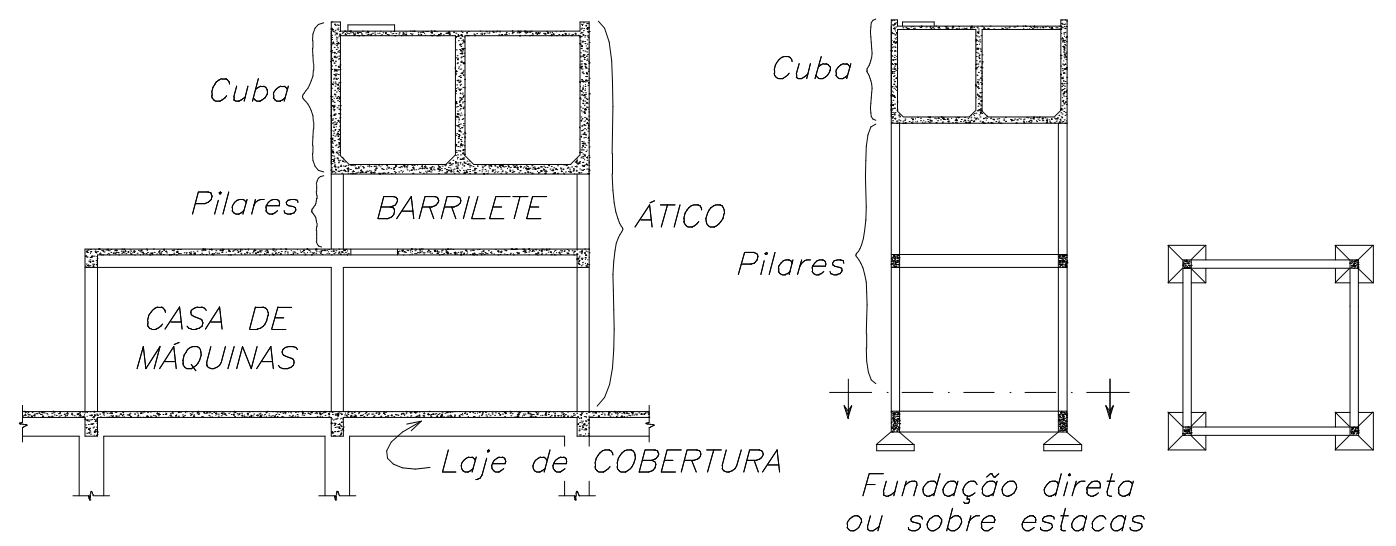

(a) Nos edifícios

(b) Escolas, indústrias, etc.

Figura 2.23 - Reservatórios elevados sobre pilares, mais comuns.

\section{b) Reservatórios térreos}

\section{Fundação sobre estacas}

Piscinas, reservatórios médios e grandes de abastecimento de cidade, quando o solo é ruim para fundação direta.

Obs.: A solução para a laje do fundo é obrigatoriamente em laje-cogumelo!

Fundação direta (é a mais econômica) (Figura 2.24)

\section{REGRA:}

"Só projetar em fundação direta quando o solo for próprio para este tipo de fundação."

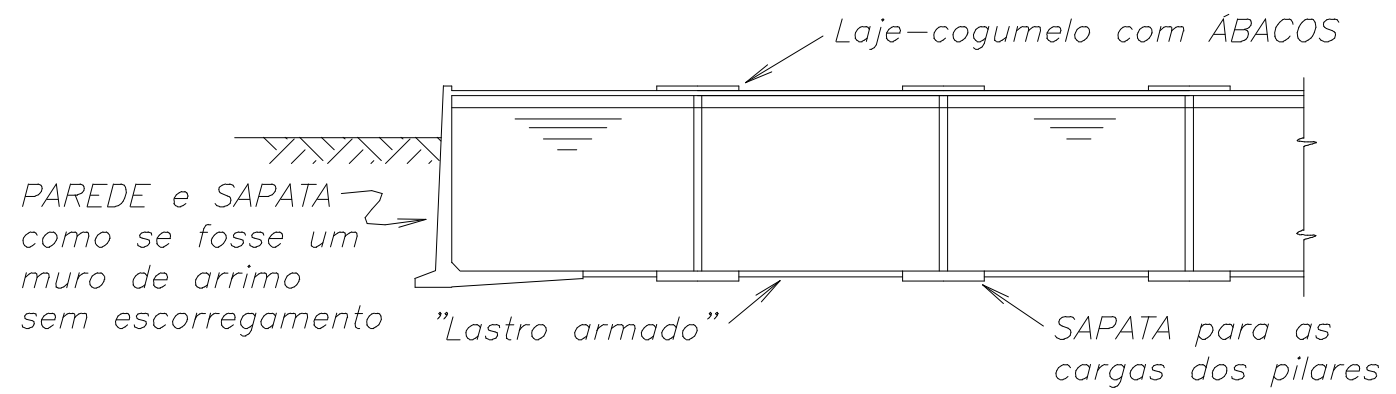

Figura 2.24 - Seção transversal de um reservatório em fundação direta com cobertura em lajecogumelo com ábacos. 
Obs.: Como exceção a esta regra, pequenos e rígidos reservatórios totalmente enterrados podem ser apoiados diretamente sobre "solos não aterrados". Ex.: reservatórios inferiores de edifícios residenciais são normalmente executados em fundação direta.

\subsubsection{Quanto à forma das superfícies média das cubas ${ }^{9}$}

Quanto às formas das superfícies médias dos elementos estruturais de superfície que compõem as suas cubas, os reservatórios podem ser classificados em:

a) Reservatórios em cascas (superfícies médias curvas) (Figura 2.25)

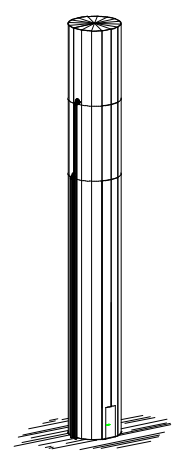

(a) Cubas Cilíndricas

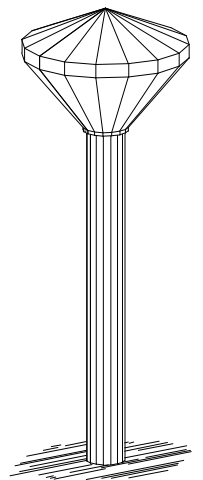

(b) Cubas Cônicas

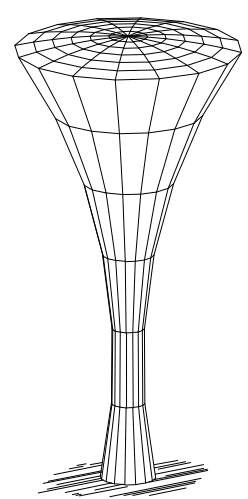

(c) Cubas de revolução com geratriz curva

Figura 2.25 - Reservatórios elevados com as cubas em cascas

b) Reservatórios piramidais (superfícies médias planas, em forma de troncos de pirâmides, eventualmente com pequenos trechos prismáticos) (Figura 2.26)

São de ocorrência mais rara, sendo mais comum entre eles os elevados de base quadrada.

9 Esta classificação é muito importante do ponto de vista estrutural porque separa os reservatórios em três grupos bem diferentes quanto aos aspectos estruturais e construtivos, ou seja, o grupo das CASCAS, que apresenta um grau maior de dificuldade na execução dos projetos e das estruturas, o grupo dos PIRAMIDAIS, com dificuldade apenas de projeto, e o grupo dos PRISMÀTICOS, que em geral não apresentam maiores dificuldades nestes aspectos. 


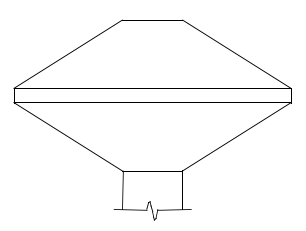

Figura 2.26 - Cubas tronco-piramidais

c) Reservatórios prismáticos (superfícies médias planas, em forma de prismas retos) (Figura 2.27)

São projetados com seção triangular, hexagonal, octogonal e, com muito mais frequiência, com seção retangular. Estes, denominados reservatórios PARALELEPIPÉDICOS ${ }^{10}$, formam a grande maioria dos reservatórios térreos e até dos pequenos reservatórios elevados e a elaboração dos seus projetos é exatamente o objetivo principal da dissertação.

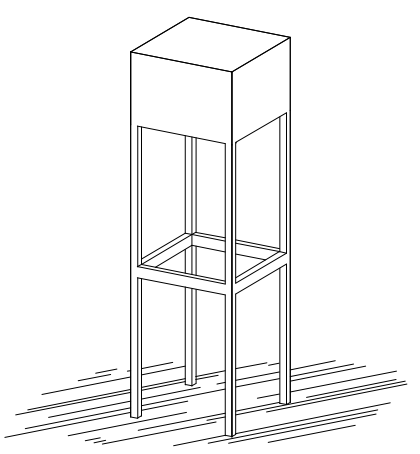

(a) Reservatórios elevados para indústrias, escolas, etc.
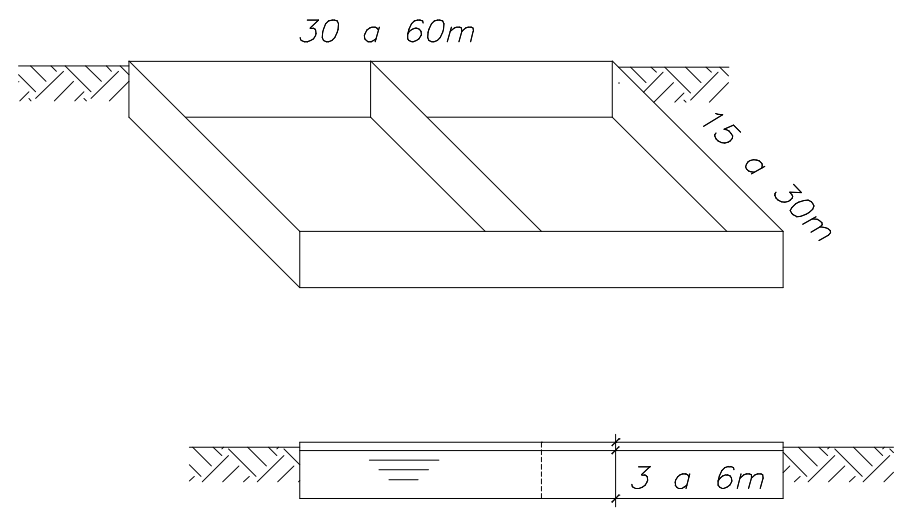

(b) Reservatórios para abastecimento de cidades.

Figura 2.27 - Exemplos de reservatórios paralelepipédicos

Assim sendo, será introduzida agora uma complementação nesta classificação, muito importante para o cálculo e para as análises dos esforços dos reservatórios paralelepipédicos, que é a separação das suas cubas nos seguintes grupos:

\footnotetext{
${ }^{10}$ A diferença, do ponto de vista de projeto estrutural, entre os reservatórios PARALELEPIPÉDICOS e os demais PRISMÁTICOS, é muito pequena. A dissertação analisa só os paralelepipédicos com a intenção de simplificar as exposições e as exemplificações.
} 
- Cubas achatadas: são aquelas onde a altura é muito menor do que os outros dois lados, ou seja, $\mathrm{h}<<\underline{\mathrm{a}}$ e $\underline{\mathrm{b}}$.

Ocorrência:

A quase totalidade dos grandes reservatórios térreos e das piscinas, etc.

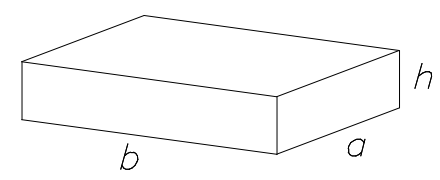

- Cubas alongadas: são aquelas onde o comprimento é bem maior do que a largura e a altura, ou seja, a $>>\underline{b}$ e $\underline{h}$.

Ocorrência:

Reservatórios especiais para captação de água, tanques, canais, etc.

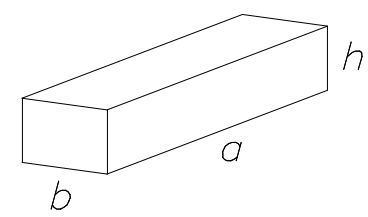

- Cubas cúbicas: são aquelas onde os dois lados e a altura são da mesma ordem de grandeza ${ }^{11}$, ou seja, $a \sim b \sim h$.

Ocorrência:

Reservatórios térreos dos edifícios, pequenos reservatórios elevados de indústrias, escolas e residências,

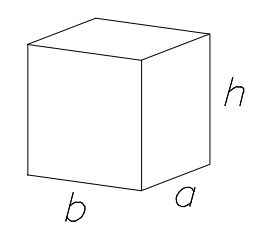
etc.

\subsubsection{Quanto ao tipo de fundação}

a) Em fundação direta

b) Sobre estacas e/ou tubulões

Obs.: Só se usam tubulões em reservatórios elevados e, evidentemente, se for a solução técnica e economicamente mais indicada.

11 Por mesma ordem de grandeza, entende-se aqui uma relação entre dois comprimentos que não sejam inferiores a $1 / 3$ e nem superem 3 . 


\title{
2.4.4. Quanto ao processo construtivo
}

\author{
a) Moldados in loco
}

Com fôrmas tradicionais

Com fôrmas deslizantes (Figura 2.28)
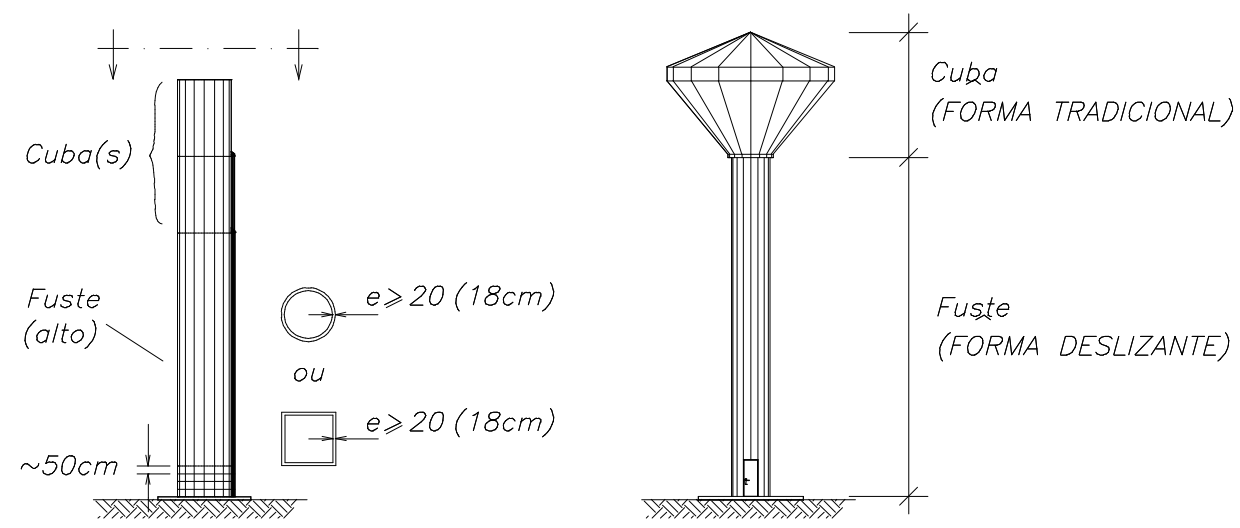

Figura 2.28 - Reservatórios executados mais freqüentemente com fôrmas deslizantes.

Com fôrmas trepantes (Figura 2.29)

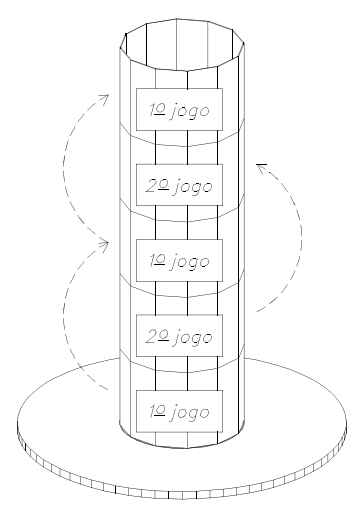

Figura 2.29 - Indicação do uso de fôrmas trepantes em um reservatório.

Usam-se dois jogos de fôrmas especiais de até $2 \mathrm{~m}$ de altura (folhas de madeirit plastificado com reforço metálico nas bordas para fixação com parafusos).

Os jogos de fôrmas se alternam nas concretagens: enquanto endurece a segunda concretagem desforma-se o primeiro trecho concretado, posicionando-se esse jogo 
de fôrmas sobre o segundo trecho concretado, concretando-se em seguida um terceiro trecho do fuste. E assim sucessivamente.

Obs.: Em geral usa-se a fôrma tradicional para os reservatórios térreos e para os elevados sobre pilares. Para os elevados sobre fustes, são mais usuais as fôrmas deslizantes e trepantes.

b) Pós-elevados ${ }^{12}$

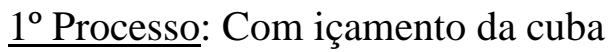

Primeiro o fuste é executado com fôrmas deslizantes e depois a cuba é feita em torno do fuste, no chão, pelo processo tradicional. Finalmente a cuba é içada por macacos hidráulicos posicionados no topo do fuste, até a posição prevista no projeto e aí fixada ao fuste por concretagens de trechos com chumbadores comuns a ambas as partes (Figura 2.30).

Obs.: Este processo já se usa no BRASIL há mais de 30 anos e veio para concorrer com o sistema de cimbramentos tubulares, necessários para reservatórios elevados com $\phi_{\text {cuba }}>\phi_{\text {fuste }}$

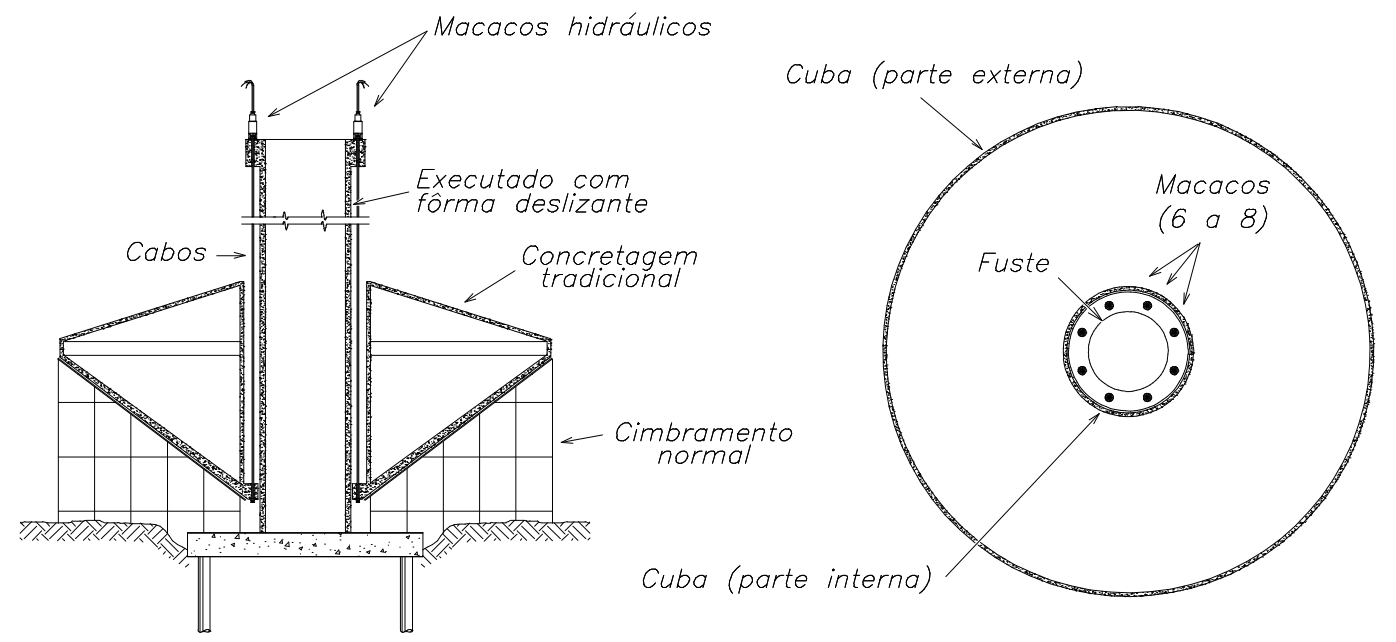

Figura 2.30 - Ilustração do início da suspensão via macacos hidráulicos, posicionados no topo do fuste, da cuba executada no chão, com uso de fôrmas tradicionais.

${ }^{12}$ HANAI, J.B. (1977). Reservatórios com parede ondulada: Introdução. Dissertação (Mestrado) EESC-USP. 
$\underline{2^{\circ} \text { Processo: }}$ Com execução do fuste por trechos, sob a cuba.

A cuba é feita no chão (concretagem tradicional). O fuste é executado sob a cuba que por sua vez é levantada com macacos apoiados no fuste já endurecido (Figura 2.31).

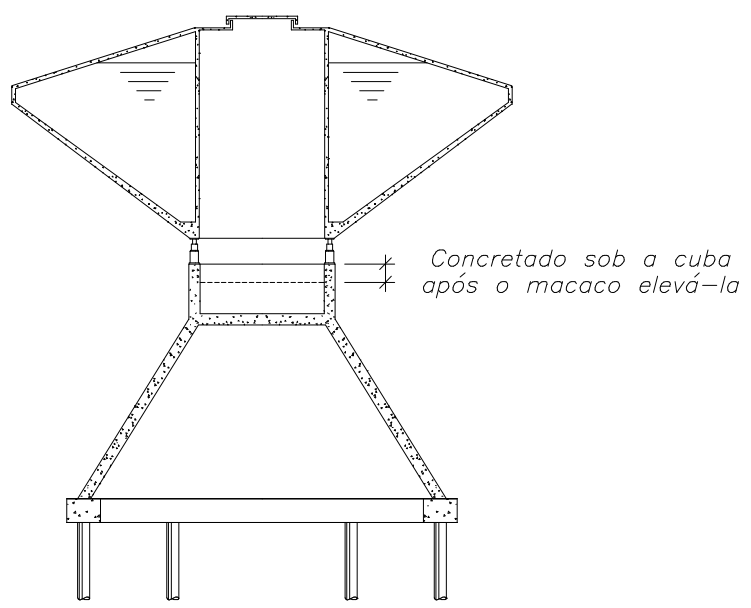

Figura 2.31 - Ilustração do início da concretagem do fuste sob a cuba

Obs.: Este processo, muito usado na Europa, não foi incorporado ou adotado pelas construtoras nacionais.

\section{c) Pré-moldados}

É mais comum a ocorrência desse sistema nos reservatórios elevados, pequenos e médios.

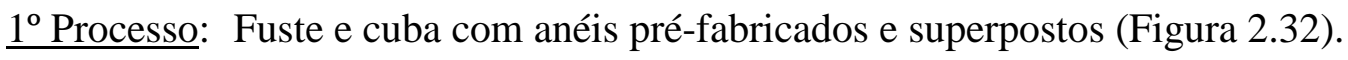
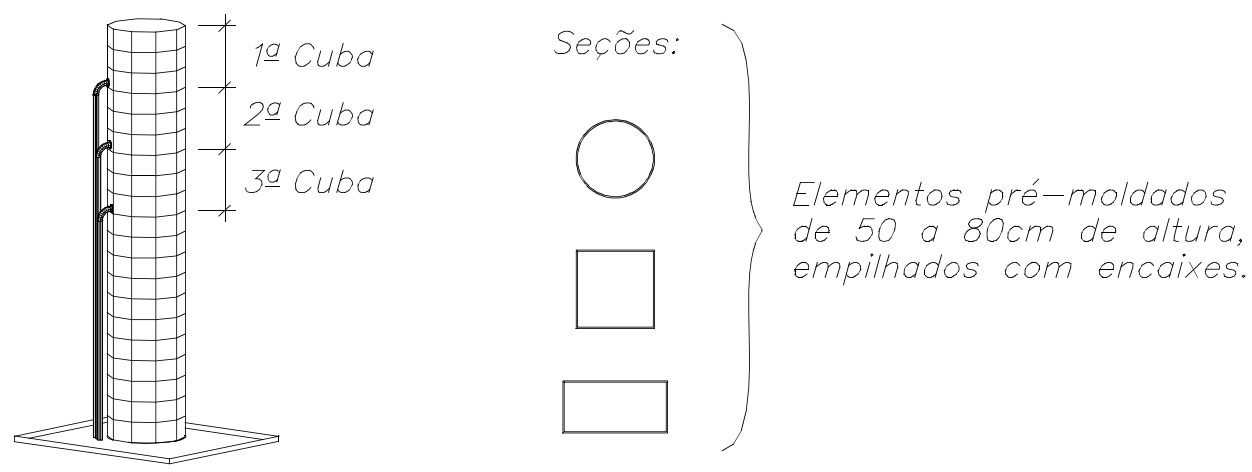

Figura 2.32- Reservatório cilíndrico executado com elementos pré-fabricados. 
2 ${ }^{\circ}$ Processo: Torres de pilares, em geral subdivididas em trechos pré-moldados e superpostos, que recebem cubas também pré-moldadas (Figuras 2.33 e 2.34$)$.

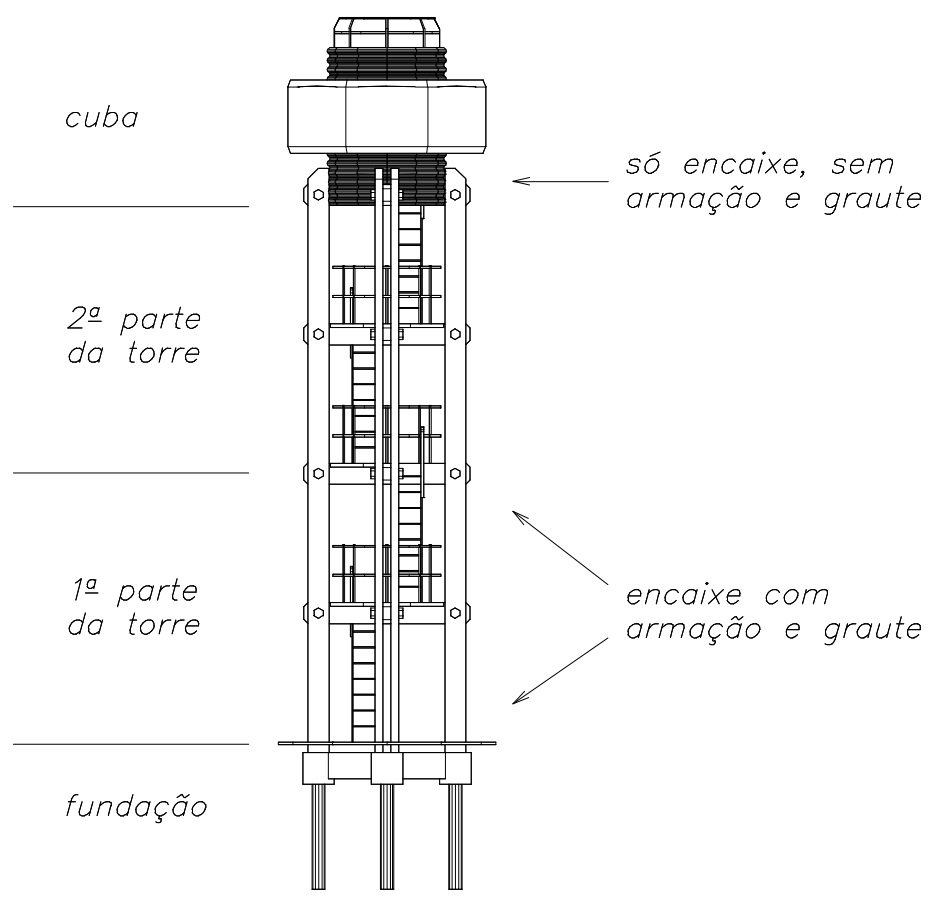

Figura 2.33- Reservatório elevado e pré-fabricado para a Faculdade de Engenharia Civil da Unicamp.

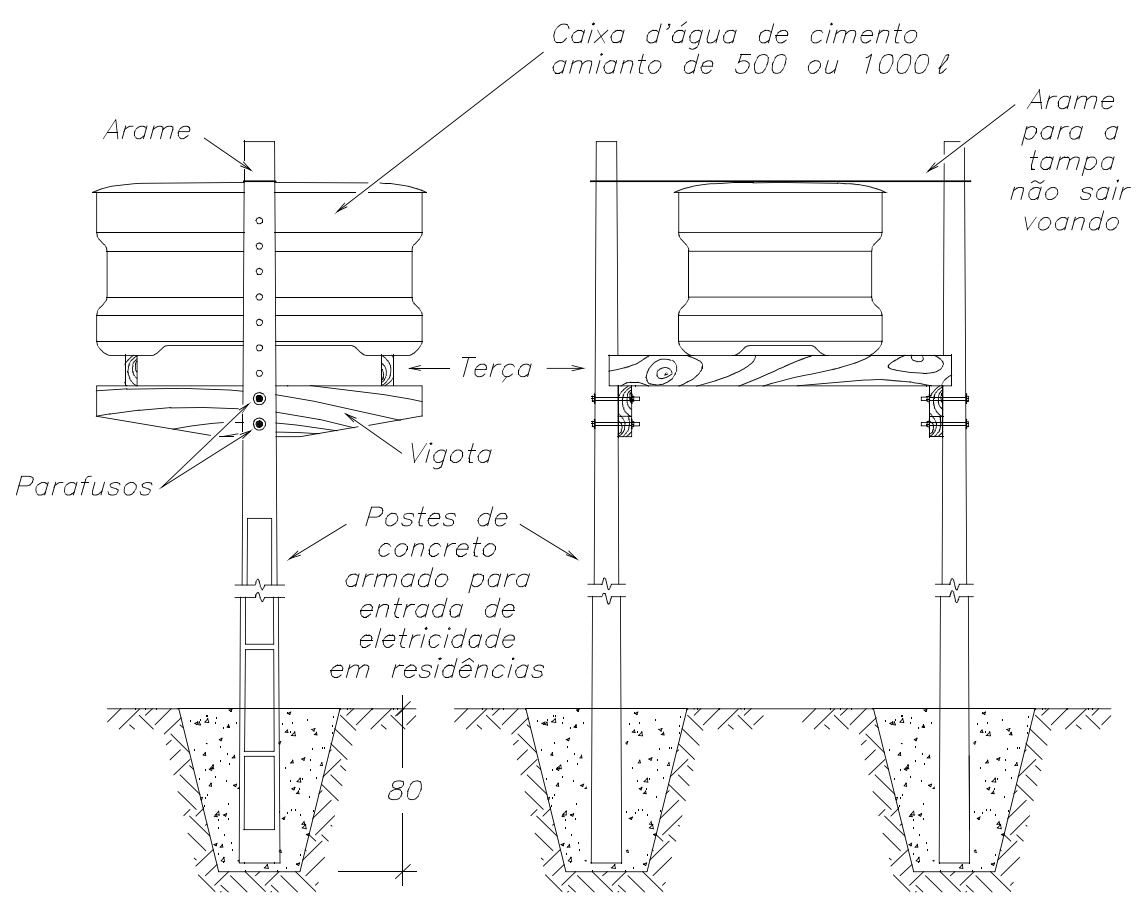

Figura 2.34 - Caixa d'água de 1000 1, executada em propriedade rural. 


\subsubsection{Quanto ao volume de água $\operatorname{armazenada}^{13}$}

Será apresentada aqui uma classificação, pessoal, para os reservatórios elevados e uma outra para os térreos, uma vez que são dois tipos de estruturas bem diferentes. Por exemplo as dificuldades para a elaboração de um projeto estrutural bem como para a execução de um reservatório térreo de $5000 \mathrm{~m}^{3}$, nem de longe se comparam com as dificuldades correspondentes ao reservatório elevado com essa mesma capacidade. Assim sendo, temos:

- Para os elevados:

$$
\begin{aligned}
& \text { pequenos............ V }<50 \mathrm{~m}^{3} \\
& \text { médios...... } 50 \mathrm{~m}^{3} \leq \mathrm{V}<500 \mathrm{~m}^{3} \\
& \text { grandes................ } \mathrm{V} \geq 500 \mathrm{~m}^{3}
\end{aligned}
$$

- Para os térreos:

$$
\begin{aligned}
& \text { pequenos.............. V }<500 \mathrm{~m}^{3} \\
& \text { médios...... } 500 \mathrm{~m}^{3} \leq \mathrm{V}<5000 \mathrm{~m}^{3} \\
& \text { grandes................. V } \geq 5000 \mathrm{~m}^{3}
\end{aligned}
$$

\section{NOTAS:}

É comum encontrar reservatórios pequenos e até alguns médios, paralelepipédicos e sobre pilares, em pequenas indústrias e pequenas escolas.

Também é muito usual encontrar reservatórios médios em fôrmas cilíndricas com fustes e cubas de mesmo diâmetro, em indústrias, escolas e em redes de abastecimento de água de municípios.

Já os reservatórios grandes são mais encontrados em cascas de revolução, troncônicas e ainda cilíndricas, com $\phi_{\text {cuba }}>\phi_{\text {fuste }}$.

13 Esta classificação pode parecer não ter muita importância para os projetos estruturais. Entretanto, são bons indicadores de tipos de reservatórios bem como das dificuldades que se pode ter com os seus respectivos projetos estruturais. 


\subsubsection{Resumo das classificações}

1-Quanto à posição da cuba
em relação ao solo $\left\{\begin{array}{l}\text { elevados } \\ \text { térreos }\end{array}\left\{\begin{array}{l}\text { torres com pilares } \\ \text { torres com fuste }\end{array}\right.\right.$

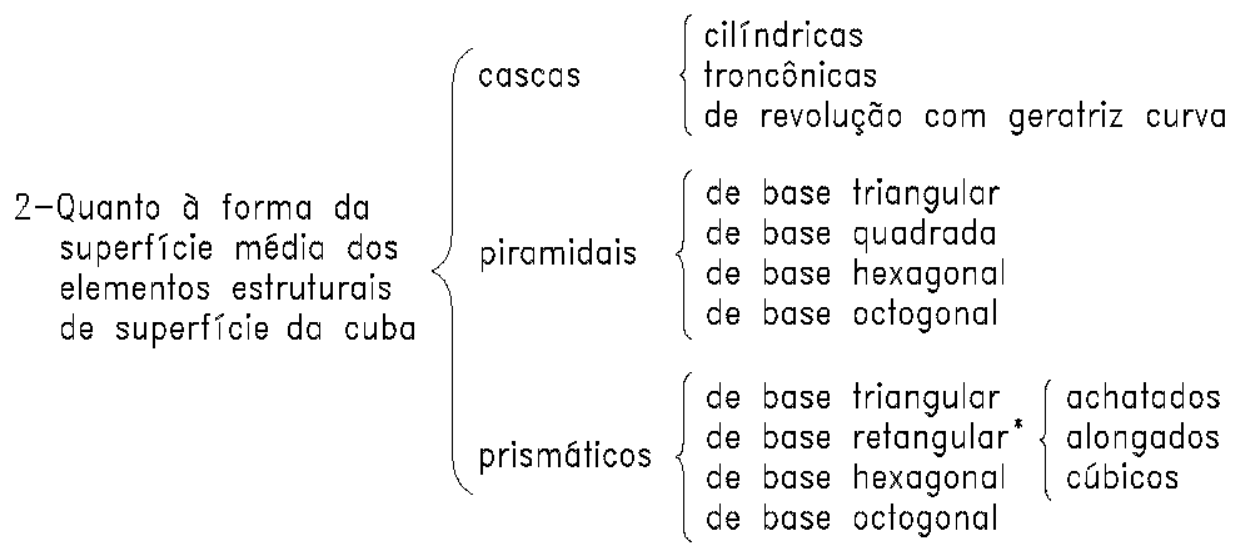

3-Quanto às fundações $\left\{\begin{array}{l}\text { diretas } \\ \text { sobre estacas ou tubulões }\end{array}\right.$

4-Quanto do processo construtivo $\left\{\begin{array}{l}\text { moldados in loco }\left\{\begin{array}{l}\text { com fôrmas tradicionais } \\ \text { com fôrmas deslizantes } \\ \text { com fôrmas trepantes }\end{array}\right. \\ \text { pós-elevados, com içamento posterior da cuba } \\ \text { pré-moldados, com a torre dividida em segmentos }\end{array}\right.$

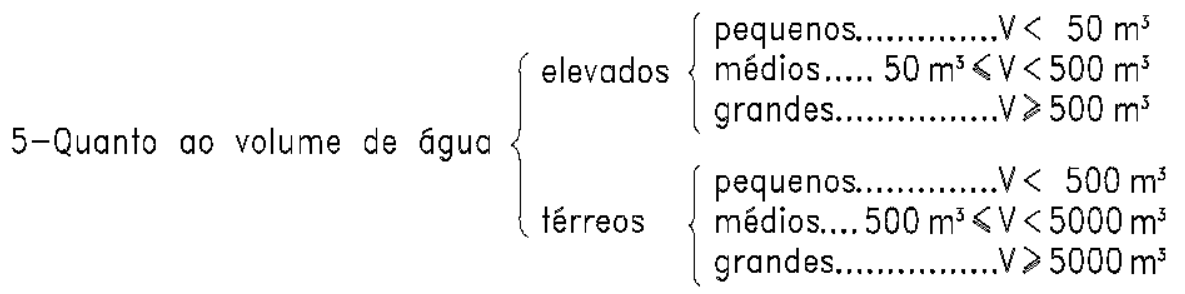

* denominados reservatórios paralelepipédicos 


\subsubsection{Tipos de reservatórios paralelepipédicos}

Com a classificação apresentada no item anterior, fica fácil estabelecer os TIPOS DE RESERVATÓRIOS PARALELEPIPÉDICOS, que estão indicados na tabela 2.1.

Tabela 2.1 - Tipos de reservatórios paralelepipédicos em concreto armado

\begin{tabular}{|c|c|c|c|}
\hline POSIÇÃOO RE & A AO SOLO & TIPO DAS FUNDAÇÕES & FORMA DA CUBA \\
\hline \multirow{4}{*}{ ELEVADOS } & \multirow{2}{*}{ COM PILARES } & DIRETA & CÚBICA \\
\hline & & $\begin{array}{l}\text { COM ESTACAS } \\
\text { (OU TUBULOES) }\end{array}$ & CUBICA \\
\hline & \multirow{2}{*}{ COM FUSTE } & DIRETA & $\begin{array}{c}\text { CUBICA } \\
\text { ALONGADA }\end{array}$ \\
\hline & & $\begin{array}{l}\text { COM ESTACAS } \\
\text { (OU TUBULOES) }\end{array}$ & $\begin{array}{c}\text { CUBBICA } \\
\text { ALONGADA }\end{array}$ \\
\hline \multirow{2}{*}{\multicolumn{2}{|c|}{ TERREOS }} & DIRETA & $\begin{array}{c}\text { ACHATADA } \\
\text { ALONGADA } \\
\text { CUBICA }\end{array}$ \\
\hline & & COM ESTACAS & $\begin{array}{c}\text { ACHATADA } \\
\text { ALONGADA } \\
\text { CUBICA }\end{array}$ \\
\hline
\end{tabular}




\section{CONSIDERAÇÕES SOBRE OS PROJETOS DE RESERVATÓRIOS PARALELEPIPÉDICOS}

Em geral, os projetos estruturais têm as mesmas etapas, com algumas diferenças conforme o tipo da estrutura.

Para as estruturas de reservatórios estas etapas são:

1a Etapa - Escolha do material de que deve ser feito o reservatório, definição da sua forma ideal bem como dos seus elementos estruturais principais;

2 a Etapa - Prever todas as ações que atuam no reservatório e definir os carregamentos;

3a Etapa - Para cada carregamento, definir os diferentes trechos estruturais do reservatório com os respectivos esquemas estáticos, calculando para cada um deles os seus principais esforços. Verificar as fundações. Verificar também a estabilidade, quando necessário.

4a Etapa - Dimensionar todos os elementos estruturais dos reservatórios, detalhar as respectivas armaduras e verificar a fissuração nos pontos mais críticos. 


\subsection{MATERIAIS, FORMAS E ELEMENTOS ESTRUTURAIS PRINCIPAIS: 1a ETAPA}

O concreto armado, em função da sua resistência, da sua durabilidade e, principalmente, da sua estanqueidade, é o material mais adequado e mais utilizado na execução de reservatórios.

Em situações especiais outros materiais são empregados, tais como:

- Argamassa armada;

- Aço;

- Alvenaria estrutural com blocos de concreto;

- Alvenaria estrutural com tijolos maciços.

Estes dois últimos são usados apenas para pequenas alturas de água.

Por limitações dos objetivos deste trabalho, analisar-se-ão aqui apenas os reservatórios compostos de lajes e paredes de concreto armado e na forma paralelepipedal.

Entretanto, por serem muito mais frequientes as construções destes reservatórios, não será menor a importância dos assuntos aqui apresentados, mesmo porque muitos deles continuam valendo ou são facilmente adaptados para outros tipos de materiais ou de formas adotadas.

Ainda, pela ênfase à durabilidade ${ }^{1}$ das estruturas dada pela nova redação da NB-1, recomenda-se, nas paredes e nas lajes de fundo, o uso do concreto classe C25 $\left(f_{c k}=25 \mathrm{MPa}\right)$ com $a / c=0,60$. Já nas lajes de cobertura é recomendado usar concreto C 30 com $a / c=0,55$, devido às suas faces inferiores estarem expostas em ambiente de agressividade forte com grande risco de deterioração da mesma ao longo do tempo. Quanto aos aços deve ser usado apenas o CA-50 e com bitolas até $22 \mathrm{~mm}$. Bitolas acima de $22 \mathrm{~mm}$, além de não serem necessárias, são inviáveis em face da fissu-

${ }^{1}$ Ver item 10.4 do capítulo 10 da nova redação, com atenção especial ao item 10.4.5 que diz: "A durabilidade das estruturas de concreto armado e protendido é altamente dependente da qualidade e da espessura do concreto de cobrimento das armaduras". 
ração, como pela mesma razão é inviável também o emprego do aço CA-60, qualquer que seja a sua bitola ${ }^{2}$.

Finalizando, deve-se registrar que lamentavelmente os projetos hidráulicos dos reservatórios, na grande maioria dos casos, chegam às mãos dos calculistas com os materiais e as formas já definidas, cabendo a estes apenas a escolha da classe do concreto e da categoria do aço, das dimensões necessárias para as lajes e paredes, e a escolha dos arranjos estruturais, das lajes de cobertura, das lajes de fundo e das fundações.

\subsection{AÇÕES E CARREGAMENTOS: 2a ETAPA}

\subsubsection{Conceitos e definições}

Admitir-se-á aqui o conhecimento prévio dos principais conceitos e definições da norma de AÇÕES E SEGURANÇA NAS ESTRUTURAS (NBR-8681). Entretanto, alguns deles serão particularizados e ou ligeiramente modificados, visando sempre os aspectos didáticos, mesmo que com isto se perca um pouco de generalidade.

Assim sendo, apresentam-se a seguir as simplificações, as modificações e algumas simbologias particulares adotadas.

\section{a) Ações que podem atuar nos reservatórios}

Por ação, entende-se toda e qualquer causa que provoque o aparecimento de esforços e deformações nas estruturas. São de dois tipos: AÇÕES INDIRETAS e DIRETAS.

As AÇÕES INDIRETAS são aquelas que impõem deformações nas estruturas e, conseqüentemente, esforços. Ou sejam:

- Fluência;

\footnotetext{
2 A nova NB-1 em seu item 8.2.2 especifica para os aços CA-60 em região de boa aderência, os valores de $\eta=1,0$ para as barras lisas e $\eta=1,2$ para as barras dentadas. Para os aços CA-50, nas mesmas condições de aderência ela especifica $\eta=2,25$. Assim, pelas expressões do item 17.2.2.1, obtém-se com CA-60 uma abertura de fissura 3,3 maior às fissuras obtidas com o aço CA-50.
} 
- Retração;

- Variação de temperatura;

- Deslocamentos de apoio e

- Imperfeições geométricas.

Contudo, assim como para os edifícios comuns, estas ações não fazem parte dos carregamentos com que se calculam os reservatórios. Na prática são tomados alguns cuidados especiais na elaboração dos projetos estruturais dos reservatórios, bem como na execução dos mesmos, para se minimizar as influências deletérias dessas ações.

Quanto a estes cuidados, pode-se dizer que para FLUÊNCIA não existe nenhuma recomendação especial, a não ser respeitar os prazos mínimos para as desformas, especificadas no item 14.2.1 da NBR-6118.

Para minimizar os problemas com a RETRAÇÃO é recomendável indicar nos projetos estruturais as posições das juntas de concretagem verticais e horizontais, conforme visto em 2.3.2a. Ainda, deve-se adotar uma boa armadura mínima por face, para todas as paredes e lajes do fundo, independentemente das direções das armaduras e de se ter ou não esforços de tração. Diante da omissão das normas brasileiras quanto a esta armadura, sugere-se adotar o valor especificado pelo ACI 318-63, ou seja, $A_{\mathrm{s} \min }=0,125 \% \mathrm{~b} \cdot \mathrm{h}$ por face, onde $\mathrm{b}$ é a largura de cálculo $(1,00 \mathrm{~m})$ e $\mathrm{h}$ é a espessura da laje ou parede (Figura 3.1).

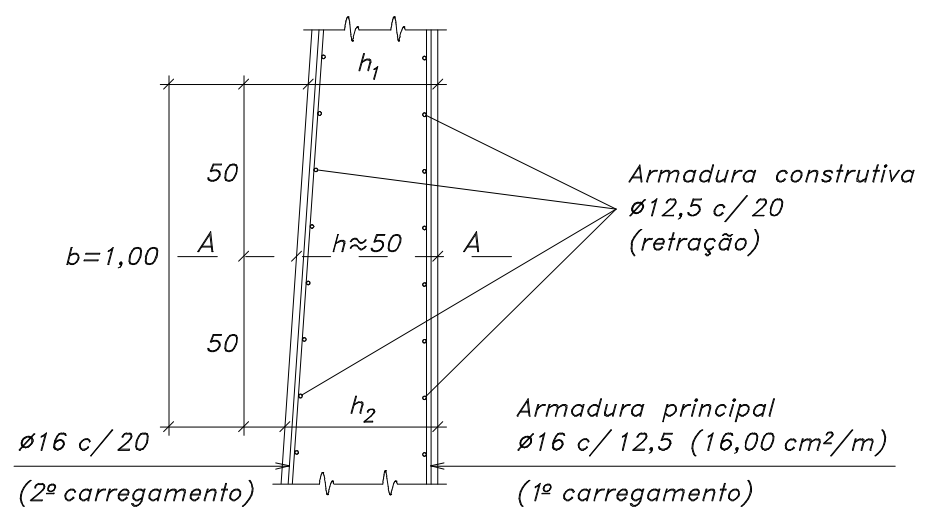

Figura 3.1 - Corte vertical de um trecho de uma parede de um reservatório. 
Se se tomar como exemplo que a figura 3.1 seja a seção vertical (parte inferior, perto da laje do fundo) na região central de uma parede de $30 \mathrm{~m}$ de comprimento, a armadura horizontal construtiva deve ser igual ou superior a $0,125 \times 50=6,25 \mathrm{~cm}^{2} / \mathrm{m} \times$ face ou $\phi 12,5 \mathrm{c} / 20$. Para a metade superior das paredes, como h é igual ou inferior a $30 \mathrm{~cm}$, pode-se colocar nos trechos centrais das paredes $\phi 10 \mathrm{c} / 20$ por face.

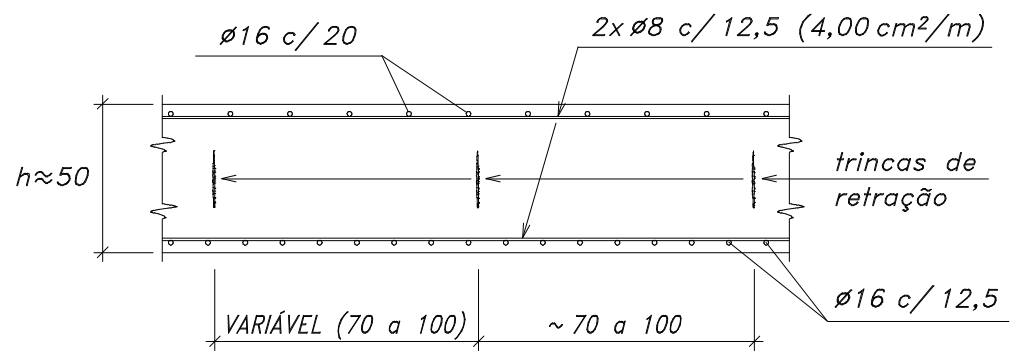

Figura 3.2 -Corte A da figura 3.1 com armadura de retração inferior à mínima.

A não obediência destes valores mínimos permitirá o desenvolvimento de trincas, maiores no centro e diminuindo nas proximidades das armaduras construtivas, que podem comprometer a estanqueidade do reservatório (Figura 3.2).

Finalizando, para espessuras maiores de $50 \mathrm{~cm}$ pode ser mais eficiente a colocação de barras no meio da espessura da parede, adaptando a expressão do ACI para $\mathrm{A}_{\mathrm{s} \min }=\frac{0,25 \% \mathrm{~b} \cdot \mathrm{h}}{\mathrm{n}}$, onde $\mathrm{n}$ é o número de barras colocadas na espessura para combater a retração.

Já na execução, três recomendações devem ser seguidas:

- Uma cura muito bem executada ainda é o melhor e o mais econômico meio para se atenuar os problemas com a retração;

- Evitar juntas desnecessárias, limitando-se se possível apenas às duas juntas de concretagem verticais, no início e no fim das paredes;

- E, finalmente, executar e tratar as juntas inevitáveis, com a orientação de um engenheiro especialista em tecnologia de concreto.

Para a TEMPERATURA têm-se dois tipos de variação que podem provocar 
deslocamentos e conseqüentemente esforços nas estruturas, ou sejam:

- VARIAÇÃO NÃO UNIFORME SIMULTÂNEA;

- VARIAÇÃO UNIFORME AO LONGO DO TEMPO.

A VARIAÇÃO NÃO UNIFORME SIMULTÂNEA, existindo em pontos próximos de um elemento estrutural hiperestático, pode provocar nele esforços significativos. Entretanto as maiores diferenças simultâneas de temperatura que ocorrem nas lajes e paredes de reservatórios provocam deslocamentos muito pequenos e seus esforços são normalmente desprezados.

Já para a VARIAÇÃO UNIFORME AO LONGO DO TEMPO, as lajes de cobertura e paredes de reservatórios térreos quando expostas ao sol podem sofrer deformações e, conseqüentemente, esforços significativos que podem se estender até às lajes de fundo. Até, com a intenção de diminuir esses esforços, é usual colocar argila expandida sobre as lajes de cobertura.

Quanto à parte estrutural, as análises e as recomendações que se pode fazer são as seguintes.

No item 3.1.1.4, a NBR-6118 dispensa o cálculo da influência da variação da temperatura para as peças permanentemente envolvidas por terra ou água e para os edifícios que não tenham dimensão em planta maior do que $30 \mathrm{~m}$.

Ainda nesse item, ela especifica que as temperaturas sejam uniformes em toda a estrutura como também as temperaturas máximas e mínimas que possam ocorrer ao longo da sua vida útil. Também, permite supor que as obras sejam executadas na temperatura média do local das mesmas e impõe uma oscilação em torno dessa média de $\pm 10{ }^{\circ} \mathrm{C} \mathrm{a} \pm 15^{\circ} \mathrm{C}^{3}$. Fixa também, um coeficiente de dilatação térmica para o

\footnotetext{
${ }^{3}$ VAN LANGENDONCK, T.H.M. (1962). Cálculo de Concreto Armado: Comentários à Norma Brasileira NB-1 - Itens 1 a 13. São Paulo, Associação Brasileira de Cimento Portland. p.8388.
}

Nesse trabalho, na página 87 , é indicado que para os estados do norte se tome o primeiro intervalo de $\Delta \mathrm{t}\left( \pm 10^{\circ} \mathrm{C}\right)$ pois que a diferença entre o máximo e o mínimo absolutos, durante todo o ano, raramente ultrapassa $20^{\circ} \mathrm{C}$, e que para os estados do sul se tome o segundo intervalo $\left( \pm 15^{\circ} \mathrm{C}\right)$, uma vez que a diferença entre a maior média mensal das máximas e a menor média mensal das mínimas anda em torno de $20{ }^{\circ} \mathrm{C}$. Como estes valores foram fixados com base em dados de 1938 (ver final do $§ 78$, p.150 em VAN LANGENDONCK, T.H.M. (1959). Cálculo de Concreto Armado. ABCP. 3.ed. Rio de Janeiro, Editora Científica. v.1.), eles poderiam ser revistos agora com análises estatísticas em cima de um universo bem maior de temperaturas e à luz dos novos conceitos probabilísticos de 
concreto armado igual $10^{-5}$ por um grau Celsius.

Analisando os vários tipos de reservatórios sob a luz deste item da norma, vêse facilmente que os elevados e os térreos sem lajes de cobertura (piscinas, canais, tanques, etc. ${ }^{4}$ ) não são afetados pela variação da temperatura.

Apenas os reservatórios térreos e com lajes de cobertura expostas ao sol é que podem sofrer com essa variação. Assim sendo, serão feitas a seguir, análises da influência da temperatura em cada um dos elementos estruturais dos reservatórios térreos cobertos.

As lajes do fundo, quer seja pelo contato das suas superfícies com água e terra e também por não se projetar cubas com mais de $30 \mathrm{~m}$, não se tem problemas com a temperatura com exceção de acréscimos em seus momentos de até $20 \%$, pelo efeito da temperatura nas lajes de cobertura.

Quanto às paredes, elementos muito rígidos nos seus planos verticais, mesmo sendo de reservatórios térreos ao nível da superfície, com uma de suas faces exposta ao sol, não acusam os efeitos negativos da variação da temperatura pelos seguintes motivos: primeiro porque a face permanentemente em contato com a água acaba reduzindo em muito as variações da temperatura $\Delta t$ ao longo da vida útil da estrutura e, segundo, porque as paredes não são impedidas de se deformarem no plano vertical, tanto quando em fundação sobre estacas como em fundação direta.

Entretanto, quanto a deslocamentos perpendiculares aos seus planos, as paredes já são mais sensíveis e conseqüentemente podem sofrer com os deslocamentos provocados pela variação da temperatura nas lajes de cobertura.

Finalmente, as lajes de cobertura, por terem espessuras pequenas e não estarem em contato com a água, atingem temperaturas médias extremas maiores que as do ambiente e, consequientemente, apresentam amplitudes $\Delta \mathrm{t}$ maiores do que as especificadas no item 3.1.1.2 da NBR-6118.

ações. Assim, definir-se-ia valores característicos de $\Delta \mathrm{t}$ para as novas regiões NORTE, NORDESTE, CENTRO OESTE, SUL e SUDESTE, bem como se poderia fazer um mapa das ISOTERMAS de $\Delta \mathrm{t}$, a exemplo das ISOPLETAS da NBR-6123.

${ }^{4}$ Nos tanques e piscinas, quando vazios por tempo excessivamente grandes, pode-se ter fissuras de cisalhamento nos cantos se lá não existirem armaduras nas duas direções e nas duas faces. 
Assim, os efeitos da variação de temperatura não devem ser mais desprezados, sem qualquer verificação e indicação de eventuais armaduras complementares.

Como critério para estas verificações, admite-se que as lajes sejam protegidas com argila expandida ou com um outro material isolante qualquer e adotam-se os valores da norma:

$$
\begin{aligned}
& \alpha=10^{-5} \text { por grau Celsius } \\
& \Delta \mathrm{t}= \pm 10^{\circ} \mathrm{C} \text { a } \pm 15^{\circ} \mathrm{C}
\end{aligned}
$$

Antes, porém, de se fazer qualquer cálculo, é preciso saber o quêe, onde e como calcular. Assim sendo, indicam-se na figura 3.3 os dois tipos de fissuração possíveis de ocorrer nas coberturas dos reservatórios, se não forem calculadas e detalhadas corretamente, avaliando-se a seguir a participação da variação da temperatura em cada uma delas, bem como a sua extensão às paredes e lajes de fundo.

\section{TRINCAS I (Figura 3.3)}

São as trincas de flexão que podem surgir na laje de cobertura, junto às paredes e na região central de cada um dos seus quatro lados. Podem ocorrer nas faces inferior ou superior, dependendo dos carregamentos críticos a que esteja submetida, ou seja:

- face inferior: reservatório cheio, sem empuxo de terra e com a variação limite inferior da temperatura $-\Delta \mathrm{t}$;

- face superior: reservatório vazio, com empuxo de terra e com a variação limite superior da temperatura $+\Delta \mathrm{t}$. 


\section{TRINCAS II (Figura 3.3a)}

São trincas de cisalhamento ${ }^{5}$ que podem aparecer nos quatro cantos da laje de cobertura. Resultam do comportamento da laje como chapa que, quando submetida a uma variação de temperatura $\Delta \mathrm{t}$, é impedida de se deslocar nos cantos (em face da grande rigidez aos deslocamentos horizontais neles existente). Conforme o sinal de $\Delta \mathrm{t}$, se desenvolvem nas seguintes direções:

- das bissetrizes dos cantos: reservatório cheio, sem empuxo de terra e com $+\Delta \mathrm{t}$;

- normal às bissetrizes: reservatório vazio, com empuxo de terra e com $-\Delta \mathrm{t}$.

Para não se afastar muito dos objetivos deste trabalho, analisar-se-ão aqui apenas as trincas I, deixando em aberto as análises das trincas II, para serem estudadas posteriormente.

\section{Análises das trincas I}

Tomou-se uma faixa central de $1,00 \mathrm{~m}$ de largura de um reservatório semelhante ao da figura 3.3, com os carregamentos abaixo e com as dimensões e as ações indicadas no esquema estático simplificado da figura 3.4 e, usando um programa para pórtico plano, obteve-se os momentos e as trações das lajes da cobertura, paredes e lajes do fundo, apresentados a seguir.

Carregamento 1a: peso próprio do concreto, peso da camada de regularização da cobertura, peso da argila expandida sobre a cobertura, peso da água no fundo e empuxo dela nas paredes e variação limite inferior da temperatura $\Delta \mathrm{t}=-15^{\circ} \mathrm{C}$.

Carregamento $1 \mathrm{~b}$ : idem ao carregamento $1 \mathrm{a}$, mas com $\Delta \mathrm{t}=+15^{\circ} \mathrm{C}$.

Carregamento 2a: idem ações do carregamento 1, trocando-se o peso e o empuxo da água pelo empuxo de terra bem como, considerando $\Delta \mathrm{t}=+15^{\circ} \mathrm{C}$.

Carregamento 2b: idem ao carregamento $2 \mathrm{a}$, mas com $\Delta \mathrm{t}=-15^{\circ} \mathrm{C}$.

5 Uma parcela destas trincas pode ser computada aos momentos volventes, que provocam trações inferiores nas bissetrizes dos cantos $\left(\mathrm{M}^{+}\right)$e tração superior perpendicularmente a essas bissetrizes $\left(\mathrm{M}^{-}\right)$. 


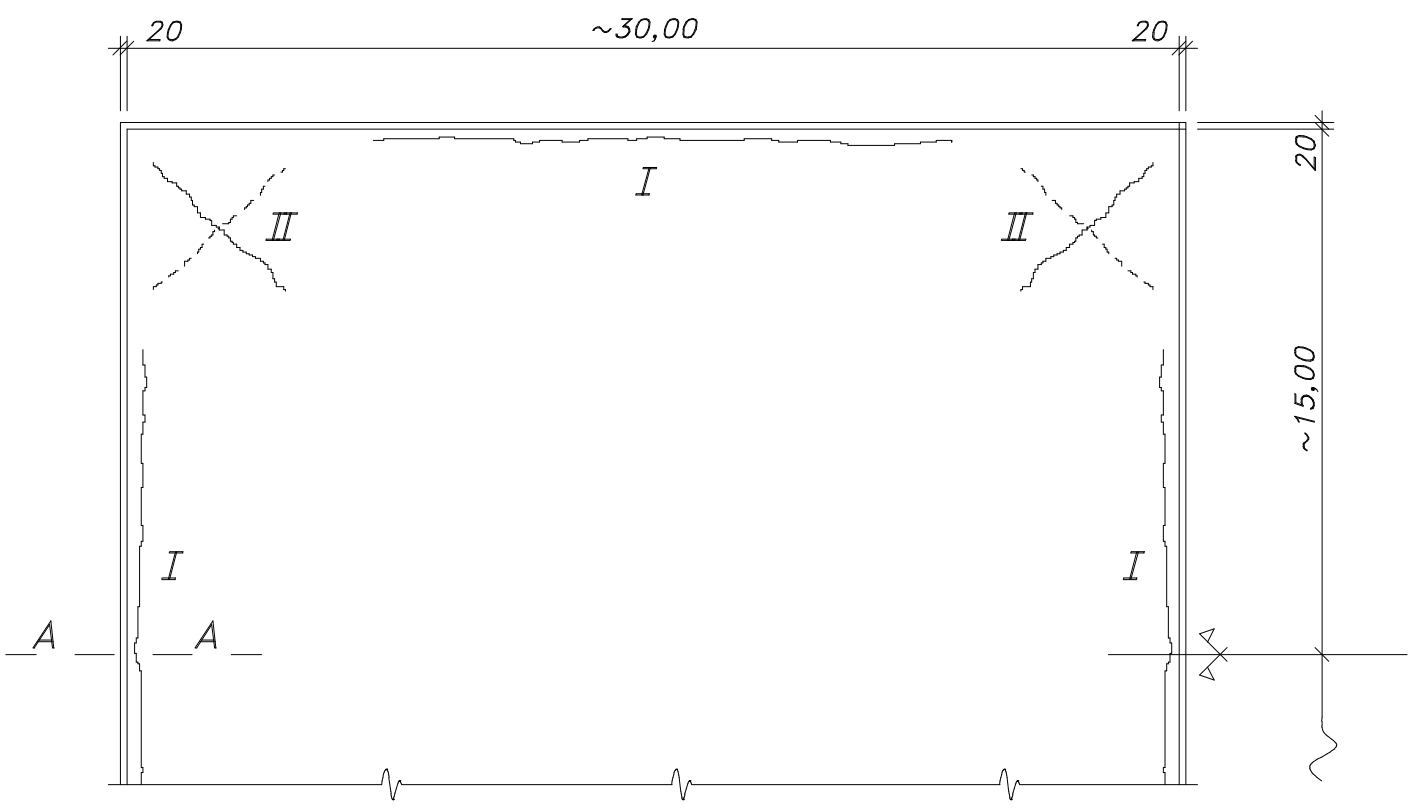

a) Fôrma da cobertura de um reservatório, com indicações das trincas I e II.

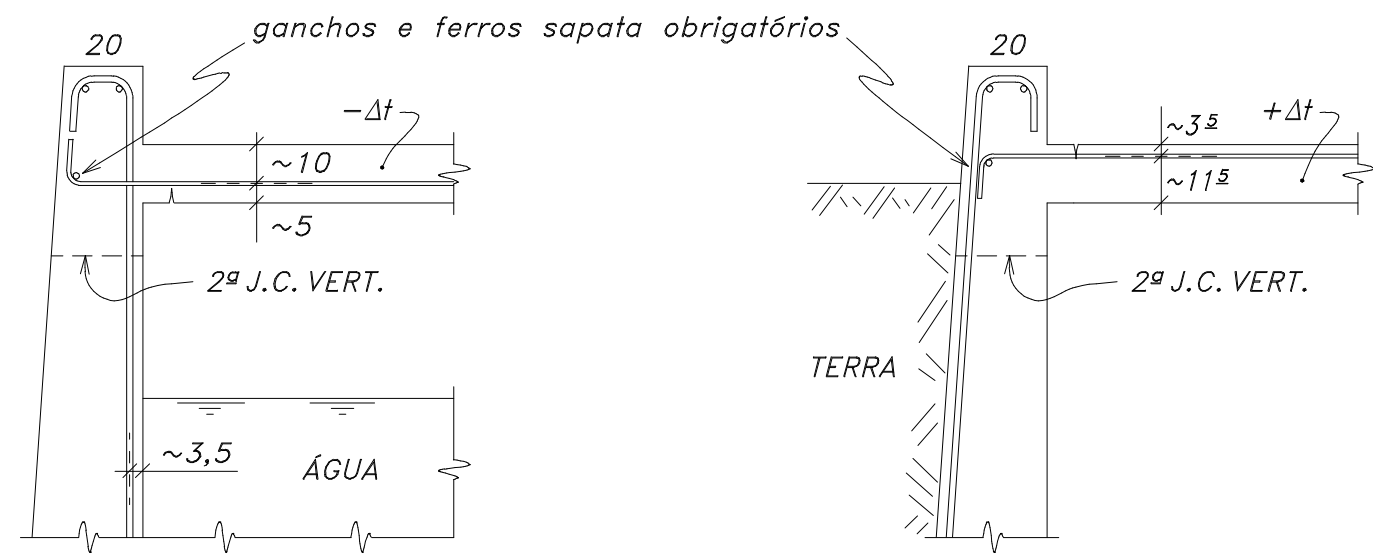

b) Trinca tipo I, inferior (corte A)

c) Trinca tipo I, superior (corte A)

Figura 3.3 : Dois tipos de trincas, I e II, possíveis de ocorrer em coberturas de reservatórios, devidas às cargas de uso (água e terra), agravadas com as variações de temperatura. 


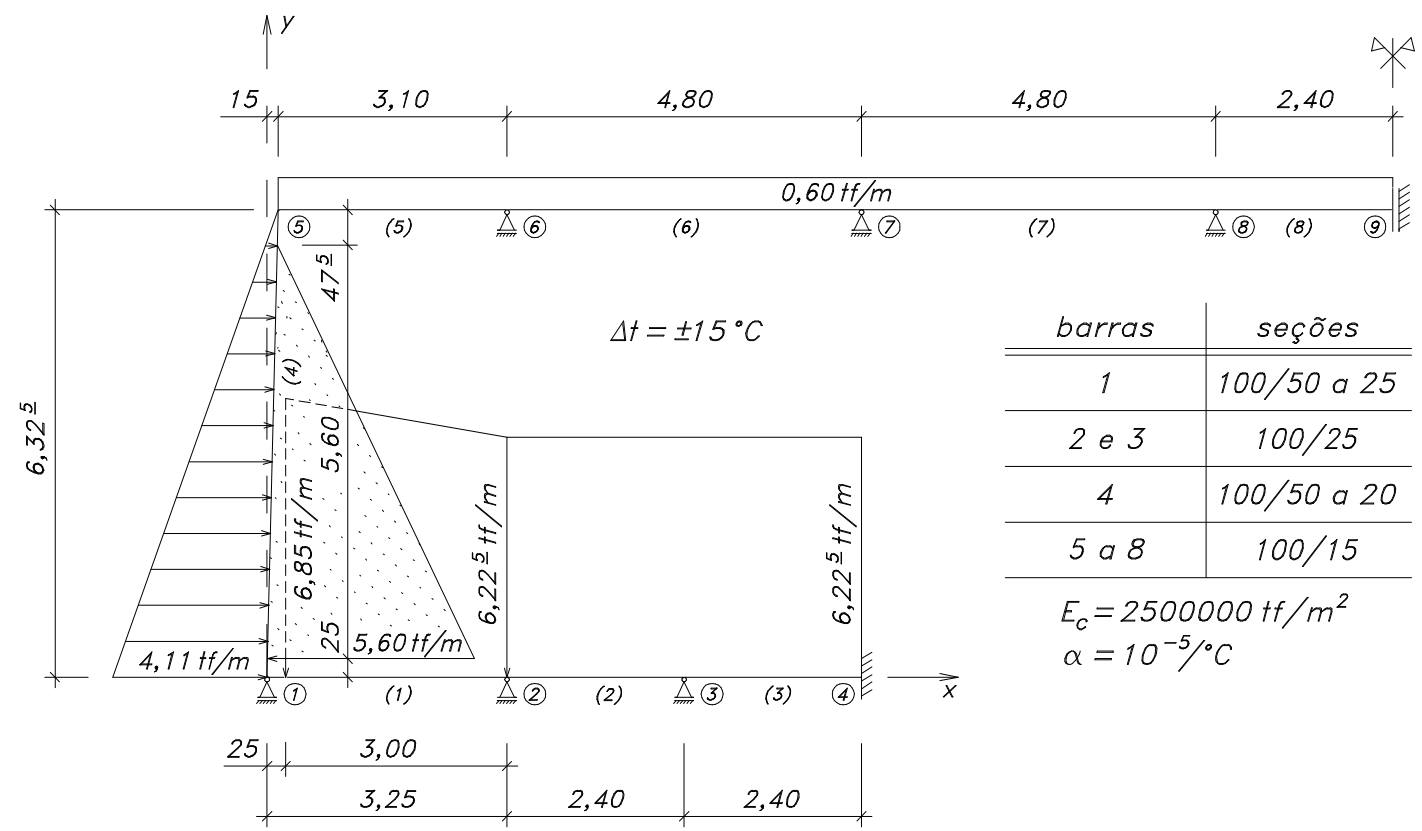

Figura 3.4 - Esquema estático simplificado da região central do reservatório, com indicação de todas as ações dos carregamentos 1a, 1b, 2a e 2b.

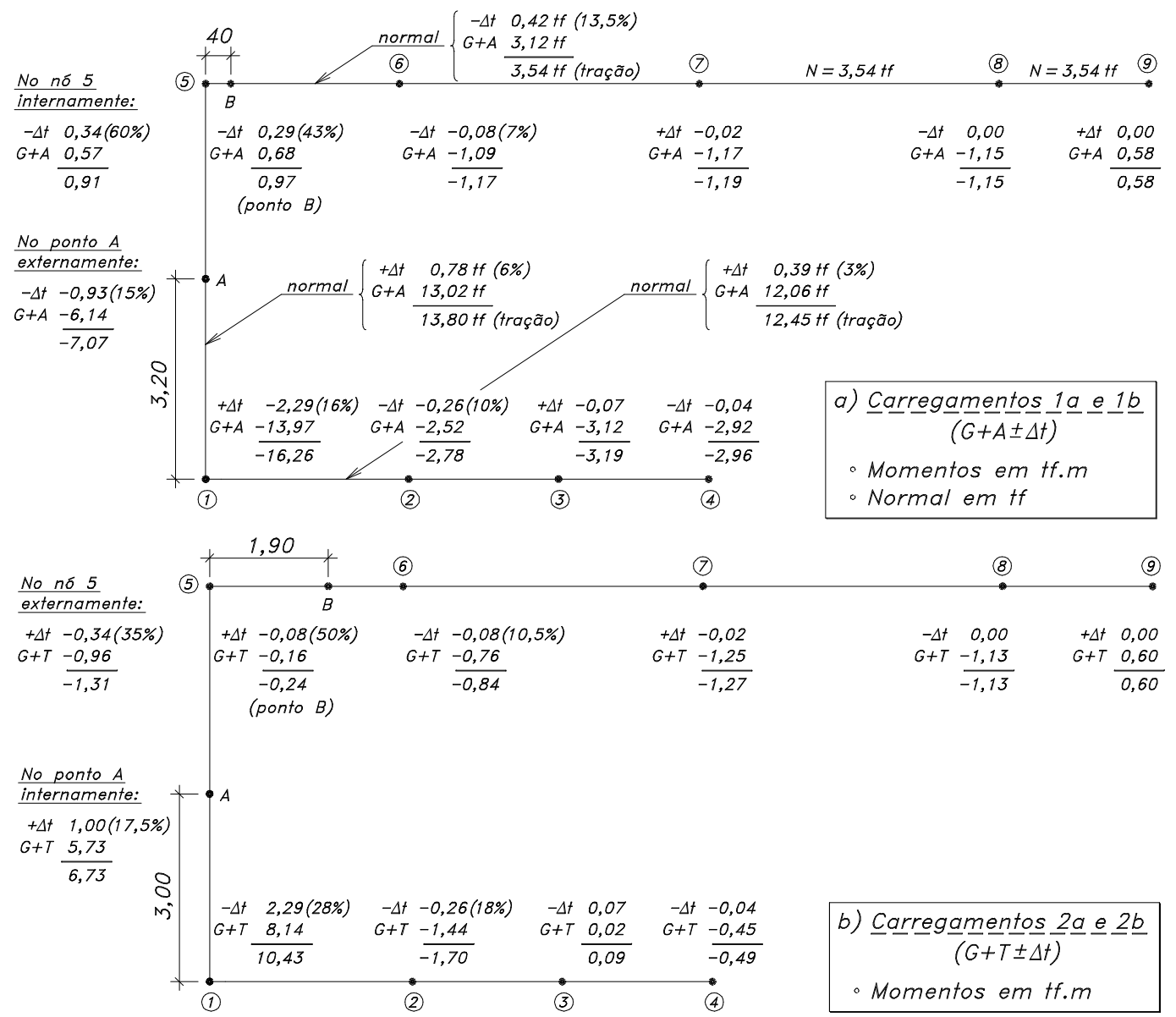

Figura 3.5 - Esforços máximos e mínimos de uma faixa central de largura unitária de um reservatório achatado sobre estacas, devidos ás ações dos pesos próprios permanentes $(\mathrm{G})$, água (A), empuxo de terra $(\mathrm{T})$ e variação da temperatura $( \pm \Delta \mathrm{t})$. 
Observando esses resultados, vê-se que a variação da temperatura nas lajes da cobertura produz efeitos significativos não só nela como também em toda a parede e inclusive no primeiro vão da laje do fundo.

Fazendo um resumo dos principais aumentos, tem-se:

Tabela 3.1 - Ilustra os aumentos dos principais esforços de um reservatório achatado, devido à variação de temperatura na cobertura.

\begin{tabular}{|c|c|c|c|c|c|c|}
\hline \multirow[b]{2}{*}{ seções } & \multirow{2}{*}{$\frac{\text { Fundo }}{\text { nó } 2}$} & \multicolumn{2}{|c|}{ Parede } & \multicolumn{3}{|c|}{ Cobertura } \\
\hline & & nó 1 & ponto A & nó 5 & ponto B & nó 6 \\
\hline $\begin{array}{l}\text { carregamentos } 1 \mathrm{a} \text { e } 1 \mathrm{~b} \\
(\mathrm{G}+\mathrm{A} \pm \Delta \mathrm{t})\end{array}$ & $\begin{array}{r}10 \% \mathrm{em} \mathrm{M} \\
3 \% \mathrm{em} \mathrm{N}\end{array}$ & $\begin{array}{r}16 \% \mathrm{em} \mathrm{M} \\
6 \% \mathrm{em} \mathrm{N}\end{array}$ & $\begin{array}{r}15 \% \text { em M } \\
6 \% \text { em N }\end{array}$ & $\begin{array}{l}60,0 \% \text { em M } \\
13,5 \% \text { em N }\end{array}$ & $\begin{array}{l}43,0 \% \mathrm{em} \mathrm{M} \\
13,5 \% \mathrm{em} \mathrm{N}\end{array}$ & $\begin{array}{r}7,0 \% \text { em M } \\
13,5 \% \mathrm{em} \mathrm{N}\end{array}$ \\
\hline $\begin{array}{l}\text { carregamentos } 2 \mathrm{a} \text { e } 2 \mathrm{~b} \\
(\mathrm{G}+\mathrm{T} \pm \Delta \mathrm{t})\end{array}$ & $18 \% \mathrm{em} \mathrm{M}$ & $28 \% \mathrm{em} \mathrm{M}$ & $17,5 \%$ em M & $35 \%$ em M & $50 \%$ em M & $10,5 \%$ em M \\
\hline
\end{tabular}

E finalizando esta análise sobre a influência da temperatura, é conveniente destacar dois aspectos.

O primeiro é que o reservatório modelo que gerou estes resultados, um tanto quanto surpreendentes, tem em planta $30 \mathrm{~m} \times 30 \mathrm{~m}$. É de se esperar que em reservatórios de dimensões menores estes efeitos sejam também menores.

O segundo, é que os esforços analisados depende da rigidez dos elementos estruturais do reservatório, ou seja, do tipo de fundação, das dimensões das lajes e das paredes e, principalmente, dos seus vãos entre apoios.

Assim, por falta de tempo, deixa-se para um outro trabalho a realização de uma pesquisa mais detalhada sobre esse assunto.

Quanto aos DESLOCAMENTOS DE APOIO, a nova NB-1 diz em seu item 11.2.3.3 que "os deslocamentos de apoio só devem ser considerados quando gerarem esforços significativos em relação ao conjunto das outras ações, isto é, quando a estrutura for hiperestática e rígida o suficiente. O deslocamento de cada apoio deve ser avaliado em função das características físicas do correspondente material de fundação". 
Assim sendo, as paredes dos reservatórios, e apenas quando em fundação sobre estacas, são os únicos elementos dos reservatórios que se enquadram neste perfil.

Entretanto muitas destas paredes por terem grandes alturas $(\geq 5 \mathrm{~m})$ e se apoiarem em estacas pouco afastadas ( 2 a $3 \mathrm{~m}$ ) acabam dispensando estas ações.

As IMPERFEIÇÕES GEOMÉTRICAS podem ser globais e locais.

As imperfeições globais podem ocorrer nos reservatórios elevados devidos a desaprumos dos pilares e do fuste.

Entretanto, segundo o item 11.2.3.4 da nova NB-1, estes desaprumos não precisam ser superpostos às ações do vento. Entre os dois, vento e desaprumo, fica-se com o vento por ser mais desfavorável.

Quanto às imperfeições locais, ou seja, desaprumo de pilar, falta de retilinidade de seu eixo, e etc., são normalmente considerados em seus dimensionamentos usuais.

Erros de cravação das estacas são bem assimilados pelas paredes e lajes de fundo dos reservatórios térreos não sendo comum o uso de blocos sobre as mesmas.

As AÇÕES DIRETAS são esforços externos que atuam nas estruturas gerando deslocamentos e esforços internos em seus elementos estruturais.

No Brasil, as principais ações diretas que podem atuar nos reservatórios, conforme sejam térreos ou elevados, são apresentadas a seguir, juntamente com suas notações simplificadas.

- Para reservatórios térreos:

- peso próprio + sobrecarga $^{6}: \quad G$

- água (peso e empuxo) : $\quad$ A

- terra (empuxo nas paredes) : $\mathrm{T}$

- lençol freático (sub-pressão) : L
- Para reservatórios elevados:

- peso próprio + sobrecarga ${ }^{6}: G$

- água (peso e empuxo) : A

- vento :

V

${ }^{6}$ Como em geral essas sobrecargas das lajes de cobertura são muito pequenas em relação à carga total das mesmas (da ordem de 8\%) e com efeitos desprezíveis nos demais elementos do reservatório, será aqui considerada agregada ao peso próprio da laje, podendo ser descartada se for a favor da segurança. 


\section{b) Carregamentos dos reservatórios}

Considerando essas ações diretas, juntamente com a variação da temperatura $\pm \Delta \mathrm{t}$, pode-se prever as combinações possíveis dessas ações que podem atuar simultaneamente em cada tipo de reservatório paralelepipédico.

Denomina-se aqui de CARREGAMENTO a qualquer combinação entre essas sete ações independentes que, podendo ocorrer simultaneamente, provocam em pelo menos um ponto da estrutura ou de suas fundações, um esforço máximo. Este esforço também pode ser mínimo se isto for contra a segurança.

Ainda, as ações $\mathrm{T}$ e $\pm \Delta \mathrm{t}$ podem apresentar uma ou mais formas diferentes de atuar nas estruturas.

Por razões didáticas estes carregamentos recebem os números dos carregamentos básicos apresentados abaixo, seguidos das letras minúsculas $\mathrm{a}, \mathrm{b}, \mathrm{c}, \ldots$ conforme o número de formas diferentes com que essas ações se apresentam nos carregamentos.

Carregamentos básicos dos reservatórios:

- Para reservatórios térreos:

-carregamento 1a,1b: $\quad \mathrm{G}+\mathrm{A} \pm \Delta \mathrm{t}^{7}$

-carregamento 2a, 2b, 2c: $\mathrm{G}+\mathrm{T} \pm \Delta \mathrm{t}^{7}$

-carregamento 3a, 3b: $\quad \mathrm{G}+\mathrm{A}+\mathrm{T}-\Delta \mathrm{t}^{7}$

-carregamento 4: $\quad \mathrm{G}+\mathrm{T}+\mathrm{L}^{8}$
- Para reservatórios elevados:

-carregamento 1: $\quad \mathrm{G}+\mathrm{A}$

-carregamento 2: $\quad 0,9 \mathrm{G}+\mathrm{V}$

-carregamento 3: $\quad \mathrm{G}+\mathrm{A}+\mathrm{V}$

Apresentam-se a seguir, para cada tipo de reservatórios e para cada carregamento, as ações atuando nos elementos estruturais dos reservatórios, com a indicação das seções críticas a serem dimensionadas e das fundações a serem verificadas.

7 Esta ação só se aplica em reservatórios achatados e com lajes de cobertura.

8 Esta ação não é muito comum. Sua ocorrência. bastante rara é registrada apenas em reservatórios cúbicos e longados. 


\subsubsection{Carregamentos dos reservatórios térreos}

a) Reservatórios achatados sobre estacas, com cobertura

- Carregamentos 1a e 1b: $\mathrm{G}+\mathrm{A} \pm \Delta \mathrm{t}$

Hipótese: reservatório cheio, sem empuxo de terra e $\pm \Delta \mathrm{t}$.

Verificação das fundações: $\mathrm{E}_{\max } \leq \overline{\mathrm{E}}$;

Seções de momentos máximos: ver pontos indicados na figura 3.6, nas faces tracionadas e com o sinal da ação $\Delta$ t.

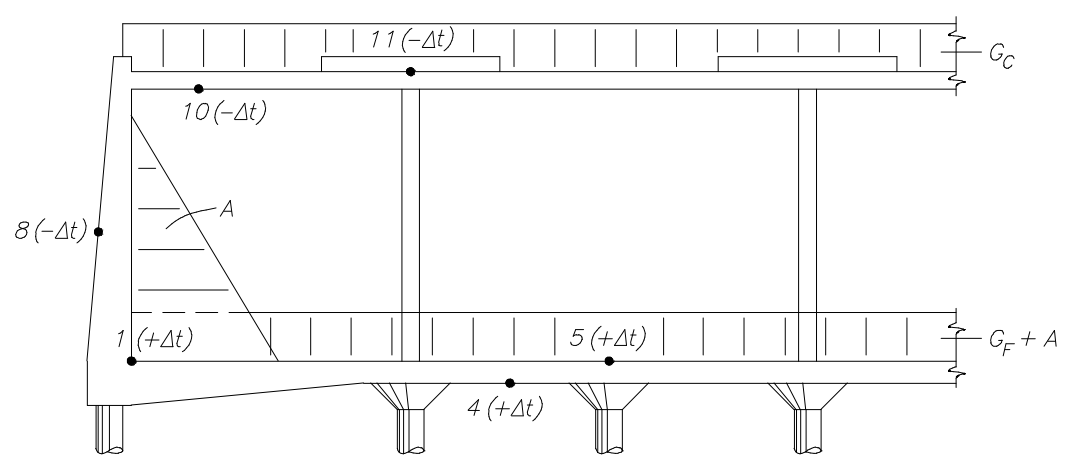

Figura 3.6 - Trecho principal de um reservatório achatado com indicação das ações dos carregamentos $1 \mathrm{a}$ e $1 \mathrm{~b}$ e das suas seções críticas para dimensionamento.

- Carregamentos $2 \mathrm{a}$ e $2 \mathrm{~b}: \quad \mathrm{G}+\mathrm{T} \pm \Delta \mathrm{t}$

Hipótese: reservatório vazio, com empuxo de terra e $\pm \Delta \mathrm{t}$.

Seções de momentos máximos: ver pontos indicados na figura 3.7, nas faces tracionadas e com o sinal da ação $\Delta$ t.

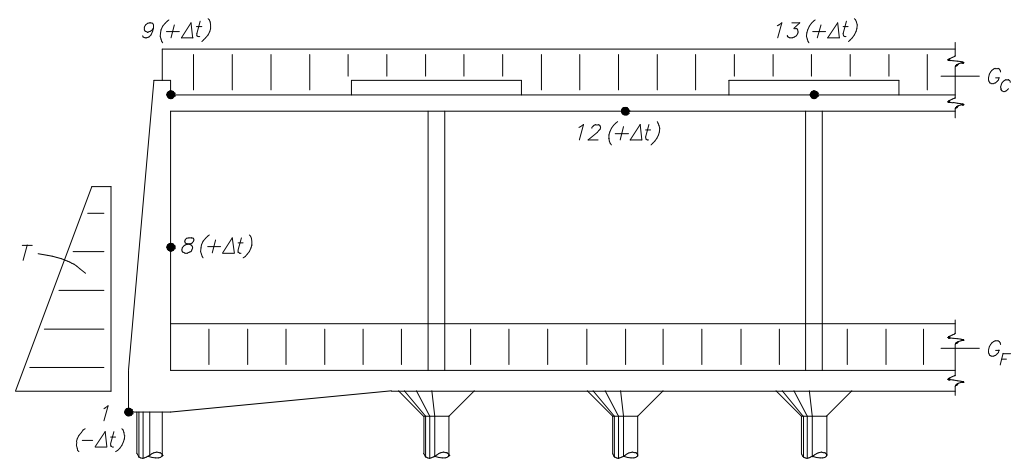

Figura 3.7 - Trecho principal de um reservatório achatado com indicação das ações dos carregamentos $2 \mathrm{a}$ e $2 \mathrm{~b}$ e das suas seções críticas para dimensionamento.

$$
\mathrm{G}+\mathrm{A}+\mathrm{T}-\Delta \mathrm{t}
$$




\section{- ${\text { Carregamento } 3^{9}}^{\text {: }}$}

Hipótese: reservatório cheio, com empuxo de terra e - $\Delta \mathrm{t}$.

Seções de momentos máximos: ver pontos indicados na figura 3.8, nas faces tracionadas.

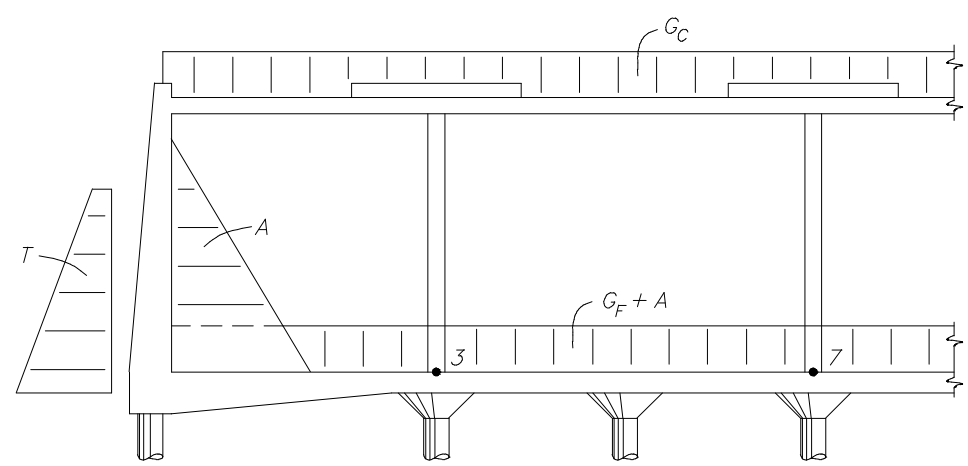

Figura 3.8 - Trecho principal de um reservatório achatado com indicação das ações do carregamento 3 e das suas seções críticas para dimensionamento.

b) Reservatórios achatados sobre estacas, sem cobertura

\section{- Carregamento 1: $\mathrm{G}+\mathrm{A}$}

Analogamente ao primeiro carregamento do reservatório coberto, só que com momentos críticos apenas nas seções dos pontos 1, 4 e 5 .

\section{- Carregamento 2: $\mathrm{G}+\mathrm{T}$}

Analogamente ao segundo carregamento do reservatório coberto, só que com momentos críticos apenas na seção do ponto 1 .

\section{- Carregamento 3: $\mathrm{G}+\mathrm{A}+\mathrm{T}$}

Analogamente ao terceiro carregamento do reservatório coberto, só que com os momentos críticos apenas nas seções dos mesmos pontos 3 e 7.

9 Para grandes alturas de paredes e grandes empuxos de terra, os momentos em 3 e em 7 deste carregamento, podem superar os correspondentes momentos do carregamento 1a em até $70 \%$ e $10 \%$, respectivamente. 
- Carregamentos 1a e $1 \mathrm{~b}: \quad \mathrm{G}+\mathrm{A} \pm \Delta \mathrm{t}$

Hipótese: reservatório cheio, sem empuxo de terra.

Verificação das fundações: $\mathrm{p}_{\mathrm{A}}+\mathrm{p}_{\mathrm{B}}$ e $\mathrm{p}_{\mathrm{C}} \leq \bar{\sigma}_{\mathrm{S}}$;

Seções de momentos máximos: ver pontos indicados na figura 3.9, nas faces tracionadas e com o sinal da ação $\Delta \mathrm{t}$.

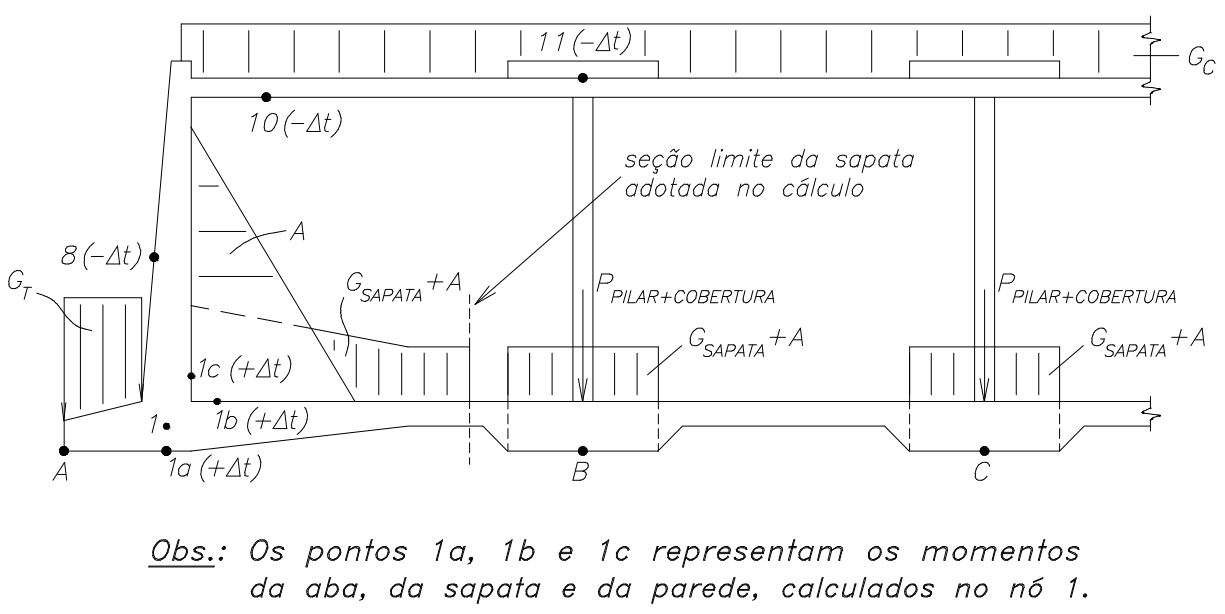

Figura 3.9 - Trecho principal de um reservatório achatado com indicação das ações dos carregamentos $1 \mathrm{a}$ e $1 \mathrm{~b}$ e das suas seções críticas para dimensionamento.

\section{- Carregamentos 2a e 2b: $\quad \mathrm{G}+\mathrm{T} \pm \Delta \mathrm{t}$}

Hipótese: reservatório vazio, com empuxo de terra e $\pm \Delta t$.

Seções de momentos máximos: ver pontos indicados na figura 3.10, nas faces tracionadas e com o sinal da ação $\Delta \mathrm{t}$.

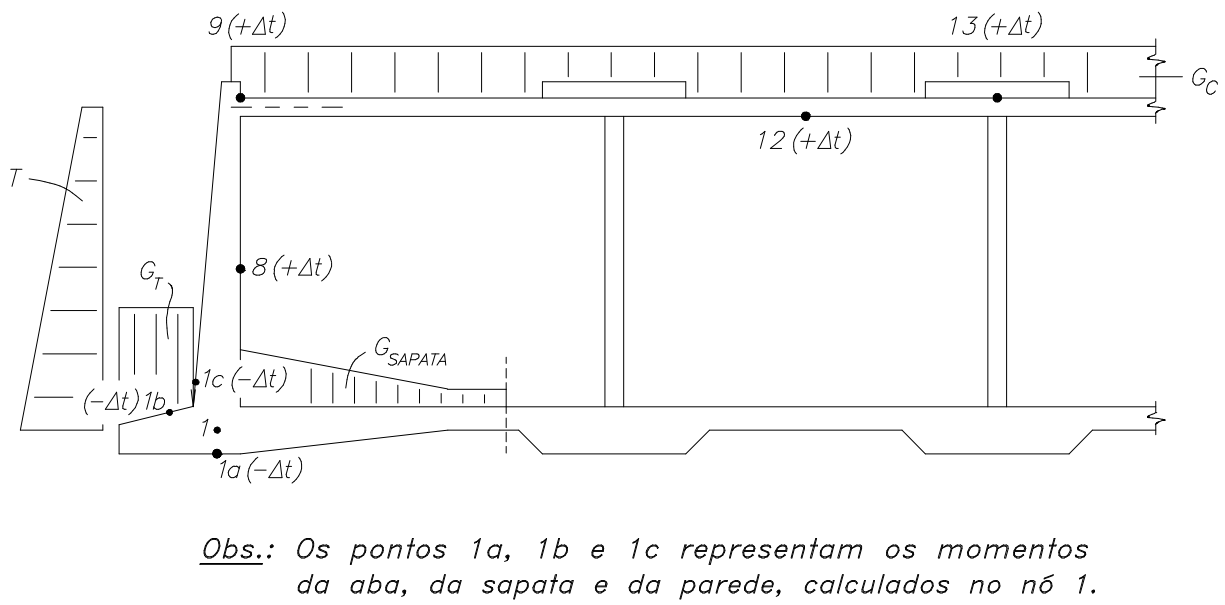

Figura 3.10 - Trecho principal de um reservatório achatado com indicação das ações dos carregamentos $2 \mathrm{a}$ e $2 \mathrm{~b}$ e das suas seções críticas para dimensionamento. 


\section{- Carregamento 1: $\mathrm{G}+\mathrm{A}$}

Analogamente ao primeiro carregamento do reservatório coberto em fundação direta, só que com momentos críticos apenas nas seções 1a, 1b e 1c do nó 1, sendo suficiente nas fundações verificar apenas que $\mathrm{p}_{\mathrm{A}} \leq \bar{\sigma}_{\mathrm{S}}$.

\section{- Carregamento 2: $\mathrm{G}+\mathrm{T}$}

Analogamente ao segundo carregamento do reservatório coberto em fundação direta, só que com momentos críticos apenas nas seções 1a, 1b e 1c do nó 1 .

e) Reservatórios alongados ${ }^{10}$ sobre estacas, com cobertura

\section{- Carregamento 1: $\mathrm{G}+\mathrm{A}$}

Hipótese: reservatório cheio, sem empuxo de terra.

Verificação das fundações: $\mathrm{E}_{\max } \leq \overline{\mathrm{E}}$

Seções de momentos máximos: ver pontos indicados na figura 3.11, nas faces tracionadas.

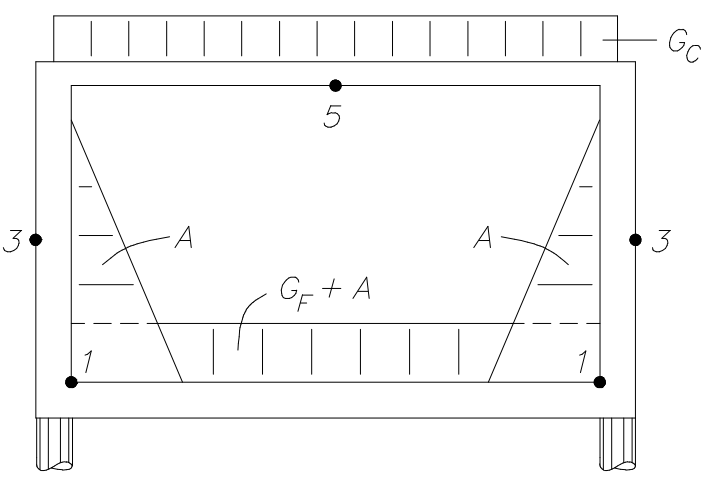

Figura 3.11 - Trecho principal de um reservatório alongado, com indicação das ações do carregamento 1 e das suas seções críticas para dimensionamento.

\footnotetext{
${ }^{10}$ Os reservatórios alongados térreos são sempre horizontais, enquanto que os elevados, sempre verticais. Assim, para simplificar a nomenclatura, se omitirá os adjetivos "horizontalmente" para os alongados térreos e "verticalmente" para os alongados elevados.
} 


\section{- Carregamento 2: $\mathrm{G}+\mathrm{T}$}

Hipótese: reservatório vazio, com empuxo de terra.

Seções de momentos máximos: ver pontos indicados, nas faces tracionadas, na figura 3.12.

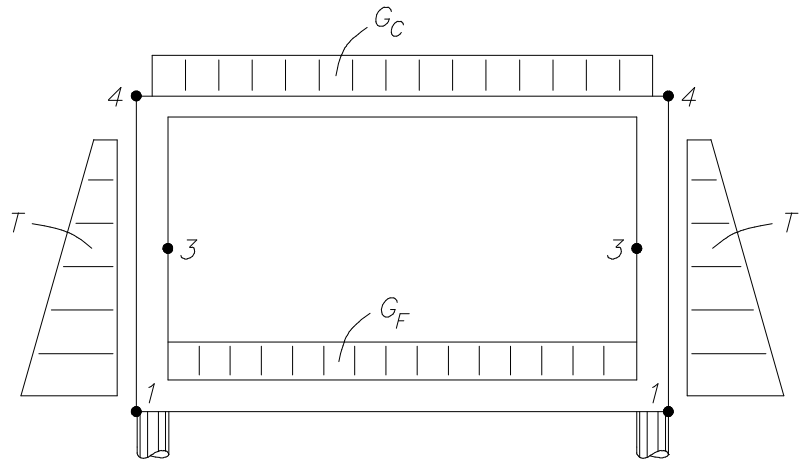

Figura 3.12 - Trecho principal de um reservatório alongado, com indicação das ações do carregamento 2 e das suas seções críticas para dimensionamento.

- Carregamento 3: $\mathrm{G}+\mathrm{A}+\mathrm{T}$

Hipótese: reservatório cheio, com empuxo de terra.

Seções de momentos máximos: ver pontos indicados, nas faces tracionadas, na figura 3.13 .

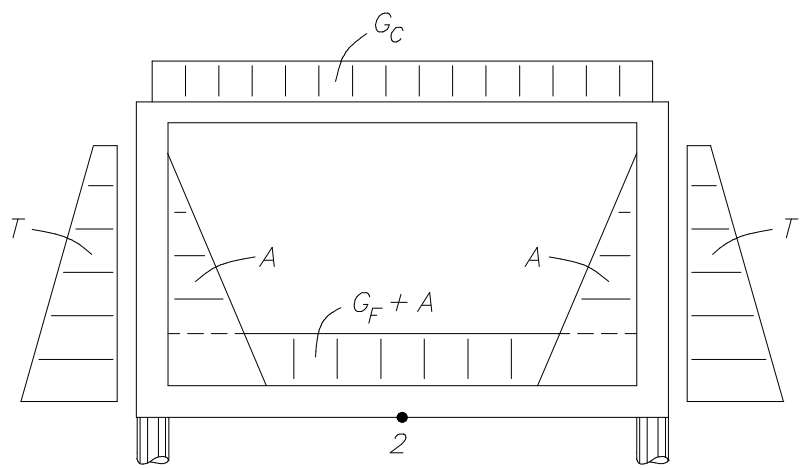

Figura 3.13 - Trecho principal de um reservatório alongado com indicação das ações do carregamento 3 e da sua seção crítica para dimensionamento. 


\section{- Carregamento 4: $\mathrm{G}+\mathrm{T}+\mathrm{L}$}

Hipótese: reservatório vazio com empuxo do lençol freático.

Verificação das fundações: $\frac{0,9 \text { (Peso do reservatório vazio) }}{\text { Empuxo do lençol freático }} \geq 1,2{ }^{11}$

Seções de momentos máximos: ver pontos indicados nas faces tracionadas, na figura 3.15 .

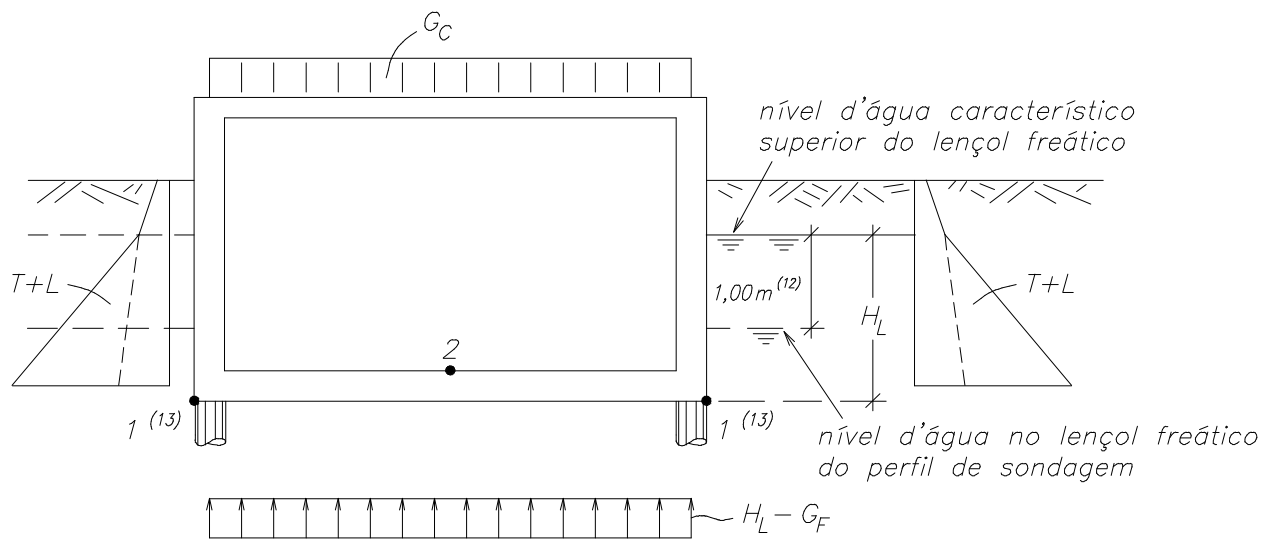

Figura 3.15 - Trecho principal de um reservatório alongado com indicação das ações do carregamento 4 e das suas seções críticas para dimensionamento.

${ }^{11}$ Esta expressão é especificada no capítulo 12 da nova redação da NB-1, mais precisamente na parte de COMENTÁRIOS sobre o capítulo 12, item C.12.8.2.3A, p.3. Como se pode deduzir da expressão, não se considera nenhuma resistência a tração nas estacas.

Quando essa relação não se verificar, deve-se engrossar as lajes e as paredes até se conseguir os $20 \%$ de segurança. Também para economizar o custo do concreto, pode-se utilizar no traço do mesmo britas maiores (brita 3) e, se possível, adotar até concreto ciclópico (Figura 3.14).

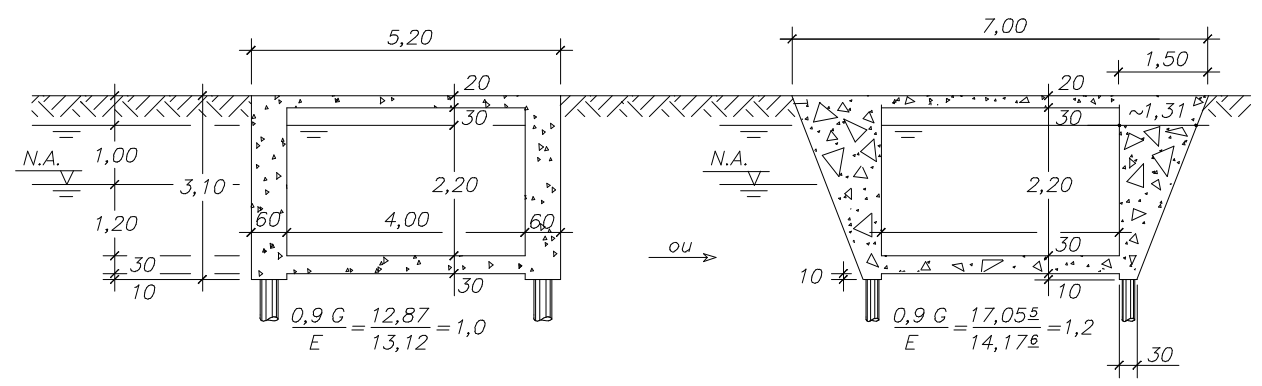

Figura 3.14 - Indicação de soluções para reservatórios térreos sob a ação de lençol freático.

${ }^{12}$ Quando da execução das sondagens, o lençol freático pode não estar na sua cota máxima. O valor de $1,00 \mathrm{~m}$ proposto aqui, foi adotado na construção da linha NORTE-SUL do metrô de São Paulo segundo especificação do consórcio internacional H.M.D. (Hochtief, Montreal e Deconsult), responável por aquele projeto.

${ }^{13}$ Quando existir este carregamento, o seu momento na seção do ponto 1, sempre supera o momento na seção do ponto 1 do carregamento 2 . 


\section{f) Reservatórios alongados sobre estacas, sem cobertura}

\section{- Carregamento 1: $\mathrm{G}+\mathrm{A}$}

Analogamente ao primeiro carregamento dos reservatórios cobertos, só que com momentos críticos apenas na seção do ponto 1 .

\section{- Carregamento 2: $\mathrm{G}+\mathrm{T}$}

Analogamente ao segundo carregamento dos reservatórios cobertos, só que com momentos críticos apenas na seção do ponto 1 .

\section{- Carregamento 3: $\mathrm{G}+\mathrm{A}+\mathrm{T}$}

Analogamente ao terceiro carregamento dos reservatórios cobertos, com momentos crítico apenas na seção do ponto 2 .

\section{- Carregamento 4: $\mathrm{G}+\mathrm{T}+\mathrm{L}$}

Analogamente ao quarto carregamento dos reservatórios cobertos, com os momentos críticos nas mesmas seções 1 e 2 .

\section{g) Reservatórios alongados em fundação direta, com cobertura}

\section{- Carregamento 1: $\mathrm{G}+\mathrm{A}$}

Hipótese: reservatório cheio, sem empuxo de terra.

Verificação das fundações: $\mathrm{p}_{\mathrm{m}}+\mathrm{G}_{\mathrm{F}}+\mathrm{A} \leq \bar{\sigma}_{\mathrm{s}}$ ou $\mathrm{p}_{\max }$ (exato) $\leq \bar{\sigma}_{\mathrm{s}}{ }^{14}$

Seções de momentos máximos: ver pontos indicados, nas faces tracionadas, na figura 3.16.

\footnotetext{
${ }^{14}$ Para reservatórios alongados e estreitos, pouco flexíveis (b até $3 \mathrm{~m} \mathrm{com} \mathrm{h}$ até $25 \mathrm{~cm}$ ) pode-se obter os momentos por processos simplificados, utilizando-se a pressão média $\mathrm{p}_{\mathrm{m}}$. Esse cálculo é a favor da segurança uma vez que em geral as reações são maiores nas extremidades.

Nesses casos, a água (A) e o peso próprio das lajes de fundo $\left(\mathrm{G}_{\mathrm{F}}\right)$ não são considerados no cálculo dos momentos, por serem praticamente anuladas pelas correspondentes reações. No entanto, devem ser somadas à $\mathrm{p}_{\mathrm{m}}$ na verificação das pressões no solo.

Para reservatórios com lajes de fundo flexíveis, essa simplificação não é mais possível tendo-se que obter todos os esforços com as lajes de fundo, apoiadas em meio elástico, conforme já analisado em 2.3.1.
} 


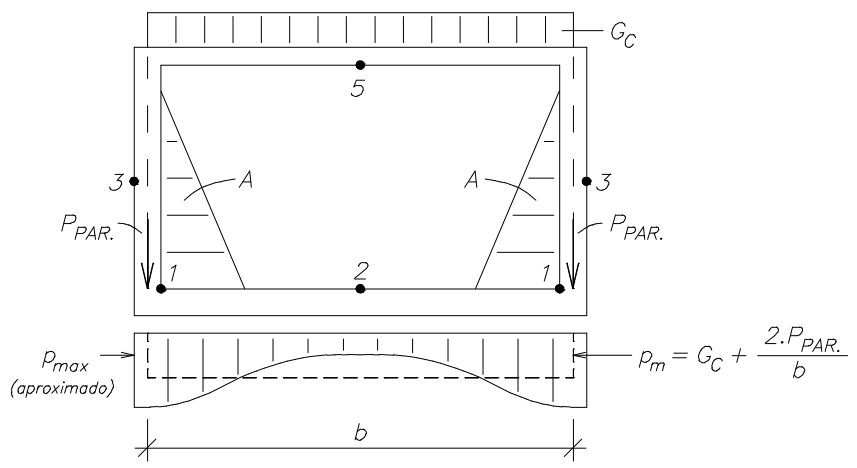

Figura 3.16 - Trecho principal de um reservatório alongado com indicação das ações do carregamento 1 e das suas seções críticas para dimensionamento.

- Carregamento 2: $\mathrm{G}+\mathrm{T}$

Hipótese: reservatório vazio, com empuxo de terra.

Seções de momentos máximos: ver pontos indicados, nas faces tracionadas, na figura 3.17.

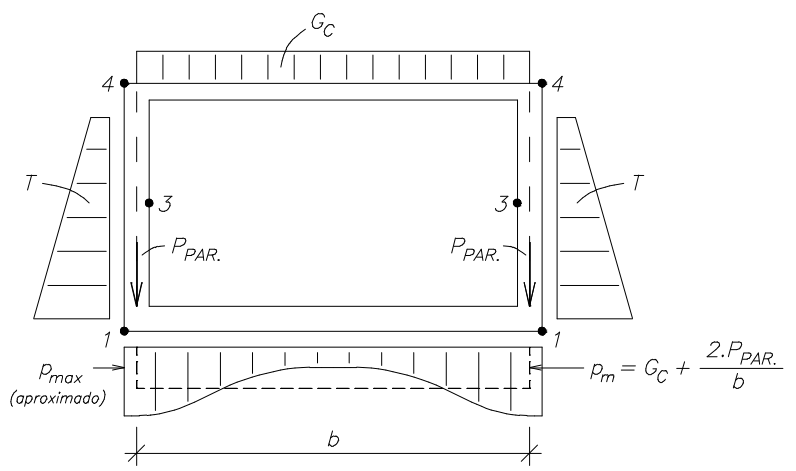

Figura 3.17 - Trecho principal de um reservatório alongado com indicação das ações do carregamento 2 e das suas seções críticas para dimensionamento.

h) Reservatórios alongados em fundação direta, sem cobertura

- Carregamento 1: $\mathrm{G}+\mathrm{A}$

Analogamente ao primeiro carregamento dos reservatórios cobertos, só que com os momentos críticos apenas nas seções dos pontos 1 e 2 . 


\section{- Carregamento 2: $\mathrm{G}+\mathrm{T}$}

Analogamente ao segundo carregamento dos reservatórios cobertos, só que com momento crítico apenas na seção do ponto 1.

\section{i) Reservatórios cúbicos sobre estacas ${ }^{15}$, com cobertura}

\section{- Carregamento 1: $\mathrm{G}+\mathrm{A}$}

Hipótese: reservatório cheio, sem empuxo de terra.

Verificação das fundações: $\mathrm{E}_{\max } \leq \overline{\mathrm{E}}$

Seções de momentos máximos: ver pontos indicados, nas faces tracionadas, na figura 3.18, onde os índices $\mathrm{x}, \mathrm{y}, \mathrm{z}$, xy e $\mathrm{xz}$, indicam as direções das armaduras.
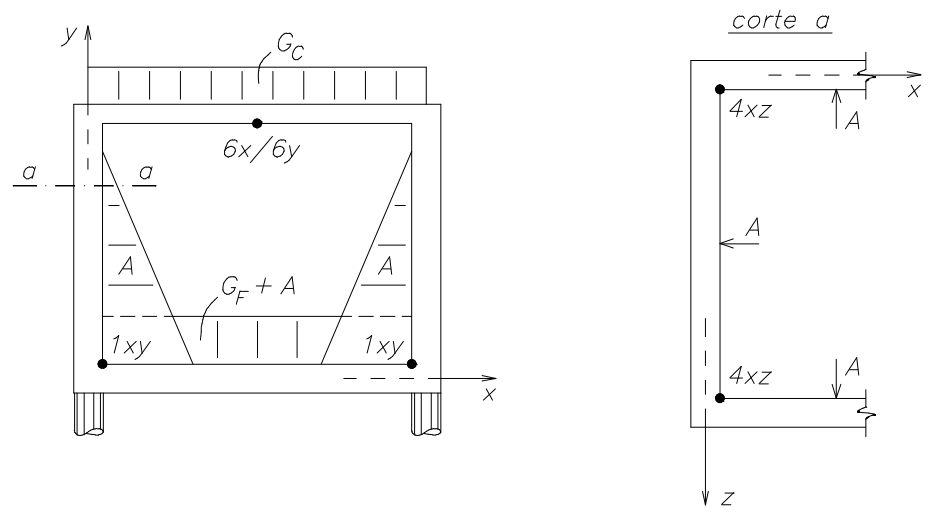

Figura 3.18.- Seção de um reservatório cúbico, com indicação das ações do carregamento 1 e das suas seções críticas para dimensionamento.

- Carregamentos 2a, 2b e 2c: $\mathrm{G}+\mathrm{T}$

Hipótese: reservatório vazio, com empuxo de terra em uma parede ou em duas paredes opostas ou ainda, em duas paredes contíguas.

Seções de momentos máximos: ver pontos indicados, nas faces tracionadas, na figura 3.19, onde os índices $\mathrm{x}, \mathrm{y}, \mathrm{z}$, xy e xz, indicam as direções das armaduras.

${ }^{15}$ Não é usual executar este tipo de reservatório sobre estacas. Ver comentários no item seguinte (3.2.2.k). 


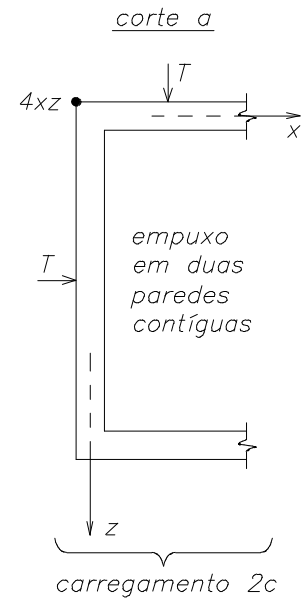

Figura 3.19 - Seção de um reservatório cúbico, com indicação das ações dos carregamentos 2a, 2b e 2c e das suas seções críticas para dimensionamento.

- Carregamentos 3a e 3b: $\mathrm{G}+\mathrm{A}+\mathrm{T}$

Hipótese: reservatório cheio, com empuxo de terra em todas as paredes ou em duas paredes opostas

Seções de momentos máximos: ver pontos indicados, nas faces tracionadas, na figura 3.19, onde os índices $\mathrm{x}, \mathrm{y}$, e $\mathrm{z}$ indicam as direções das armaduras.
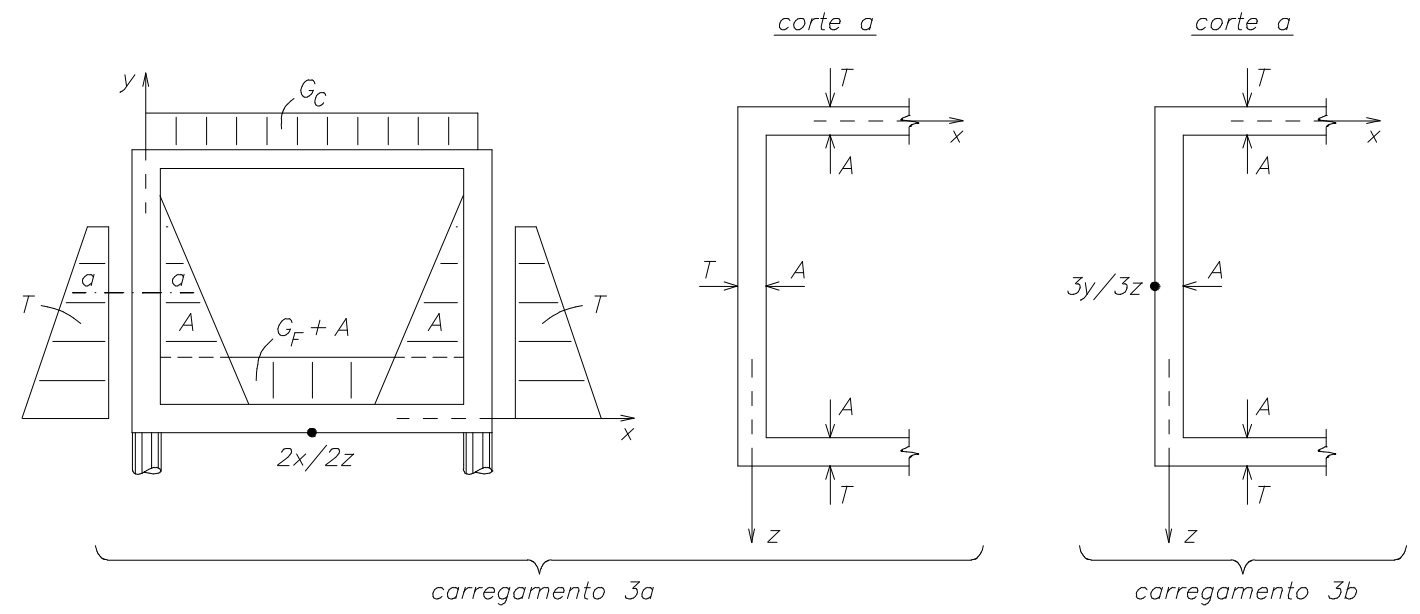

Figura 3.19 - Seções de um reservatório cúbico, com indicação das ações dos carregamentos $3 a$ e $3 b$ e das suas seções críticas para dimensionamento. 


\section{- Carregamento 4: $\mathrm{G}+\mathrm{L}$}

Hipótese: reservatório vazio com empuxo do lençol freático.

Verificação das fundações: $\frac{0,9 \text { (Peso do reservatório vazio })}{\text { Empuxo do lençol freático }} \geq 1,2$

Seções de momentos máximos: ver pontos indicados nas faces tracionadas, na figura 3.21.

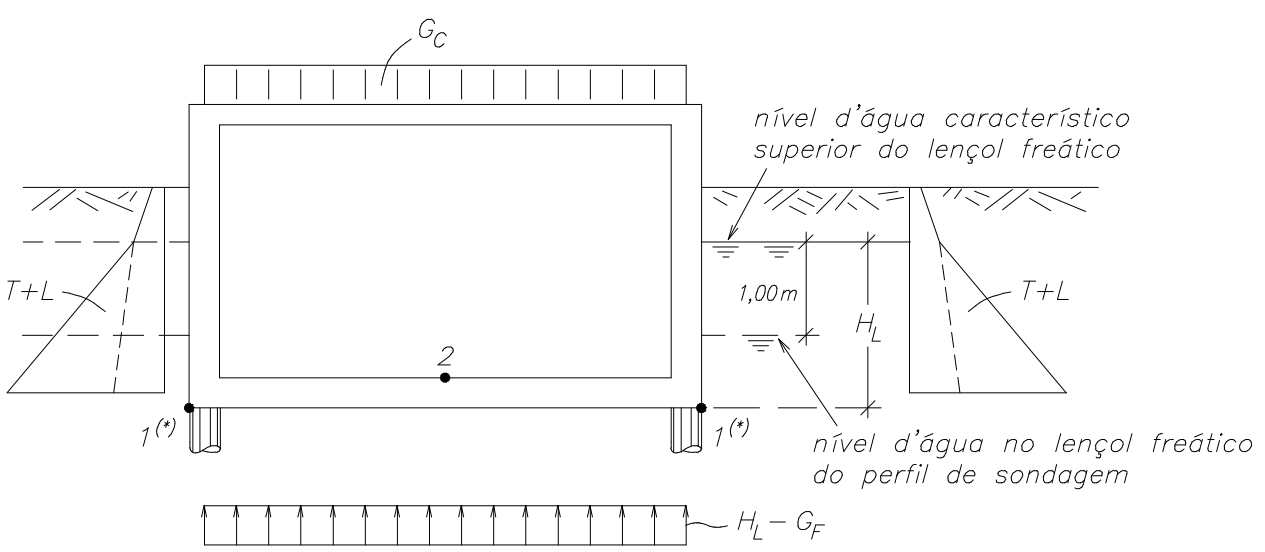

Figura 3.21 - Trecho principal de um reservatório cúbico com indicações das ações do carregamento 4 e das suas seções críticas para dimensionamento.

\section{j) Reservatórios cúbicos sobre estacas, sem cobertura}

- Carregamento 1: $\mathrm{G}+\mathrm{A}$

Analogamente ao primeiro carregamento do reservatório coberto, só que com os momentos críticos apenas nas seções dos pontos 1xy e 4xz.

- Carregamentos 2a, 2b e 2c: $\mathrm{G}+\mathrm{T}$

Analogamente ao segundo carregamento do reservatório coberto, só que com os momentos críticos apenas nas seções dos pontos 1xy, 3y/3z e 4xz.

\footnotetext{
${ }^{(*)}$ Quando existir este carregamento, o seu momento na seção do ponto 1, sempre supera o momento na seção do ponto 1 do carregamento 2 .
} 


\section{- Carregamentos 3a e 3b: $\mathrm{G}+\mathrm{A}+\mathrm{T}$}

Analogamente ao terceiro carregamento do reservatório coberto, os momentos críticos ocorrem nas mesmas seções dos pontos $2 \mathrm{x} / 2 \mathrm{z}$ e $3 \mathrm{y} / 3 \mathrm{z}$.

\section{- Carregamento 4: $\mathrm{G}+\mathrm{L}$}

Analogamente ao quarto carregamento do reservatório coberto, os momentos críticos ocorrem nas mesmas seções dos pontos 1 e 2 .

\section{k) Reservatórios cúbicos em fundação direta, com cobertura}

Ao contrário do que se especifica no item 3.3.1d para os reservatórios térreos achatados, por serem os cúbicos muito rígidos, torna-se aceitável executá-los em fundação direta, mesmo em solos não indicados tecnicamente para tal fim. Entretanto, alguns cuidados devem ser tomados para que se possa adotá-la.

Assim, não se deve projetar esses reservatórios em fundação direta em solos sujeitos a grande deformações como as argilas orgânicas, argilas marinhas, aterros não muito bem compactados, etc..Ainda os reservatórios devem ser enterrados a uma profundidade tal que o seu peso quando cheio, seja inferior ao peso da terra retirada.

As ligações das tubulações com os reservatórios devem ser flexíveis e também de fácil acesso, para facilitar vistorias e eventuais manutenções.

Devem ser evitadas tubulações de água e esgoto nas proximidades desses reservatórios e, principalmente, a penetração das águas de chuva e de limpeza, nas juntas dos pisos com as paredes.

Para encerrar estas considerações, é bom saber que a grande maioria dos reservatórios térreos dos edifícios comerciais e residenciais são executados em solos não recomendados para fundação direta, em fundação direta. 


\section{- Carregamento 1: $\mathrm{G}+\mathrm{A}$}

Hipótese: reservatório cheio, sem empuxo de terra.

Verificação das fundações: $\mathrm{p}_{\mathrm{m}}+\mathrm{G}_{\mathrm{F}}+\mathrm{A} \leq \bar{\sigma}_{\mathrm{s}}$ ou $\mathrm{h}_{\mathrm{s}} \cdot \gamma_{\mathrm{s}}{ }^{16}$

Seções de momentos máximos: ver pontos indicados, nas faces tracionadas, na figura 3.22.
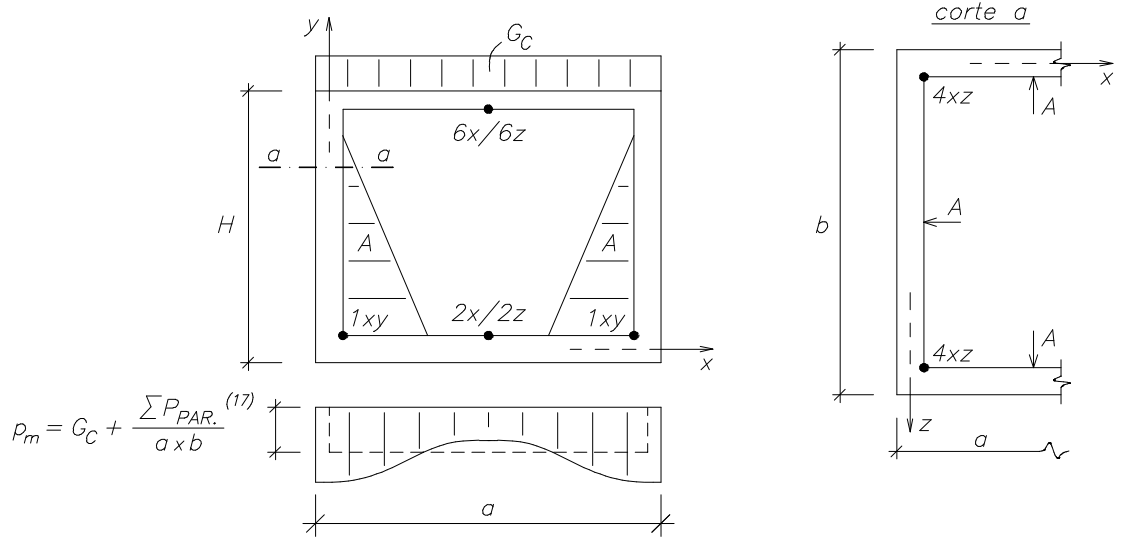

Figura 3.22 - Seção de um reservatório cúbico, com indicação das ações do carregamento 1 e das suas seções críticas para dimensionamento.

- Carregamento 2a, 2b e 2c: $\mathrm{G}+\mathrm{T}$

Hipótese: reservatório reservatório vazio, com empuxo de terra em uma parede ou em duas paredes opostas ou ainda, em duas paredes contíguas.

Seções de momentos máximos: ver pontos indicados, nas faces tracionadas, na figura 3.23.

${ }^{16}$ Para se usar no caso de argila porosa, onde $\gamma_{\mathrm{s}} \cdot \mathrm{h}_{\mathrm{s}}$ é a pressão de pré-adensamento da argila no local do reservatório, sendo $\gamma_{\mathrm{s}}$ o peso específico aparente do solo e $\mathrm{h}_{\mathrm{s}}$ a distância da cota de apoio do reservatório até a superfície natural, antes dos cortes feitos no terreno.

${ }^{17}$ Valem aqui as mesmas observações feitas quanto às cargas sob as lajes de fundo para o cálculo dos seus momentos com o carregamento 1 dos reservatórios alongados (ver rodapé do item 3.2.2g).

Entretanto nos reservatórios cúbicos é comum projetar-se casas de bombas ligadas estruturalmente a eles. Nesses casos, e quando se optar por usar a pressão média, deve-se aplicar sob as lajes do fundo das casas de bombas a carga média $\mathrm{p}_{\mathrm{m}}^{\prime}=\mathrm{G}_{\mathrm{C}}+\frac{\sum \mathrm{P}_{\mathrm{PAR}}}{\mathrm{a} \times \mathrm{b}}+\frac{\sum \mathrm{P}_{\mathrm{a} \text { gua }}}{\mathrm{a} \times \mathrm{b}}$ e sob as demais lajes de fundo, a carga $\mathrm{p}_{\mathrm{m}}=\mathrm{G}_{\mathrm{C}}+\frac{\sum \mathrm{P}_{\mathrm{PAR}}}{\mathrm{a} \times \mathrm{b}}$. 


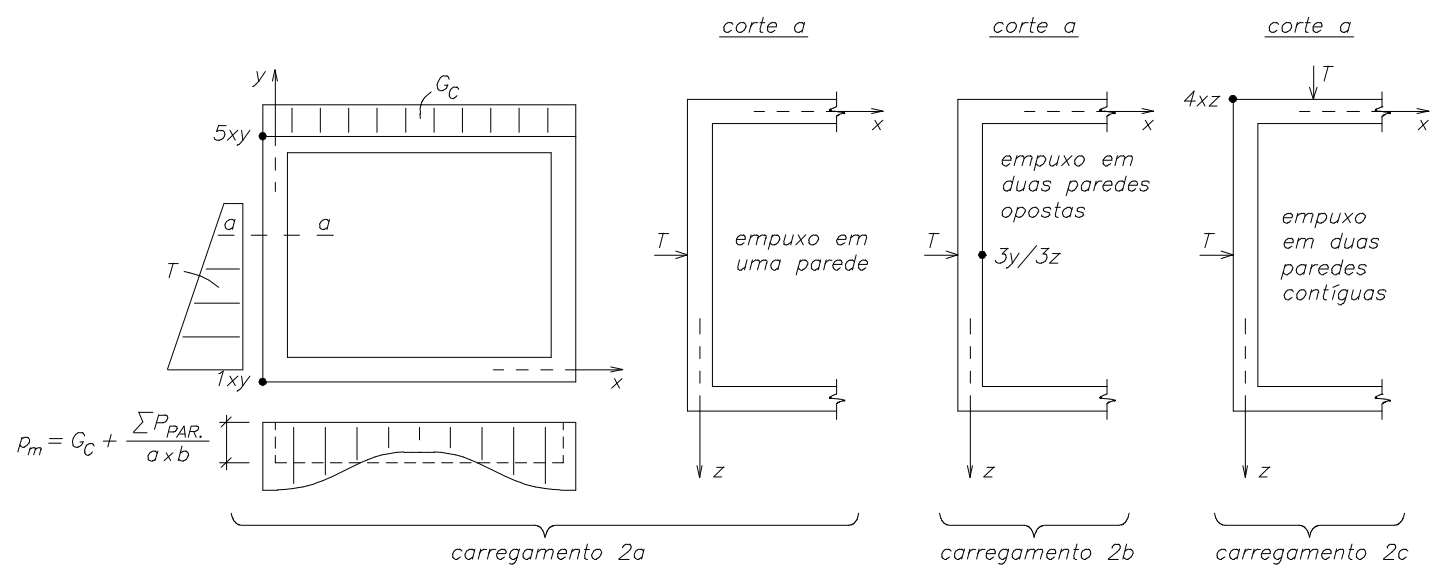

Figura 3.23 - Seção de um reservatório cúbico, com indicação das ações dos carregamentos 2a, 2b e $2 \mathrm{c}$ e das suas seções críticas para dimensionamento.

\section{- Carregamento 3: $\mathrm{G}+\mathrm{A}+\mathrm{T}$}

Hipótese: reservatório cheio, com empuxos de terra em duas paredes opostas.

Seções de momentos máximos: ver ponto indicado, na face tracionada, na figura 3.24 .
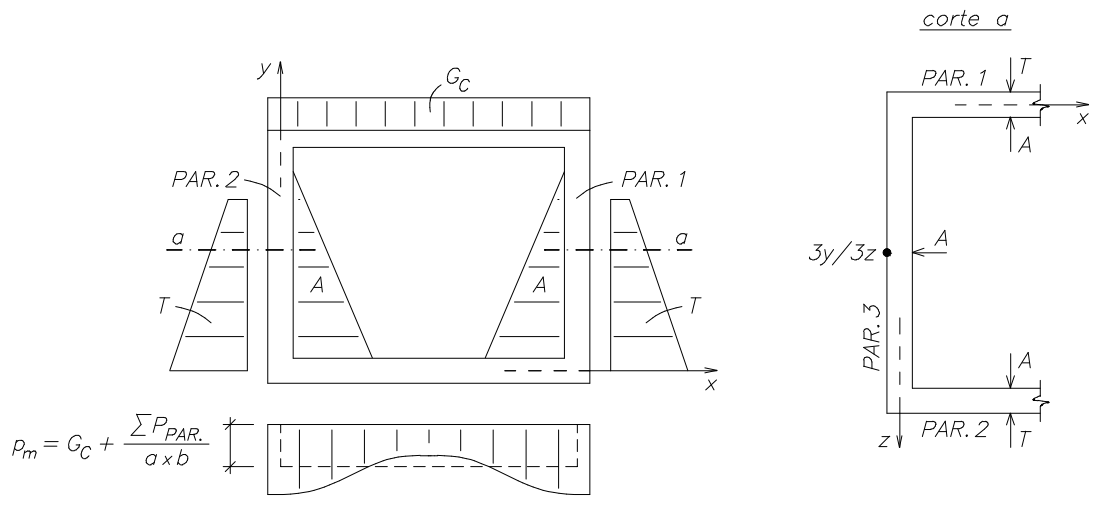

Figura 3.24 - Seção de um reservatório cúbico, com indicação das ações do carregamento 3 e da sua seção crítica para dimensionamento. 


\section{- Carregamento 4: $\mathrm{G}+\mathrm{T}+\mathrm{L}$}

Hipótese: reservatório vazio com empuxo de terra e do lençol freático.

Verificação das fundações: $\frac{0,9 \text { (Peso do reservatório vazio) }}{\text { Empuxo do lençol freático }} \geq 1,2$

Seções de momentos máximos: ver pontos indicados, nas faces tracionadas, na figura 3.25.

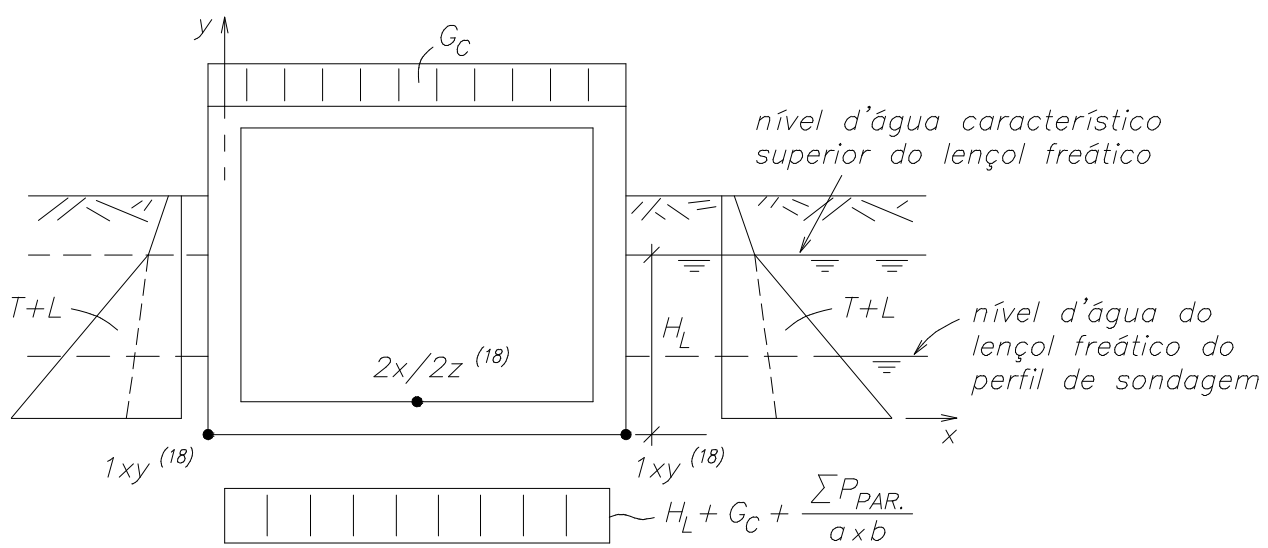

Figura 3.25 - Seção de um reservatório cúbico, com indicação das ações do carregamento 4 e suas seções críticas para dimensionamento.

\section{1) Reservatórios cúbicos em fundação direta, sem cobertura}

- Carregamento 1: $\mathrm{G}+\mathrm{A}$

Analogamente ao carregamento 1 do reservatório coberto, só que com os momentos críticos apenas nas seções dos pontos $1 \mathrm{xy}, 2 \mathrm{x} / 2 \mathrm{z}$ e $4 \mathrm{xz}$.

\section{- Carregamentos 2a, 2b e 2c: $\mathrm{G}+\mathrm{T}$}

Analogamente aos carregamentos $2 \mathrm{a}$ e $2 \mathrm{~b}$ do reservatório coberto, só que com os momentos críticos apenas nas seções dos pontos 1xy, 3y/3z e 4xz.

\section{- Carregamento 3: $\mathrm{G}+\mathrm{A}+\mathrm{T}$}

Analogamente ao carregamento 3 do reservatório coberto, com os momentos críticos também nos pontos $3 \mathrm{y}$ e $3 \mathrm{z}$.

${ }^{18}$ Quando existir este carregamento, os seus momentos nas seções 1 e 2 serão sempre maiores do que os momentos nas seções dos pontos 1 e 2 dos carregamentos 2 a e 1 , respectivamente. 


\section{- Carregamento 4: $\mathrm{G}+\mathrm{A}+\mathrm{T}$}

Analogamente ao carregamento 4 do reservatório coberto, com os momentos críticos também nos pontos $1 \mathrm{xy}$ e $2 \mathrm{x} / 2 \mathrm{z}$.

\subsubsection{Carregamentos dos reservatórios elevados}

Foi visto em 3.2.1b apenas que para os reservatórios elevados são necessários aqueles três carregamentos. Entretanto, eles são necessários apenas para se obter os esforços máximos nos pilares, quando houver, e os esforços críticos nas fundações.

Para os esforços críticos da cuba basta considerar o reservatório cheio, ou seja, o carregamento $1(\mathrm{G}+\mathrm{A})$, que já se obtém todos os esforços críticos necessários ao dimensionamento e detalhamento da mesma, independentemente dos demais carregamentos.

Assim sendo, por razões didáticas, as análises das seções críticas das cubas, conforme sejam cúbicas ou alongadas, são feitas no próximo item 3.3.

Finalmente, de forma diferente das análises feitas para os reservatórios térreos, apresenta-se aqui neste item, os carregamentos críticos para o dimensionamento dos pilares e para a verificação das fundações ${ }^{19}$ dos reservatórios elevados, fornecendo também os critérios específicos para a verificação da cada uma delas.

\footnotetext{
${ }^{19} \mathrm{Na}$ análise das fundações em geral não são necessárias as verificações das forças horizontais devidas ao vento. Já para as forças verticais, como será visto a seguir, são necessárias três verificações, ou seja, uma para o reservatório cheio, outra para o reservatório vazio sob a ação do vento e uma terceira para o reservatório cheio, também sob a ação do vento.
} 
a) Reservatórios elevados com fuste, sobre estacas

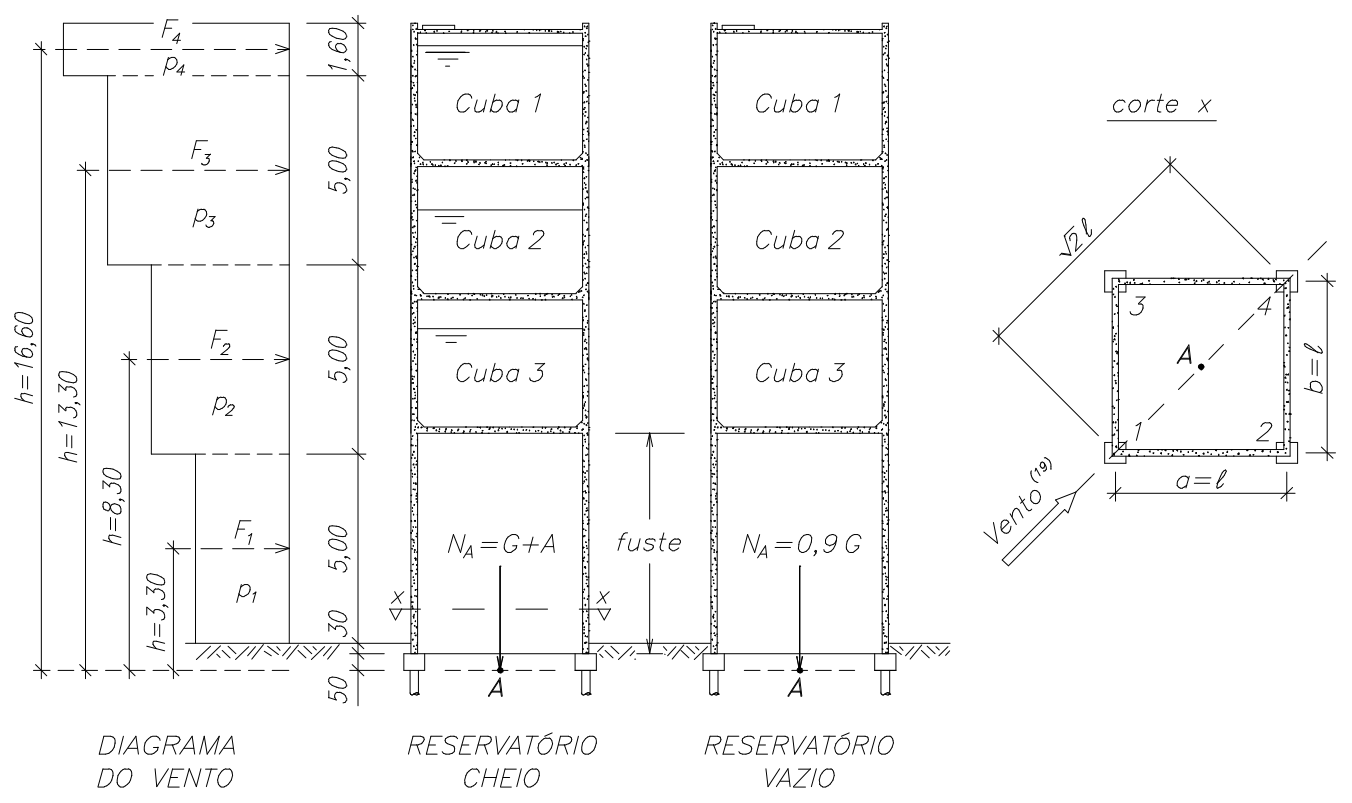

Figura 3.26 - Carregamentos para a verificação das fundações de reservatórios com fuste, sobre estacas.

- Carregamento 1: $\mathrm{G}+\mathrm{A}$

Hipótese: reservatório cheio, sem vento

Verificação das fundações: $\mathrm{E}_{1}=\mathrm{E}_{2}=\mathrm{E}_{3}=\mathrm{E}_{4}=\frac{\mathrm{G}+\mathrm{A}}{4} \leq \overline{\mathrm{E}}$

- Carregamento 2: $0,9 \mathrm{G}+\mathrm{V}$

Hipótese: reservatório vazio, com vento

Verificação das fundações: $\mathrm{E}_{1}=\frac{0,9 \cdot \mathrm{G}}{4}-\frac{\mathrm{M}_{\mathrm{A}}{ }^{(20)}}{\sqrt{2} \cdot \ell} \geq 0$

- Carregamento 3: $\mathrm{G}+\mathrm{A}+\mathrm{V}$

Hipótese: reservatório cheio, com vento

Verificação das fundações: $\mathrm{E}_{4}=\frac{\mathrm{G}+\mathrm{A}}{4}+\frac{\mathrm{M}_{\mathrm{A}}{ }^{(20)}}{\sqrt{2} \cdot \ell} \leq 1,3 \overline{\mathrm{E}}$

${ }^{20} \mathrm{O}$ vento na direção diagonal é a pior situação.

${ }^{21} \mathrm{M}_{\mathrm{A}}=\sum_{\mathrm{i}=1}^{4} \mathrm{~F}_{\mathrm{i}} \mathrm{h}_{\mathrm{i}}$ é o momento do vento em relação à face inferior dos blocos (para o caso particular da figura 3.26)

$\mathrm{p}_{\mathrm{i}}=\mathrm{q}_{\mathrm{i}} \cdot \mathrm{C}_{\mathrm{a}} \cdot \sqrt{2} \cdot \ell(\mathrm{kgf}) ; \quad \mathrm{q}_{\mathrm{i}}=\frac{\mathrm{V}_{\mathrm{k}}^{2}}{16}\left(\mathrm{kgf} / \mathrm{m}^{2}\right) ; \quad \underset{\mathrm{i}=1}{\mathrm{~F}_{\mathrm{i}}}=5 \mathrm{p}_{\mathrm{i}}(\mathrm{kgf}) \quad$ e $\quad \mathrm{F}_{4}=1,60 \mathrm{p}_{4}(\mathrm{kgf}) ;$

$\mathrm{V}_{\mathrm{k}}=\mathrm{V}_{\mathrm{o}} \mathrm{S}_{1} \mathrm{~S}_{2} 0,95 \quad$ e $\quad \mathrm{C}_{\mathrm{a}} \quad$ é tirado da tabela 10 da NBR-6123, caso $\frac{\mathrm{r}}{\mathrm{a}}=\frac{1}{48}$. 
b) Reservatórios elevados com fuste, em fundação direta

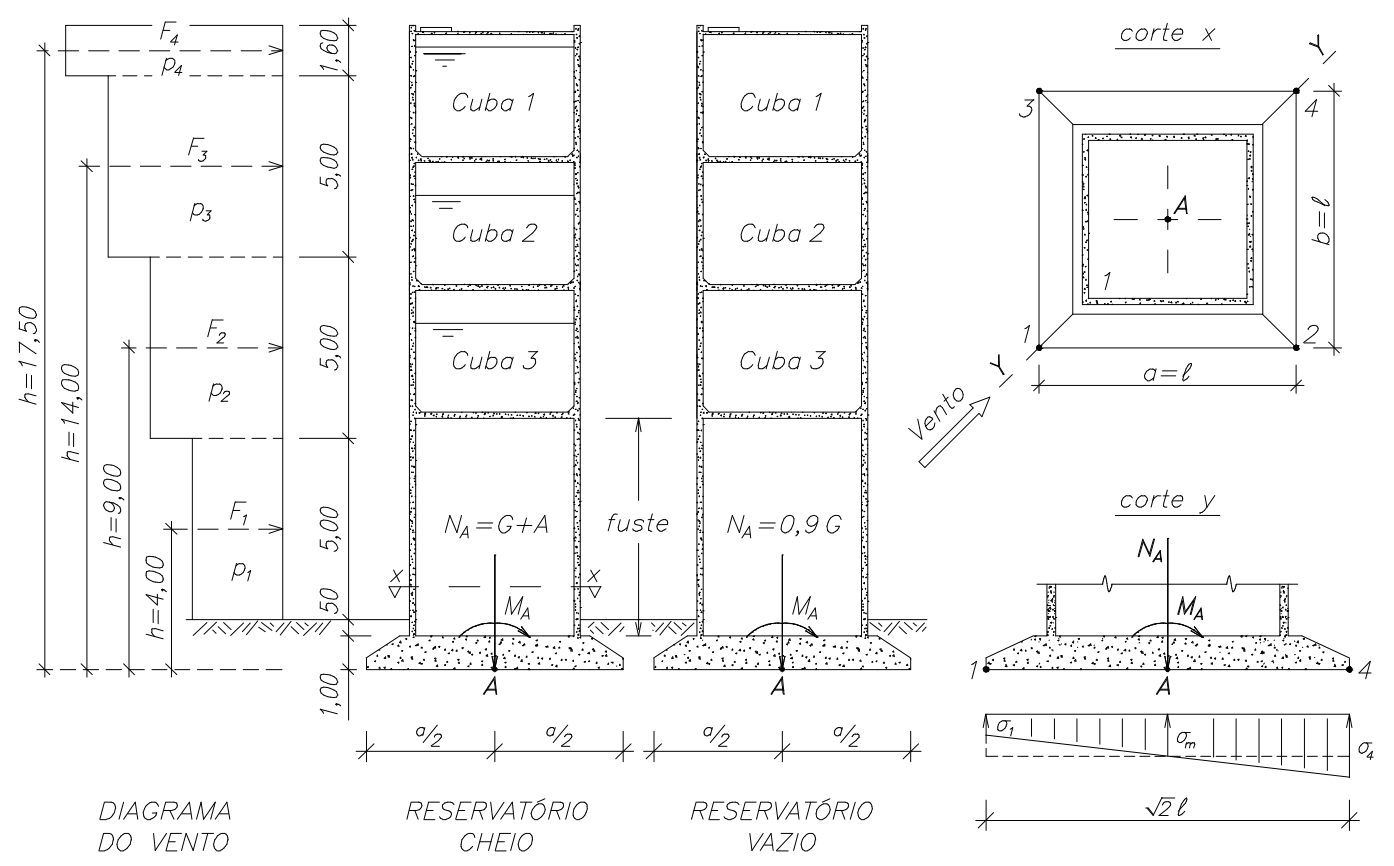

Figura 3.27 - Carregamentos para a verificação das fundações de reservatórios elevados com fuste, em fundação direta.

- Carregamento 1: $\mathrm{G}+\mathrm{A}$

Hipótese: reservatório cheio, sem vento

Verificação das fundações: $\sigma_{1}=\sigma_{2}=\sigma_{3}=\sigma_{4}=\sigma_{\mathrm{m}}=\frac{\mathrm{G}+\mathrm{A}}{\ell^{2}}$

- Carregamento 2: $0,9 \mathrm{G}+\mathrm{V}$

Hipótese: reservatório vazio, com vento

Verificação das fundações: $\sigma_{1}^{(21)}=\frac{0,9 \cdot \mathrm{G}}{\ell^{2}}-\frac{6 \sqrt{2} \mathrm{M}_{\mathrm{A}}}{\ell^{3}} \geq 0$

- Carregamento 3: $\mathrm{G}+\mathrm{A}+\mathrm{V}$

Hipótese: reservatório cheio, com vento

Verificação das fundações: $\sigma_{4}^{(21)}=\frac{\mathrm{G}}{\ell^{2}}+\frac{6 \sqrt{2} \mathrm{M}_{\mathrm{A}}}{\ell^{3}} \leq 1,3 \bar{\sigma}_{\mathrm{s}}$

${ }^{22}$ Essas expressões decorrem da fórmula geral da Resistência dos Materiais, para flexão oblíqua simétrica e $\mathrm{a}=\mathrm{b}=\ell$, ou seja, $\sigma=\frac{\mathrm{N}}{\mathrm{A}} \pm \frac{\mathrm{M}_{\mathrm{Ax}}}{\mathrm{W}_{\mathrm{x}}} \pm \frac{\mathrm{M}_{\mathrm{Ay}}}{\mathrm{W}_{\mathrm{y}}}$ onde $\mathrm{M}_{\mathrm{Ax}}=\mathrm{M}_{\mathrm{Ay}}=\frac{\sqrt{2}}{2} \mathrm{M}_{\mathrm{A}}, \mathrm{W}_{\mathrm{x}}=\frac{\mathrm{b} \mathrm{a}^{2}}{6} \mathrm{e}$ $\mathrm{W}_{\mathrm{y}}=\frac{\mathrm{ab} \mathrm{b}^{2}}{6}$ 
c) Reservatórios elevados com pilares, sobre estacas

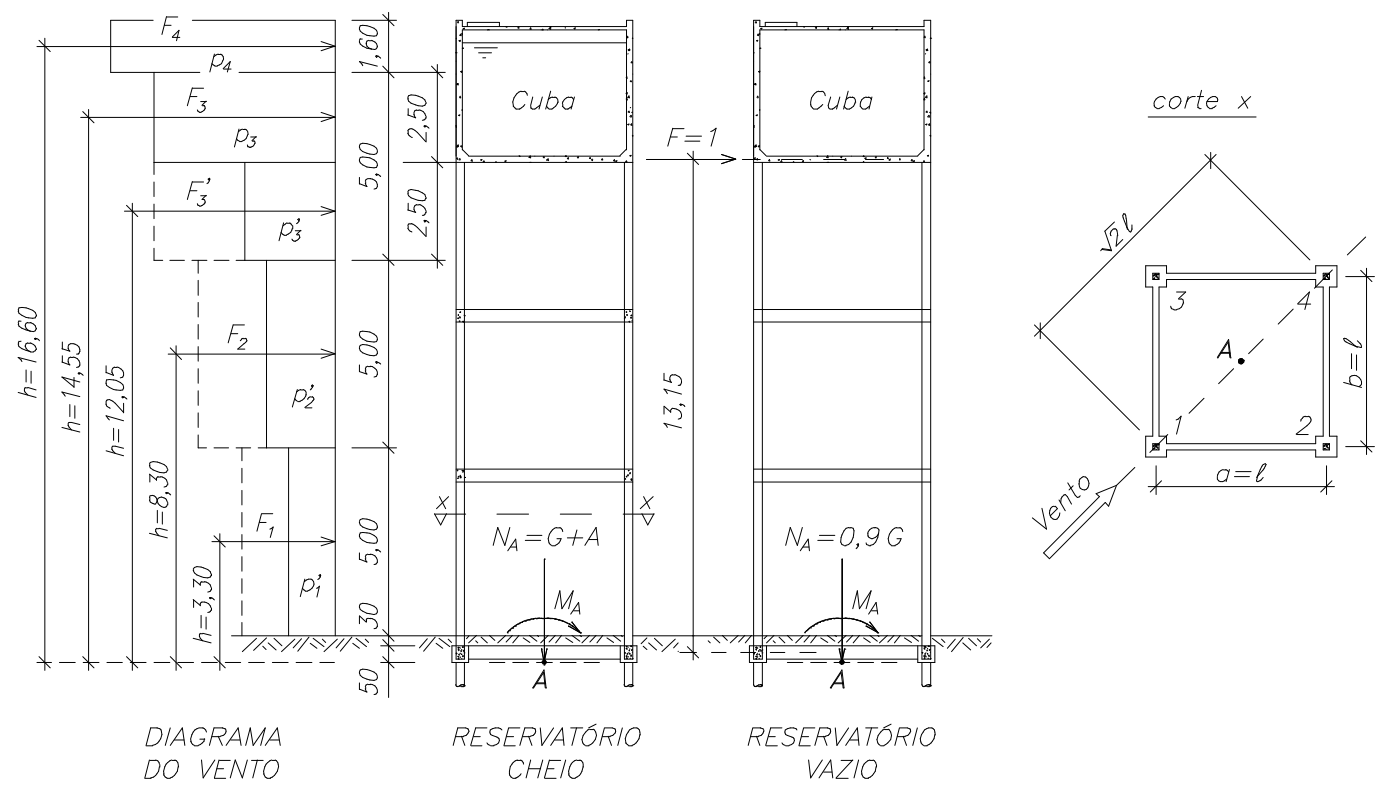

Figura 3.28 - Carregamentos para a verificação das fundações, para dimensionamento dos pilares e para se obter o coeficiente de instabilidade $\alpha$.

A verificação das fundações é a mesma dos reservatórios com fuste sobre estacas (3.2.3a), com a diferença de que o peso próprio $\mathrm{G}$, sendo agora bem menor, pode provocar problemas na verificação das fundações com o carregamento $2(0,9 \mathrm{G}+\mathrm{V})$, uma vez que os momentos não apresentam as mesmas reduções. Essa diferença é devida as ações significativas do vento nos pilares, que devem ser calculadas com o uso da tabela 11 (fator de redução k) e 12 ( coeficientes de forças $C_{x}$ e $C_{y}$ ) da NBR-6123.

Ainda, deve-se acrescentar que neste caso os pilares devem ser dimensionados com o carregamento $3(\mathrm{G}+\mathrm{A}+\mathrm{V})$.

Finalmente, e só para reservatórios elevados com pilares, deve-se aplicar uma força unitária no topo dos pilares para se fazer a verificação da estabilidade do reservatório ( ver item 3.3).

Esta força unitária não chega a ser um carregamento porque é fictícia. Entretanto, como é necessária usá-la para a verificação da instabilidade, pode ser considerada como tal. 
Assim, nos reservatórios elevados com pilares tem-se quatro carregamentos, ou seja:

carregamento 1: $\mathrm{G}+\mathrm{A}$;

carregamento 2: $0,9 \mathrm{G}+\mathrm{V}$;

carregamento 3: $\mathrm{G}+\mathrm{A}+\mathrm{V}$;

“carregamento 4": Força unitária no topo.

d) Reservatórios elevados com pilares, em fundação direta

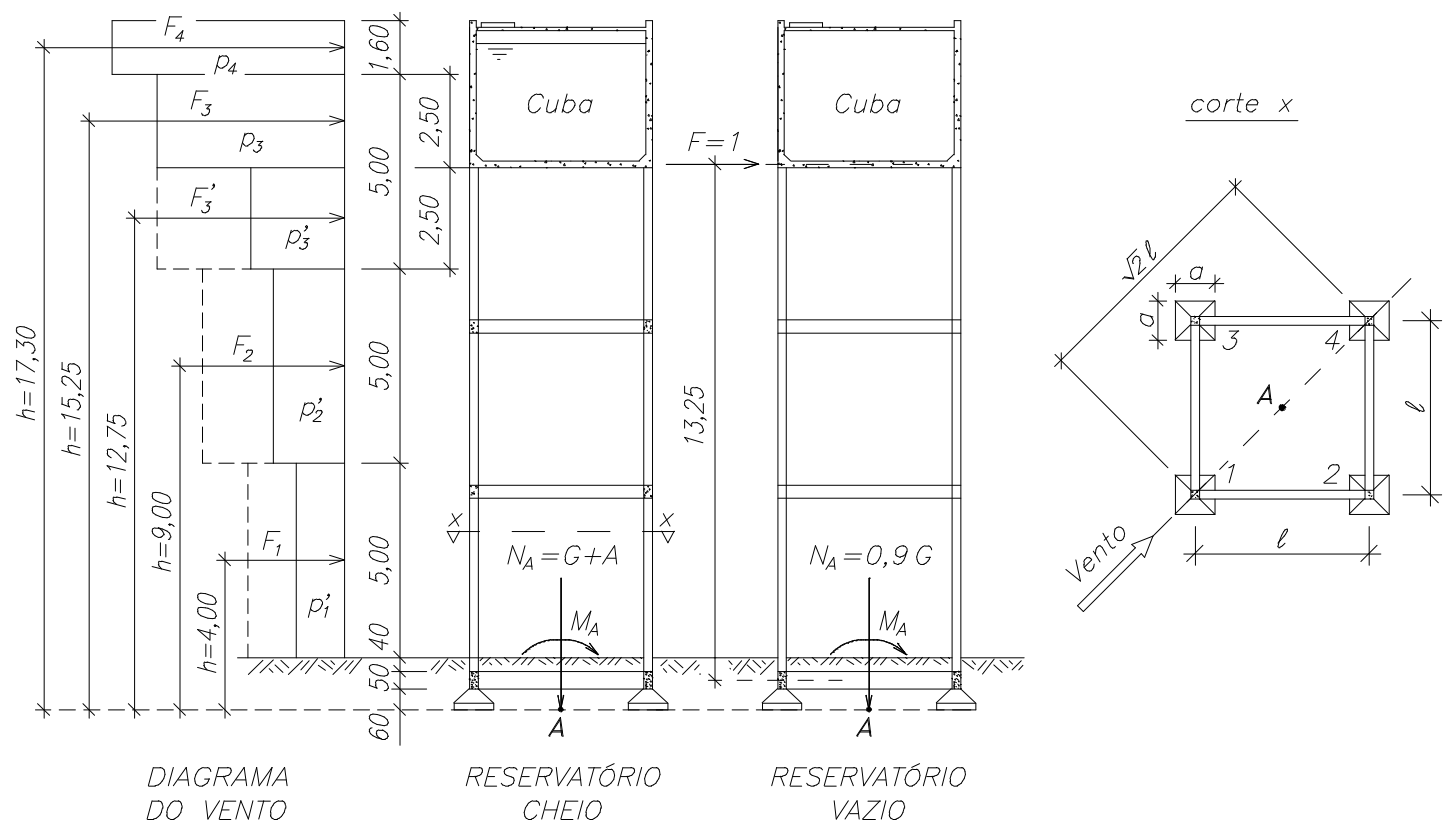

Figura 3.29 - Carregamentos para o dimensionamento dos pilares, verificação das fundações e para se obter o coeficiente de instabilidade $\alpha$.

- Carregamento 1: $\mathrm{G}+\mathrm{A}$

Hipótese: reservatório cheio, sem vento

Verificação das fundações: $\sigma_{1}=\sigma_{2}=\sigma_{3}=\sigma_{4}=\frac{\mathrm{G}+\mathrm{A}}{4 \mathrm{a}^{2}} \leq \bar{\sigma}_{\mathrm{s}}$ 
- Carregamento 2: $0,9 \mathrm{G}+\mathrm{V}$

Hipótese: reservatório vazio, com vento ${ }^{23}$

Verificação das fundações: $\sigma_{1}=\frac{0,9 \cdot \mathrm{G}}{4 \mathrm{a}^{2}}-\frac{\mathrm{M}_{\mathrm{A}}}{\sqrt{2} \ell \mathrm{a}^{2}} \geq 0^{(22)}$

- Carregamento 3: $\mathrm{G}+\mathrm{A}+\mathrm{V}$

Hipótese: reservatório cheio, com vento.

Verificação das fundações: $\sigma_{4}=\frac{G+A}{4 a^{2}}+\frac{M_{A}}{\sqrt{2} \ell a^{2}} \leq 1,3 \bar{\sigma}_{\mathrm{s}}{ }^{(22)}$

Dimensionamento dos pilares: esforços nos pilares do eixo 4.

- Carregamento 4: $\mathrm{F}=1$

Hipótese: reservatório vazio, sem peso próprio, sem vento e com carga unitária.

Verificação da instabilidade do reservatório: flecha no ponto de aplicação da carga.

\subsection{ESQUEMAS ESTÁticos dAS CUBAS E CÁlCULO DOS ESFORÇOS: 3a ETAPA}

\subsubsection{Grupos estruturais de um reservatório e trechos estruturais de uma cuba}

Cada reservatório, dependendo do tipo, apresenta dois a três grupos de elementos estruturalmente afins.

Embora os esforços quase sempre sejam obtidos com todos os elementos trabalhando juntos, os dimensionamentos e detalhamentos desses elementos são feitos com teorias e especificações próprias do grupo a que cada um pertence.

O primeiro destes grupos, existentes em todos os reservatórios, corresponde às

${ }^{23}$ Como a variação das tensões sob a sapata de um pilar é muito pequena, considera-se a tensão média. 
suas fundações. É composto de estacas, capitéis, blocos sobre estacas e sapatas, não estando necessariamente presentes numa mesma fundação.

O segundo grupo, existente apenas nos reservatórios elevados, é composto dos seus fustes, paredes e pilares contraventados.

O último grupo, obviamente também obrigatório em todos os reservatórios, é formado pelas cubas, com todas as suas lajes e paredes.

À exceção desse terceiro grupo, o cálculo dos esforços e as verificações dos elementos estruturais do primeiro e segundo grupos, não diferem muito dos cálculos e verificações feitas, para esses mesmos elementos, nos edifícios comuns.

Assim sendo, procurando não estender muito esta dissertação com informações sobre cálculos já consagrados e objetivando apenas os aspectos inéditos, faz-se a seguir uma análise apenas dos cálculos dos esforços críticos das cubas em função das suas formas (item 2.4.7): achatadas, alongadas e cúbicas.

Nesta análise, as cubas são subdivididas em trechos, com comportamento estrutural diferentes.

Assim sendo, tem-se, para as cubas achatadas e alongadas, dois trechos distintos. Um TRECHO PRINCIPAL I, que corresponde a quase todo o reservatório, onde os momentos são maiores e com eles são definidas as espessuras das lajes e das paredes. E, os TRECHOS COMPLEMENTARES II, que correspondem a pequenas regiões do reservatório, com momentos menores mas em direções diferentes das dos trechos principais e portanto tendo-se que dimensionar as seções correspondentes aos momentos máximos, positivos e negativos.

Ainda, dada a necessidade das cubas serem estanques os ESQUEMAS ESTÁTICOS de cada um destes trechos devem ser muito bem estudados, pois mudam com o tipo de fundação e , em alguns casos, mudam até com os carregamentos.

\subsubsection{Reservatórios achatados $(\mathrm{h}<<\mathrm{a}$ e b)}

a) Ocorrência: Reservatório para abastecimento público, piscinas, tanques, decantadores de estações de tratamento d'água, etc. 


\section{b) Grupos estruturais}

Os reservatórios sem cobertura apresentam elementos estruturais apenas dos grupos obrigatórios, ou seja, as fundações (primeiro grupo) e as paredes e laje do fundo (terceiro grupo).

Já nos reservatórios achatados cobertos, quase sempre de grandes dimensões em planta ( $\mathrm{a}$ e $\mathrm{b}>10 \mathrm{~m}$ ), são projetados pilares internamente que pertencem ao segundo grupo.

c) Trechos estruturais das cubas

Trecho principal I, é formado pelas lajes e paredes da parte central do reservatório.

Trecho complementar II, são formados pelas partes das lajes e paredes dos quatro cantos do reservatório.

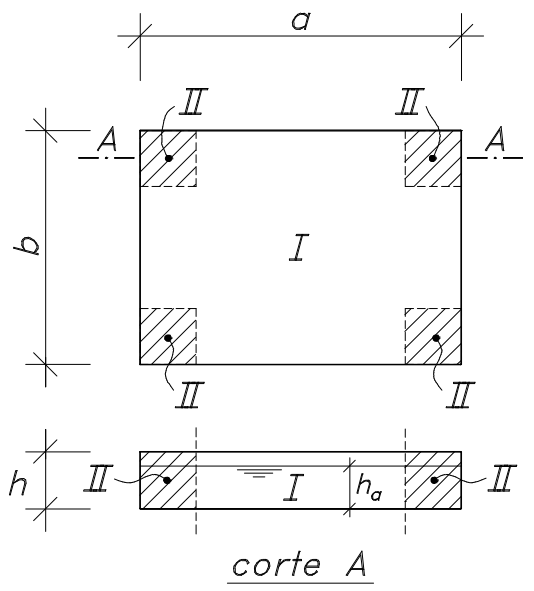

Figura 3.30 - Indicação dos trechos PRINCIPAIS (I) e COMPLEMENTARES (II) de um reservatório achatado.

d) Esquemas estáticos dos trechos estruturais das cubas

\section{$\underline{\text { Em fundação direta }}$}

São os reservatórios que apresentam as estruturas mais econômicas em face da pequena quantidade de concreto estrutural por metro cúbico de água reservada, entretanto, só devem ser projetados com essa fundação se o solo for tecnicamente indicado para tal finalidade. 
A idéia de que "a terra retirada pesa mais do que a água e portanto se pode projetar fundação direta" não deve ter crédito. Solos argilosos porosos são muito colapsíveis em presença de água, que pode aparecer sob as fundações de várias maneiras: vazamento do reservatório, vazamentos das tubulações próximas da estrutura, águas de chuva, etc.

\section{- Esquema estático do trecho principal I}

Nos reservatórios sem cobertura, as paredes e as sapatas formam um pórtico plano perfeito, uma vez que neste trecho trabalham e são calculadas numa só direção.

Nos reservatórios cobertos, embora as lajes da cobertura trabalhem em duas direções, por serem lajes-cogumelo elas podem ser calculadas em uma só direção.

Assim, as lajes de cobertura, as paredes e as respectivas sapatas podem ser consideradas como um pórtico plano que após calculado fornece as tensões no solo, os esforços nas paredes e nas sapatas. Aos esforços das lajes da cobertura devem ser aplicado o que especifica o item 3.3.2.11 da NBR-6118, relativos a lajes-cogumelo.

Os apoios internos da cobertura são compostos por pilares, que transferem as suas cargas para o solo por meio de sapatas rígidas.

Já para os apoios das paredes são projetadas sapatas flexíveis, conforme já analisado em 2.3.1c, essas sapatas são dimensionadas à flexo-tração.

Nas figuras 3.31 a 3.35 são apresentadas as seções típicas e os esquemas estáticos dos dois tipos de reservatórios achatados em fundação direta, sem e com cobertura, dando-se algumas indicações para o pré-dimensionamento. 
$\underline{\text { Reservatório em fundação direta sem cobertura: }}$

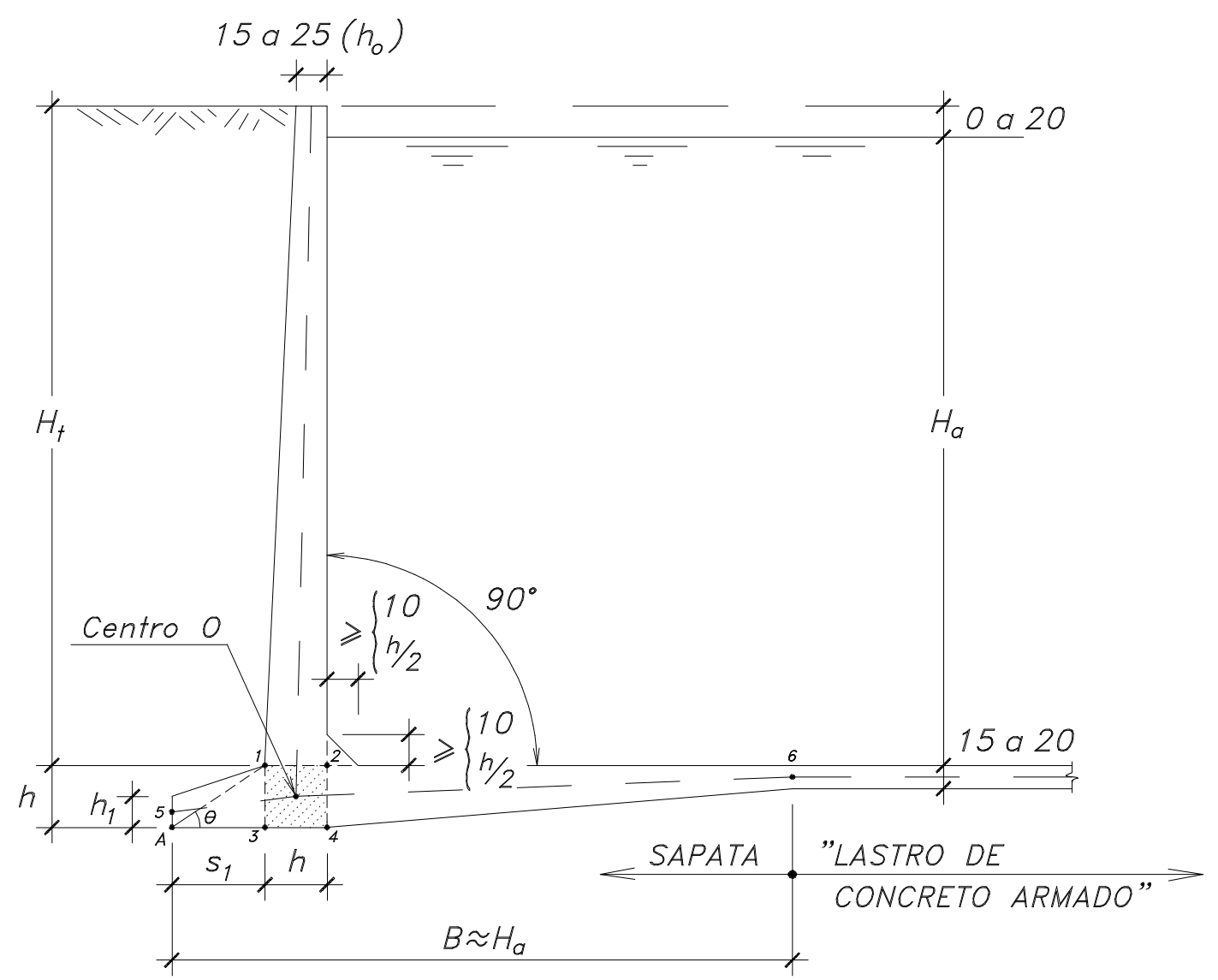

Figura 3.31 - Trecho estrutural principal I de um reservatório achatado, em fundação direta e sem cobertura, com indicações para pré-dimensionamento.

As paredes são projetadas com espessuras (h) constantes de 15 a $25 \mathrm{~cm}$, se essas medidas corresponderem às necessidades do dimensionamento.

Se necessário valores maiores, elas são projetadas com $\mathrm{h}$ do dimensionamento na base, diminuindo linearmente até a espessura $\left(\mathrm{h}_{\mathrm{o}}\right)$ de 20 a $25 \mathrm{~cm}$ na extremidade superior.

As indicações para o pré-dimensionamento da espessura $h$, principal medida, e da espessura $\left(h_{0}\right)$ estão apresentadas no item 3.4.

A sapata é projetada com a mesma espessura $\mathrm{h}$ da parede, na região do quadrado 1, 2, 3 e 4 (Figura 3.31). Externamente ao reservatório, à esquerda desse quadra- 
do, a sapata deve ter uma aba $s_{1}$ para reduzir as tensões no solo cujo valor máximo ocorre na extremidade A.

Também, essa aba ajuda na ancoragem da armadura negativa da sapata $\left(\phi_{\mathrm{SAP}}\right)$.

Ainda, adota-se $\mathrm{s}_{1} \approx 1,5 \mathrm{~h}$ para que a aba tenha comportamento de sapata rígida, ou seja, $\operatorname{tg} \phi \geq \frac{2}{3}\left(\frac{1}{2}\right)$.

A altura $h_{1}$ na extremidade A deve ter as dimensões indicadas na tabela 3.1, para viabilizar a execução dos ganchos das extremidades das armaduras das paredes e das sapatas, bem como dos "ferros sapatas" colocados internamente nesses ganchos.

Tabela 3.2 - Valores de $h_{1}$ da aba, em função do $\phi_{\text {SAP }}$

\begin{tabular}{l|c|c|c|c|c|}
\hline$\phi_{\mathrm{SAP}}(\mathrm{mm})$ & 10 & 12,5 & 16 & 20 & 22 \\
\hline $\mathrm{h}(\mathrm{cm})$ & 15 & 20 & 25 & 30 & 35 \\
\hline
\end{tabular}

Quanto à parte interna da sapata, exceção aos pequenos reservatórios com paredes e fundo de $15 \mathrm{~cm}$ constantes, as espessuras variam do valor $\mathrm{h}$ junto ao quadrado sob a parede, até 15 a $20 \mathrm{~cm}$, na ligação com o "lastro de concreto armado"24.

Para a largura total da sapata (B) adota-se um valor em torno da altura d'água $\left(\mathrm{H}_{\mathrm{a}}\right)$.

As mísulas não são obrigatórias mas ajudam, conforme mostra os ensaios de NILSON \& LOSBERG. Tradicionalmente, motivado por razões construtivas, em reservatórios com azulejos (piscinas) não se usam mísulas. Entretanto essa posição deve ser revista por se tratar da região mais solicitada dos reservatórios e de difícil execução. Ainda, trata-se aqui de preservar a ESTANQUEIDADE que é uma qualidade funcional e portanto hierarquicamente superior às outras duas que até então

\footnotetext{
${ }^{24}$ Esse termo, talvez um pouco pejorativo, há muito tempo vem sendo usado pelo autor em suas aulas para designar um concreto de pouca responsabilidade estrutural.

No caso em questão, ele é armado para absorver o empuxo de água, na suposição de que a maior rigidez do concreto da laje do fundo inibe o desenvolvimento das forças de atrito. A armadura desse "lastro" também combate as fissuras de retração na fase construtiva, como também combate as perturbações que possam ocorrer devido a eventuais esvaziamentos futuros.
} 
estão sendo preferidas, ou seja, a CONSTRUTIBILIDADE e a ECONOMIA.

Para uso de programas que simulam as reações e as deformações do solo como molas, como já visto em $2.3 .1 \mathrm{c}$, tem-se o esquema estático da figura 3.32, onde se toma a em torno de 30 a $50 \mathrm{~cm}$, conforme a espessura da sapata e a precisão que se deseja. O coeficiente da mola é $\mathrm{k} \cdot \mathrm{a}$, onde $\underline{\mathrm{k}}$ é o coeficiente de BALASTO, ou de REAÇÃO ELÁSTICA, do solo.

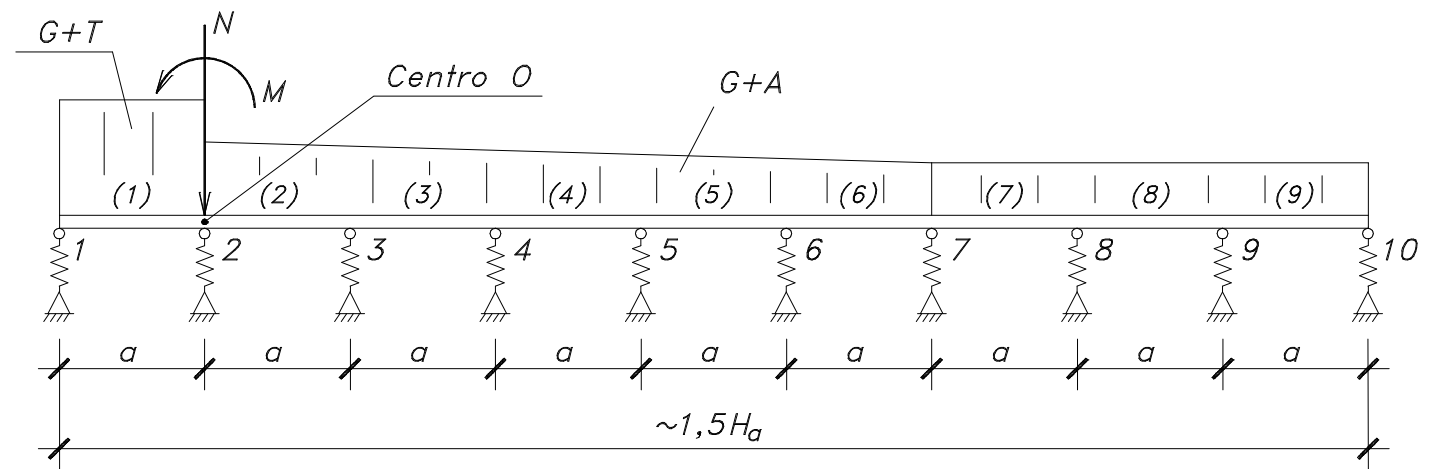

Figura 3.32 - Esquema estático do trecho principal de um reservatório achatado, em fundação direta e sem cobertura, para uso de programas de pórticos planos que substituem o solo por molas.

Também como já visto em 2.3.1c, para uso de programas de pórticos planos comuns, tem-se o mesmo esquema estático anterior só que em lugar das molas, colocam-se barras fictícias de concreto, de comprimento unitário e área $\mathrm{S}=\frac{\mathrm{k} \cdot \mathrm{a}}{\mathrm{E}_{\mathrm{c}}}$, onde $\mathrm{E}_{\mathrm{c}}$ é o módulo de elasticidade da laje que se está calculando e $\mathrm{k}$ é o coeficiente de BALASTO do solo (Figura 3.33).

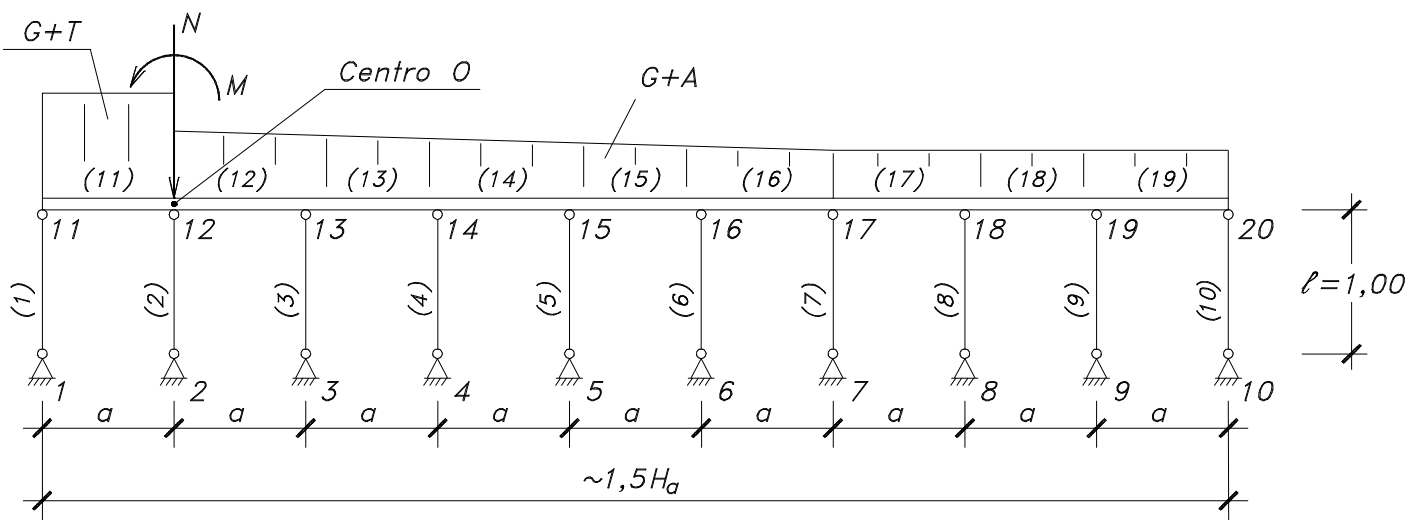

Figura 3.33 - Esquema estático do trecho principal de um reservatório achatado, em fundação direta e sem cobertura, para uso de programas de pórticos planos comuns. 
$\underline{\text { Reservatórios em fundação direta com cobertura (Figura 3.34): }}$

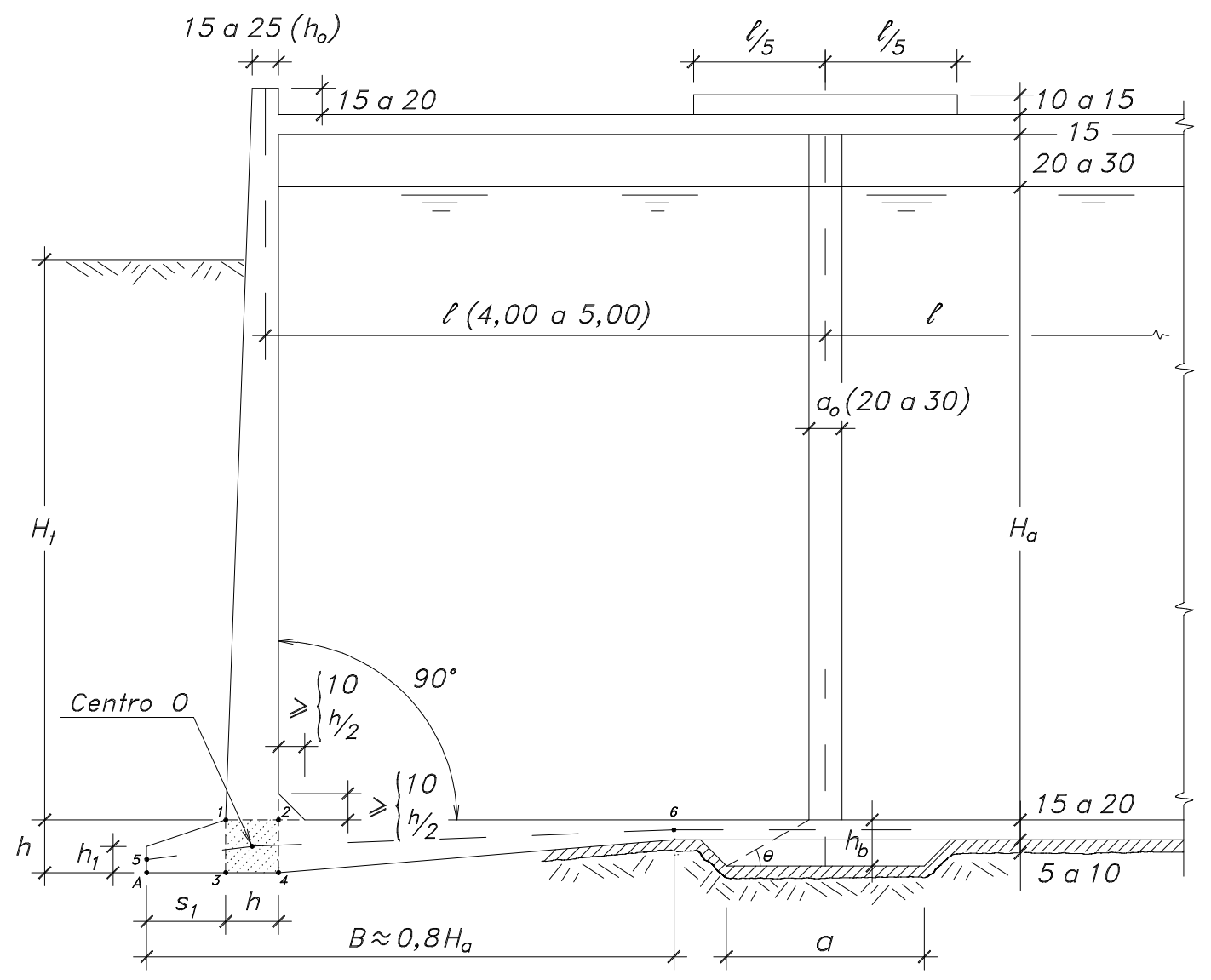

Figura 3.34 - Trecho estrutural principal I de um reservatório achatado, em fundação direta e com cobertura, com indicações para pré-dimensionamento.

As lajes de cobertura devem ser do tipo COGUMELO com $15 \mathrm{~cm}$ de espessura. As distâncias entre pilares são calculadas, em função das medidas em planta, de maneira que resulte vãos aproximadamente iguais e em torno de 4,00 a 5,00 m. Os ábacos devem ser invertidos para se ter mais economia na forma.

As sapatas sob as paredes são análogas às do reservatório descoberto com a diferença na largura total: $\mathrm{B}=0,8 \mathrm{H}_{\mathrm{a}}$.

As paredes têm as mesmas indicações das dos reservatórios sem cobertura, sendo que nesses o uso de mísulas já está consagrado. 
As sapatas dos pilares devem ser rígidas, ou seja, $\operatorname{tg} \phi \geq \frac{2}{3}\left(\frac{1}{2}\right)$, com alturas $\mathrm{h}_{\mathrm{B}}$ iguais ou superiores a $30 \mathrm{~cm}$. Em geral, para cargas normais de cobertura, conforme os vãos entre pilares e a altura d'água, o intervalo de $30 \mathrm{~cm} \leq \mathrm{h}_{\mathrm{B}} \leq 50 \mathrm{~cm}$ é suficiente.

Os "lastros de concreto armado" seguem as mesmas prescrições das do reservatório descoberto.

Os esquemas estáticos desses reservatórios são os mesmos do caso anterior, tendo-se que acrescentar apenas uma barra representando a parede e quatro barras, no máximo, representando quatro ou três vãos e meio, conforme o número de vãos seja par ou impar (Figura 3.35).

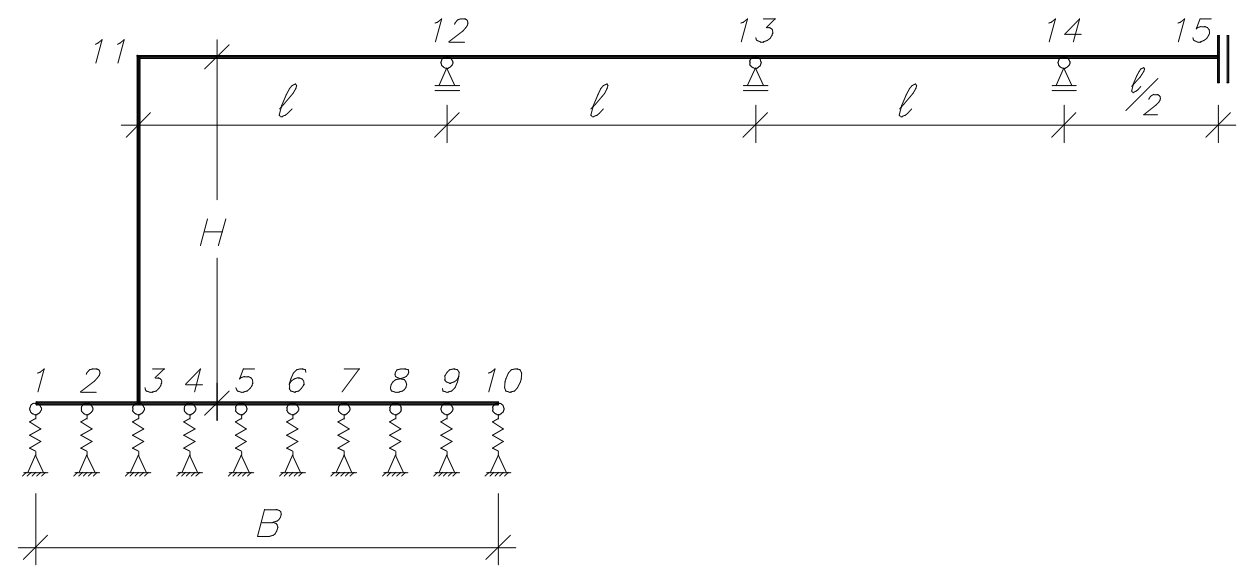

Figura 3.35 - Esquema estático do trecho principal de um reservatório achatado, em fundação direta e com cobertura, para uso de programas de pórticos planos.

- Esquema estático dos trechos complementares II

Nos reservatórios sem e com coberturas, as paredes quando se encontram provocam um engastamento mútuo que impedem deslocamentos e rotações ao longo de toda a altura.

Assim geram momentos negativos e positivos que solicitam as suas seções verticais, exigindo nelas a colocação de armaduras horizontais, às vezes superiores aos 0,125\% b·h por face, especificado pelo ACI para a retração (ver item 3.2.1a). 
$\underline{\text { Reservatório em fundação direta, sem cobertura: }}$

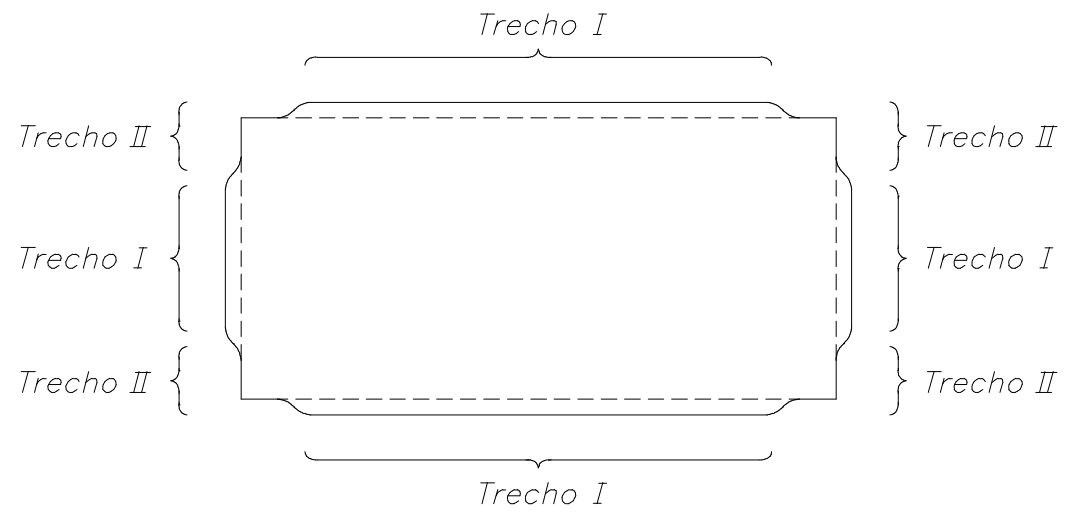

a) Planta de um reservatório achatado com indicações dos trechos I e II.

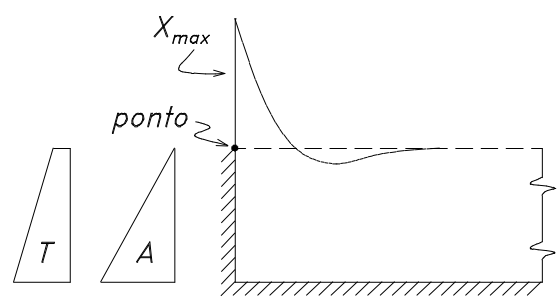

carregamento 1: só A

$$
\left\{\begin{array}{l}
\mathrm{X}_{\text {max }} \\
\text { internamente }
\end{array}\right.
$$

carregamento 3: $\mathbf{T}$ nas duas

$$
\begin{aligned}
& \text { T nas duas } \\
& \text { paredes per- } \\
& \text { pendiculares }
\end{aligned} \quad\left\{\begin{array}{l}
\mathrm{X}_{\text {max }} \\
\text { externamente }
\end{array}\right.
$$

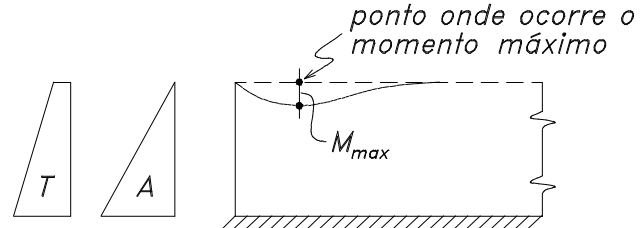

carregamento 2: $\mathbf{A}$ e $\mathbf{T}$ na parede per-
pendicular $\left\{\begin{array}{l}\mathrm{M}_{\max } \\ \text { externamente }\end{array}\right.$ carregamento 4: T em uma só parede $\left\{\begin{array}{l}\mathrm{X}_{\text {max }} \\ \text { internamente }\end{array}\right.$

b) Carregamentos e esquemas estáticos correspondentes para o cálculo dos momentos longitudinais máximos de paredes infinitas com borda livre

Figura 3.36 - Indicação dos trechos I e II de um reservatório achatado sem cobertura, carregamentos e esquemas estáticos correspondentes.

Os esforços dessas paredes, para os quatro carregamentos são obtidos com o uso da tabela A13 do anexo A.

Neste caso de paredes em balanço, os esforços são significativos e ambos os momentos máximos, negativos e positivos, ocorrem na borda livre das mesmas. Assim sendo, o momento negativo máximo deve ser usado para o pré-dimensionamento da extremidade superior das paredes dos reservatórios sem coberturas. 
Reservatórios em fundação direta, com cobertura:
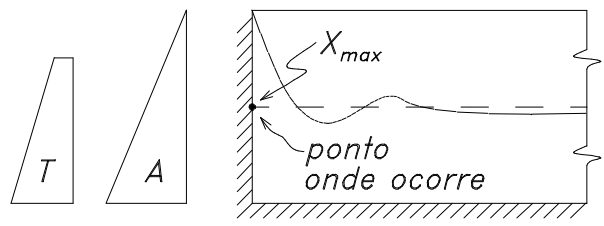

carregamento 1: só A

$$
\left\{\begin{array}{l}
\mathrm{X}_{\text {max }} \\
\text { internamente }
\end{array}\right.
$$

carregamento 3: $\mathbf{T}$ nas duas paredes per-

$$
\left\{\begin{array}{l}
\mathrm{X}_{\text {max }} \\
\text { externamente }
\end{array}\right.
$$

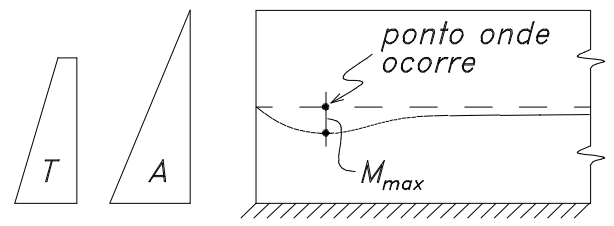

carregamento 2: A e T na parede per-
pendicular $\left\{\begin{array}{l}\mathrm{M}_{\max } \\ \text { externamente }\end{array}\right.$

carregamento 4: T em uma só parede

Figura 3.37 - Carregamentos e esquemas estáticos correspondentes para o cálculo dos momentos longitudinais máximos de paredes infinitas travadas pela cobertura na parte superior.

Os esforços dessas paredes, para os quatro carregamentos são obtidos com o uso da tabela A12 do anexo A.

Neste caso de paredes travadas por lajes, os esforços não são muito significativos. Ainda, os momentos máximos ocorrem próximos da metade da altura das paredes, onde as espessuras são maiores do que as das extremidades.

Finalizando, as tabelas 12 e 13 foram feitas para as paredes de inércia constante. Para inércia variável, os dados já foram estudados e até introduzidos nos arquivos do SAP90, faltando apenas processá-los e montar as tabelas.

\section{$\underline{\text { Em fundação sobre estacas }}$}

Nos reservatórios com fundação em estacas, as paredes sendo travadas na parte superior apresentam momentos bem menores do que os das paredes sem cobertura.

Evidentemente neste caso não há maior necessidade da aba $\mathrm{s}_{1}$ do caso em fundação direta sendo que, como naquele caso, mantém-se um trecho B mais rígido para resistir aos momentos, da ordem de $80 \%$ da altura d'água do reservatório.

A cobertura aqui também deve ser fixada em $15 \mathrm{~cm}$ e os pilares já não apresentam o mesmo vão, tendo em vista que devem acompanhar os espaçamentos das esta- 
cas nas fundações, ou seja, a cada duas estacas projeta-se um pilar, começando com pilares nas primeiras estacas internas.

As lajes do fundo devem ser, obrigatoriamente ${ }^{(*)}$, projetadas do tipo cogumelo.

A utilização de vigas, devido às grandes cargas dessas lajes, traria uma grande concentração de cargas muito grande, com conseqüente concentração de armaduras nas mesmas. Conseqüentemente dificultaria a concretagem, podendo prejudicar a estanqueidade do reservatório como também aumentaria o custo da estrutura em face do alto custo das formas.

Assim, a indicação é para lajes-cogumelo, em face da total liberdade na redução dos vãos entre estacas, da possibilidade de combater a punção executando-se capitéis tronco-cônicos de fôrmas portáteis, de não se ter concentração e nem dobramentos das armaduras e, principalmente, da grande facilidade na concretagem.

Assim sendo, embora trabalhem nas duas direções, juntamente com as lajes de cobertura, se houver, sendo lajes-cogumelo podem ser calculadas em uma direção.

Conseqüentemente, como nos casos em fundação direta, podem ser consideradas como um pórtico plano, lembrando-se que no final dos cálculos, devem ser aplicados os coeficientes da NB-1.

As estacas são em geral projetadas com vãos pequenos, de 2 a $3 \mathrm{~m}$, dependendo da altura de água.

Normalmente os vãos extremos são projetados maiores para equilibrar os momentos das paredes, não sendo conveniente uma rotação que provoque uma redução do momento de engastamento perfeito de mais de $30 \%$.

As distâncias entre as estacas internas já são calculadas em função da capacidade das estacas e dos comprimentos em planta dos reservatórios.

Usam-se dois tipos de estacas, por exemplo, umas de $65 \mathrm{t}$ para suportarem os

\footnotetext{
${ }^{(*)}$ A execução de vigas em laje de fundo de reservatório é uma cabal evidência de desorientação estrutural de um projeto. Por maior que seja o uso das vigas nas estruturas de concreto armado, elas não passam de elementos estruturais secundários ao acessórios, dos elementos básicos de uma estrutura que são as lajes, os pilares (paredes) e as fundações.

Só devem ser usadas em três situações: vencer vãos por razões funcionais, vencer vãos por razões econômicas e ajudar os pilares nos contraventamentos das estruturas.
} 
pilares e outras de $45 \mathrm{t}$, em torno de quatro vezes mais, projetadas entre os pilares.

- Esquema estático do trecho principal I

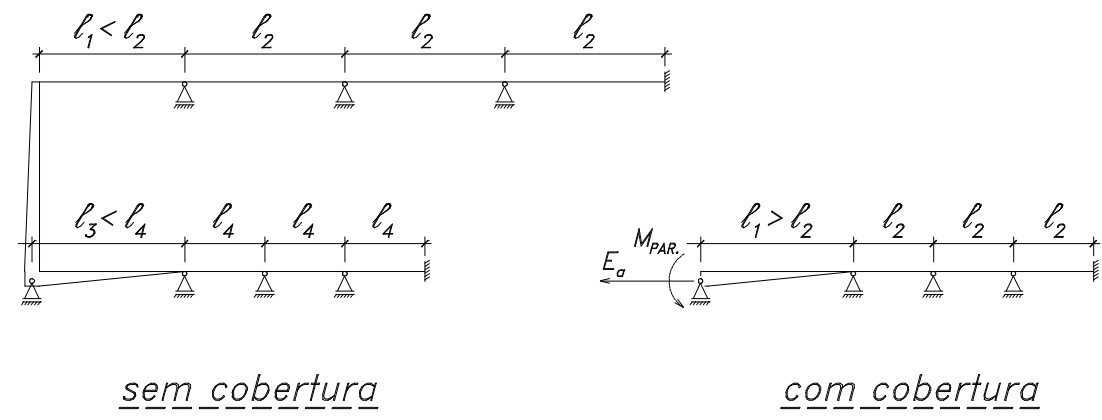

Figura 3.38 - Esquemas estáticos principais, com e sem cobertura.

- Esquema estático do trecho complementar II

Não há nenhuma diferença com as paredes dos reservatórios em fundação direta.
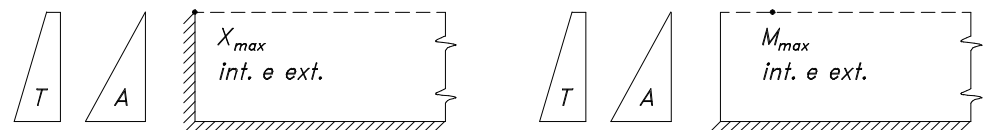

com cobertura:
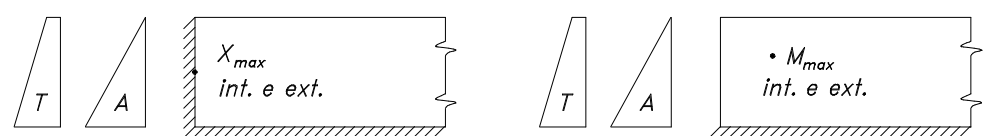

Figura 3.39 - Esquemas estáticos complementares, com e sem cobertura.

\subsubsection{Reservatórios alongados}

a) Ocorrência

- elevados com fuste ( $\mathrm{h} \gg>\mathrm{a}$ e $\mathrm{b}$ )

- térreos $(\mathrm{a} \gg \mathrm{b}$ e $\mathrm{h})$

b) Grupos estruturais

- elevados: cuba, fuste e fundação

- térreos: cuba e fundação (pilar é raro) 
c) Trechos estruturais das cubas

- elevados: $\left\{\begin{array}{l}\text { Trecho Ia e Ib } \\ \text { Trecho IIa, IIb, IIc e IId }\end{array}\right.$
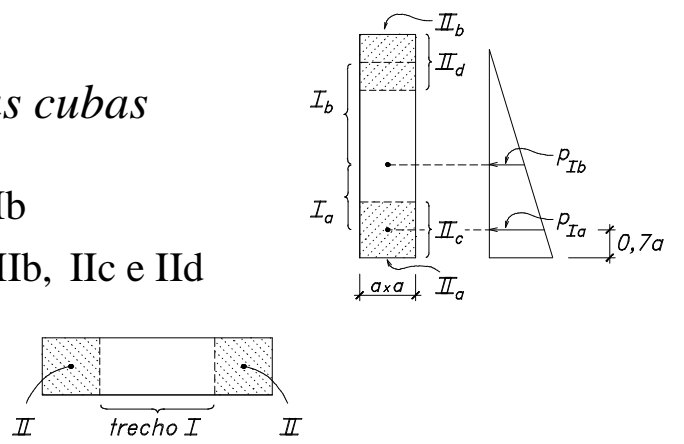

- térreos: trechos I e II

d) Esquemas estáticos dos trechos I e II

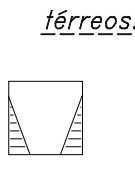

quadro

I

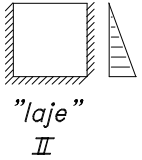

elevados:

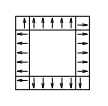

quadro

Ia $e$ Ib

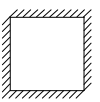

laje

fundo

II $a$
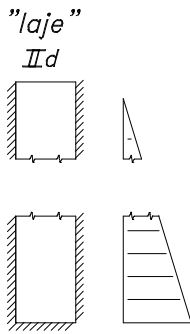

"laje"

IIC

Figura 3.40- Esquemas estáticos principais e complementares dos reservatórios elevados

e) Considerações sobre as torres e as fundações dos reservatórios elevados

Quando o aspecto do reservatório não tem muita importância no local especificado pelo projeto hidráulico para a construção do reservatório, a escolha de se executar a torre com fuste ou com pilares é feita por critérios que priorizam o menor custo. Assim, para reservatórios com cubas alongadas ou com várias cubas cúbicas superpostas, é indicado torres com fuste executados com formas deslizantes, trepantes ou com elementos pré-fabricados. Nos casos de fôrmas deslizantes, por razões construtivas, a espessura mínima das paredes é $20 \mathrm{~cm}$, podendo-se reduzí-la a $18 \mathrm{~cm}$, com consulta aos responsáveis pelo equipamento.

Já para os reservatórios cúbicos não muito altos, são indicadas as torres com pilares, sendo todo o reservatório executado no local pelo processo tradicional.

Quanto às fundações dos elevados, não é mais tolerável, como é para os reservatórios cúbicos térreos (3.2.2k), executar fundação direta em solos não indicados tecnicamente para tal fim. Quando o solo permitir essa fundação, é usual projetar para o caso de torres com pilares, sapatas rígidas isoladas em cada pilar, contraventa- 
das entre elas por vigas. No caso de torres com fuste, deve-se projetar radier.

Quando o solo não permitir fundação direta, deve-se projetar estacas cravadas sob os pilares ou, no caso de fustes, na projeção dos encontros das paredes. Se essas posições forem insuficientes para combater o vento, as estacas devem ser afastadas simetricamente em relação à projeção do centro do reservatório.

Como os reservatórios elevados paralelepipédicos são em geral pequenos $\left(\mathrm{V}_{\text {água }} \leq 50 \mathrm{~m}^{3}\right)$, quatro estacas são suficientes.

Eventualmente, para reservatórios maiores sobre fuste, pode-se projetar seis ou oito estacas, sendo no entanto, por problemas de estabilidade, necessário projetar elementos de transição (vigas ou blocos rígidos, ou também pórticos troncopiramidais) entre a base do fuste e as estacas.

Ainda, quando o solo for adequado para a execução de tubulões, é sempre mais econômico projetar esses reservatórios maiores sobre um bloco rígido apoiado em quatro tubulões.

\subsubsection{Reservatórios "cúbicos" $(a \approx b \approx c)$}

São reservatórios que apresentam as três dimensões da cuba $(a, b, h)$ com a mesma ordem de grandeza, ou seja, nenhuma delas é maior do que o dobro de qualquer uma das outras duas.

a) Ocorrência: residências (residências de alto padrão), escolas, indústrias, edifícios (inferior e superior) etc.

b) Grupos estruturais: Os elevados possuem sempre os três grupos estruturais. Os térreos possuem apenas os dois obrigatórios: cubas e fundações. Os tipos de reservatórios cúbicos mais comuns (Figura 3.41), são:

- térreos em fundação direta com ou sem parede divisória;

- apoiados sobre pilares com ou sem parede divisória;

- apoiados sobre fuste com ou sem parede divisória. 

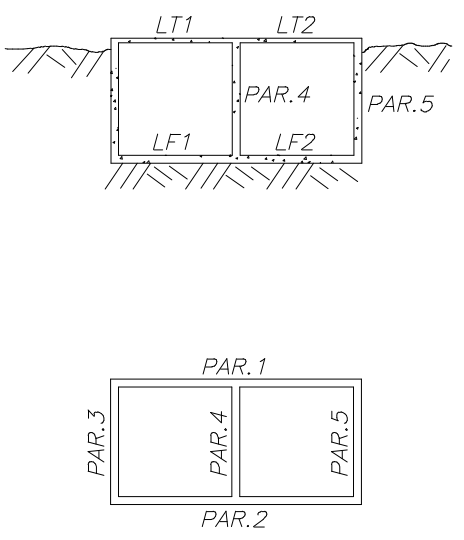

(a) Em subsolo de edifícios, indústrias, etc.
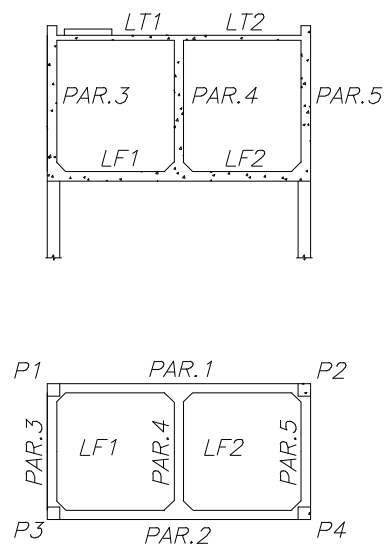

(b) No ático dos edifícios, escolas, etc.
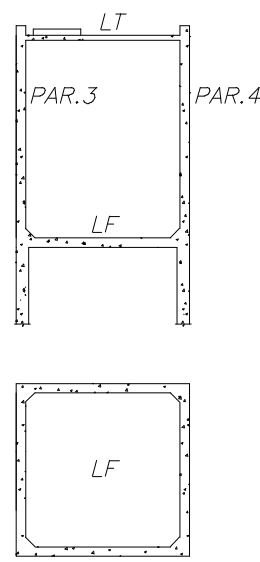

(c) Indústrias, escolas, etc.

Figura 3.41 - Tipos de reservatórios cúbicos usuais

\section{c) Trechos estruturais das cubas}

As cubas cúbicas não apresentam trechos estruturais distintos. São compostas de lajes e paredes que, em todos os tipos desses reservatórios, funcionam como placas trabalhando em duas direções, apenas com diferenças nos tipos de carregamentos que atuam em cada uma delas, uns triangulares ou trapezoidais, outros uniformemente distribuídos. Entretanto as paredes das cubas que se apoiam em pilares ou sobre estacas apresentam também o funcionamento de vigas paredes, quer com apoios diretos quer com apoios sobre outras paredes, ou seja, com apoios indiretos.

Assim, nas outras cubas este funcionamento não era significativo, aqui no caso das paredes que servem de apoios para outras paredes, o funcionamento como vigas-parede exigem armaduras mais significativas com detalhamento adequado nas regiões dos apoios e nas seções de maiores momentos.

d) Esquemas estáticos das lajes e paredes, no funcionamento como placas

A rigor, os esforços principais, das lajes e das paredes que formam as cubas desses reservatórios, podem ser obtidos através de programas específicos para microcomputadores, utilizando-se o processo dos elementos finitos.

Pode-se, também, mais simplificadamente, considerar as lajes e as paredes di- 
vididas em um grande número de barras ortogonais que forneçam os esforços por meio de programas específicos de pórticos tridimensionais.

Com qualquer um desses métodos de calculo dos esforços e seguindo as indicações dadas em 3.2.2 e 3.2.3, para os reservatórios cúbicos, obtém-se facilmente a envoltória dos momentos que atuam em suas cubas, de acordo com o tipo de reservatório que se queira calcular.

Entretanto, é oportuno dizer que na prática já consagrado há muito tempo, usase um processo simplificado, ainda muito utilizado pelos calculistas em face do cálculo ser manual, rápido e com bons resultados. Este processo consiste em:

$1^{\circ}$ ) Consideram-se as lajes e as paredes "funcionando" isoladamente, cada uma com as respectivas cargas e vinculações, sendo estas últimas definidas pela regra básica de que quando duas placas contíguas num apoio tendem a girar em torno deste, pelas suas cargas, no mesmo sentido, então esse apoio deve ser considerado como uma articulação. Se em sentidos opostos, então o apoio é um engaste para as placas.

$2^{\circ}$ ) Definem-se todos os carregamentos que possam contribuir com a envoltória dos momentos e calculam-se os esforços críticos.

$3^{\circ}$ ) Se os momentos de engastamento perfeito de duas placas num apoio comum, não forem muito diferentes, adota-se a média como valor final, para as duas placas. Em caso contrário, adota-se para esse momento comum, $80 \%$ do maior dos momentos.

$4^{\circ}$ ) No final do equilíbrio dos momentos de engastamento perfeito, não é usual recalcular os momentos positivos de cada placa. Entretanto, dependendo da forma dos reservatórios e das várias combinações possíveis entre as ações terra e água, pode-se ter, para algumas lajes do fundo, momentos finais positivos superiores aos correspondentes momentos positivos do engastamento perfeito.

Assim sendo, para preservar a estanqueidade, nesses casos de lajes do fundo deve-se recalcular os momentos positivos finais.

Para isto o autor propõe um processo simples com o uso de uma matriz denomi- 
nada por ele de "tensor dos momentos positivos" da laje do fundo, que, para um reservatório de base quadrada, consiste nos seguintes:

- Após se obter os momentos de engastamento das paredes engastadas na laje do fundo $\left(\bar{X}_{(\mathrm{P})}=0,91 \mathrm{tf} . \mathrm{m} / \mathrm{m}\right.$, por exemplo) e da laje do fundo engastada nas paredes $\left(\bar{X}=2,54\right.$ tf.m $/ \mathrm{m}$ e $\left.\overline{\mathrm{m}}_{\mathrm{a}}=\overline{\mathrm{m}}_{\mathrm{b}}=1,04\right)$, toma-se para o momento final de equilíbrio o menor entre $X=0,8 \bar{X}=2,03 \mathrm{tf} . \mathrm{m} / \mathrm{m}$ e $X=\frac{\bar{X}+\bar{X}_{(P)}}{2}=$ $=1,72 \underline{5}$ tf. $\mathrm{m} / \mathrm{m}$. No caso do exemplo, $X=1,72 \underline{5}$ tf. $\mathrm{m} / \mathrm{m}$.

- Considerando a laje do fundo simplesmente apoiada nos quatro lados, obtémse os momentos positivos máximos $\left(\mathrm{m}_{\mathrm{ao}}=\mathrm{m}_{\mathrm{bo}}=2,18 \mathrm{tf} . \mathrm{m} / \mathrm{m}\right)$.

- Obtém-se os momentos positivos máximos finais, resolvendo-se a equação matricial abaixo:

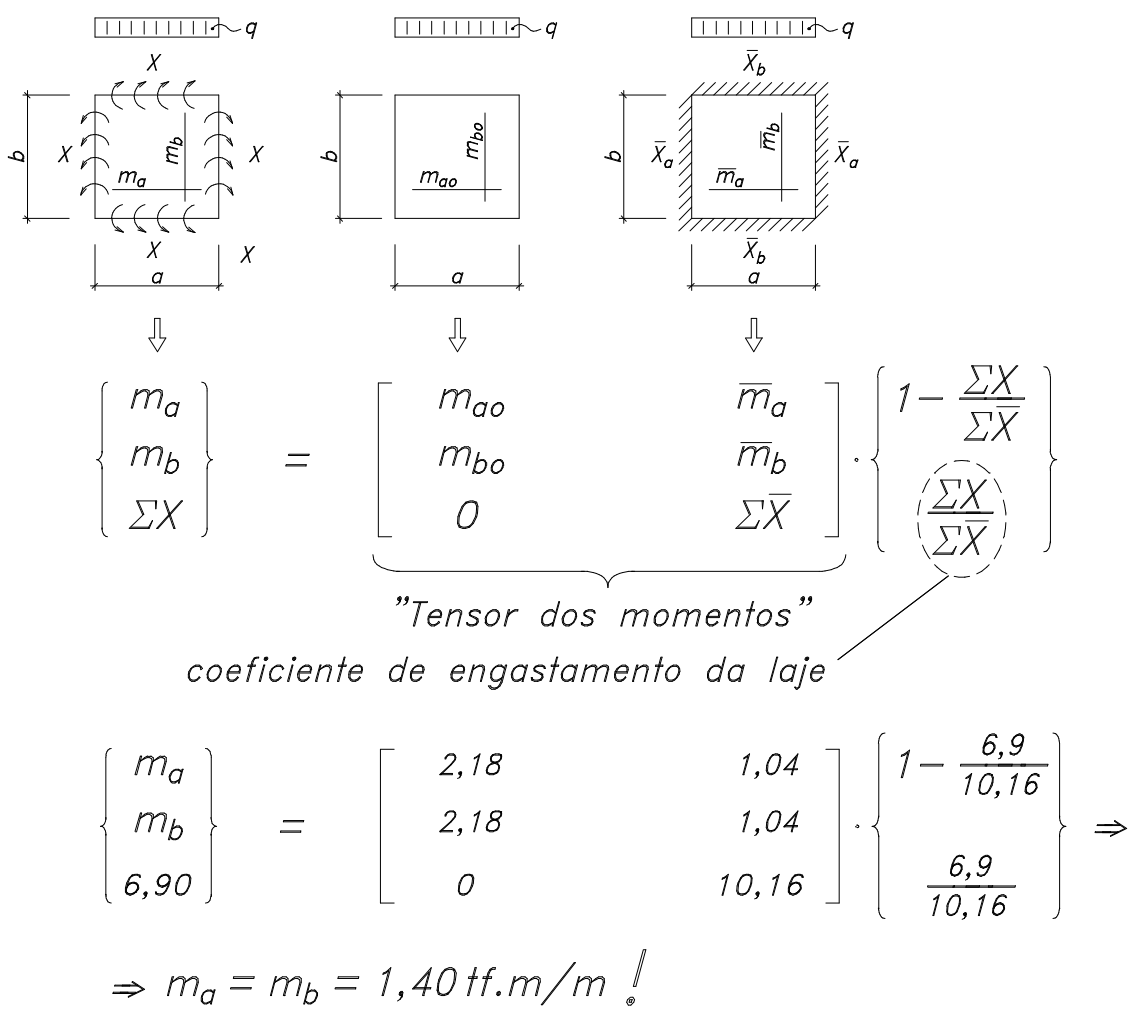

Nota: Os valores numéricos foram obtidos de um reservatório com $4,20 \times 4,20 \times 2,80$ entre eixos e com uma altura d'água de 2,30 m . 


\subsection{DIMENSIONAMENTO E DETALHAMENTO: 4a ETAPA}

3.4.1. Tabelas inéditas A1 a A4 para pré-dimensionamento de lajes e paredes

3.4.2. Fissuração, simplificação e tabela inédita A11 para prédimensionamento com fissuração embutida

3.4.3. Tabelas inéditas A5 a A10 para dimensionamento de seções retangulares com $k_{6}, \rho$ e $\beta_{x}$, e processo simplificado para dimensionamento à flexo-tração.

3.4.4. Tabelas inéditas A12 e A13 para a obtenção dos momentos e normais longitudinais de paredes de comprimento infinito, sob carregamentos hidrostáticos e uniformemente distribuidos.

3.4.5. Critérios para dimensionamento das paredes de cada tipo de reservatório

3.4.6. Detalhes das armações entre uniões de lajes e de lajes com paredes

3.4.7. Detalhes típicos dos principais elementos estruturais dos reservatórios 


\section{CAPÍTULO 4}

\section{CONSIDERAÇÕES FINAIS E CONCLUSÕES}

Como este trabalho tem por objetivo orientar estudantes e engenheiros calculistas sem muita experiência na execução de projetos estruturais de reservatórios paralelepipédicos, procurou-se nele apresentar os critérios mais lógicos e didáticos possíveis na busca da melhor solução, transmitindo, sempre que possível, alguns conhecimentos práticos adquiridos pelo autor.

De grande importância são os comentários feitos no item 2.3, em relação às informações complementares de áreas afins ao concreto armado, tais como de Arquitetura, Mecânica dos Solos e Materiais e Técnicas de Construção que, por serem conhecimentos de outros especialistas, apresentam uma dificuldade maior de assimilação pelos engenheiros de estruturas. Muito embora a maioria dessas informações não sejam fundamentais para a execução dos projetos estruturais, complementam a formação dos calculistas, aguçando-lhes o espírito crítico quanto à obra e aos dados recebidos e, conseqüentemente, levando-os a projetarem melhor as suas estruturas.

As classificações dos reservatórios levando em conta apenas os aspectos estruturais significativos, como por exemplo a que separa os reservatórios em função da forma das suas cubas em achatados, alongados e cúbicos, favorecem muito a análise estrutural dos mesmos. Com essa classificação espera-se substituir as antigas classi- 
ficações, como por exemplo a que classifica os reservatórios pela posição das suas armaduras principais, ou seja, "reservatórios armados horizontalmente, reservatórios armados verticalmente e reservatórios armados em duas direções". Por ela os reservatórios achatados e os reservatórios cúbicos fazem parte de um mesmo grupo, o que é uma péssima classificação uma vez que eles apresentam comportamentos estruturais completamente diferentes. Ainda, como um segundo exemplo de classificação estrutural inútil, pode-se citar a que separa os reservatórios em "enterrados, semi-enterrados e ao nível do solo".

No capítulo 3, as quatro etapas apresentadas acabam funcionando como um roteiro de projeto estrutural, uma vez que os reservatórios paralelepipédicos são sempre os mesmos, não apresentando novidades como nas estruturas dos edifícios, por exemplo. Assim, com todas as indicações dos carregamentos, dos esquemas estáti$\cos$, dos trechos estruturais a serem calculados e dos pontos críticos a serem dimensionados, acredita-se que o objetivo principal deste trabalho tenha sido cumprido, muito embora, por falta de tempo, o item 3.4 não tenha sido desenvolvido.

Complementando a dissertação, fornecem-se no anexo A fórmulas e tabelas inéditas para o cálculo dos momentos de engastamento perfeito de barras com inércia variável e carregamentos hidrostáticos e uniformemente distribuídos. Também são fornecidas tabelas inéditas para o cálculo dos momentos e normais longitudinais de paredes de inércia constante ${ }^{1}$ e comprimento infinito, também sob carregamentos hidrostáticos e uniformemente distribuidos. Ainda, nesse anexo, são fornecidas tabelas inéditas de $\mathrm{k}_{6}, \rho$ e $\beta_{\mathrm{x}}$ feitas pelo processo exato do Estado Limite Último, que considera o diagrama parábola-retângulo em lugar do diagrama retangular das tensões de compressão no concreto. Por estabelecer uma relação direta entre o coeficiente $\mathrm{k}_{6}$ e a taxa de armadura $\rho=\frac{\mathrm{A}_{\mathrm{s}}}{\mathrm{b} . \mathrm{d}}$, eliminando o coeficiente $\mathrm{k}_{3}$, é muito mais prática para o cálculo manual das armaduras. Uma outra vantagem desta nova tabela é que ao usar a taxa de armadura $\rho$ em lugar do coeficiente $k_{3}$, que não tem nenhum significado físico, tem-se uma melhor referência nos dimensionamentos.

${ }^{1}$ Em face da falta de tempo para a conclusão desta dissertação, deixamos de fornecer os resultados das paredes infinitas com inércia variável. 
No anexo B, são apresentadas as fórmulas e as tabelas corretas para serem usadas nos escritórios de projetos no cálculo dos comprimentos das armaduras dobradas, de barras e de estribos. Acredita-se que as tabelas, para o cálculo desses comprimentos, utilizadas pela maioria dos projetistas, bem como as fornecidas em todas as publicações nacionais, além de incompletas e inadequadas, apresentam erros que induzem a comprimentos maiores. Estes erros geram pontas retas excessivas nos ganchos dos estribos, os quais são muitas vezes corrigidos pelos armadores para não dificultar a montagem das armaduras. Podem gerar também reduções dos cobrimentos nominais das armaduras, de conseqüências já mais sérias tendo em vista o comprometimento da durabilidade da obra.

Por fim, ainda nesse anexo B, analisa-se como se faz o dobramento das armaduras na obra, fornecendo tabelas para serem usadas pelos armadores e pelos engenheiros construtores. Nelas são indicadas também as sequiências de dobramentos de uma armadura, bem como são fornecidas as fórmulas para o cálculo dos respectivos gabaritos. 


\section{ANEXOA}

Neste anexo apresentam-se fórmulas, tabelas e gráficos inéditos que fornecem os momentos máximos positivos e negativos correspondentes aos engastamentos perfeitos das lajes e paredes, ainda inexistentes na bibliografia disponível para a engenharia estrutural. Também são fornecidas tabelas inéditas de $\mathrm{k}_{6}, \rho$ e $\beta_{\mathrm{x}}$ muito mais práticas do que as tradicionais tabelas de $\mathrm{k}_{6}, \mathrm{k}_{3}$ e $\beta_{\mathrm{x}}$.

\section{A.1. BARRAS HIPERESTÁTICAS CALCULADAS NUMA SÓ DIREÇÃO}

\section{A.1.1. Barras engastadas e apoiadas, com inércia e carregamento linearmente variável ao longo do vão}

Aplicando a definição de momento de engastamento de barras da Estática das Estruturas, em que $M=\frac{\mathfrak{A}}{\mathcal{G}^{\prime}}$, onde $\mathcal{A}$ é a reação fictícia e $\mathcal{G}^{\prime}$ o fator de forma, ambos relativos à base, em 1972 o autor obteve, para o momento de engastamento na base, a expressão:

$$
\mathrm{M}=\frac{\mathrm{q} \ell^{2}}{\mathrm{k}} \mathrm{com} \mathrm{k}=\frac{6\left(\mathrm{~m}^{2}-2 \mathrm{~m}+1\right) \ln (\mathrm{m})-9 \mathrm{~m}^{2}+30 \mathrm{~m}-36-\frac{3}{\mathrm{~m}^{2}}+\frac{18}{\mathrm{~m}}}{\left(\mathrm{~m}^{2}-2 \mathrm{~m}-5\right) \ln (\mathrm{m})-2 \mathrm{~m}^{2}+9 \mathrm{~m}-\frac{1}{\mathrm{~m}}-6}
$$

com $m=\frac{h_{0}}{h}$. Assim, tabelando k em função de m obtém-se as fór-

mulas cômodas para operar.

\begin{tabular}{c|c|c|c|c|c|c|c|}
$\mathrm{m}=\frac{\mathrm{h}_{\mathrm{O}}}{\mathrm{h}}$ & 1,0 & 1,33 & 2,0 & 2,2 & 2,27 & 2,25 & 2,5 \\
\hline $\mathrm{k}$ & 15,0 & 13,1 & 11,9 & 11,6 & 11,5 & 11,55 & 11,22
\end{tabular}

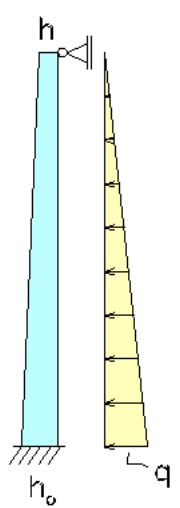


A.1.2. Momentos máximos devidos aos engastamentos nos apoios de uma barra com vão $\ell$ e mísula $\ell_{0}$, submetido a carregamentos linearmente variáveis e uniformemente distribuídos

TABELA A.1 - Momentos máximos: $\mathrm{M}=\frac{\mathrm{k}}{10^{4}} \mathrm{q} \ell^{2}$

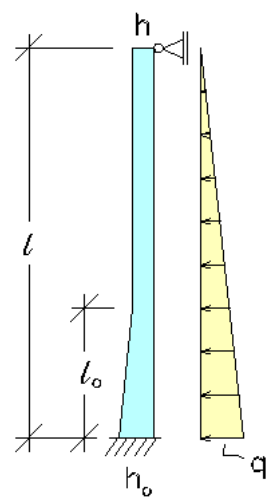

\begin{tabular}{|c|c|c|c|c|c|c|c|c|c|c|}
\hline & \multicolumn{5}{|c|}{$k$ para $M^{-}$no engaste } & \multicolumn{5}{|c|}{$\mathrm{k}$ para $\mathrm{M}^{+} \max$. no vão } \\
\hline \multirow[t]{2}{*}{$\mathbf{h} / \mathbf{h}_{\circ}$} & \multicolumn{5}{|c|}{$\ell_{0} / \ell$} & \multicolumn{5}{|c|}{$\ell_{0} / \ell$} \\
\hline & $\mathbf{0 , 1 5}$ & 0,20 & 0,25 & 0,30 & 1,00 & 0,15 & 0,20 & 0,25 & 0,30 & 1,00 \\
\hline 0,30 & 887 & 946 & 1001 & 1049 & 954 & 205 & 181 & 162 & 145 & 178 \\
\hline 0,35 & 872 & 927 & 976 & 1019 & 919 & 211 & 189 & 170 & 155 & 192 \\
\hline 0,40 & 857 & 907 & 951 & 989 & 888 & 217 & 197 & 180 & 166 & 205 \\
\hline 0,45 & 842 & 887 & 926 & 958 & 861 & 223 & 205 & 190 & 177 & 216 \\
\hline $\mathbf{0 , 5 0}$ & 826 & 866 & 900 & 928 & 836 & 230 & 214 & 200 & 189 & 226 \\
\hline 0,55 & 810 & 845 & 874 & 897 & 812 & 236 & 222 & 210 & 201 & 235 \\
\hline 0,60 & 793 & 824 & 849 & 868 & 791 & 243 & 230 & 221 & 213 & 244 \\
\hline 0,65 & 777 & 803 & 823 & 839 & 772 & 249 & 239 & 231 & 224 & 251 \\
\hline $\mathbf{0 , 7 0}$ & 761 & 782 & 799 & 811 & 753 & 256 & 246 & 240 & 236 & 259 \\
\hline 0,75 & 744 & 762 & 775 & 784 & 736 & 263 & 255 & 250 & 246 & 267 \\
\hline 0,80 & 728 & 741 & 751 & 758 & 720 & 271 & 265 & 260 & 257 & 274 \\
\hline 0,85 & 712 & 721 & 728 & 733 & 705 & 278 & 273 & 270 & 268 & 281 \\
\hline 0,90 & 696 & 702 & 706 & 709 & 691 & 285 & 282 & 280 & 279 & 287 \\
\hline 0,95 & 680 & 683 & 685 & 686 & 677 & 292 & 291 & 290 & 289 & 293 \\
\hline 1,00 & 665 & 665 & 665 & 665 & 665 & 299 & 299 & 299 & 299 & 299 \\
\hline
\end{tabular}

NOTAS:

1ㅇ) O coeficiente $\mathrm{k}$ é adimensional;

20) As relações $\mathrm{h} / \mathrm{h}_{0}$ entre as espessuras das barras, consideradas nessa tabela, foram escolhidas tendo em vista os valores usados nos projetos de lajes e paredes de reservatórios paralelepipédicos;

30) Os valores de $\mathrm{k}$ foram obtidos com a TEORIA DAS CASCAS do SAP90, MODELADAS com elementos à FLEXÃO e FUNCIONAMENTO DE MEMBRANA;

4으 Coeficiente de Poisson $v=0,2$. 
TABELA A.2 - Momentos máximos: $\mathrm{M}=\frac{\mathrm{k}}{10^{4}} \mathrm{q} \ell^{2}$

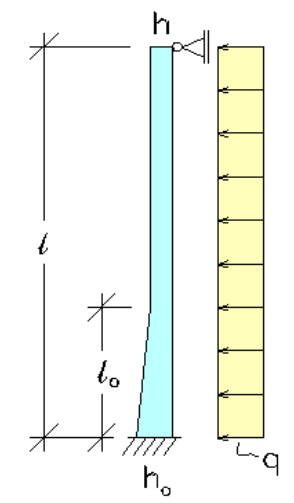

\begin{tabular}{|c|c|c|c|c|c|c|c|c|c|c|}
\hline & \multicolumn{5}{|c|}{$k$ para $\mathrm{M}^{-}$no engaste } & \multicolumn{5}{|c|}{$k$ para $M^{+} \max$ no vão } \\
\hline \multirow[t]{2}{*}{$\mathbf{h} / \mathbf{h}_{\circ}$} & \multicolumn{5}{|c|}{$\ell_{0} / \ell$} & \multicolumn{5}{|c|}{$\ell_{0} / \ell$} \\
\hline & 0,15 & 0,20 & 0,25 & 0,30 & 1,00 & 0,15 & $\mathbf{0 , 2 0}$ & 0,25 & 0,30 & 1,00 \\
\hline 0,30 & 1693 & 1825 & 1952 & 2072 & 1963 & 545 & 502 & 464 & 428 & 461 \\
\hline $\mathbf{0 , 3 5}$ & 1663 & 1784 & 1899 & 2005 & 1870 & 556 & 515 & 480 & 448 & 489 \\
\hline 0,40 & 1632 & 1742 & 1845 & 1938 & 1788 & 566 & 528 & 497 & 469 & 514 \\
\hline 0,45 & 1600 & 1700 & 1790 & 1870 & 1717 & 577 & 543 & 513 & 489 & 537 \\
\hline 0,50 & 1568 & 1656 & 1735 & 1803 & 1653 & 589 & 558 & 530 & 509 & 559 \\
\hline 0,55 & 1536 & 1613 & 1681 & 1738 & 1595 & 600 & 573 & 549 & 529 & 579 \\
\hline 0,60 & 1503 & 1570 & 1627 & 1674 & 1543 & 611 & 588 & 568 & 552 & 597 \\
\hline 0,65 & 1470 & 1527 & 1574 & 1612 & 1496 & 623 & 603 & 587 & 573 & 614 \\
\hline 0,70 & 1438 & 1484 & 1523 & 1553 & 1452 & 634 & 618 & 605 & 594 & 629 \\
\hline 0,75 & 1405 & 1442 & 1473 & 1496 & 1411 & 646 & 633 & 622 & 614 & 643 \\
\hline 0,80 & 1373 & 1401 & 1424 & 1441 & 1374 & 657 & 647 & 639 & 633 & 657 \\
\hline 0,85 & 1340 & 1361 & 1377 & 1389 & 1339 & 668 & 661 & 656 & 651 & 669 \\
\hline 0,90 & 1309 & 1322 & 1332 & 1339 & 1306 & 679 & 675 & 671 & 669 & 680 \\
\hline 0,95 & 1278 & 1284 & 1289 & 1292 & 1276 & 690 & 688 & 687 & 685 & 691 \\
\hline 1,00 & 1247 & 1247 & 1247 & 1247 & 1247 & 701 & 701 & 701 & 701 & 701 \\
\hline
\end{tabular}

\section{NOTAS:}

1ㅇ) O coeficiente $\mathrm{k}$ é adimensional;

20) As relações $\mathrm{h} / \mathrm{h}_{0}$ entre as espessuras das barras, consideradas nessa tabela, foram escolhidas tendo em vista os valores usados nos projetos de lajes e paredes de reservatórios paralelepipédicos;

30) Os valores de $\mathrm{k}$ foram obtidos com a TEORIA DAS CASCAS do SAP90, MODELADAS com elementos à FLEXÃO e FUNCIONAMENTO DE MEMBRANA;

4으) Coeficiente de Poisson $v=0,2$. 
TABELA A.3 - Momentos máximos: $M=\frac{\mathrm{k}}{10^{4}} \mathrm{q} \ell^{2}$

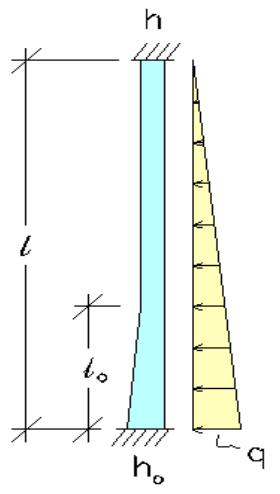

\begin{tabular}{|c|c|c|c|c|c|c|c|c|c|c|}
\hline & \multicolumn{5}{|c|}{$\mathrm{k}$ para $\mathrm{M}^{-}$no engaste inferior } & \multicolumn{5}{|c|}{$k$ para $M^{-}$no engaste superior } \\
\hline \multirow[t]{2}{*}{$\mathbf{h} / \mathbf{h}_{\circ}$} & \multicolumn{5}{|c|}{$\ell_{0} / \ell$} & \multicolumn{5}{|c|}{$\ell_{0} / \ell$} \\
\hline & 0,15 & 0,20 & 0,25 & 0,30 & $\mathbf{1 , 0 0}$ & $\mathbf{0 , 1 5}$ & 0,20 & 0,25 & 0,30 & $\mathbf{1 , 0 0}$ \\
\hline $\mathbf{0 , 3 0}$ & 723 & 785 & 840 & 888 & 808 & 231 & 207 & 187 & 170 & 121 \\
\hline 0,35 & 707 & 763 & 812 & 853 & 769 & 238 & 216 & 198 & 184 & 139 \\
\hline 0,40 & 691 & 741 & 783 & 818 & 735 & 245 & 226 & 210 & 197 & 157 \\
\hline 0,45 & 674 & 718 & 755 & 783 & 704 & 253 & 235 & 221 & 211 & 174 \\
\hline 0,50 & 657 & 696 & 727 & 750 & 676 & 260 & 245 & 233 & 224 & 191 \\
\hline 0,55 & 640 & 673 & 699 & 718 & 652 & 268 & 254 & 245 & 237 & 207 \\
\hline 0,60 & 624 & 652 & 673 & 688 & 629 & 275 & 264 & 256 & 250 & 223 \\
\hline 0,65 & 607 & 630 & 647 & 659 & 608 & 283 & 274 & 267 & 262 & 238 \\
\hline $\mathbf{0 , 7 0}$ & 590 & 609 & 623 & 631 & 589 & 291 & 283 & 277 & 274 & 253 \\
\hline 0,75 & 574 & 589 & 599 & 605 & 571 & 298 & 292 & 288 & 285 & 267 \\
\hline $\mathbf{0 , 8 0}$ & 558 & 569 & 577 & 581 & 554 & 305 & 301 & 298 & 296 & 281 \\
\hline 0,85 & 542 & 550 & 555 & 558 & 539 & 313 & 309 & 307 & 306 & 295 \\
\hline 0,90 & 527 & 532 & 535 & 537 & 524 & 320 & 318 & 316 & 316 & 308 \\
\hline 0,95 & 512 & 515 & 516 & 517 & 511 & 327 & 326 & 325 & 325 & 321 \\
\hline 1,00 & 498 & 498 & 498 & 498 & 498 & 333 & 333 & 333 & 333 & 333 \\
\hline
\end{tabular}

\begin{tabular}{|c|c|c|c|c|c|}
\hline & \multicolumn{5}{|c|}{$k$ para $M^{+}$max. no vão } \\
\hline \multirow[t]{2}{*}{$\mathbf{h} / \mathbf{h}_{\circ}$} & \multicolumn{5}{|c|}{$\ell_{0} / \ell$} \\
\hline & 0,15 & 0,20 & 0,25 & 0,30 & 1,00 \\
\hline 0,30 & 148 & 131 & 118 & 105 & 168 \\
\hline 0,35 & 152 & 136 & 124 & 113 & 176 \\
\hline 0,40 & 157 & 142 & 130 & 122 & 181 \\
\hline 0,45 & 162 & 148 & 137 & 130 & 186 \\
\hline 0,50 & 166 & 155 & 145 & 138 & 191 \\
\hline 0,55 & 171 & 161 & 153 & 147 & 196 \\
\hline 0,60 & 175 & 167 & 161 & 156 & 199 \\
\hline 0,65 & 180 & 173 & 168 & 165 & 202 \\
\hline 0,70 & 185 & 179 & 175 & 172 & 204 \\
\hline 0,75 & 190 & 185 & 182 & 180 & 206 \\
\hline 0,80 & 195 & 191 & 188 & 187 & 208 \\
\hline 0,85 & 200 & 198 & 196 & 195 & 210 \\
\hline 0,90 & 206 & 204 & 203 & 202 & 212 \\
\hline 0,95 & 211 & 210 & 209 & 209 & 214 \\
\hline 1,00 & 216 & 216 & 216 & 216 & 216 \\
\hline
\end{tabular}

NOTAS:

1ㅇ) O coeficiente $\mathrm{k}$ é adimensional;

2ㅇ) As relações $h / h$ 。 entre as espessuras das barras, consideradas nessa tabela, foram escolhidas tendo em vista os valores usados nos projetos de lajes e paredes de reservatórios paralelepipédi$\cos$;

3ㅇ) Os valores de $\mathrm{k}$ foram obtidos com a TEORIA DAS CASCAS do SAP90, MODELADAS com elementos à FLEXÃO e FUNCIONAMENTO DE MEMBRANA;

4을 Coeficiente de Poisson $v=0,2$. 
TABELA A.4 - Momentos máximos: $\mathrm{M}=\frac{\mathrm{k}}{10^{4}} \mathrm{q} \ell^{2}$

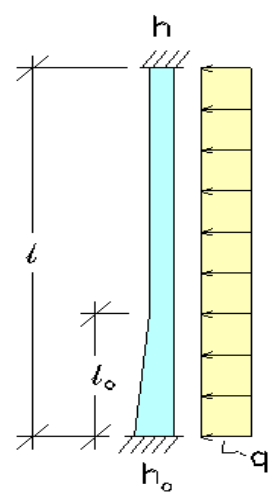

\begin{tabular}{|c|c|c|c|c|c|c|c|c|c|c|}
\hline & \multicolumn{5}{|c|}{$\mathrm{k}$ para $\mathrm{M}^{-}$no engaste inferior } & \multicolumn{5}{|c|}{$\mathrm{k}$ para $\mathrm{M}^{-}$no engaste superior } \\
\hline \multirow[t]{2}{*}{$\mathbf{h} / \mathbf{h}_{\circ}$} & \multicolumn{5}{|c|}{$\ell_{0} / \ell$} & \multicolumn{5}{|c|}{$\ell_{0} / \ell$} \\
\hline & 0,15 & $\mathbf{0 , 2 0}$ & 0,25 & 0,30 & 1,00 & 0,15 & 0,20 & 0,25 & 0,30 & 1,00 \\
\hline 0,30 & 1234 & 1355 & 1471 & 1578 & 1524 & 649 & 602 & 559 & 523 & 364 \\
\hline 0,35 & 1205 & 1314 & 1416 & 1507 & 1428 & 662 & 619 & 581 & 550 & 409 \\
\hline 0,40 & 1175 & 1272 & 1361 & 1438 & 1346 & 675 & 636 & 603 & 576 & 451 \\
\hline 0,45 & 1145 & 1231 & 1307 & 1371 & 1274 & 688 & 654 & 626 & 603 & 491 \\
\hline 0,50 & 1114 & 1189 & 1254 & 1306 & 1211 & 702 & 672 & 648 & 629 & 529 \\
\hline 0,55 & 1084 & 1148 & 1202 & 1244 & 1155 & 716 & 690 & 669 & 654 & 566 \\
\hline 0,60 & 1054 & 1108 & 1152 & 1186 & 1105 & 729 & 707 & 690 & 678 & 600 \\
\hline 0,65 & 1024 & 1069 & 1105 & 1131 & 1060 & 743 & 724 & 710 & 701 & 633 \\
\hline 0,70 & 994 & 1031 & 1059 & 1079 & 1019 & 756 & 741 & 730 & 723 & 665 \\
\hline 0,75 & 966 & 994 & 1016 & 1030 & 981 & 769 & 757 & 749 & 743 & 695 \\
\hline $\mathbf{0 , 8 0}$ & 937 & 959 & 975 & 985 & 946 & 782 & 773 & 767 & 763 & 725 \\
\hline 0,85 & 910 & 925 & 936 & 942 & 914 & 795 & 789 & 784 & 781 & 753 \\
\hline 0,90 & 883 & 892 & 899 & 903 & 885 & 807 & 803 & 801 & 799 & 780 \\
\hline 0,95 & 857 & 861 & 864 & 866 & 857 & 819 & 818 & 816 & 816 & 806 \\
\hline 1,00 & 831 & 831 & 831 & 831 & 831 & 831 & 831 & 831 & 831 & 831 \\
\hline
\end{tabular}

\begin{tabular}{|l|lll|l|l|}
\hline & \multicolumn{5}{|c|}{ k para $\mathbf{M}^{+}$max. no vão } \\
\hline $\mathbf{h} / \mathbf{h}$ & \multicolumn{5}{|c|}{$\ell_{0} / \ell$} \\
\hline & $\mathbf{0 , 1 5}$ & $\mathbf{0 , 2 0}$ & 0,25 & 0,30 & $\mathbf{1 , 0 0}$ \\
\hline $\mathbf{0 , 3 0}$ & 325 & 297 & 276 & 255 & 372 \\
\hline $\mathbf{0 , 3 5}$ & 331 & 306 & 285 & 267 & 384 \\
\hline $\mathbf{0 , 4 0}$ & 337 & 315 & 294 & 279 & 391 \\
\hline $\mathbf{0 , 4 5}$ & 344 & 324 & 305 & 290 & 396 \\
\hline $\mathbf{0 , 5 0}$ & 350 & 333 & 317 & 304 & 401 \\
\hline $\mathbf{0 , 5 5}$ & 356 & 341 & 329 & 318 & 406 \\
\hline $\mathbf{0 , 6 0}$ & 362 & 350 & 339 & 331 & 410 \\
\hline $\mathbf{0 , 6 5}$ & 368 & 358 & 350 & 343 & 412 \\
\hline $\mathbf{0 , 7 0}$ & 375 & 366 & 359 & 355 & 413 \\
$\mathbf{0 , 7 5}$ & 383 & 374 & 368 & 365 & 414 \\
\hline $\mathbf{0 , 8 0}$ & 390 & 384 & 379 & 376 & 415 \\
\hline $\mathbf{0 , 8 5}$ & 398 & 393 & 390 & 388 & 417 \\
\hline $\mathbf{0 , 9 0}$ & 405 & 402 & 400 & 399 & 418 \\
\hline $\mathbf{0 , 9 5}$ & 412 & 411 & 410 & 409 & 419 \\
\hline $\mathbf{1 , 0 0}$ & 419 & 419 & 419 & 419 & 419 \\
\hline & & & & & \\
\hline
\end{tabular}

NOTAS:

1ㅇ) O coeficiente $\mathrm{k}$ é adimensional;

2o) As relações $h / h$ 。 entre as espessuras das barras, consideradas nessa tabela, foram escolhidas tendo em vista os valores usados nos projetos de lajes e paredes de reservatórios paralelepipédi$\cos$;

3ㅇ) Os valores de $\mathrm{k}$ foram obtidos com a TEORIA DAS CASCAS do SAP90, MODELADAS com elementos à FLEXÃO e FUNCIONAMENTO DE MEMBRANA;

4으) Coeficiente de Poisson $v=0,2$. 

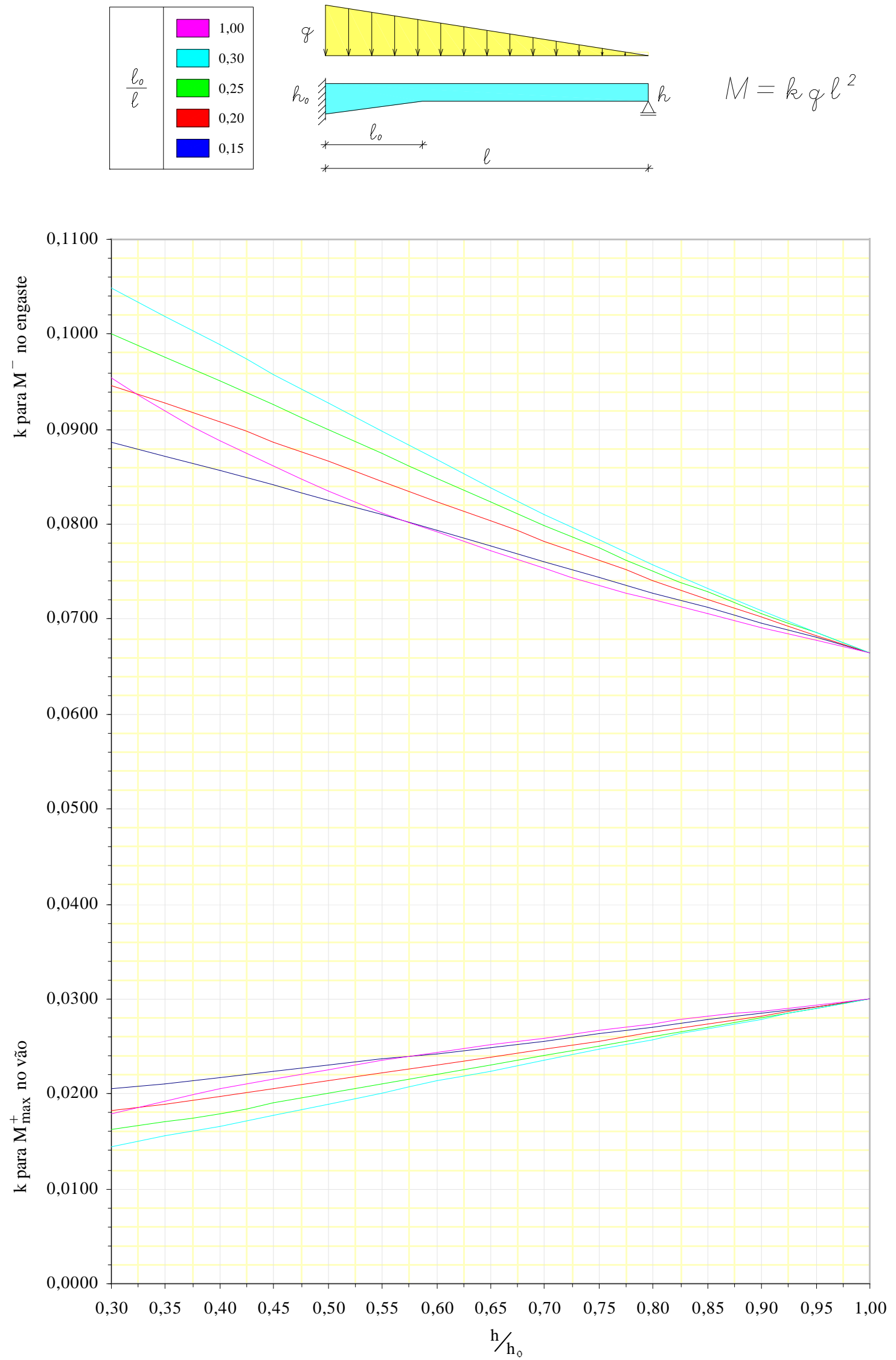

Figura A.1 - Variação dos coeficientes $\mathbf{k}$ dos momentos, em função das relações $h / h_{0}$ e $\ell_{0} / \ell$. 

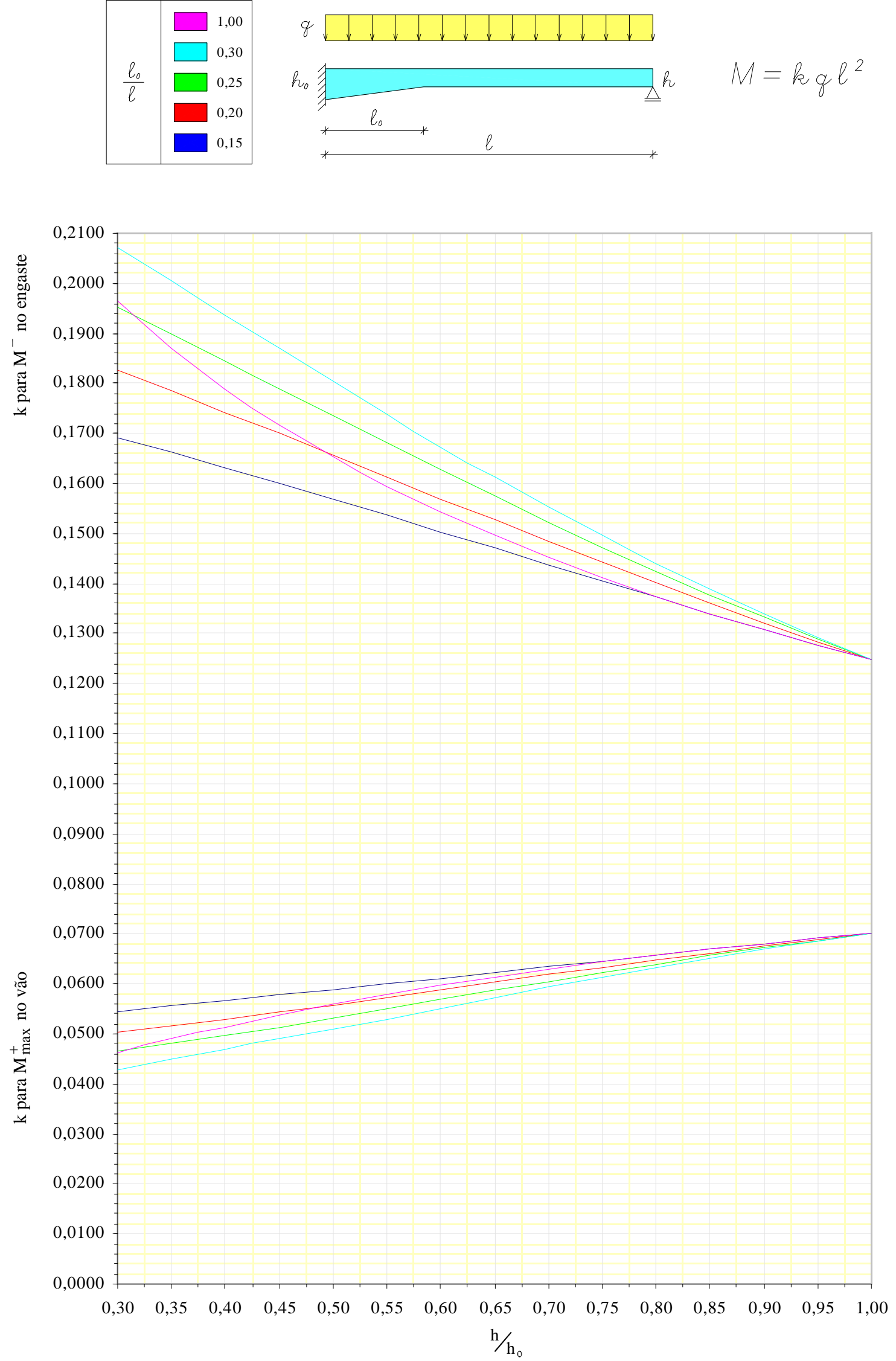

Figura A.2 - Variação dos coeficientes $\mathbf{k}$ dos momentos, em função das relações $h / h_{0}$ e $\ell_{0} / \ell$. 

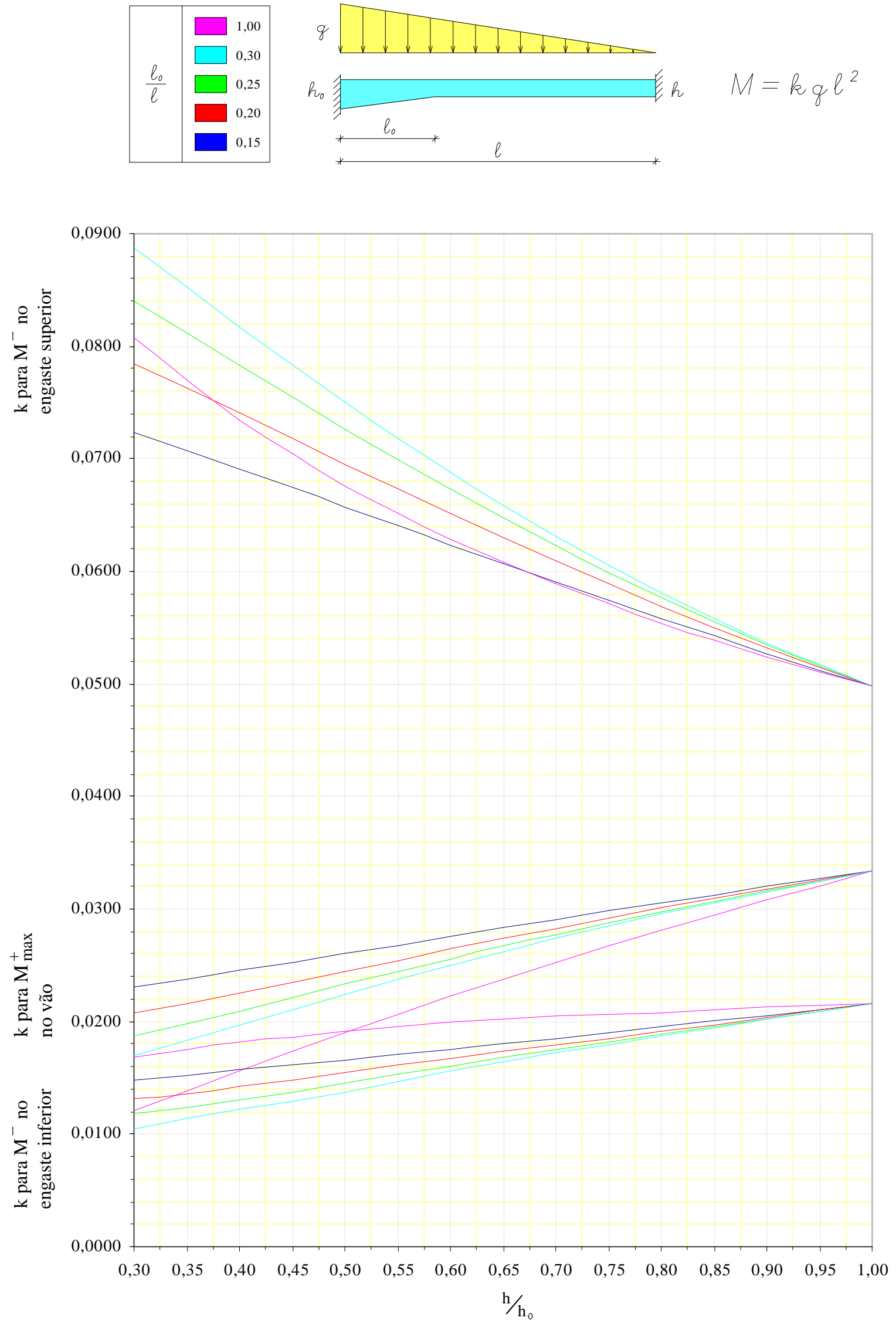

Figura A.3 - Variação dos coeficientes $\mathbf{k}$ dos momentos, em função das relações $h / h_{0}$ e $\ell_{0} / \ell$. 

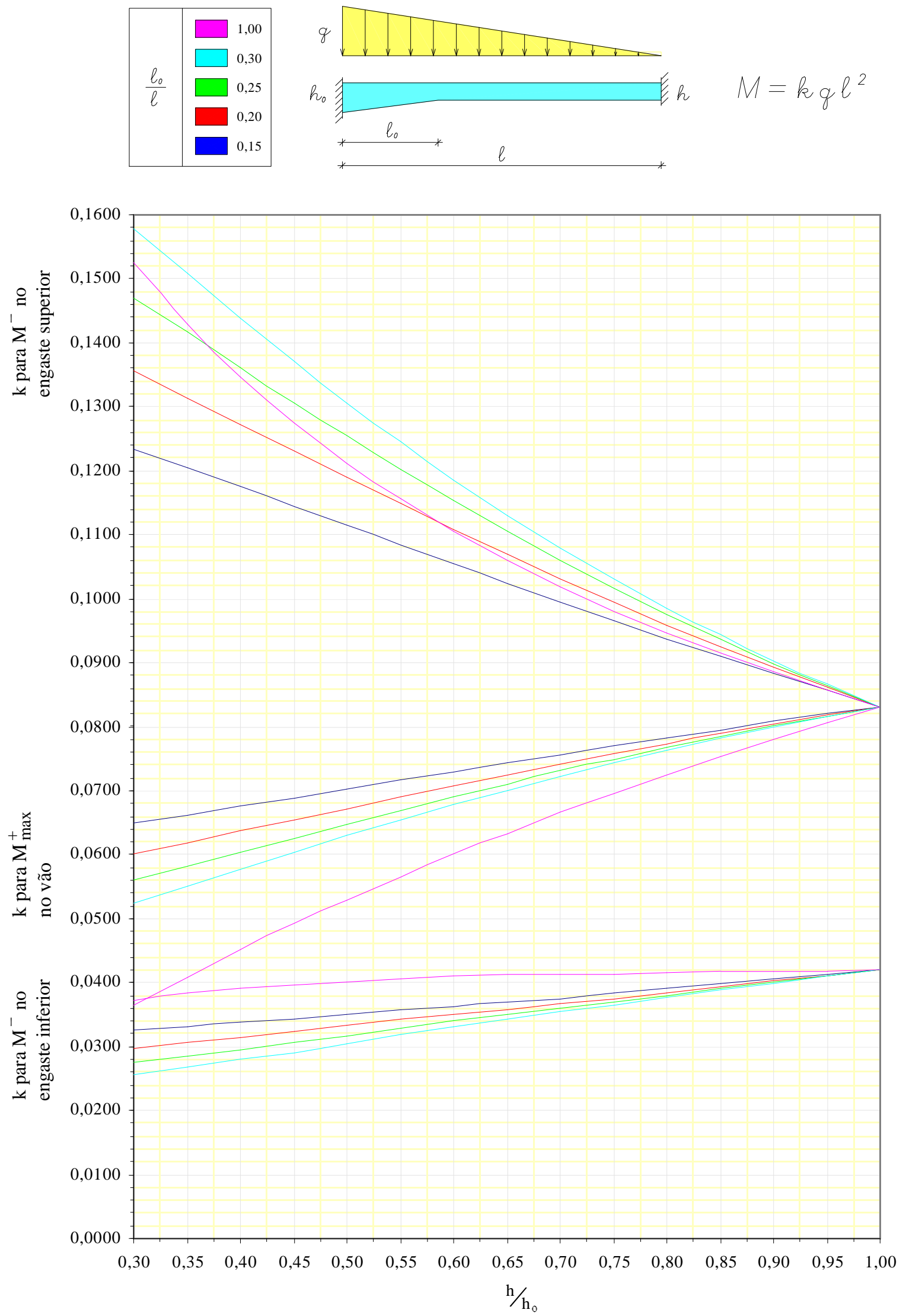

Figura A.4 - Variação dos coeficientes $\mathbf{k}$ dos momentos, em função das relações $h / h_{0}$ e $\ell_{0} / \ell$. 


\section{A.2. DIMENSIONAMENTO DE SEÇÕES RETANGULA- RES À FLEXÃO SIMPLES}

Tabela A5 - Para dimensionamento no Estado Limite Último de seções retangulares à flexão simples com diagrama parábola-retângulo e coeficientes $\gamma_{\mathbf{f}}=\gamma_{\mathbf{c}}=\mathbf{1 , 4}$ e $\gamma_{\mathbf{s}}=\mathbf{1 , 1 5}$.

C 15

\begin{tabular}{|c|c|c|c|}
\hline \multirow{2}{*}{$\begin{array}{c}\mathrm{k}_{6}=\frac{\mathrm{bd}^{2}}{\mathrm{M}} \\
(\mathrm{tf} ; \mathrm{cm})\end{array}$} & \multicolumn{2}{|c|}{$\rho(\%)=\frac{100 \cdot A_{s}}{b \cdot d}$} & \multirow[t]{2}{*}{$\beta_{x}=\frac{x}{d}$} \\
\hline & CA-50A & CA-60B & \\
\hline 253,0 & 0,133 & 0,111 & 0,120 \\
\hline 248,1 & 0,136 & 0,113 & 0,122 \\
\hline 243,3 & 0,138 & 0,115 & 0,123 \\
\hline 238,6 & 0,141 & 0,118 & 0,124 \\
\hline 233,9 & 0,144 & 0,120 & 0,126 \\
\hline 229,4 & 0,147 & 0,123 & 0,127 \\
\hline 224,9 & 0,150 & 0,125 & 0,129 \\
\hline 220,6 & 0,153 & 0,128 & 0,130 \\
\hline 216,3 & 0,156 & 0,130 & 0,132 \\
\hline 212,1 & 0,160 & 0,133 & 0,133 \\
\hline 208,0 & 0,163 & 0,136 & 0,135 \\
\hline 204,0 & 0,166 & 0,138 & 0,136 \\
\hline 200,0 & 0,169 & 0,141 & 0,138 \\
\hline 196,2 & 0,173 & 0,144 & 0,140 \\
\hline 192,4 & 0,176 & 0,147 & 0,141 \\
\hline 188,7 & 0,180 & 0,150 & 0,143 \\
\hline 185,0 & 0,184 & 0,153 & 0,145 \\
\hline 181,5 & 0,187 & 0,156 & 0,146 \\
\hline 178,0 & 0,191 & 0,159 & 0,148 \\
\hline 174,6 & 0,195 & 0,163 & 0,150 \\
\hline 171,2 & 0,199 & 0,166 & 0,152 \\
\hline 167,9 & 0,203 & 0,169 & 0,153 \\
\hline 164,7 & 0,207 & 0,173 & 0,155 \\
\hline 161,6 & 0,212 & 0,176 & 0,157 \\
\hline 158,5 & 0,216 & 0,180 & 0,159 \\
\hline 155,4 & 0,220 & 0,184 & 0,161 \\
\hline 152,5 & 0,225 & 0,187 & 0,163 \\
\hline 149,6 & 0,229 & 0,191 & 0,165 \\
\hline 146,7 & 0,234 & 0,195 & 0,167 \\
\hline 144,0 & 0,239 & 0,199 & 0,169 \\
\hline 141,2 & 0,244 & 0,203 & 0,172 \\
\hline 138,5 & 0,249 & 0,207 & 0,174 \\
\hline 135,9 & 0,254 & 0,212 & 0,176 \\
\hline 133,4 & 0,259 & 0,216 & 0,178 \\
\hline 130,9 & 0,264 & 0,220 & 0,181 \\
\hline 128,4 & 0,270 & 0,225 & 0,183 \\
\hline 126,0 & 0,275 & 0,229 & 0,186 \\
\hline 123,6 & 0,281 & 0,234 & 0,188 \\
\hline 121,3 & 0,287 & 0,239 & 0,191 \\
\hline 119,0 & 0,292 & 0,244 & 0,193 \\
\hline 116,8 & 0,298 & 0,249 & 0,196 \\
\hline 114,7 & 0,304 & 0,254 & 0,199 \\
\hline 112,5 & 0,311 & 0,259 & 0,202 \\
\hline 110,4 & 0,317 & 0,264 & 0,204 \\
\hline 108,4 & 0,323 & 0,270 & 0,207 \\
\hline 106,4 & 0,330 & 0,275 & 0,210 \\
\hline 104,4 & 0,337 & 0,281 & 0,213 \\
\hline 102,5 & 0,344 & 0,286 & 0,216 \\
\hline 100,6 & 0,351 & 0,292 & 0,219 \\
\hline 98,8 & 0,358 & 0,298 & 0,223 \\
\hline 97,0 & 0,365 & 0,304 & 0,226 \\
\hline 95,2 & 0,373 & 0,311 & 0,229 \\
\hline
\end{tabular}

C 15

\begin{tabular}{|c|c|c|c|}
\hline \multirow{2}{*}{$\begin{array}{c}\mathrm{k}_{6}=\frac{\mathrm{bd}^{2}}{\mathrm{M}} \\
(\mathrm{tf} ; \mathrm{cm})\end{array}$} & \multicolumn{2}{|c|}{$\rho(\%)=\frac{100 \cdot A_{s}}{b \cdot d}$} & \multirow[t]{2}{*}{$\beta_{x}=\frac{x}{d}$} \\
\hline & CA-50A & CA-60B & \\
\hline 93,5 & 0,380 & 0,317 & 0,233 \\
\hline 91,8 & 0,388 & 0,323 & 0,236 \\
\hline 90,2 & 0,396 & 0,330 & 0,240 \\
\hline 88,5 & 0,404 & 0,337 & 0,243 \\
\hline 86,9 & 0,412 & 0,344 & 0,247 \\
\hline 85,4 & 0,421 & 0,351 & 0,251 \\
\hline 83,9 & 0,429 & 0,358 & 0,255 \\
\hline 82,4 & 0,438 & 0,365 & 0,259 \\
\hline 80,9 & 0,447 & 0,372 & 0,264 \\
\hline 79,5 & 0,456 & 0,380 & 0,269 \\
\hline 78,1 & 0,465 & 0,388 & 0,274 \\
\hline 76,8 & 0,475 & 0,396 & 0,280 \\
\hline 75,4 & 0,485 & 0,404 & 0,286 \\
\hline 74,1 & 0,494 & 0,412 & 0,292 \\
\hline 72,8 & 0,505 & 0,420 & 0,298 \\
\hline 71,6 & 0,515 & 0,429 & 0,304 \\
\hline 70,4 & 0,525 & 0,438 & 0,310 \\
\hline 69,2 & 0,536 & 0,447 & 0,316 \\
\hline 68,0 & 0,547 & 0,456 & 0,323 \\
\hline 66,8 & 0,558 & 0,465 & 0,329 \\
\hline 65,7 & 0,570 & 0,475 & 0,336 \\
\hline 64,6 & 0,581 & 0,484 & 0,343 \\
\hline 63,5 & 0,593 & 0,494 & 0,350 \\
\hline 62,5 & 0,605 & 0,504 & 0,357 \\
\hline 61,5 & 0,617 & 0,515 & 0,364 \\
\hline 60,4 & 0,630 & 0,525 & 0,372 \\
\hline 59,5 & 0,643 & 0,536 & 0,379 \\
\hline 58,5 & 0,656 & 0,547 & 0,387 \\
\hline 57,5 & 0,669 & 0,558 & 0,395 \\
\hline 56,6 & 0,683 & 0,569 & 0,403 \\
\hline 55,7 & 0,697 & 0,581 & 0,411 \\
\hline 54,8 & 0,711 & 0,593 & 0,419 \\
\hline 54,0 & 0,726 & 0,605 & 0,428 \\
\hline 53,1 & 0,741 & $0,617(1)$ & 0,437 \\
\hline 52,3 & 0,756 & 0,635 & 0,446 \\
\hline 51,5 & 0,771 & 0,655 & 0,455 \\
\hline 50,7 & 0,787 & 0,675 & 0,464 \\
\hline 49,9 & 0,803 & 0,697 & 0,474 \\
\hline 49,2 & 0,819 & 0,719 & 0,483 \\
\hline 48,5 & 0,836 & 0,742 & 0,493 \\
\hline 47,7 & 0,853 & 0,766 & 0,503 \\
\hline 47,0 & 0,871 & 0,792 & 0,513 \\
\hline 46,3 & 0,888 & 0,818 & 0,524 \\
\hline 45,7 & 0,906 & 0,846 & 0,535 \\
\hline 45,0 & 0,925 & 0,875 & 0,545 \\
\hline 44,4 & 0,944 & 0,906 & 0,557 \\
\hline 43,8 & 0,963 & 0,938 & 0,568 \\
\hline 43,2 & 0,983 & $0,973(2)$ & 0,580 \\
\hline 42,6 & 1,003 & & 0,591 \\
\hline 42,0 & 1,023 & & 0,603 \\
\hline 41,5 & 1,044 & & 0,616 \\
\hline 40,9 & $1,065(1)$ & & 0,628 \\
\hline
\end{tabular}

(1) Último valor de $\rho$ para seção subarmada $\left(\sigma_{\mathrm{s}}=\mathrm{f}_{\mathrm{yd}}\right)$

(2) Último valor de $\rho$ para seção superarmada utilizável $\left(\sigma_{\mathrm{s}}<\mathrm{f}_{\mathrm{yd}}\right)$

(3) Divisa dos domínios $2 \mathrm{a}$ e $2 \mathrm{~b}$

(4) Divisa dos domínios $2 \mathrm{~b}$ e 3 
Tabela A6 - Para dimensionamento no Estado Limite Último de seções retangulares à flexão simples com diagrama parábola-retângulo e coeficientes $\gamma_{\mathbf{f}}=\gamma_{\mathbf{c}}=\mathbf{1 , 4}$ e $\gamma_{\mathrm{s}}=\mathbf{1 , 1 5}$.

\begin{tabular}{|c|c|c|c|}
\hline \multirow{2}{*}{$\begin{array}{c}\mathrm{k}_{6}=\frac{\mathrm{bd}^{2}}{\mathrm{M}} \\
(\mathrm{tf} ; \mathrm{cm})\end{array}$} & \multicolumn{2}{|c|}{$\rho(\%)=\frac{100 \cdot A_{s}}{b \cdot d}$} & \multirow[t]{2}{*}{$\beta_{x}=\frac{x}{d}$} \\
\hline & CA-50A & CA-60B & \\
\hline 189,8 & 0,177 & 0,148 & 0,120 \\
\hline 186,1 & 0,181 & 0,151 & 0,122 \\
\hline 182,5 & 0,185 & 0,154 & 0,123 \\
\hline 178,9 & 0,188 & 0,157 & 0,124 \\
\hline 175,4 & 0,192 & 0,160 & 0,126 \\
\hline 172,0 & 0,196 & 0,163 & 0,127 \\
\hline 168,7 & 0,200 & 0,167 & 0,129 \\
\hline 165,4 & 0,204 & 0,170 & 0,130 \\
\hline 162,2 & 0,208 & 0,174 & 0,132 \\
\hline 159,1 & 0,213 & 0,177 & 0,133 \\
\hline 156,0 & 0,217 & 0,181 & 0,135 \\
\hline 153,0 & 0,221 & 0,185 & 0,136 \\
\hline 150,0 & 0,226 & 0,188 & 0,138 \\
\hline 147,1 & 0,231 & 0,192 & 0,140 \\
\hline 144,3 & 0,235 & 0,196 & 0,141 \\
\hline 141,5 & 0,240 & 0,200 & 0,143 \\
\hline 138,8 & 0,245 & 0,204 & 0,145 \\
\hline 136,1 & 0,250 & 0,208 & 0,146 \\
\hline 133,5 & 0,255 & 0,213 & 0,148 \\
\hline 130,9 & 0,260 & 0,217 & 0,150 \\
\hline 128,4 & 0,266 & 0,221 & 0,152 \\
\hline 125,9 & 0,271 & 0,226 & 0,153 \\
\hline 123,5 & 0,277 & 0,230 & 0,155 \\
\hline 121,2 & 0,282 & 0,235 & 0,157 \\
\hline 118,9 & 0,288 & 0,240 & 0,159 \\
\hline 116,6 & 0,294 & 0,245 & 0,161 \\
\hline 114,4 & 0,300 & 0,250 & 0,163 \\
\hline 112,2 & 0,306 & 0,255 & 0,165 \\
\hline 110,1 & 0,312 & 0,260 & 0,167 \\
\hline 108,0 & 0,319 & 0,265 & 0,169 \\
\hline 105,9 & 0,325 & 0,271 & 0,172 \\
\hline 103,9 & 0,332 & 0,276 & 0,174 \\
\hline 101,9 & 0,338 & 0,282 & 0,176 \\
\hline 100,0 & 0,345 & 0,288 & 0,178 \\
\hline 98,1 & 0,352 & 0,294 & 0,181 \\
\hline 96,3 & 0,360 & 0,300 & 0,183 \\
\hline 94,5 & 0,367 & 0,306 & 0,186 \\
\hline 92,7 & 0,374 & 0,312 & 0,188 \\
\hline 91,0 & 0,382 & 0,318 & 0,191 \\
\hline 89,3 & 0,390 & 0,325 & 0,193 \\
\hline 87,6 & 0,398 & 0,332 & 0,196 \\
\hline 86,0 & 0,406 & 0,338 & 0,199 \\
\hline 84,4 & 0,414 & 0,345 & 0,202 \\
\hline 82,8 & 0,423 & 0,352 & 0,204 \\
\hline 81,3 & 0,431 & 0,359 & 0,207 \\
\hline 79,8 & 0,440 & 0,367 & 0,210 \\
\hline 78,3 & 0,449 & 0,374 & 0,213 \\
\hline 76,9 & 0,458 & 0,382 & 0,216 \\
\hline 75,5 & 0,468 & 0,390 & 0,219 \\
\hline 74,1 & 0,477 & 0,398 & 0,223 \\
\hline 72,8 & 0,487 & 0,406 & 0,226 \\
\hline 71,4 & 0,497 & 0,414 & 0,229 \\
\hline
\end{tabular}

\begin{tabular}{|c|c|c|c|}
\hline \multirow{2}{*}{$\begin{array}{c}\mathrm{k}_{6}=\frac{\mathrm{bd}^{2}}{\mathrm{M}} \\
(\mathrm{tf} ; \mathrm{cm})\end{array}$} & \multicolumn{2}{|c|}{$\rho(\%)=\frac{100 \cdot \mathrm{A}_{\mathrm{s}}}{\mathrm{b} \cdot \mathrm{d}}$} & \multirow[t]{2}{*}{$\beta_{x}=\frac{x}{d}$} \\
\hline & CA-50A & CA-60B & \\
\hline 70,1 & 0,507 & 0,422 & 0,233 \\
\hline 68,9 & 0,517 & 0,431 & 0,236 \\
\hline 67,6 & 0,528 & 0,440 & 0,240 \\
\hline 66,4 & 0,539 & 0,449 & 0,243 \\
\hline 65,2 & 0,550 & 0,458 & 0,247 \\
\hline 64,0 & 0,561 & 0,467 & 0,251 \\
\hline 62,9 & 0,572 & 0,477 & 0,255 \\
\hline 61,8 & 0,584 & 0,487 & 0,259 \\
\hline 60,7 & 0,596 & 0,497 & 0,264 \\
\hline 59,6 & 0,608 & 0,507 & 0,269 \\
\hline 58,6 & 0,620 & 0,517 & 0,274 \\
\hline 57,6 & 0,633 & 0,528 & 0,280 \\
\hline 56,6 & 0,646 & 0,538 & 0,286 \\
\hline 55,6 & 0,659 & 0,549 & 0,292 \\
\hline 54,6 & 0,673 & 0,561 & 0,298 \\
\hline 53,7 & 0,686 & 0,572 & 0,304 \\
\hline 52,8 & 0,700 & 0,584 & 0,310 \\
\hline 51,9 & 0,715 & 0,596 & 0,316 \\
\hline 51,0 & 0,729 & 0,608 & 0,323 \\
\hline 50,1 & 0,744 & 0,620 & 0,329 \\
\hline 49,3 & 0,759 & 0,633 & 0,336 \\
\hline 48,5 & 0,775 & 0,646 & 0,343 \\
\hline 47,7 & 0,791 & 0,659 & 0,350 \\
\hline 46,9 & 0,807 & 0,672 & 0,357 \\
\hline 46,1 & 0,823 & 0,686 & 0,364 \\
\hline 45,3 & 0,840 & 0,700 & 0,372 \\
\hline 44,6 & 0,857 & 0,714 & 0,379 \\
\hline 43,9 & 0,875 & 0,729 & 0,387 \\
\hline 43,2 & 0,893 & 0,744 & 0,395 \\
\hline 42,5 & 0,911 & 0,759 & 0,403 \\
\hline 41,8 & 0,929 & 0,775 & 0,411 \\
\hline 41,1 & 0,948 & 0,790 & 0,419 \\
\hline 40,5 & 0,968 & 0,806 & 0,428 \\
\hline 39,8 & 0,987 & 0,823 (1) & 0,437 \\
\hline 39,2 & 1,008 & 0,847 & 0,446 \\
\hline 38,6 & 1,028 & 0,873 & 0,455 \\
\hline 38,0 & 1,049 & 0,901 & 0,464 \\
\hline 37,5 & 1,071 & 0,929 & 0,474 \\
\hline 36,9 & 1,092 & 0,959 & 0,483 \\
\hline 36,3 & 1,115 & 0,990 & 0,493 \\
\hline 35,8 & 1,137 & 1,022 & 0,503 \\
\hline 35,3 & 1,161 & 1,055 & 0,513 \\
\hline 34,8 & 1,184 & 1,091 & 0,524 \\
\hline 34,3 & 1,209 & 1,128 & 0,535 \\
\hline 33,8 & 1,233 & 1,167 & 0,545 \\
\hline 33,3 & 1,258 & 1,208 & 0,557 \\
\hline 32,8 & 1,284 & 1,251 & 0,568 \\
\hline 32,4 & 1,310 & $1,297(2)$ & 0,580 \\
\hline 31,9 & 1,337 & & 0,591 \\
\hline 31,5 & 1,364 & & 0,603 \\
\hline 31,1 & 1,392 & & 0,616 \\
\hline 30,7 & $1,421(1)$ & & 0,628 \\
\hline
\end{tabular}

(1) Último valor de $\rho$ para seção subarmada $\left(\sigma_{\mathrm{s}}=\mathrm{f}_{\mathrm{yd}}\right)$

(2) Último valor de $\rho$ para seção superarmada utilizável $\left(\sigma_{\mathrm{s}}<\mathrm{f}_{\mathrm{yd}}\right)$

(3) Divisa dos domínios $2 \mathrm{a}$ e $2 \mathrm{~b}$

(4) Divisa dos domínios $2 \mathrm{~b}$ e 3 
Tabela A7 - Para dimensionamento no Estado Limite Último de seções retangulares à flexão simples com diagrama parábola-retângulo e coeficientes $\gamma_{\mathbf{f}}=\gamma_{\mathbf{c}}=\mathbf{1 , 4}$ e $\gamma_{\mathrm{s}}=\mathbf{1 , 1 5}$.

\begin{tabular}{|c|c|c|c|}
\hline \multirow{2}{*}{$\begin{array}{c}\mathrm{k}_{6}=\frac{\mathrm{bd}^{2}}{\mathrm{M}} \\
(\mathrm{tf} ; \mathrm{cm})\end{array}$} & \multicolumn{2}{|c|}{$\rho(\%)=\frac{100 \cdot A_{s}}{b \cdot d}$} & \multirow[t]{2}{*}{$\beta_{x}=\frac{x}{d}$} \\
\hline & CA-50A & CA-60B & \\
\hline 151,8 & 0,222 & 0,185 & 0,120 \\
\hline 148,9 & 0,226 & 0,188 & 0,122 \\
\hline 146,0 & 0,231 & 0,192 & 0,123 \\
\hline 143,1 & 0,235 & 0,196 & 0,124 \\
\hline 140,4 & 0,240 & 0,200 & 0,126 \\
\hline 137,6 & 0,245 & 0,204 & 0,127 \\
\hline 135,0 & 0,250 & 0,209 & 0,129 \\
\hline 132,3 & 0,255 & 0,213 & 0,130 \\
\hline 129,8 & 0,261 & 0,217 & 0,132 \\
\hline 127,3 & 0,266 & 0,222 & 0,133 \\
\hline 124,8 & 0,271 & 0,226 & 0,135 \\
\hline 122,4 & 0,277 & 0,231 & 0,136 \\
\hline 120,0 & 0,282 & 0,235 & 0,138 \\
\hline 117,7 & 0,288 & 0,240 & 0,140 \\
\hline 115,4 & 0,294 & 0,245 & 0,141 \\
\hline 113,2 & 0,300 & 0,250 & 0,143 \\
\hline 111,0 & 0,306 & 0,255 & 0,145 \\
\hline 108,9 & 0,312 & 0,260 & 0,146 \\
\hline 106,8 & 0,319 & 0,266 & 0,148 \\
\hline 104,7 & 0,325 & 0,271 & 0,150 \\
\hline 102,7 & 0,332 & 0,277 & 0,152 \\
\hline 100,8 & 0,339 & 0,282 & 0,153 \\
\hline 98,8 & 0,346 & 0,288 & 0,155 \\
\hline 96,9 & 0,353 & 0,294 & 0,157 \\
\hline 95,1 & 0,360 & 0,300 & 0,159 \\
\hline 93,3 & 0,367 & 0,306 & 0,161 \\
\hline 91,5 & 0,375 & 0,312 & 0,163 \\
\hline 89,7 & 0,382 & 0,319 & 0,165 \\
\hline 88,0 & 0,390 & 0,325 & 0,167 \\
\hline 86,4 & 0,398 & 0,332 & 0,169 \\
\hline 84,7 & 0,406 & 0,339 & 0,172 \\
\hline 83,1 & 0,415 & 0,346 & 0,174 \\
\hline 81,6 & 0,423 & 0,353 & 0,176 \\
\hline 80,0 & 0,432 & 0,360 & 0,178 \\
\hline 78,5 & 0,441 & 0,367 & 0,181 \\
\hline 77,0 & 0,450 & 0,375 & 0,183 \\
\hline 75,6 & 0,459 & 0,382 & 0,186 \\
\hline 74,2 & 0,468 & 0,390 & 0,188 \\
\hline 72,8 & 0,478 & 0,398 & 0,191 \\
\hline 71,4 & 0,487 & 0,406 & 0,193 \\
\hline 70,1 & 0,497 & 0,414 & 0,196 \\
\hline 68,8 & 0,507 & 0,423 & 0,199 \\
\hline 67,5 & 0,518 & 0,431 & 0,202 \\
\hline 66,3 & 0,528 & 0,440 & 0,204 \\
\hline 65,0 & 0,539 & 0,449 & 0,207 \\
\hline 63,8 & 0,550 & 0,458 & 0,210 \\
\hline 62,7 & 0,561 & 0,468 & 0,213 \\
\hline 61,5 & 0,573 & 0,477 & 0,216 \\
\hline 60,4 & 0,585 & 0,487 & 0,219 \\
\hline 59,3 & 0,596 & 0,497 & 0,223 \\
\hline 58,2 & 0,609 & 0,507 & 0,226 \\
\hline 57,1 & 0,621 & 0,518 & 0,229 \\
\hline
\end{tabular}

\begin{tabular}{|c|c|c|c|}
\hline \multirow{2}{*}{$\begin{array}{c}\mathrm{k}_{6}=\frac{\mathrm{bd}^{2}}{\mathrm{M}} \\
(\mathrm{tf} ; \mathrm{cm})\end{array}$} & \multicolumn{2}{|c|}{$\rho(\%)=\frac{100 \cdot \mathrm{A}_{\mathrm{s}}}{\mathrm{b} \cdot \mathrm{d}}$} & \multirow[t]{2}{*}{$\beta_{x}=\frac{x}{d}$} \\
\hline & CA-50A & CA-60B & \\
\hline 56,1 & 0,634 & 0,528 & 0,233 \\
\hline 55,1 & 0,647 & 0,539 & 0,236 \\
\hline 54,1 & 0,660 & 0,550 & 0,240 \\
\hline 53,1 & 0,673 & 0,561 & 0,243 \\
\hline 52,2 & 0,687 & 0,573 & 0,247 \\
\hline 51,2 & 0,701 & 0,584 & 0,251 \\
\hline 50,3 & 0,715 & 0,596 & 0,255 \\
\hline 49,4 & 0,730 & 0,608 & 0,259 \\
\hline 48,6 & 0,745 & 0,621 & 0,264 \\
\hline 47,7 & 0,760 & 0,633 & 0,269 \\
\hline 46,9 & 0,776 & 0,646 & 0,274 \\
\hline 46,1 & 0,791 & 0,660 & 0,280 \\
\hline 45,3 & 0,808 & 0,673 & 0,286 \\
\hline 44,5 & 0,824 & 0,687 & 0,292 \\
\hline 43,7 & 0,841 & 0,701 & 0,298 \\
\hline 43,0 & 0,858 & 0,715 & 0,304 \\
\hline 42,2 & 0,876 & 0,730 & 0,310 \\
\hline 41,5 & 0,893 & 0,745 & 0,316 \\
\hline 40,8 & 0,912 & 0,760 & 0,323 \\
\hline 40,1 & 0,930 & 0,775 & 0,329 \\
\hline 39,4 & 0,949 & 0,791 & 0,336 \\
\hline 38,8 & 0,969 & 0,807 & 0,343 \\
\hline 38,1 & 0,988 & 0,824 & 0,350 \\
\hline 37,5 & 1,009 & 0,840 & 0,357 \\
\hline 36,9 & 1,029 & 0,858 & 0,364 \\
\hline 36,3 & 1,050 & 0,875 & 0,372 \\
\hline 35,7 & 1,072 & 0,893 & 0,379 \\
\hline 35,1 & 1,093 & 0,911 & 0,387 \\
\hline 34,5 & 1,116 & 0,930 & 0,395 \\
\hline 34,0 & 1,139 & 0,949 & 0,403 \\
\hline 33,4 & 1,162 & 0,968 & 0,411 \\
\hline 32,9 & 1,185 & 0,988 & 0,419 \\
\hline 32,4 & 1,210 & 1,008 & 0,428 \\
\hline 31,9 & 1,234 & 1,029 (1) & 0,437 \\
\hline 31,4 & 1,260 & 1,059 & 0,446 \\
\hline 30,9 & 1,285 & 1,091 & 0,455 \\
\hline 30,4 & 1,311 & 1,126 & 0,464 \\
\hline 30,0 & 1,338 & 1,161 & 0,474 \\
\hline 29,5 & 1,366 & 1,198 & 0,483 \\
\hline 29,1 & 1,393 & 1,237 & 0,493 \\
\hline 28,6 & 1,422 & 1,277 & 0,503 \\
\hline 28,2 & 1,451 & 1,319 & 0,513 \\
\hline 27,8 & 1,480 & 1,363 & 0,524 \\
\hline 27,4 & 1,511 & 1,410 & 0,535 \\
\hline 27,0 & 1,542 & 1,458 & 0,545 \\
\hline 26,6 & 1,573 & 1,509 & 0,557 \\
\hline 26,3 & 1,605 & 1,564 & 0,568 \\
\hline 25,9 & 1,638 & $1,621(2)$ & 0,580 \\
\hline 25,6 & 1,671 & & 0,591 \\
\hline 25,2 & 1,705 & & 0,603 \\
\hline 24,9 & 1,740 & & 0,616 \\
\hline 24,6 & $1,776(1)$ & & 0,628 \\
\hline
\end{tabular}

(1) Último valor de $\rho$ para seção subarmada $\left(\sigma_{\mathrm{s}}=\mathrm{f}_{\mathrm{yd}}\right)$

(2) Último valor de $\rho$ para seção superarmada utilizável $\left(\sigma_{\mathrm{s}}<\mathrm{f}_{\mathrm{yd}}\right)$

(3) Divisa dos domínios $2 \mathrm{a}$ e $2 \mathrm{~b}$

(4) Divisa dos domínios $2 \mathrm{~b}$ e 3 
Tabela A8 - Para dimensionamento no Estado Limite Último de seções retangulares à flexão simples com diagrama parábola-retângulo e coeficientes $\gamma_{\mathbf{f}}=\gamma_{\mathbf{c}}=\mathbf{1 , 4}$ e $\gamma_{\mathrm{s}}=\mathbf{1 , 1 5}$.

\begin{tabular}{|c|c|c|c|}
\hline \multirow{2}{*}{$\begin{array}{c}\mathrm{k}_{6}=\frac{\mathrm{bd}^{2}}{\mathrm{M}} \\
(\mathrm{tf} ; \mathrm{cm})\end{array}$} & \multicolumn{2}{|c|}{$\rho(\%)=\frac{100 \cdot A_{s}}{b \cdot d}$} & \multirow[t]{2}{*}{$\beta_{x}=\frac{x}{d}$} \\
\hline & CA-50A & CA-60B & \\
\hline 126,5 & 0,266 & 0,222 & 0,120 \\
\hline 124,1 & 0,271 & 0,226 & 0,122 \\
\hline 121,6 & 0,277 & 0,231 & 0,123 \\
\hline 119,3 & 0,283 & 0,235 & 0,124 \\
\hline 117,0 & 0,288 & 0,240 & 0,126 \\
\hline 114,7 & 0,294 & 0,245 & 0,127 \\
\hline 112,5 & 0,300 & 0,250 & 0,129 \\
\hline 110,3 & 0,306 & 0,255 & 0,130 \\
\hline 108,1 & 0,313 & 0,261 & 0,132 \\
\hline 106,1 & 0,319 & 0,266 & 0,133 \\
\hline 104,0 & 0,326 & 0,271 & 0,135 \\
\hline 102,0 & 0,332 & 0,277 & 0,136 \\
\hline 100,0 & 0,339 & 0,282 & 0,138 \\
\hline 98,1 & 0,346 & 0,288 & 0,140 \\
\hline 96,2 & 0,353 & 0,294 & 0,141 \\
\hline 94,3 & 0,360 & 0,300 & 0,143 \\
\hline 92,5 & 0,367 & 0,306 & 0,145 \\
\hline 90,7 & 0,375 & 0,312 & 0,146 \\
\hline 89,0 & 0,383 & 0,319 & 0,148 \\
\hline 87,3 & 0,390 & 0,325 & 0,150 \\
\hline 85,6 & 0,398 & 0,332 & 0,152 \\
\hline 84,0 & 0,407 & 0,339 & 0,153 \\
\hline 82,4 & 0,415 & 0,346 & 0,155 \\
\hline 80,8 & 0,423 & 0,353 & 0,157 \\
\hline 79,2 & 0,432 & 0,360 & 0,159 \\
\hline 77,7 & 0,441 & 0,367 & 0,161 \\
\hline 76,2 & 0,450 & 0,375 & 0,163 \\
\hline 74,8 & 0,459 & 0,382 & 0,165 \\
\hline 73,4 & 0,468 & 0,390 & 0,167 \\
\hline 72,0 & 0,478 & 0,398 & 0,169 \\
\hline 70,6 & 0,488 & 0,406 & 0,172 \\
\hline 69,3 & 0,498 & 0,415 & 0,174 \\
\hline 68,0 & 0,508 & 0,423 & 0,176 \\
\hline 66,7 & 0,518 & 0,432 & 0,178 \\
\hline 65,4 & 0,529 & 0,441 & 0,181 \\
\hline 64,2 & 0,539 & 0,450 & 0,183 \\
\hline 63,0 & 0,550 & 0,459 & 0,186 \\
\hline 61,8 & 0,562 & 0,468 & 0,188 \\
\hline 60,7 & 0,573 & 0,478 & 0,191 \\
\hline 59,5 & 0,585 & 0,487 & 0,193 \\
\hline 58,4 & 0,597 & 0,497 & 0,196 \\
\hline 57,3 & 0,609 & 0,507 & 0,199 \\
\hline 56,3 & 0,621 & 0,518 & 0,202 \\
\hline 55,2 & 0,634 & 0,528 & 0,204 \\
\hline 54,2 & 0,647 & 0,539 & 0,207 \\
\hline 53,2 & 0,660 & 0,550 & 0,210 \\
\hline 52,2 & 0,674 & 0,561 & 0,213 \\
\hline 51,3 & 0,687 & 0,573 & 0,216 \\
\hline 50,3 & 0,701 & 0,585 & 0,219 \\
\hline 49,4 & 0,716 & 0,596 & 0,223 \\
\hline 48,5 & 0,730 & 0,609 & 0,226 \\
\hline 47,6 & 0,745 & 0,621 & 0,229 \\
\hline
\end{tabular}

\begin{tabular}{|c|c|c|c|}
\hline \multirow{2}{*}{$\begin{array}{c}\mathrm{k}_{6}=\frac{\mathrm{bd}^{2}}{\mathrm{M}} \\
(\mathrm{tf} ; \mathrm{cm})\end{array}$} & \multicolumn{2}{|c|}{$\rho(\%)=\frac{100 \cdot \mathrm{A}_{\mathrm{s}}}{\mathrm{b} \cdot \mathrm{d}}$} & \multirow[t]{2}{*}{$\beta_{x}=\frac{x}{d}$} \\
\hline & CA-50A & CA-60B & \\
\hline 46,8 & 0,760 & 0,634 & 0,233 \\
\hline 45,9 & 0,776 & 0,647 & 0,236 \\
\hline 45,1 & 0,792 & 0,660 & 0,240 \\
\hline 44,3 & 0,808 & 0,673 & 0,243 \\
\hline 43,5 & 0,824 & 0,687 & 0,247 \\
\hline 42,7 & 0,841 & 0,701 & 0,251 \\
\hline 41,9 & 0,858 & 0,715 & 0,255 \\
\hline 41,2 & 0,876 & 0,730 & 0,259 \\
\hline 40,5 & 0,894 & 0,745 & 0,264 \\
\hline 39,7 & 0,912 & 0,760 & 0,269 \\
\hline 39,1 & 0,931 & 0,776 & 0,274 \\
\hline 38,4 & 0,950 & 0,791 & 0,280 \\
\hline 37,7 & 0,969 & 0,808 & 0,286 \\
\hline 37,1 & 0,989 & 0,824 & 0,292 \\
\hline 36,4 & 1,009 & 0,841 & 0,298 \\
\hline 35,8 & 1,030 & 0,858 & 0,304 \\
\hline 35,2 & 1,051 & 0,876 & 0,310 \\
\hline 34,6 & 1,072 & 0,893 & 0,316 \\
\hline 34,0 & 1,094 & 0,912 & 0,323 \\
\hline 33,4 & 1,116 & 0,930 & 0,329 \\
\hline 32,9 & 1,139 & 0,949 & 0,336 \\
\hline 32,3 & 1,162 & 0,969 & 0,343 \\
\hline 31,8 & 1,186 & 0,988 & 0,350 \\
\hline 31,2 & 1,210 & 1,009 & 0,357 \\
\hline 30,7 & 1,235 & 1,029 & 0,364 \\
\hline 30,2 & 1,260 & 1,050 & 0,372 \\
\hline 29,7 & 1,286 & 1,072 & 0,379 \\
\hline 29,2 & 1,312 & 1,093 & 0,387 \\
\hline 28,8 & 1,339 & 1,116 & 0,395 \\
\hline 28,3 & 1,366 & 1,139 & 0,403 \\
\hline 27,9 & 1,394 & 1,162 & 0,411 \\
\hline 27,4 & 1,423 & 1,185 & 0,419 \\
\hline 27,0 & 1,452 & 1,210 & 0,428 \\
\hline 26,6 & 1,481 & $1,234(1)$ & 0,437 \\
\hline 26,2 & 1,511 & 1,270 & 0,446 \\
\hline 25,7 & 1,542 & 1,310 & 0,455 \\
\hline 25,4 & 1,574 & 1,351 & 0,464 \\
\hline 25,0 & 1,606 & 1,394 & 0,474 \\
\hline 24,6 & 1,639 & 1,438 & 0,483 \\
\hline 24,2 & 1,672 & 1,484 & 0,493 \\
\hline 23,9 & 1,706 & 1,533 & 0,503 \\
\hline 23,5 & 1,741 & 1,583 & 0,513 \\
\hline 23,2 & 1,777 & 1,636 & 0,524 \\
\hline 22,8 & 1,813 & 1,692 & 0,535 \\
\hline 22,5 & 1,850 & 1,750 & 0,545 \\
\hline 22,2 & 1,888 & 1,811 & 0,557 \\
\hline 21,9 & 1,926 & 1,876 & 0,568 \\
\hline 21,6 & 1,965 & 1,945 (2) & 0,580 \\
\hline 21,3 & 2,006 & & 0,591 \\
\hline 21,0 & 2,046 & & 0,603 \\
\hline 20,7 & 2,088 & & 0,616 \\
\hline 20,5 & $2,131(1)$ & & 0,628 \\
\hline
\end{tabular}

(1) Último valor de $\rho$ para seção subarmada $\left(\sigma_{\mathrm{s}}=\mathrm{f}_{\mathrm{yd}}\right)$

(2) Último valor de $\rho$ para seção superarmada utilizável $\left(\sigma_{\mathrm{s}}<\mathrm{f}_{\mathrm{yd}}\right)$

(3) Divisa dos domínios $2 \mathrm{a}$ e $2 \mathrm{~b}$

(4) Divisa dos domínios $2 \mathrm{~b}$ e 3 
Tabela A9 - Para dimensionamento no Estado Limite Último de seções retangulares à flexão simples de reservatórios com diagrama parábola-retângulo e coeficientes $\gamma_{\mathbf{c}}=\mathbf{1 , 4}, \gamma_{\mathrm{f}}=\mathbf{1 , 3}$ e $\gamma_{\mathrm{s}}=\mathbf{1 , 1 5}$.

\begin{tabular}{|c|c|c|c|}
\hline \multirow{2}{*}{$\begin{array}{c}\mathrm{k}_{6}=\frac{\mathrm{bd}^{2}}{\mathrm{M}} \\
(\mathrm{tf} ; \mathrm{cm})\end{array}$} & \multicolumn{2}{|c|}{$\rho(\%)=\frac{100 \cdot A_{s}}{b \cdot d}$} & \multirow[t]{2}{*}{$\beta_{x}=\frac{x}{d}$} \\
\hline & CA-50A & CA-60B & \\
\hline 141,0 & 0,222 & 0,185 & 0,120 \\
\hline 138,2 & 0,226 & 0,188 & 0,122 \\
\hline 135,5 & 0,231 & 0,192 & 0,123 \\
\hline 132,9 & 0,235 & 0,196 & 0,124 \\
\hline 130,3 & 0,240 & 0,200 & 0,126 \\
\hline 127,8 & 0,245 & 0,204 & 0,127 \\
\hline 125,3 & 0,250 & 0,209 & 0,129 \\
\hline 122,9 & 0,255 & 0,213 & 0,130 \\
\hline 120,5 & 0,261 & 0,217 & 0,132 \\
\hline 118,2 & 0,266 & 0,222 & 0,133 \\
\hline 115,9 & 0,271 & 0,226 & 0,135 \\
\hline 113,6 & 0,277 & 0,231 & 0,136 \\
\hline 111,4 & 0,282 & 0,235 & 0,138 \\
\hline 109,3 & 0,288 & 0,240 & 0,140 \\
\hline 107,2 & 0,294 & 0,245 & 0,141 \\
\hline 105,1 & 0,300 & 0,250 & 0,143 \\
\hline 103,1 & 0,306 & 0,255 & 0,145 \\
\hline 101,1 & 0,312 & 0,260 & 0,146 \\
\hline 99,2 & 0,319 & 0,266 & 0,148 \\
\hline 97,3 & 0,325 & 0,271 & 0,150 \\
\hline 95,4 & 0,332 & 0,277 & 0,152 \\
\hline 93,6 & 0,339 & 0,282 & 0,153 \\
\hline 91,8 & 0,346 & 0,288 & 0,155 \\
\hline 90,0 & 0,353 & 0,294 & 0,157 \\
\hline 88,3 & 0,360 & 0,300 & 0,159 \\
\hline 86,6 & 0,367 & 0,306 & 0,161 \\
\hline 85,0 & 0,375 & 0,312 & 0,163 \\
\hline 83,3 & 0,382 & 0,319 & 0,165 \\
\hline 81,8 & 0,390 & 0,325 & 0,167 \\
\hline 80,2 & 0,398 & 0,332 & 0,169 \\
\hline 78,7 & 0,406 & 0,339 & 0,172 \\
\hline 77,2 & 0,415 & 0,346 & 0,174 \\
\hline 75,7 & 0,423 & 0,353 & 0,176 \\
\hline 74,3 & 0,432 & 0,360 & 0,178 \\
\hline 72,9 & 0,441 & 0,367 & 0,181 \\
\hline 71,5 & 0,450 & 0,375 & 0,183 \\
\hline 70,2 & 0,459 & 0,382 & 0,186 \\
\hline 68,9 & 0,468 & 0,390 & 0,188 \\
\hline 67,6 & 0,478 & 0,398 & 0,191 \\
\hline 66,3 & 0,487 & 0,406 & 0,193 \\
\hline 65,1 & 0,497 & 0,414 & 0,196 \\
\hline 63,9 & 0,507 & 0,423 & 0,199 \\
\hline 62,7 & 0,518 & 0,431 & 0,202 \\
\hline 61,5 & 0,528 & 0,440 & 0,204 \\
\hline 60,4 & 0,539 & 0,449 & 0,207 \\
\hline 59,3 & 0,550 & 0,458 & 0,210 \\
\hline 58,2 & 0,561 & 0,468 & 0,213 \\
\hline 57,1 & 0,573 & 0,477 & 0,216 \\
\hline 56,1 & 0,585 & 0,487 & 0,219 \\
\hline 55,0 & 0,596 & 0,497 & 0,223 \\
\hline 54,0 & 0,609 & 0,507 & 0,226 \\
\hline 53,1 & 0,621 & 0,518 & 0,229 \\
\hline
\end{tabular}

\begin{tabular}{|c|c|c|c|}
\hline \multirow{2}{*}{$\begin{array}{c}\mathrm{k}_{6}=\frac{\mathrm{bd}^{2}}{\mathrm{M}} \\
(\mathrm{tf} ; \mathrm{cm})\end{array}$} & \multicolumn{2}{|c|}{$\rho(\%)=\frac{100 \cdot \mathrm{A}_{\mathrm{s}}}{\mathrm{b} \cdot \mathrm{d}}$} & \multirow[t]{2}{*}{$\beta_{x}=\frac{x}{d}$} \\
\hline & CA-50A & CA-60B & \\
\hline 52,1 & 0,634 & 0,528 & 0,233 \\
\hline 51,2 & 0,647 & 0,539 & 0,236 \\
\hline 50,2 & 0,660 & 0,550 & 0,240 \\
\hline 49,3 & 0,673 & 0,561 & 0,243 \\
\hline 48,4 & 0,687 & 0,573 & 0,247 \\
\hline 47,6 & 0,701 & 0,584 & 0,251 \\
\hline 46,7 & 0,715 & 0,596 & 0,255 \\
\hline 45,9 & 0,730 & 0,608 & 0,259 \\
\hline 45,1 & 0,745 & 0,621 & 0,264 \\
\hline 44,3 & 0,760 & 0,633 & 0,269 \\
\hline 43,5 & 0,776 & 0,646 & 0,274 \\
\hline 42,8 & 0,791 & 0,660 & 0,280 \\
\hline 42,0 & 0,808 & 0,673 & 0,286 \\
\hline 41,3 & 0,824 & 0,687 & 0,292 \\
\hline 40,6 & 0,841 & 0,701 & 0,298 \\
\hline 39,9 & 0,858 & 0,715 & 0,304 \\
\hline 39,2 & 0,876 & 0,730 & 0,310 \\
\hline 38,5 & 0,893 & 0,745 & 0,316 \\
\hline 37,9 & 0,912 & 0,760 & 0,323 \\
\hline 37,2 & 0,930 & 0,775 & 0,329 \\
\hline 36,6 & 0,949 & 0,791 & 0,336 \\
\hline 36,0 & 0,969 & 0,807 & 0,343 \\
\hline 35,4 & 0,988 & 0,824 & 0,350 \\
\hline 34,8 & 1,009 & 0,840 & 0,357 \\
\hline 34,2 & 1,029 & 0,858 & 0,364 \\
\hline 33,7 & 1,050 & 0,875 & 0,372 \\
\hline 33,1 & 1,072 & 0,893 & 0,379 \\
\hline 32,6 & 1,093 & 0,911 & 0,387 \\
\hline 32,1 & 1,116 & 0,930 & 0,395 \\
\hline 31,5 & 1,139 & 0,949 & 0,403 \\
\hline 31,0 & 1,162 & 0,968 & 0,411 \\
\hline 30,6 & 1,185 & 0,988 & 0,419 \\
\hline 30,1 & 1,210 & 1,008 & 0,428 \\
\hline 29,6 & 1,234 & $1,029(1)$ & 0,437 \\
\hline 29,1 & 1,260 & 1,059 & 0,446 \\
\hline 28,7 & 1,285 & 1,091 & 0,455 \\
\hline 28,3 & 1,311 & 1,126 & 0,464 \\
\hline 27,8 & 1,338 & 1,161 & 0,474 \\
\hline 27,4 & 1,366 & 1,198 & 0,483 \\
\hline 27,0 & 1,393 & 1,237 & 0,493 \\
\hline 26,6 & 1,422 & 1,277 & 0,503 \\
\hline 26,2 & 1,451 & 1,319 & 0,513 \\
\hline 25,8 & 1,480 & 1,363 & 0,524 \\
\hline 25,5 & 1,511 & 1,410 & 0,535 \\
\hline 25,1 & 1,542 & 1,458 & 0,545 \\
\hline 24,7 & 1,573 & 1,509 & 0,557 \\
\hline 24,4 & 1,605 & 1,564 & 0,568 \\
\hline 24,1 & 1,638 & $1,621(2)$ & 0,580 \\
\hline 23,7 & 1,671 & & 0,591 \\
\hline 23,4 & 1,705 & & 0,603 \\
\hline 23,1 & 1,740 & & 0,616 \\
\hline 22,8 & $1,776(1)$ & & 0,628 \\
\hline
\end{tabular}

(1) Último valor de $\rho$ para seção subarmada $\left(\sigma_{\mathrm{s}}=\mathrm{f}_{\mathrm{yd}}\right)$

(2) Último valor de $\rho$ para seção superarmada utilizável $\left(\sigma_{\mathrm{s}}<\mathrm{f}_{\mathrm{yd}}\right)$

(3) Divisa dos domínios $2 \mathrm{a}$ e $2 \mathrm{~b}$

(4) Divisa dos domínios $2 \mathrm{~b}$ e 3 
Tabela A10 - Para dimensionamento no Estado Limite Último de seções retangulares à flexão simples de reservatórios com diagrama parábola-retângulo e coeficientes $\gamma_{\mathbf{c}}=\mathbf{1 , 4}, \gamma_{\mathrm{f}}=\mathbf{1 , 3}$ e $\gamma_{\mathrm{s}}=\mathbf{1 , 1 5}$.

\begin{tabular}{|c|c|c|c|}
\hline \multirow{2}{*}{$\begin{array}{c}\mathrm{k}_{6}=\frac{\mathrm{bd}^{2}}{\mathrm{M}} \\
(\mathrm{tf} ; \mathrm{cm})\end{array}$} & \multicolumn{2}{|c|}{$\rho(\%)=\frac{100 \cdot A_{s}}{b \cdot d}$} & \multirow[t]{2}{*}{$\beta_{x}=\frac{x}{d}$} \\
\hline & CA-50A & CA-60B & \\
\hline 117,5 & 0,266 & 0,222 & 0,120 \\
\hline 115,2 & 0,271 & 0,226 & 0,122 \\
\hline 113,0 & 0,277 & 0,231 & 0,123 \\
\hline 110,8 & 0,283 & 0,235 & 0,124 \\
\hline 108,6 & 0,288 & 0,240 & 0,126 \\
\hline 106,5 & 0,294 & 0,245 & 0,127 \\
\hline 104,4 & 0,300 & 0,250 & 0,129 \\
\hline 102,4 & 0,306 & 0,255 & 0,130 \\
\hline 100,4 & 0,313 & 0,261 & 0,132 \\
\hline 98,5 & 0,319 & 0,266 & 0,133 \\
\hline 96,6 & 0,326 & 0,271 & 0,135 \\
\hline 94,7 & 0,332 & 0,277 & 0,136 \\
\hline 92,9 & 0,339 & 0,282 & 0,138 \\
\hline 91,1 & 0,346 & 0,288 & 0,140 \\
\hline 89,3 & 0,353 & 0,294 & 0,141 \\
\hline 87,6 & 0,360 & 0,300 & 0,143 \\
\hline 85,9 & 0,367 & 0,306 & 0,145 \\
\hline 84,3 & 0,375 & 0,312 & 0,146 \\
\hline 82,6 & 0,383 & 0,319 & 0,148 \\
\hline 81,0 & 0,390 & 0,325 & 0,150 \\
\hline 79,5 & 0,398 & 0,332 & 0,152 \\
\hline 78,0 & 0,407 & 0,339 & 0,153 \\
\hline 76,5 & 0,415 & 0,346 & 0,155 \\
\hline 75,0 & 0,423 & 0,353 & 0,157 \\
\hline 73,6 & 0,432 & 0,360 & 0,159 \\
\hline 72,2 & 0,441 & 0,367 & 0,161 \\
\hline 70,8 & 0,450 & 0,375 & 0,163 \\
\hline 69,4 & 0,459 & 0,382 & 0,165 \\
\hline 68,1 & 0,468 & 0,390 & 0,167 \\
\hline 66,8 & 0,478 & 0,398 & 0,169 \\
\hline 65,6 & 0,488 & 0,406 & 0,172 \\
\hline 64,3 & 0,498 & 0,415 & 0,174 \\
\hline 63,1 & 0,508 & 0,423 & 0,176 \\
\hline 61,9 & 0,518 & 0,432 & 0,178 \\
\hline 60,8 & 0,529 & 0,441 & 0,181 \\
\hline 59,6 & 0,539 & 0,450 & 0,183 \\
\hline 58,5 & 0,550 & 0,459 & 0,186 \\
\hline 57,4 & 0,562 & 0,468 & 0,188 \\
\hline 56,3 & 0,573 & 0,478 & 0,191 \\
\hline 55,3 & 0,585 & 0,487 & 0,193 \\
\hline 54,2 & 0,597 & 0,497 & 0,196 \\
\hline 53,2 & 0,609 & 0,507 & 0,199 \\
\hline 52,2 & 0,621 & 0,518 & 0,202 \\
\hline 51,3 & 0,634 & 0,528 & 0,204 \\
\hline 50,3 & 0,647 & 0,539 & 0,207 \\
\hline 49,4 & 0,660 & 0,550 & 0,210 \\
\hline 48,5 & 0,674 & 0,561 & 0,213 \\
\hline 47,6 & 0,687 & 0,573 & 0,216 \\
\hline 46,7 & 0,701 & 0,585 & 0,219 \\
\hline 45,9 & 0,716 & 0,596 & 0,223 \\
\hline 45,0 & 0,730 & 0,609 & 0,226 \\
\hline 44,2 & 0,745 & 0,621 & 0,229 \\
\hline
\end{tabular}

\begin{tabular}{|c|c|c|c|}
\hline \multirow{2}{*}{$\begin{array}{c}\mathrm{k}_{6}=\frac{\mathrm{bd}^{2}}{\mathrm{M}} \\
(\mathrm{tf} ; \mathrm{cm})\end{array}$} & \multicolumn{2}{|c|}{$\rho(\%)=\frac{100 \cdot \mathrm{A}_{\mathrm{s}}}{\mathrm{b} \cdot \mathrm{d}}$} & \multirow[t]{2}{*}{$\beta_{x}=\frac{x}{d}$} \\
\hline & CA-50A & CA-60B & \\
\hline 43,4 & 0,760 & 0,634 & 0,233 \\
\hline 42,6 & 0,776 & 0,647 & 0,236 \\
\hline 41,9 & 0,792 & 0,660 & 0,240 \\
\hline 41,1 & 0,808 & 0,673 & 0,243 \\
\hline 40,4 & 0,824 & 0,687 & 0,247 \\
\hline 39,6 & 0,841 & 0,701 & 0,251 \\
\hline 38,9 & 0,858 & 0,715 & 0,255 \\
\hline 38,2 & 0,876 & 0,730 & 0,259 \\
\hline 37,6 & 0,894 & 0,745 & 0,264 \\
\hline 36,9 & 0,912 & 0,760 & 0,269 \\
\hline 36,3 & 0,931 & 0,776 & 0,274 \\
\hline 35,6 & 0,950 & 0,791 & 0,280 \\
\hline 35,0 & 0,969 & 0,808 & 0,286 \\
\hline 34,4 & 0,989 & 0,824 & 0,292 \\
\hline 33,8 & 1,009 & 0,841 & 0,298 \\
\hline 33,2 & 1,030 & 0,858 & 0,304 \\
\hline 32,7 & 1,051 & 0,876 & 0,310 \\
\hline 32,1 & 1,072 & 0,893 & 0,316 \\
\hline 31,6 & 1,094 & 0,912 & 0,323 \\
\hline 31,0 & 1,116 & 0,930 & 0,329 \\
\hline 30,5 & 1,139 & 0,949 & 0,336 \\
\hline 30,0 & 1,162 & 0,969 & 0,343 \\
\hline 29,5 & 1,186 & 0,988 & 0,350 \\
\hline 29,0 & 1,210 & 1,009 & 0,357 \\
\hline 28,5 & 1,235 & 1,029 & 0,364 \\
\hline 28,1 & 1,260 & 1,050 & 0,372 \\
\hline 27,6 & 1,286 & 1,072 & 0,379 \\
\hline 27,2 & 1,312 & 1,093 & 0,387 \\
\hline 26,7 & 1,339 & 1,116 & 0,395 \\
\hline 26,3 & 1,366 & 1,139 & 0,403 \\
\hline 25,9 & 1,394 & 1,162 & 0,411 \\
\hline 25,5 & 1,423 & 1,185 & 0,419 \\
\hline 25,1 & 1,452 & 1,210 & 0,428 \\
\hline 24,7 & 1,481 & $1,234(1)$ & 0,437 \\
\hline 24,3 & 1,511 & 1,270 & 0,446 \\
\hline 23,9 & 1,542 & 1,310 & 0,455 \\
\hline 23,5 & 1,574 & 1,351 & 0,464 \\
\hline 23,2 & 1,606 & 1,394 & 0,474 \\
\hline 22,8 & 1,639 & 1,438 & 0,483 \\
\hline 22,5 & 1,672 & 1,484 & 0,493 \\
\hline 22,2 & 1,706 & 1,533 & 0,503 \\
\hline 21,8 & 1,741 & 1,583 & 0,513 \\
\hline 21,5 & 1,777 & 1,636 & 0,524 \\
\hline 21,2 & 1,813 & 1,692 & 0,535 \\
\hline 20,9 & 1,850 & 1,750 & 0,545 \\
\hline 20,6 & 1,888 & 1,811 & 0,557 \\
\hline 20,3 & 1,926 & 1,876 & 0,568 \\
\hline 20,0 & 1,965 & 1,945 (2) & 0,580 \\
\hline 19,8 & 2,006 & & 0,591 \\
\hline 19,5 & 2,046 & & 0,603 \\
\hline 19,2 & 2,088 & & 0,616 \\
\hline 19,0 & $2,131(1)$ & & 0,628 \\
\hline
\end{tabular}

(1) Último valor de $\rho$ para seção subarmada $\left(\sigma_{\mathrm{s}}=\mathrm{f}_{\mathrm{yd}}\right)$

(2) Último valor de $\rho$ para seção superarmada utilizável $\left(\sigma_{\mathrm{s}}<\mathrm{f}_{\mathrm{yd}}\right)$

(3) Divisa dos domínios $2 \mathrm{a}$ e $2 \mathrm{~b}$

(4) Divisa dos domínios $2 \mathrm{~b}$ e 3 


\section{A.3. PRÉ-DIMENSIONAMENTO DE LAJES E PAREDES DE RESERVATÓRIOS JÁ LEVANDO EM CONTA A FISSURAÇÃO}

Tabela A11 - Pré-dimensionamento de Lajes e Paredes de Reservatórios

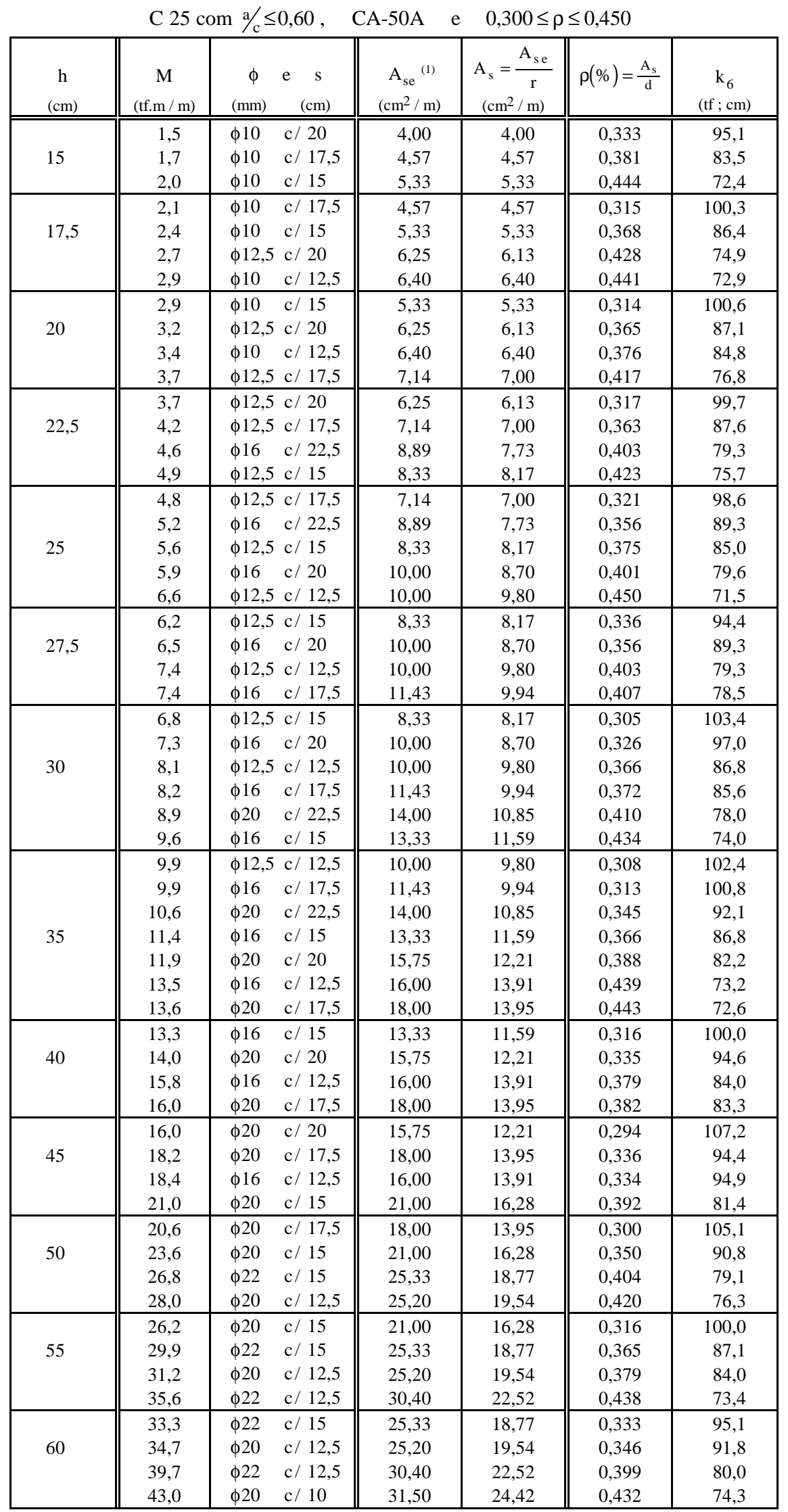

(1) $\mathrm{A}_{\mathrm{se}}$ (área efetiva) é a área de cálculo ( $\mathrm{A}_{\mathrm{s}}$ ) majo-

rada do coeficiente $\mathbf{r}$ para combater a fissuração.

\begin{tabular}{c|c|c|c|c|c}
$\phi$ & $\leq 10$ & 12,5 & 16 & 20 & 22 \\
\hline $\mathrm{r}$ & 1 & 1,02 & 1,15 & 1,29 & 1,35
\end{tabular}




\section{A.4. MOMENTOS E NORMAIS LONGITUDINAIS DE PAREDES DE COMPRIMENTO INFINITO}

Tabela A12 - Paredes de comprimento infinito, inércia constante, com carregamentos triangu$\mathbf{v}=\mathbf{0 , 2}$ lar e retangular, apoiadas na borda superior. Momentos longitudinais nos pontos indicados e normais longitudinais apenas nos pontos $1,10,19,28$ e 37 .

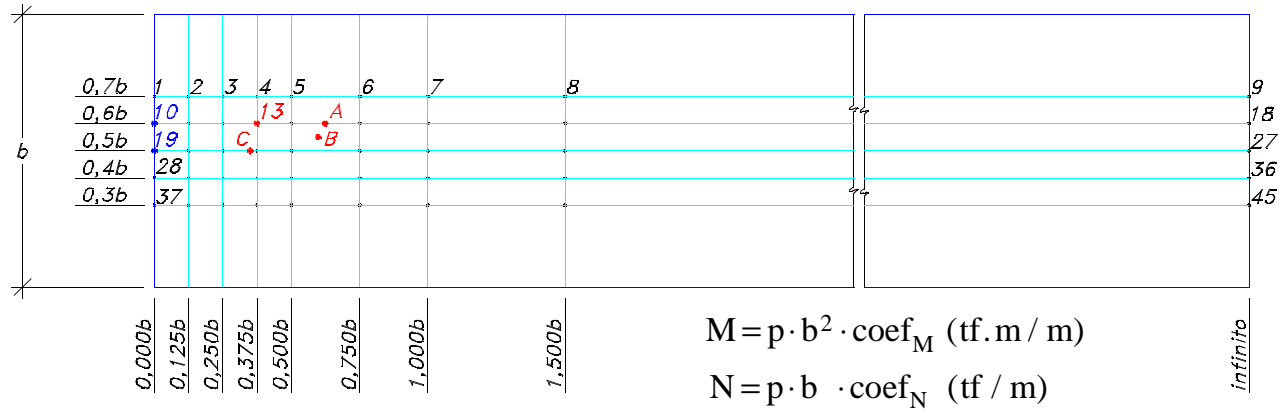

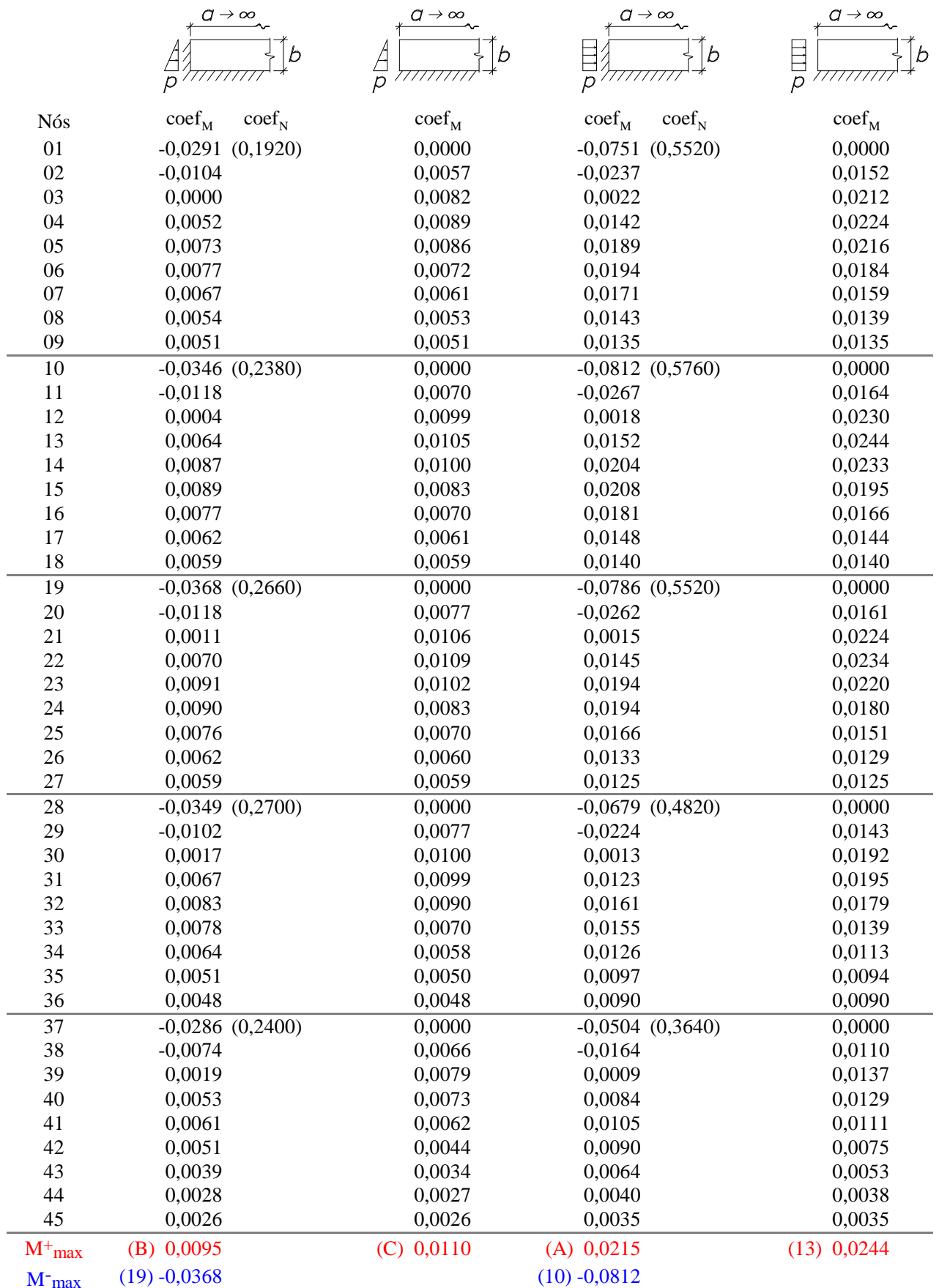


Tabela A13 - Paredes de comprimento infinito, inércia constante, com carregamento triangu$v=\mathbf{0}, 2$ lar e retangular, livres na borda superior. Momentos longitudinais nos pontos indicados.
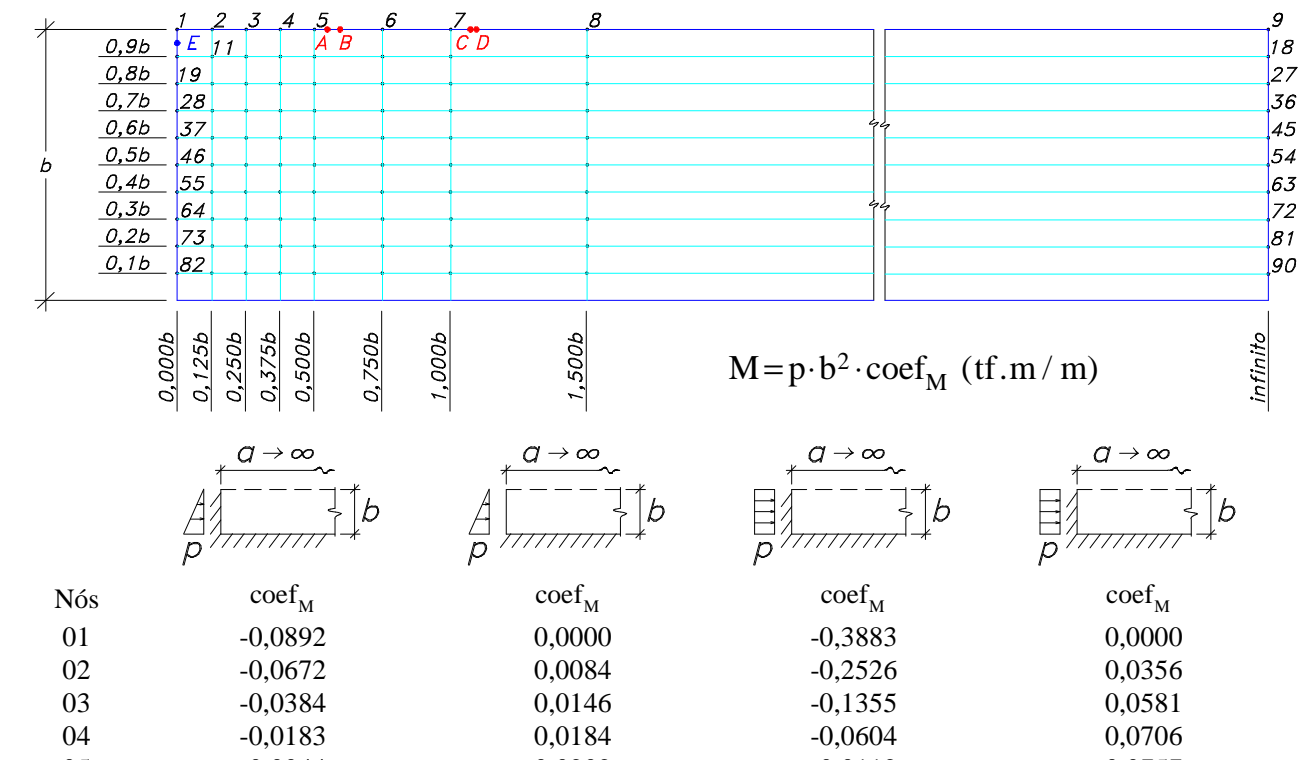

$\operatorname{coef}_{\mathrm{M}}$

0,0000

$0,0084-0,0356$

$0,0146 \quad-0,1355 \quad 0,0581$

$-0,0183$

0,0184

$-0,0604$

0,0706

$-0,0044$

0,0150

0,0202

0,0198

0,0167

$-0,0112$

0,0400

0,0555

0,0757

\begin{tabular}{rr}
08 & 0,0125 \\
09 & 0,0008 \\
\hline 10 & $-0,1003$
\end{tabular}

0,0005

0,0000

0,0460

\begin{tabular}{|c|c|c|c|c|}
\hline & & & & \\
\hline 10 & $-0,1003$ & 0,0000 & $-0,3928$ & 0,0000 \\
\hline 11 & $-0,0609$ & 0,0083 & $-0,2259$ & 0,0332 \\
\hline 12 & $-0,0348$ & 0,0142 & $-0,1235$ & 0,0540 \\
\hline 13 & $-0,0162$ & 0,0177 & $-0,0554$ & 0,0653 \\
\hline 14 & $-0,0034$ & 0,0193 & $-0,0102$ & 0,0697 \\
\hline 15 & 0,0101 & 0,0185 & 0,0367 & 0,0661 \\
\hline 16 & 0,0141 & 0,0154 & 0,0506 & 0,0550 \\
\hline 17 & 0,0115 & 0,0087 & 0,0412 & 0,0314 \\
\hline 18 & 0,0007 & 0,0004 & 0,0018 & 0,0007 \\
\hline 19 & $-0,0865$ & 0,0000 & $-0,3173$ & 0,0000 \\
\hline 20 & $-0,0549$ & 0,0086 & $-0,1989$ & 0,0308 \\
\hline 21 & $-0,0306$ & 0,0142 & $-0,1098$ & 0,0495 \\
\hline 22 & $-0,0135$ & 0,0172 & $-0,0492$ & 0,0591 \\
\hline 23 & $-0,0020$ & 0,0183 & $-0,0088$ & 0,0624 \\
\hline 24 & 0,0099 & 0,0170 & 0,0327 & 0,0579 \\
\hline 25 & 0,0131 & 0,0139 & 0,0442 & 0,0470 \\
\hline 26 & 0,0102 & 0,0076 & 0,0343 & 0,0251 \\
\hline 27 & 0,0004 & 0,0001 & $-0,0015$ & $-0,0025$ \\
\hline 28 & $-0,0757$ & 0,0000 & $-0,2562$ & 0,0000 \\
\hline 29 & $-0,0477$ & 0,0089 & $-0,1672$ & 0,0279 \\
\hline 30 & $-0,0258$ & 0,0140 & $-0,0944$ & 0,0440 \\
\hline 31 & $-0,0105$ & 0,0165 & $-0,0425$ & 0,0517 \\
\hline 32 & $-0,0004$ & 0,0170 & $-0,0076$ & 0,0535 \\
\hline 33 & 0,0096 & 0,0152 & 0,0275 & 0,0477 \\
\hline 34 & 0,0118 & 0,0119 & 0,0362 & 0,0369 \\
\hline 35 & 0,0086 & 0,0061 & 0,0255 & 0,0167 \\
\hline 36 & $-0,0003$ & $-0,0006$ & $-0,0069$ & $-0,0077$ \\
\hline 37 & $-0,0661$ & 0,0000 & $-0,2026$ & 0,0000 \\
\hline 38 & $-0,0399$ & 0,0090 & $-0,1343$ & 0,0244 \\
\hline 39 & $-0,0206$ & 0,0135 & $-0,0775$ & 0,0374 \\
\hline 40 & $-0,0074$ & 0,0152 & $-0,0354$ & 0,0426 \\
\hline 41 & 0,0010 & 0,0152 & $-0,0069$ & 0,0429 \\
\hline 42 & 0,0087 & 0,0127 & 0,0209 & 0,0356 \\
\hline 43 & 0,0099 & 0,0094 & 0,0264 & 0,0249 \\
\hline 44 & 0,0063 & 0,0039 & 0,0148 & 0,0063 \\
\hline 45 & $-0,0017$ & $-0,0019$ & $-0,0142$ & $-0,0149$ \\
\hline $\mathrm{M}^{+} \max$ & (D) 0,0153 & (B) 0,0206 & (C) 0,0563 & (A) 0,0763 \\
\hline $\mathrm{M}^{-} \max$ & (E) $-0,1128$ & & (E) $-0,4569$ & \\
\hline
\end{tabular}


Tabela A13 - Continuação...

$v=\mathbf{0 , 2}$
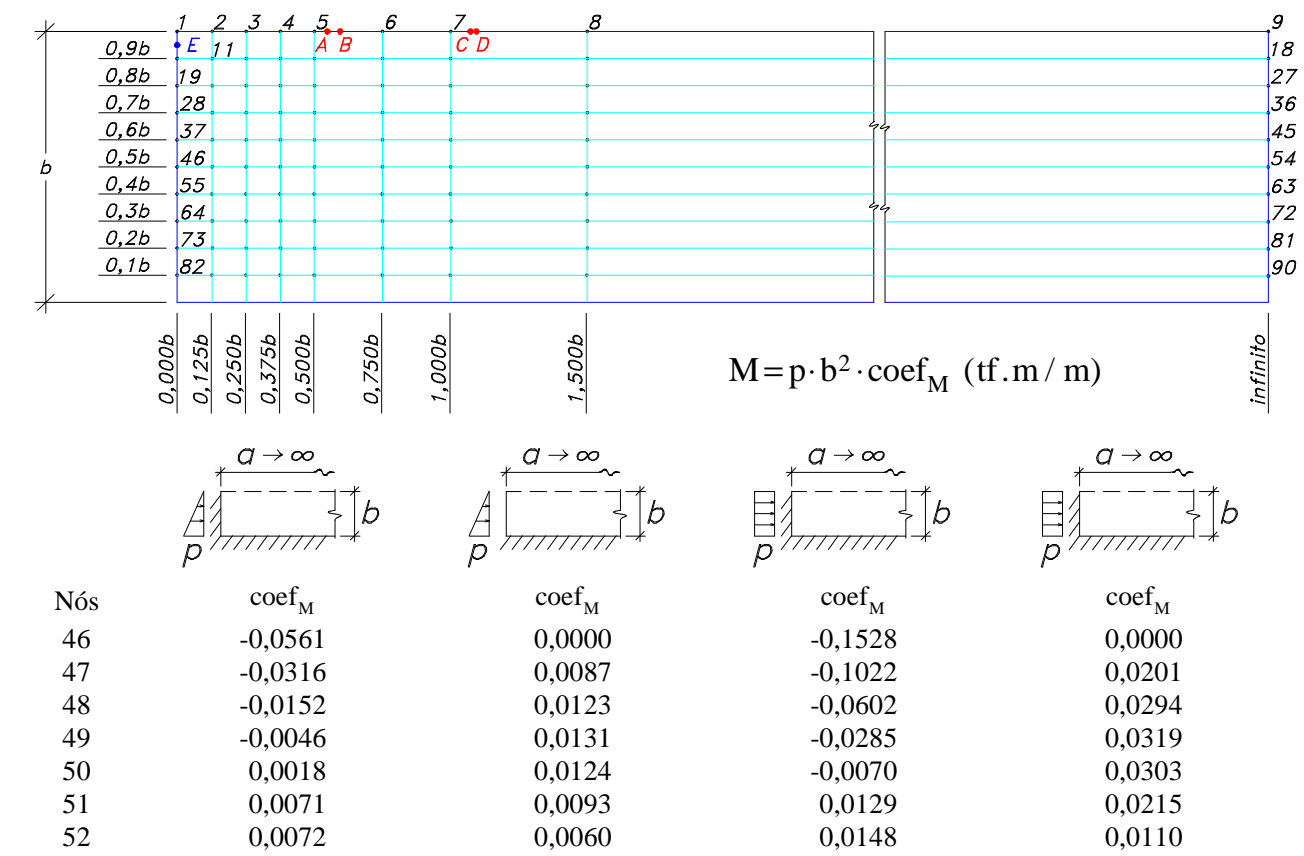

$\operatorname{coef}_{\mathrm{M}}$

0,0000

0,0087

0,0123

0,0131

0,0124

0,0093

0,0060

0,0033

0,0010

$-0,0038$

$-0,0039$

\begin{tabular}{l}
54 \\
\hline 55 \\
56
\end{tabular}

$-0,0233$

$-0,0103$

$-0,0025$

0,0017

0,0044

0,0034

$-0,0007$

0,0000

0,0078

0,0101

0,0098

0,0084

0,0048

\begin{tabular}{l}
61 \\
62 \\
63 \\
\hline
\end{tabular}

$-0,0069$

0,0016

$-0,0029$

64

$65-0,0152$

$66-0,0062$

$\begin{array}{lr}67 & -0,0016 \\ 68 & 0,0004\end{array}$

$69 \quad 0,0005$

$-0,0015$

\begin{tabular}{ll}
71 & $-0,0058$ \\
72 & $-0,0112$ \\
\hline 73 & $-0,0180$
\end{tabular}

$\begin{array}{ll}73 & -0,0180 \\ 74 & -0,0082 \\ 75 & -0,0037\end{array}$

$-0,0037$

$-0,0022$

$-0,0024$

$-0,0047$

$-0,0076$

$-0,0122$

$-0,0169$

$-0,0032$

$-0,0032$

$-0,0048$

$-0,0069$

$-0,0113$

$-0,0151$

$-0,0199$

(D) 0,0153

$-0,0070$

0,0060

0,0065

0,0051

0,0031

$-0,0008$

$-0,0039$

$-0,0078$

$-0,0113$

$c$

coef $_{\mathrm{M}}$

$-0,1528$

$-0,1022$

$-0,0602$

$-0,0285$

$-0,0070$

0,0129

0,0148

0,0021

$-0,0235$

$-0,0725$

$-0,0439$

$-0,0223$

$-0,0081$

0,0032

0,0014

$-0,0124$

$-0,0348$

$-0,0461$

$-0,0297$

$-0,0176$

$-0,0105$

$-0,0081$

$-0,0136$

$-0,0284$

0,0029

0,0014

$-0,0011$

$-0,0036$

$-0,0077$

$-0,0106$

$-0,0141$

$-0,0169$

$-0,0480$

$-0,0273$

$-0,0247$

$-0,0185$

$-0,0150$

$-0,0148$

$-0,0208$

$-0,0300$

$-0,0460$

$0,0000 \quad-0,0040$

$-0,0017$

$-0,0054$

$-0,0087$

$-0,0116$

$-0,0158$

$-0,0186$

$-0,0218$

$-0,0040$

$-0,0094$

$-0,0110$

$-0,0152$

$-0,0211$

$-0,0348$

$-0,0474$

$-0,0647$

(B) 0,0206

$-0,0803$

coef $_{\mathrm{M}}$

0,0000

0,0201

0,0294

0,0319

0,0303

0,0215

0,0110

$-0,0059$

$-0,0241$

0,0000

0,0149

0,0199

0,0193

0,0157

0,0056

$-0,0047$

$-0,0199$

$-0,0353$

0,0000

0,0086

0,0086
0,0086

0,0048

$-0,0005$

$-0,0120$

$-0,0219$

$-0,0356$

$-0,0484$

(C) 0,0563

0,0000

0,0010

$-0,0042$

$-0,0111$

$-0,0181$

$-0,0307$

$-0,0405$

$-0,0528$

$-0,0635$

$\mathrm{M}^{-}$max

(E) $-0,1128$

(E) $-0,4569$

$-0,0079$

$-0,0182$

$-0,0279$

$-0,0365$

$-0,0502$

$-0,0599$

$-0,0714$

$-0,0806$ 


\section{B.1. INTRODUÇÃO}

Há muito tempo, interpretações superficiais e equivocadas sobre afirmações, muito provavelmente feitas por operários, de que "AS ARMADURAS CRESCEM DURANTE OS SEUS DOBRAMENTOS", vêm sendo aceitas e indevidamente divulgadas entre muitos projetistas e construtores de obras em concreto armado.

Várias publicações nacionais editadas nos últimos anos fazem uma abordagem superficial do problema e apresentam tabelas como valores dos "COMPRIMENTOS

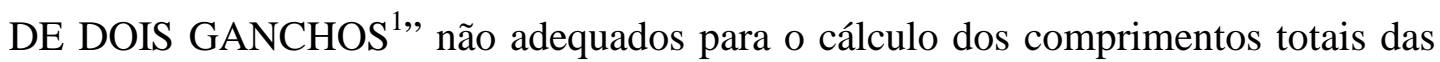
barras dobradas. Estes valores levam os projetistas a especificarem comprimentos maiores para estas barras, principalmente no caso de estribos.

Assim, é comum encontrar nas construções estribos dobrados com pontas retas excessivas, como na figura B.1.

Algumas daquelas publicações chegam até a justificar estes excessos dos comprimentos, que se notam apenas após os dobramentos, como consequiência de um “ALONGAMENTO PLÁSTICO” sofrido pelas armaduras.

\footnotetext{
${ }^{1}$ Melhor seria a denominação de CORREÇÃO DO COMPRIMENTO de uma barra dobrada.
} 

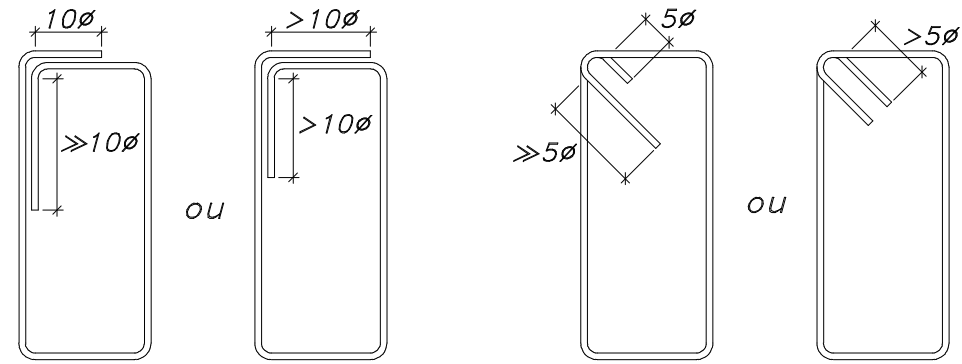

Figura B.1 - Casos comuns de estribos dobrados encontrados nas construções.

É evidente que esta justificativa para os "CRESCIMENTOS DAS ARMADURAS” durante os dobramentos não está correta ${ }^{2}$. Nestas operações as barras se deformam sob a ação apenas de MOMENTOS que provocam deformações plásticas antimétricas ao longo das seções das mesmas. As deformações residuais, também antimétricas, que resultam destas deformações plásticas, são as responsáveis pelos trechos curvos que as barras apresentam após os dobramentos.

Por outro lado, estes trechos onde se aplicam os momentos de plastificação e se obtém as curvaturas são muito pequenos.

Assim, mesmo que fosse possível aplicar grandes trações com uma simples chave de dobramento manual, não se conseguiria qualquer alongamento plástico significativo nas barras dobradas.

Por exemplo, um estribo comum de $10 \mathrm{~mm}, \mathrm{CA}-50 \mathrm{~A}$ e ganchos de $45^{\circ}$, tendo em todos os seus dobramentos um comprimento curvo de $\ell=(3+2 \times 1,5) \pi \phi=188,5 \mathrm{~mm}$, se submetido a uma tração simples de $4000 \mathrm{kgf}$, teria um alongamento de $\Delta \ell=\frac{\mathrm{N} \ell}{\mathrm{SE}}=0,45 \mathrm{~mm}$ !

Sem contestar a extravagante tração considerada, mas apenas olhando o inexpressível valor deste alongamento, conclui-se que a justificativa do "crescimento das armaduras" por alongamento plástico é gratuita ou no mínimo completamente equivocada.

A explicação para estes "crescimentos" está simplesmente no fato de se usarem

${ }^{2}$ Se correto fosse tal absurdo, os ARMADORES não seriam mais encontrados nas obras, pois como verdadeiros FENÔMENOS HUMANOS estariam dando SHOWS em CIRCOS ou ENSAIANDO BARRAS em LABORATÓRIOS DE MATERIAIS DE CONSTRUÇÃO. 
tabelas erradas no cálculo dos comprimentos das armaduras dobradas.

Assim sendo, neste anexo é feita a análise geométrica correta para o cálculo dos comprimentos dos principais tipos de estribos e de barras, fornecendo no final tabelas para serem usadas pelos projetistas no cálculo dos comprimentos das armaduras dobradas (tabelas B.2 e B.3 do item B.5).

Também são dadas tabelas para o cálculo dos gabaritos dos TAMANHOS das armaduras, com sugestões para o dobramento manual de estribos e de barras (Tabelas B.4 e B.5 do item B.5).

Finalmente, neste item B.1 e no item B.2 seguinte, serão introduzidos conceitos, definições e classificações originais, com a finalidade de facilitar a exposição feita no item B.4 das deduções das fórmulas dos comprimentos de vários tipos de estribos e de barras dobradas. 


\section{B.1.1. ARMADURAS EXISTENTES E UTILIZADAS NAS CONSTRUÇÕES DAS ESTRUTURAS DE CONCRETO ARMADO}

As armaduras utilizadas nas estruturas de concreto armado, são:

FIOS.......... São armaduras trefiladas fornecidas nas obras em rolos. Encontram-se mais facilmente na categoria CA-60B com comprimento de $60 \mathrm{~m}$.

BARRAS ${ }^{3} \ldots$ São as armaduras laminadas que pela NBR 7480 devem ser fabricadas com 11,00 m de comprimento, com uma tolerância de $9 \%$ para mais ou para menos. Comumente são mais encontradas as barras com 12,00 m de comprimento.

São especificadas nas categorias CA-25A, CA-40A e B, CA-50A e B e CA-60B. Entretanto por razões didáticas e também por serem pouco usadas, não se fará mais aqui, qualquer menção aos aços CA-25A e CA-40A e B.

Finalmente as bitolas fabricadas para fios e barras com as respectivas áreas e pesos por metro linear são apresentados na tabela AN1.

Obs. É interessante observar que as áreas e os pesos se repetem, a menos de potências de 10 , de cinco em cinco valores.

${ }^{3}$ Neste texto, da NBR 7480, a palavra BARRA é usada com o significado de elemento linear de aço reto e não muito longo, se contrapondo com FIOS que já dá a idéia de elemento linear de aço longo e enrolado.

A NBR 6118 também se utiliza deste mesmo significado, em 7.1 "Qualidade. Somente barras e fios de aço...".

Entretanto, é bom chamar a atenção para o fato de que na NBR 6118 a palavra BARRA é usada ainda com mais três outros significados, porém sem deixar dúvidas devido ao contexto em que nela aparece. O seu segundo sentido aparece muito no item 6, por exemplo em 6.3.1.1 "Lajes. O diâmetro das barras não deve ultrapassar 1/10 da espessura da laje." Nele, a palavra BARRA é usada com o significado genérico de uma armadura, sem qualquer alusão ao processo construtivo e à forma de como é fornecida na obra.

Ainda, um terceiro uso desse termo BARRA, aparece, por exemplo, nos itens 6.3.4.1 e 6.3.4.2, porém, usado com a finalidade de separar as armaduras em dois subconjuntos: o dos estribos e o das barras, representando este último o subconjunto das demais armaduras, que não seja um estribo.

Finalmente, já não mais se referindo a armadura, um quarto e último uso do termo BARRA é empregado várias vezes quando aquela norma quer se referir, indistintamente, às vigas e aos pilares, como por exemplo, em seus itens 4.1.1.3 e 4.2.3.1. 
Exemplo:
$\phi 3,2$
$\mathrm{A}=0,08 \mathrm{~cm}^{2}$
$\mathrm{p}=0,063 \mathrm{~kg} / \mathrm{m}$
$\phi 10$
$\mathrm{A}=0,80 \mathrm{~cm}^{2}$
$\mathrm{p}=0,63 \mathrm{~kg} / \mathrm{m}$
$\phi 32$
$\mathrm{A}=8,00 \mathrm{~cm}^{2}$
$\mathrm{p}=6,3 \mathrm{~kg} / \mathrm{m}$

\section{B.1.2. TIPOS DE ARMADURAS DOBRADAS}

Do ponto de vista de dobramento pode-se dividir as armaduras em cinco grupos:

a) Estribos;

b) Armaduras de vigas e lajes;

c) Armaduras dobradas em lajes e paredes;

d) Armaduras dobradas em nós de pórticos

e) Armaduras com dobras e ganchos não comuns, ou seja, todas as armaduras com dobras e/ou ganchos que não se enquadram nos quatro grupos de armaduras acima!

\section{B.2. DEFINIÇÕES, CLASSIFICAÇÕES E CONCEITOS REFERENTES AOS DOBRAMENTOS DAS AR- MADURAS}

Adotando aqui o terceiro significado da palavra BARRA conforme nota de rodapé 3 do item 1.1 deste anexo, separar-se-ão as armaduras dobradas em dois conjuntos: o dos ESTRIBOS e o das BARRAS.

Apresentar-se-ão as especificações dos itens 6.3.4.1 e 6.3.4.2, separadamente para os estribos e para os ganchos, visando contornar a ligeira confusão que estes dois itens da NBR 6118 apresentam.

Ainda, por razões didáticas, tratar-se-ão apenas dos estribos com diâmetros não 
superiores a $10 \mathrm{~mm}$. Estribos com diâmetros maiores já são menos comuns e suas inclusões aumentariam em muito as análises, as fórmulas e as tabelas, prejudicando a clareza das idéias que se pretende expor neste anexo.

Também, pelas mesmas razões didáticas, será considerado apenas o aço CA50, uma vez que a quase totalidade dos projetos são feitos com aços desta categoria.

Aos engenheiros que precisarem utilizar qualquer tipo de armadura não analisada aqui, recomenda-se seguir a seqüência apresentada neste trabalho, porém trocando os valores dos diâmetros de dobramento de acordo com a categoria e diâmetro do aço por eles empregados, especificados naqueles dois itens da NBR 6118.

\section{B.2.1. GANCHO}

É a dobra que se faz numa extremidade de uma armadura com a finalidade de melhorar a sua ancoragem no concreto.

São compostos de duas partes. Uma parte reta já denominada pela NBR 6118 de PONTA RETA, com o seu comprimento aqui designado de $\mathrm{p}_{\alpha}$ (segmento $\mathrm{AE}_{1}$ ) e de uma parte circular denominada aqui de CURVA DO GANCHO ou simplesmente CURVA, com o comprimento ao longo do seu eixo designado por $\mathrm{C}_{\alpha}$ (arcos de circunferências $\left.E_{1} E_{2}\right)$. Ainda, este arco é tangente no ponto $E_{1}$ à ponta reta bem como tangente no ponto $\mathrm{E}_{2}$ à parte restante da armadura a qual o gancho pertence.

Assim, se se designar por $\mathrm{g}_{\alpha}$ o comprimento de um gancho ao longo do seu eixo, pode-se escrever: $g_{\alpha}=p_{\alpha}+C_{\alpha}$.

Ainda, conforme os ângulos de dobramentos e de acordo com as denominações do item 6.3.4.1 da NBR 6118, os ganchos podem ser: de $90^{\circ}$, de $45^{\circ}$ (dobramento de $135^{\circ}$ ) e semicirculares (dobramento de $180^{\circ}$ ).

Finalmente, e de acordo ainda com esse mesmo item da norma, os valores das pontas retas, dos raios mínimos de dobramentos e dos trechos circulares correspondentes a cada um dos ganchos são indicados na figura B.2. 

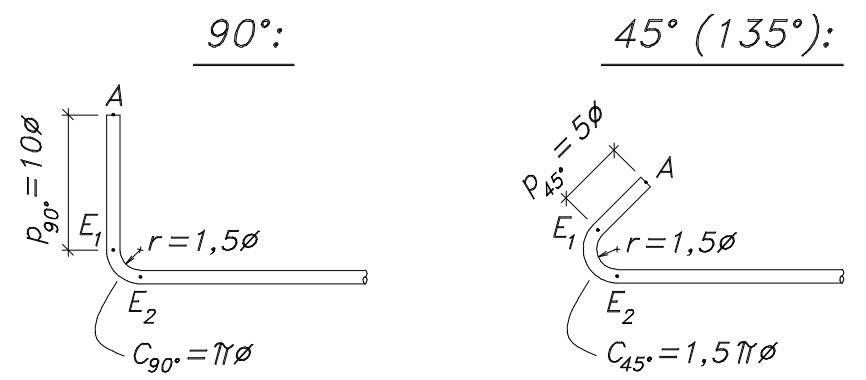

semicircular $\left(180^{\circ}\right)$ :

a) Para os estribos (para $\phi \leq 10 \mathrm{~mm}$ )
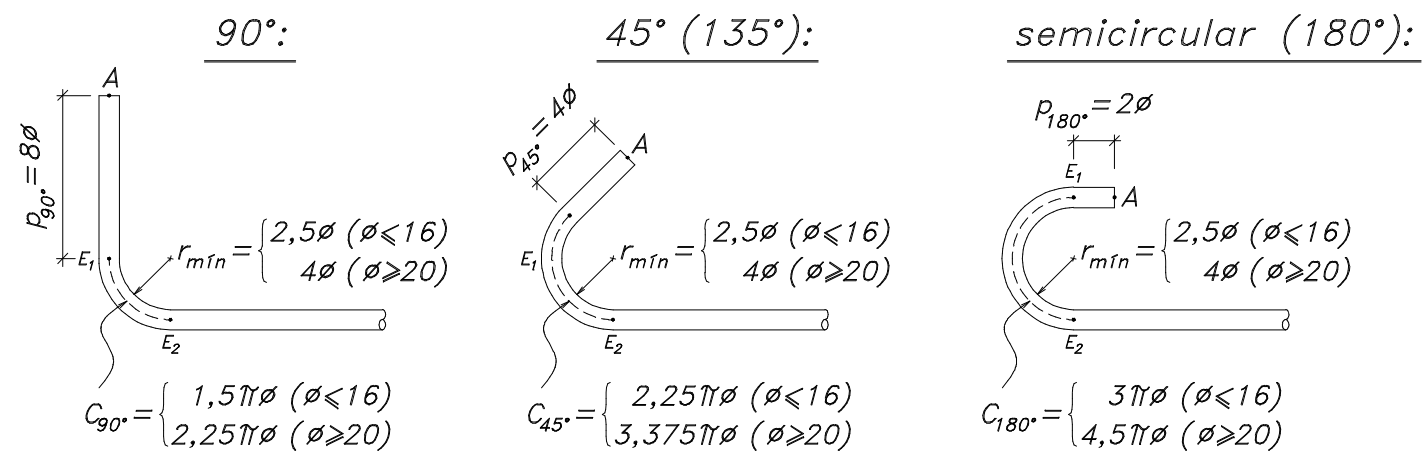

b) Para as barras (para CA-50)

Figura B.2 - Valores normalizados para pontas retas, raios mínimos de dobramentos e trechos circulares

\section{B.2.2. DOBRA DE UM ARMADURA}

\section{B.2.2.1. Curva de uma dobra}

Nos estribos e nos projetos das ligações entre paredes, entre paredes e lajes, entre lajes e vigas e entre vigas e pilares, existe sempre a necessidade de se dobrar armaduras com um certo ângulo, em geral de $90^{\circ}$.

Cada uma destas dobras divide as armaduras em dois trechos retos ligados por um trecho circular denominado aqui de CURVA DE UMA DOBRA ou simplesmente de CURVA. Este trecho circular é tangente aos dois trechos retos e o seu comprimento ao longo do eixo será designado genericamente também por $\mathrm{C}_{\alpha}$, como no caso dos ganchos. 
Assim sendo, ainda de acordo com os itens 6.3.4.1 e 6.3.4.2, tem-se os casos indicados na figura B.3.

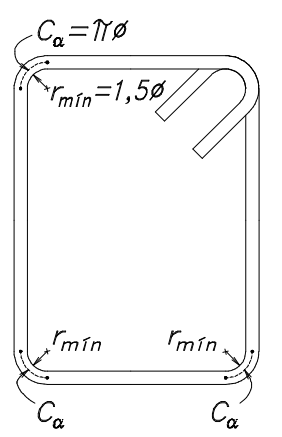

a) Para os estribos com $\phi \leq 10$
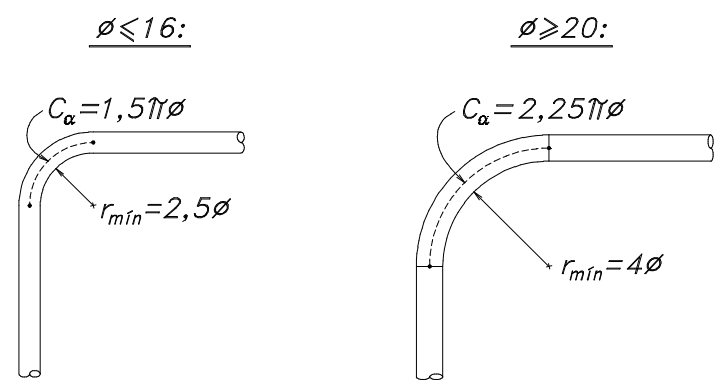

b) Para barras não tracionadas, tracionadas com tensões baixas e para barras com $\phi \leq 10$ qualquer que seja a tensão

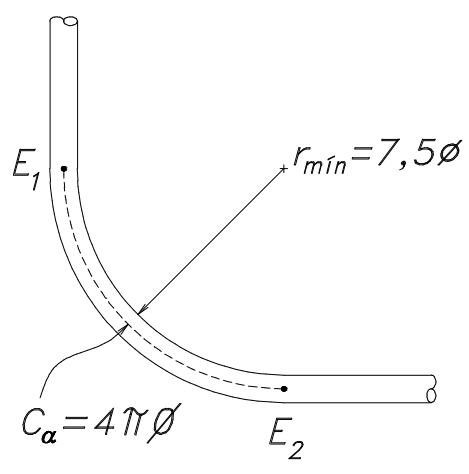

c) Para as barras tracionadas com tensão $\sigma_{\mathrm{s}} \approx \mathrm{f}_{\mathrm{yd}}$ e $\phi \geq 12,5$

Obs.:

Se $\sigma_{\mathrm{s}}<\mathrm{f}_{\mathrm{yd}}, \mathrm{r}_{\text {mín }}$ pode ser reduzido proporcionalmente, ou seja, $\mathrm{r}_{\text {mín }} \geq \frac{\sigma_{\mathrm{s}}}{\mathrm{f}_{\mathrm{yd}}} \cdot 7,5 \phi$.

Entretanto, esta redução, não poderá levar os limites mínimos a valores inferiores aos exigidos para os ganchos, ou seja, $(4 \phi) 2,5 \phi \leq \mathrm{r}_{\text {mín }} \leq 7,5 \phi$.

Figura B.3 - Curvas e raios mínimos de uma dobra de estribos e barras. 


\section{B.2.2.2. Trechos retos de uma dobra}

Uma armadura pode ter uma, duas, ou mais dobras e conseqüentemente o mesmo número de curvas (Figura B.4).
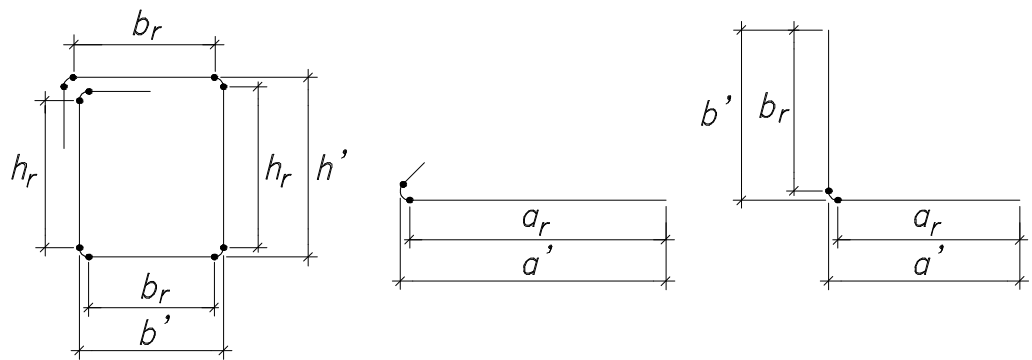

Figura B.4 - Exemplos de dobras comumente encontradas.

Separados por estas curvas, sobram segmentos retos denominados de TRECHOS RETOS $^{4}$ e designados por $\mathrm{a}_{\mathrm{r}}, \mathrm{b}_{\mathrm{r}}, \mathrm{c}_{\mathrm{r}}, \ldots, \mathrm{h}_{\mathrm{r}}$, etc. Ainda, tratar-se-ão aqui apenas das dobras de $90^{\circ}$ que, por serem quase a totalidade dos casos existentes, justificam por si só esta simplificação.

\section{B.2.3. TAMANHO DE UM TRECHO RETO}

Define-se como sendo a distância entre as tangentes externas às curvas das duas extremidades, perpendiculares ao trecho reto correspondente. Quando um trecho reto não apresenta dobras em uma das suas extremidades, o seu TAMANHO é a distância dessa extremidade à tangente externa a curva da outra extremidade, perpendicular a este trecho reto.

Em lugar de TAMANHO, conforme o tipo e a posição da armadura dobrada são empregadas também as palavras LARGURA e ALTURA.

É facilmente calculado conhecendo-se o tamanho da peça de concreto na direção do trecho reto $(a, b, c, \ldots)$, os cobrimentos mínimos adotados $\left(c_{\text {mín }}\right)$ e, se existir,

4 De pouca ocorrência mas pode-se ter armaduras circulares com ganchos nas extremidades. Nestes casos por trechos retos devem-se entender trechos circulares de diâmetros muito maiores do que os das curvas dos ganchos. 
o diâmetro $\phi^{\prime}$ de barras mais externas à barra em questão.

Serão designados aqui por a', b', c',... em correspondência aos tamanhos das peças de concreto que juntamente com os comprimentos das armaduras são as medidas normalmente fornecidas na maioria dos desenhos de concreto armado.
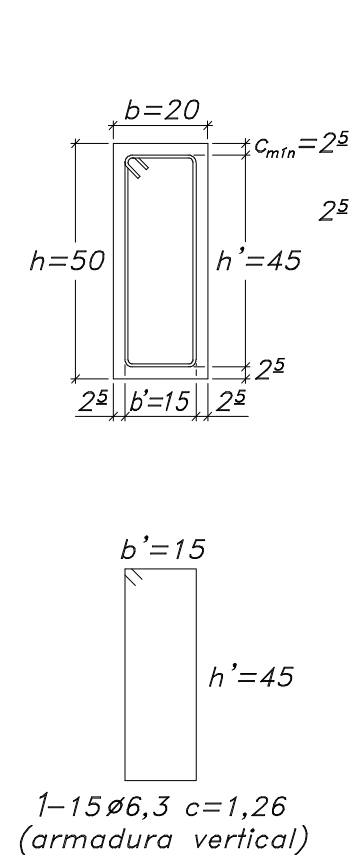

(a) Estribo de uma viga de $20 / 50$ com $15 \mathrm{~cm}$ de largura e $45 \mathrm{~cm}$ de altura.
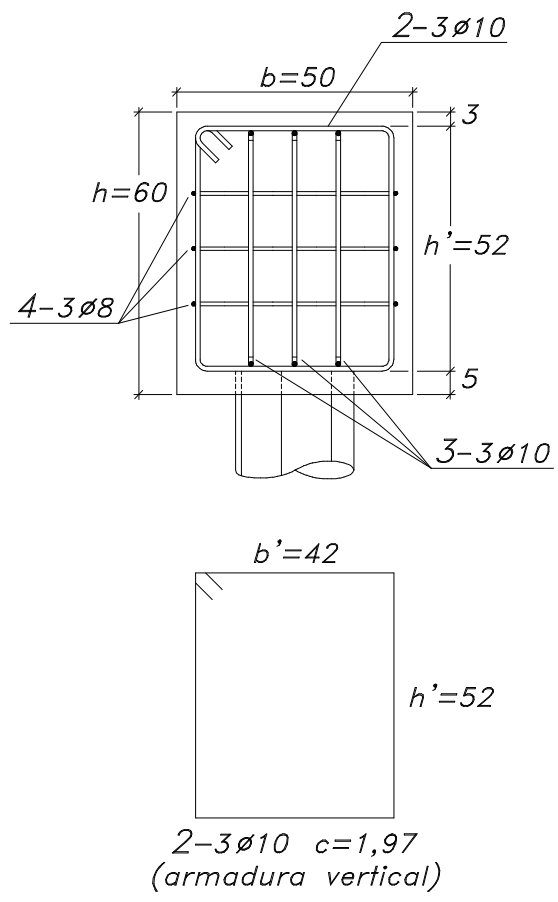
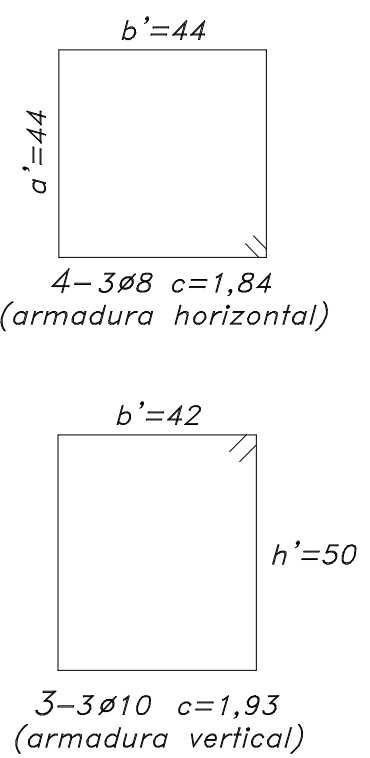

(b) Armaduras de bloco de 50/50/60 com cobrimentos de $5 \mathrm{~cm}$ no fundo e $3 \mathrm{~cm}$ nas demais faces:

Armadura no 2: $42 \mathrm{~cm}$ de largura e $52 \mathrm{~cm}$ de altura;

Armadura $\mathrm{n}-3: 42 \mathrm{~cm}$ de largura e $50 \mathrm{~cm}$ de altura;

Armadura no 4: $44 \mathrm{~cm}$ de largura nas duas direções.

20

2,95

$5-2 \not 12,5 \quad c=3,29$

(c) Armadura positiva de uma viga de $3 \mathrm{~m}$ de comprimento com cobrimento de 2,5 $\mathrm{cm}$ ! Esta armadura tem de tamanho $2,95 \mathrm{~m}$ e $20 \mathrm{~cm}$ de altura nas extremidades.

Figura B.5 - Exemplos de três tipos de armaduras como usualmente são desenhadas, com seus tamanhos e seus comprimentos totais. Observe-se que na figura (c), o comprimento total é inferior a soma dos tamanhos dos seus três trechos retos, o que está geometricamente correto. 


\section{B.2.4. DESCONTO DE UM TRECHO RETO $(\Delta)$}

Finalmente, definir-se-á como DESCONTO para o cálculo do comprimento de um trecho reto de um armadura dobrada, como sendo a distância de um dos pontos de tangência desse trecho reto até a tangente externa à curva correspondente, traçada perpendicularmente a este trecho.

O desconto, designado aqui por $\Delta$, pode ser usado, se houver interesse, no cálculo do comprimento dos trechos retos, mas o seu uso será imprescindível na obra para o cálculo dos gabaritos ${ }^{5}$ dos TAMANHOS das armaduras a serem dobradas.

Conforme os trechos retos tenham CURVAS numa ou nas duas extremidades, as relações entre os comprimentos dos trechos retos $\left(a_{r}, b_{r}\right.$, etc. ) e os seus TAMANHOS (a', b', etc.) são, respectivamente $a_{r}=a^{\prime}-\Delta$ ou $a_{r}=a^{\prime}-2 \Delta$.

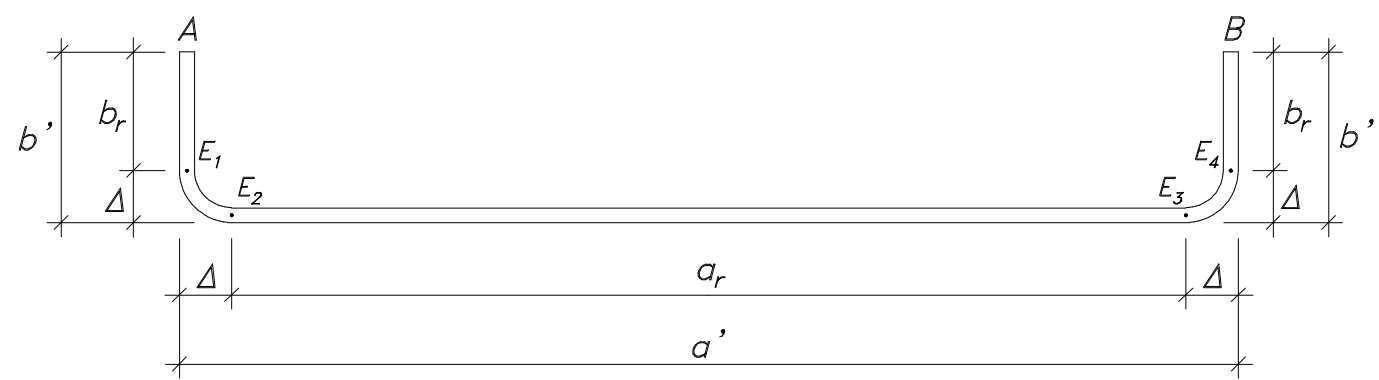

Figura B.6 - Armadura usada em blocos sobre estacas, em vigas, em paredes de reservatórios, etc., onde $a_{r}=a^{\prime}-2 \Delta$ e $b_{r}=b^{\prime}-\Delta$.

\section{B.2.5. GABARITOS UTILIZADOS NA OPERAÇÃO DE DO- BRAMENTO DE UMA ARMADURA}

A rigor as armaduras podem ser dobradas de dois modos:

- Com uso de uma chave especial, as armaduras são dobradas manualmente em torno de um pino, sobre uma mesa comumente chamada de bancada de dobramento.

- Com máquinas de dobrar armaduras.

\footnotetext{
${ }^{5}$ Ver item A.2.5, apresentado a seguir.
} 
Deixando para os manuais das máquinas as explicações dos seus dobramentos, fornecer-se-ão aqui apenas as explicações e os detalhes para os dobramentos manuais feitos pelos armadores com as suas chaves e em torno do pino de dobramento.

De uma maneira geral, no projeto estrutural de uma obra existem sempre muitas armaduras iguais para serem dobradas, como por exemplo as armaduras das lajes, das paredes e principalmente dos estribos. Recorre-se então a marcas feitas sobre as bancadas que dispensam as marcações de todos os pontos de tangência de uma armadura que, no caso de estribos comuns, são em número de dez.

Elas são feitas sobre a bancada de dobramento, porém somente uma vez para o mesmo tipo de armadura.

As distâncias destas marcas ao pino de dobramento denominam-se GABARITOS DOS TAMANHOS das armaduras e podem ser de dois tipos, conforme a sua marcação seja à esquerda ou à direita do referido pino.

Define-se então por GABARITO À ESQUERDA DO TAMANHO a' de um trecho de armadura dobrada como sendo a diferença $\mathrm{a}^{\prime}-\Delta$ onde $\Delta$ é o DESCONTO, já definido no item anterior.

Designando essa grandeza por $\operatorname{gab}_{\mathrm{e}} \mathrm{a}^{\prime}$, tem-se $\mathrm{gab}_{\mathrm{e}} \mathrm{a}^{\prime}=\mathrm{a}^{\prime}-\Delta$ que é a distância a ser marcada na bancada de dobramento, a partir do pino de dobramento e à sua esquerda.

As figuras B.7a e B.7b mostram respectivamente as posições do quarto e quinto (e último) dobramento de um estribo comum, segundo uma seqüência de dobramentos usada pelos armadores. O gabarito da figura B.7c já é indicado para barras com trechos a' e b' grandes.

As marcações destes gabaritos nas bancadas são feitas com riscos de giz ou com pregos, sendo preferível esta última por possibilitar maior velocidade e eficiência no dobramento.

Define-se GABARITO À DIREITA DO TAMANHO b' de um trecho de armadura dobrada pequena, às expressões: para trechos retos pequenos $\mathrm{gab}_{\mathrm{d}} \mathrm{b}^{\prime}=\mathrm{b}^{\prime}-\Delta+\mathrm{C}_{\alpha}$ onde $\Delta$ e $_{\alpha}$ são respectivamente o desconto e o comprimento da curva. 

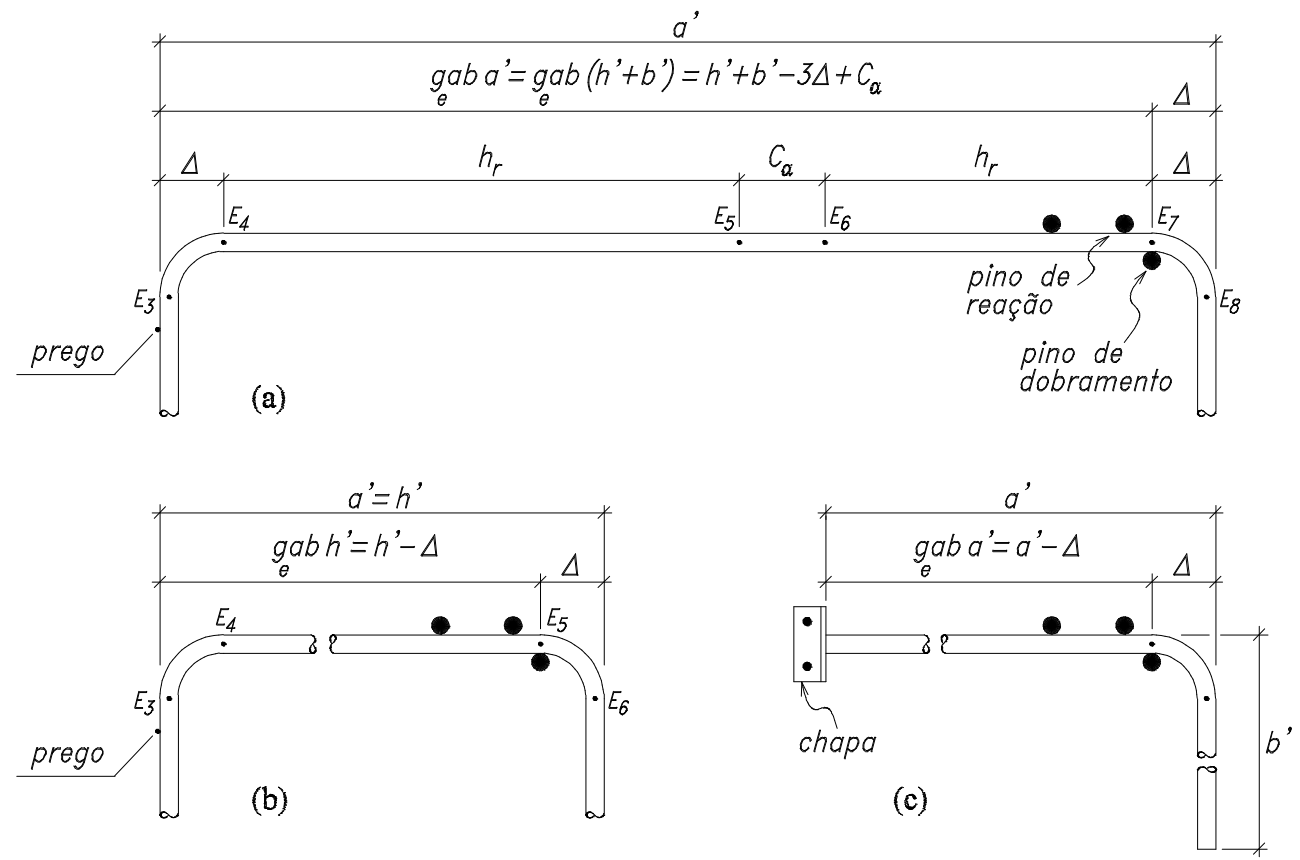

Figura B.7 - Exemplos de alguns gabaritos à esquerda, mais comuns, de trechos de armaduras dobradas.

Já para os dobramentos dos ganchos, os gabaritos são os seus próprios comprimentos, ou seja, designando-os por gab $\mathrm{g}_{\alpha}$, tem-se $\mathrm{gab}_{\mathrm{d}} \mathrm{g}_{\alpha}=\mathrm{p}_{\alpha}+\mathrm{C}_{\alpha}$ onde $\mathrm{p}_{\alpha}$ e $\mathrm{C}_{\alpha}$ são respectivamente a ponta reta e o comprimento da curva do gancho (Figura B.8).

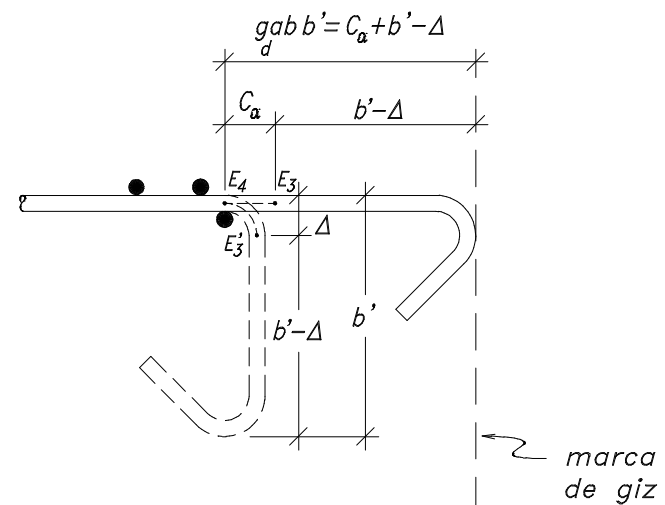

(a) gabarito à direita para valores pequenos de b' como por exemplo o lado menor da grande maioria dos estribos.

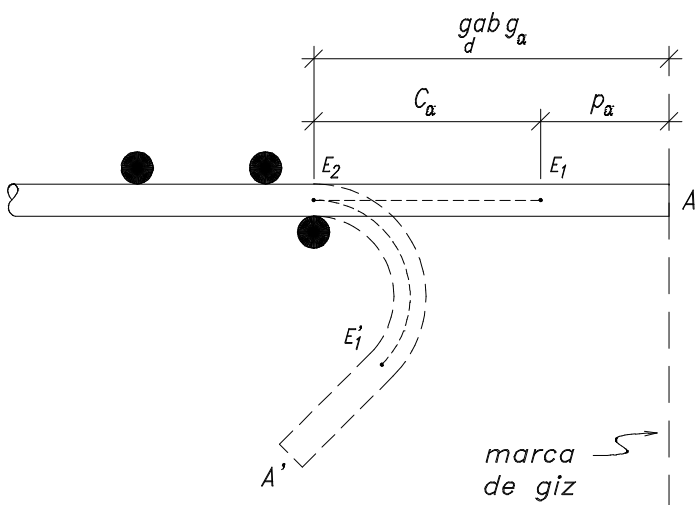

(b) gabarito à direita para dobramentos dos ganchos.

Figura B.8 - Exemplos de alguns gabaritos à direita mais comuns de trechos de armaduras dobradas. 
Estes dois tipos de gabaritos são marcados na bancada, a partir e à direita do pino de dobramento, com giz.

Para eles uma marcação saliente com pregos ou chapas não seria possível pois atrapalhariam os movimentos das armaduras durante as operações de dobramentos.

Finalmente, para efetuar um dobramento é necessário estudar a armadura a ser dobrada e escolher para ela a sequiência de operação mais eficiente possível.

Para exemplificar, dá-se como exemplo a sequiência de operações adotada pelos armadores para o dobramento de um estribo comum com ganchos de $45^{\circ}$ (Figura B.9).

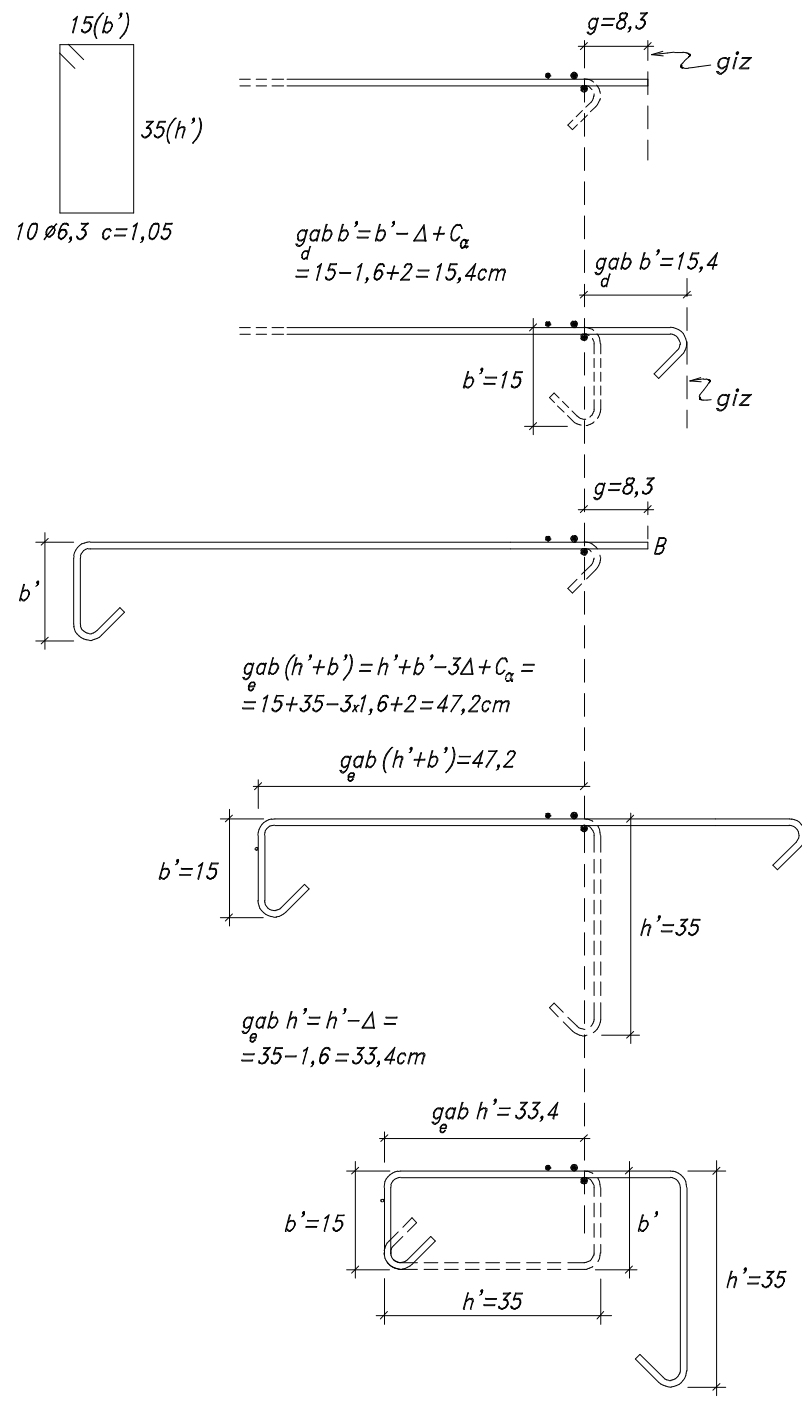

19 operação: cortar a armadura no comprimento $c=1,06 \mathrm{~m}$ e ajustá-la na posiçäo do $\underset{d}{\operatorname{dab} g=g}$ e dobrar o primeiro gancho;

2a operação: deslocar a armadura para a direita do valor gabb' e dobrar o lado menor b';

3a operação: virar a armadura de 180, posicionar a outra extremidade reta no gabg e dobrar o segundo gancho;

4q operação: apoiar o lado menor b' no prego do gab $\left(h^{\prime}+b^{\prime}\right)$ e efetuar o dobramento obtendo o lado maior h';

Figura B.9 - Seqüência das operações para dobrar um estribo, adotada pelos armadores. 


\section{B.2.6. POSIÇÃO DA CHAVE EM RELAÇÃO AO PINO DE DOBRAMENTO}

De início, tem-se que separar as armaduras em dois grupos. O dos estribos e os das barras.

a) Estribos $(\phi \leq 10)$

O dobramento é feito de uma só vez, com a chave em uma única posição. O diâmetro do pino de dobramento e as dimensões x e y das chaves (Figura B.10) devem ser compatíveis com a bitola da armadura a ser dobrada.

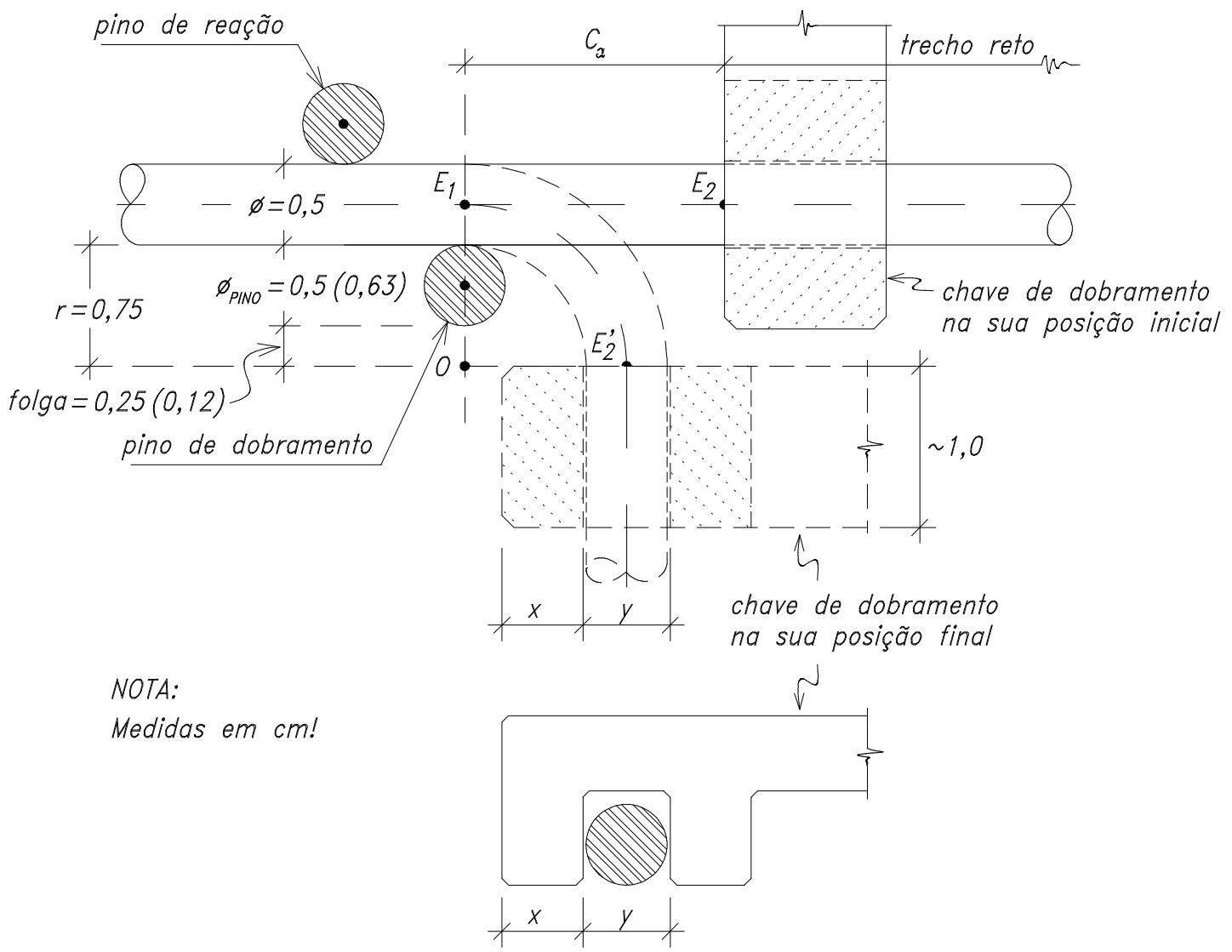

Figura B.10 - Orientação para o dobramento de estribos em uma só operação.

A chave de dobramento deve ser posicionada à direita do pino, com a face mais próxima distante deste um valor igual ao comprimento $\mathrm{C}_{\alpha}$ da curva a ser dobrada. 
Aqui, os diâmetros dos pinos de dobramento não devem ser muito superiores aos das armaduras a serem dobradas, pois a folga indicada no exemplo da figura B.10 poderá não existir, em face dos raios de curvaturas especificados para os estribos serem pequenos $\left(\mathrm{r}_{\text {mín }}=1,5 \phi\right)$.

\section{b) $\operatorname{Barras}(\phi \geq 8)$}

Dependendo do diâmetro da barra $\phi$ e do comprimento a ser dobrado $\left(E_{1} E_{2}\right)$, o dobramento poderá ser feito em uma, duas ou mais etapas, mudando em cada uma delas a posição da chave.

Assim sendo, as curvas das barras com $\phi \leq 10 \mathrm{~mm}\left(\mathrm{~d}_{\text {mín }}=5 \phi\right)$ poderão ser executadas por um armador experiente, de uma só vez, com a face esquerda da chave distante $\mathrm{C}_{\alpha}$ do eixo do pino de dobramento, como nos estribos (Figura B.11).

Já não há mais aqui qualquer preocupação com interferências entre os pinos e as chaves durante a operação de dobramento, por serem maiores que os raios especificados para as curvas das barras $\left(r_{\text {mín }}=2,5 \phi\right.$ e $\left.4 \phi\right)$.

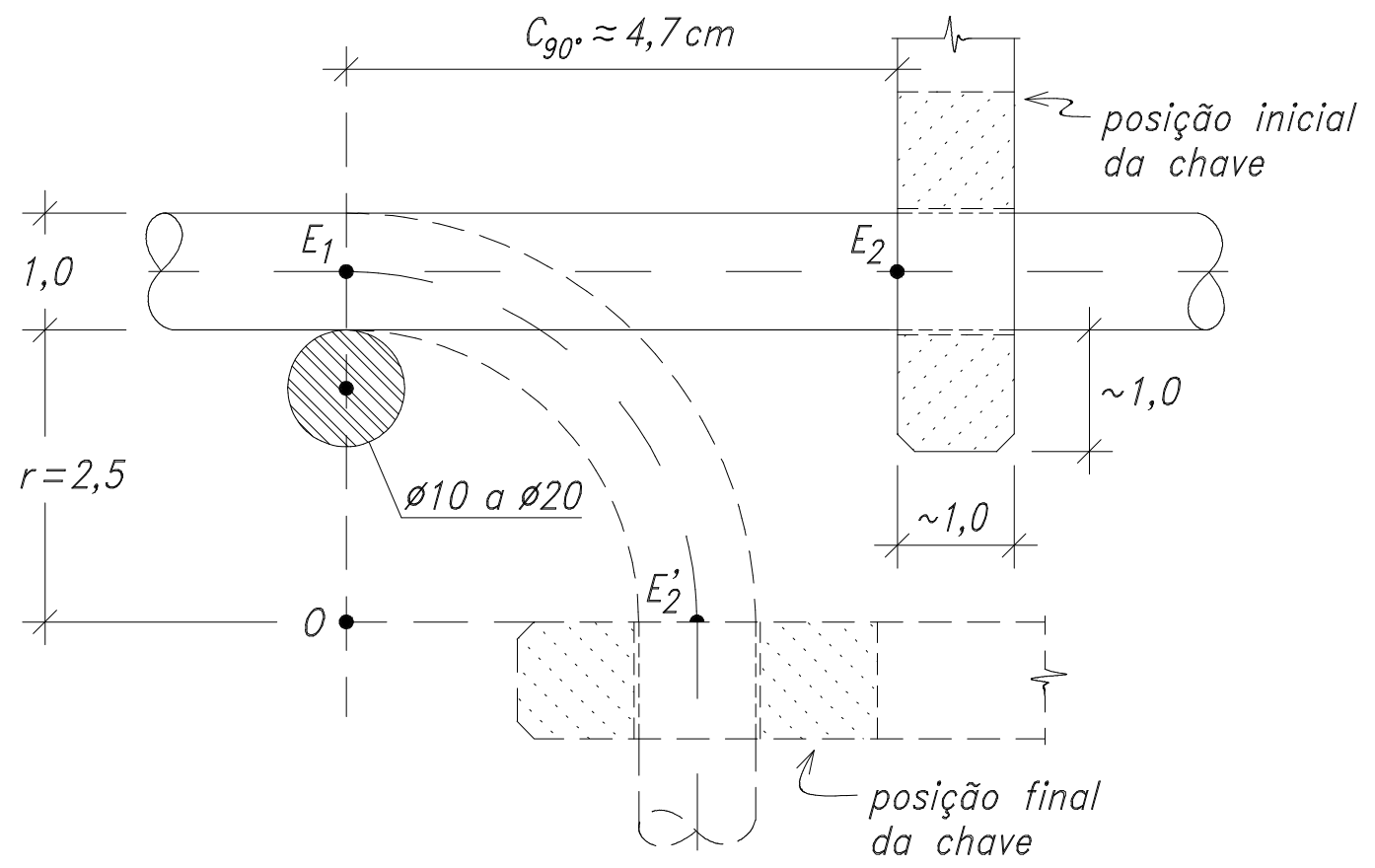

Figura B.11 - Dobramento de $90^{\circ}$ de uma barra de $1 \mathrm{~cm}$ de diâmetro, com indicação das posições iniciais e finais da chave durante a operação de dobramento. 
Por outro lado, para a execução das barras com $\phi \geq 12,5 \mathrm{~mm}\left(\mathrm{~d}_{\text {mín }}=5\right.$ e $\left.8 \phi\right)$ como também das curvas das barras tracionadas com tensões altas $\left(\mathrm{d}_{\text {mín }}=15 \phi\right)$, já são necessárias duas ou mais etapas em cada dobramento, dependendo da bitola e do comprimento a ser dobrado.

Para ilustrar o assunto, faz-se a seguir uma descrição das duas etapas do dobramento a $90^{\circ}$ com raio mínimo, de uma barra de $12,5 \mathrm{~mm}$ de diâmetro.

A escolha deste exemplo, com dobramento em duas etapas para simplificar os desenhos, não prejudica a generalidade do exemplo, uma vez que para qualquer outro número de etapas mudam-se apenas o comprimento a ser dobrado em cada etapa $\left(\frac{\mathrm{C}_{90^{\circ}}}{\mathrm{n}}\right)$ e o respectivo ângulo de dobramento $\left(\frac{90^{\circ}}{\mathrm{n}}\right)$.

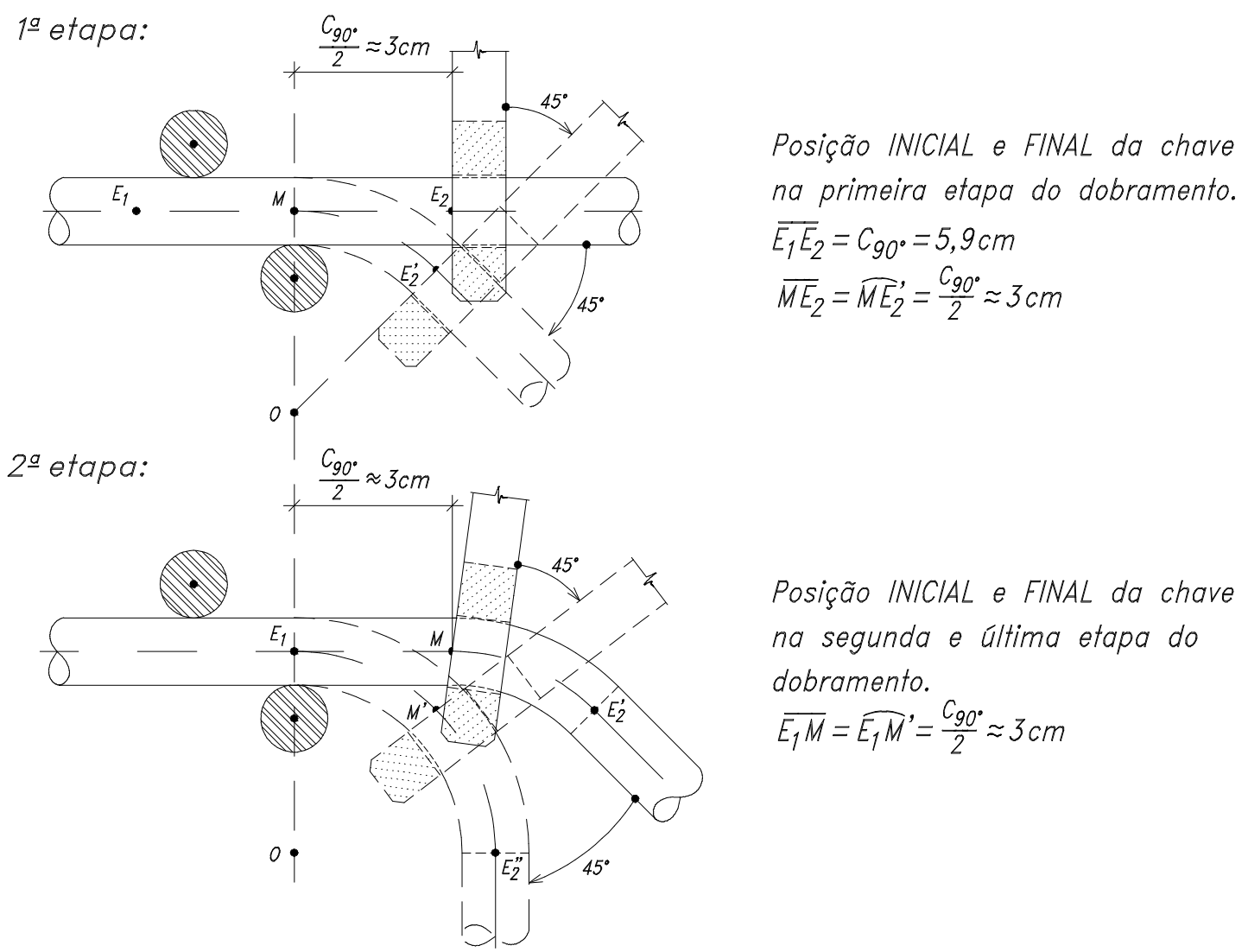

Figura B.12 - Dobramento a $90^{\circ}$, com raio mínimo e em duas etapas de uma barra de $\phi 12,5$. 
Na hipótese de se fazer esse dobramento em $\mathrm{n}$ etapas, tem-se que dobrar na primeira, o comprimento de $\frac{C_{90^{\circ}}}{n}$ com um ângulo de $\frac{90^{\circ}}{n}$, tomando-se o cuidado de iniciar a operação com a chave sempre no ponto $E_{2}$, à direita e distante $\frac{C_{90^{\circ}}}{n}$ do pino de dobramento.

Repete-se esta operação para cada uma das etapas intermediárias, deslocandose sempre a barra para a direita do valor $\frac{\mathrm{C}_{90^{\circ}}}{\mathrm{n}}$, até que o ponto $\mathrm{E}_{1}$ fique sobre o pino de dobramento, quando então se iniciará a última etapa.

Eventualmente pode ser útil como gabarito traçar linhas radiais saindo do pino de dobramento para baixo, com ângulos entre si de $\frac{90^{\circ}}{\mathrm{n}}$, para que com o paralelismo se possa orientar os dobramentos de cada etapa, procurando obter assim uma curva mais próxima possível de um arco de circunferência.

Apresenta-se, a seguir, um exemplo de dobramento de barra onde as curvas são feitas em três etapas.

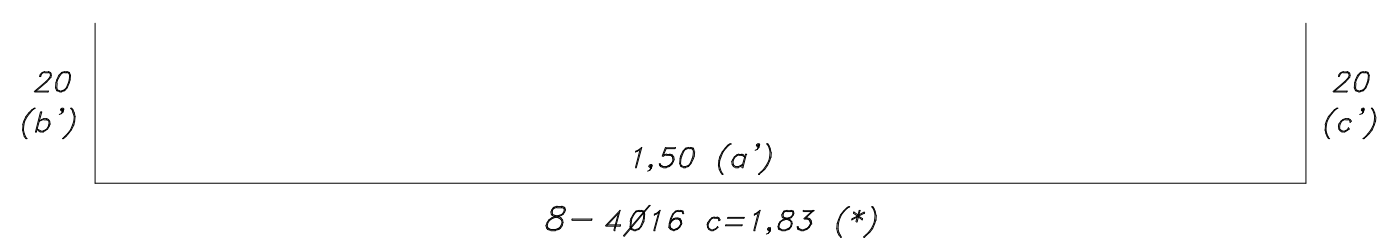

Figura B.13 - Exemplo de uma armadura dobrada, desenhada no SISTEMA SIMPLIFICADO ${ }^{6}$.

Assim sendo, para o dobramento desta armadura (Figura B.13) deve-se obedecer o seguinte roteiro:

(*) Note-se que o comprimento total "c" da armadura é inferior à soma dos seus TAMANHOS a', b' e c', ou seja, $190-183=7 \mathrm{~cm}$. Esse valor é o erro que se comete quando se trocam os arcos $\left(\mathrm{C}_{90^{\circ}}\right)$ pelas tangentes $(\Delta)$, ver tabelas:

Erro $=2\left(2 \Delta-\mathrm{C}_{90^{\circ}}\right)=4 \Delta-2 \mathrm{C}_{90^{\circ}}=4 \times 5,6-2 \times 7,5=7,4 \mathrm{~cm}$ !

6 Ver item AP.3.2 deste apêndice. Neste sistema de desenho, quando não se especificam raios ou diâmetros de dobramentos, é para se considerar como sendo os seus valores mínimos. 
- Definição do número de etapas necessárias em cada curva.

Embora as curvas não sejam muito grandes $\left(\mathrm{C}_{90^{\circ}}=7,5 \mathrm{~cm}\right)$, mas sendo a bitola um pouco grossa $(\phi 16)$, é bom dobrar cada uma das curvas desta armadura em pelo menos três etapas cada uma.

- Seqüência dos dobramentos.

Como nesta armadura só existem duas curvas e simétricas, não há uma sequiência de dobramento preferencial a escolher. Começa-se por qualquer uma das curvas.

- Escolha e cálculo dos gabaritos

Já neste item e para esta armadura, opta-se pelos GABARITOS À DIREITA PARA TRECHOS RETOS PEQUENOS, ou seja,

$1 \stackrel{\mathrm{o}^{\prime}}{\mathrm{gab}_{\mathrm{d}}} \mathrm{b}^{\prime}=\mathrm{b}^{\prime}-\Delta+\frac{\mathrm{C}_{\alpha}}{\mathrm{n}}$ e $2 \stackrel{\mathrm{o}}{\mathrm{gab}_{\mathrm{d}}} \mathrm{a}^{\prime}=\frac{\mathrm{C}_{\alpha}}{\mathrm{n}}$.

Da tabela 5 têm-se:

1 o $\mathrm{gab}_{\mathrm{d}} \mathrm{b}^{\prime}=20-5,6+\frac{7,5}{3}=\underline{\underline{16,9 \mathrm{~cm}}} \mathrm{e}$

$2 \underline{\mathrm{o}} \mathrm{gab}_{\mathrm{d}} \mathrm{b}^{\prime}=\frac{7,5}{3}=\underline{\underline{2,5 \mathrm{~cm}}}$

A posição inicial das chaves nas três etapas do dobramento de cada curva é uma só, tendo como gabarito o mesmo do segundo gabarito de b', ou seja, $\operatorname{gab}_{\mathrm{d}}$ chave $=\frac{\mathrm{C}_{90^{\circ}}}{3}=2,5 \mathrm{~cm}$. As posições finais do trecho reto serão controladas por gabaritos radiais inclinados em relação à posição inicial da armadura, de $30^{\circ}$, $60^{\circ}$ e $90^{\circ}$.

- Marcação dos gabaritos na bancada e etapas de dobramento de uma das curvas (para a segunda curva, vira-se a armadura e repetem-se as operações indicadas na figura B. 14) 
1. etapa: $\operatorname{gab}_{\mathrm{d}}$ chave $=2,5 \mathrm{~cm}$ e $\operatorname{gab}_{\mathrm{d}} \mathrm{b}^{\prime}=16,9 \mathrm{~cm}$

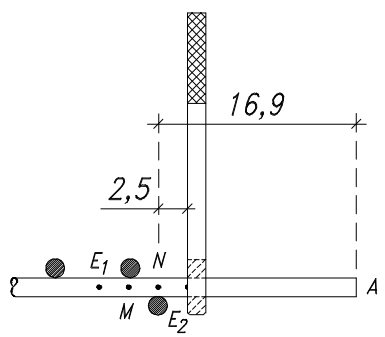

(a) Posição inicial

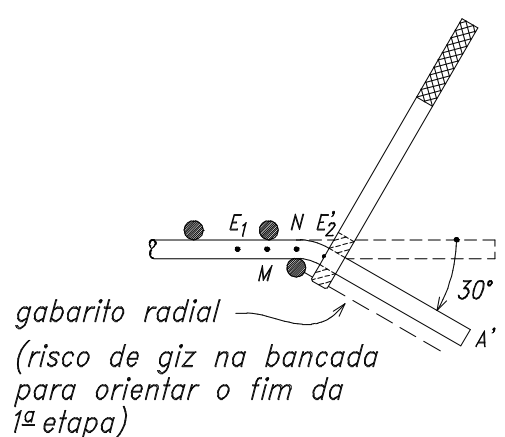

(b) Posição final

2. etapa: Após deslocar a barra para a direita de $\frac{C 90^{\circ}}{3}=2,5 \mathrm{~cm}$ e usando $\mathrm{gab}_{\mathrm{d}}$ chave $=2,5 \mathrm{~cm}$ e 2o $\mathrm{gab}_{\mathrm{d}} \mathrm{b}^{\prime}=2,5 \mathrm{~cm}$, tem-se:

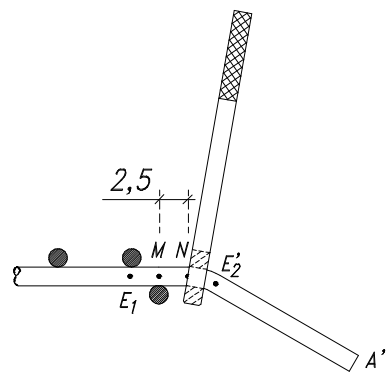

(c) Posição inicial

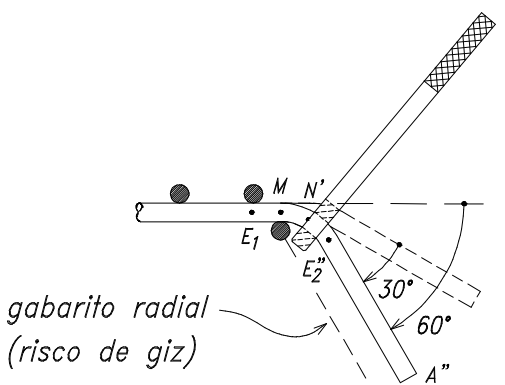

(d) Posição final

3a etapa: Após deslocar a barra para a direita de $\frac{\mathrm{C}_{90^{\circ}}}{3}=2,5 \mathrm{~cm}$ e usando $\mathrm{gab}_{\mathrm{d}}$ chave $=2,5 \mathrm{~cm} \mathrm{e}$ 2o $\mathrm{gab}_{\mathrm{d}} \mathrm{b}^{\prime}=2,5 \mathrm{~cm}$, tem-se:

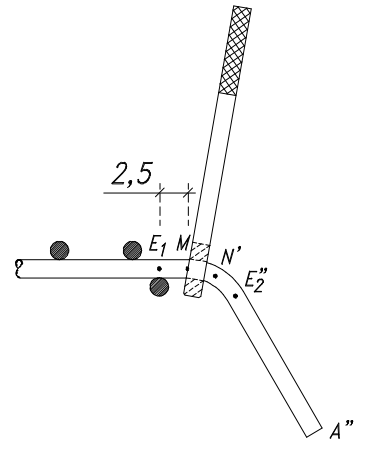

(e) Posição inicial

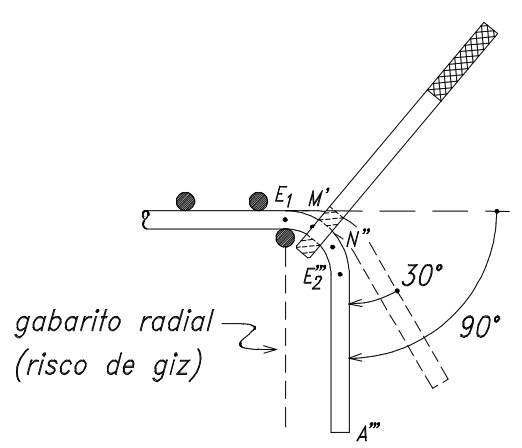

(f) Posição final

Figura B.14 - Etapas de dobramento de uma curva. 


\section{B.3. SISTEMAS DE DESENHAR UMA ARMADURA DOBRADA}

\section{B.3.1. SISTEMA DETALHADO}

Desenha-se o eixo da armadura, indicando todos os seus comprimentos parciais: trechos retos e curvas, com indicações dos seus raios de dobramentos.

Este sistema é muito usado em barras dobradas com $\phi \geq 12,5$, submetidas a tensões altas. Nestes casos os diâmetros são bem maiores aos dos ganchos e são fixados pelo cálculo $\phi \approx \frac{\sigma_{\mathrm{s} \text { calc }}}{\mathrm{f}_{\mathrm{yd}}} 15 \phi$.

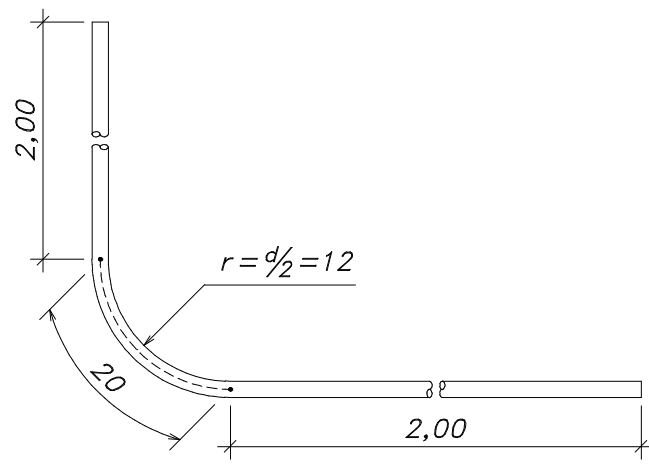

$5=22 \varnothing 16 \quad c=4,20$

Figura B.15 - Armaduras das ligações PAREDES x LAJES de reservatórios.

\section{B.3.2. SISTEMA SIMPLIFICADO}

Consiste em representar as armaduras com uma poligonal, aberta ou fechada, circunscrita aos mesmos. As curvas $\left(\mathrm{C}_{\alpha}\right)$ entre os trechos retos $\left(\mathrm{a}_{\mathrm{r}}, \mathrm{b}_{\mathrm{r}}\right.$, etc.. $)$ não são desenhadas. Em seus lugares entram as suas tangentes $\Delta$, através do prolongamento dos trechos retos.

Obtém-se assim poligonais, circunscritas às armaduras, mais fáceis de se desenhar, onde os lados representam os TAMANHOS (a', b', etc.) dos trechos retos. 
Os ganchos são também representados esquematicamente com tracinhos como mostra a figura B.16.
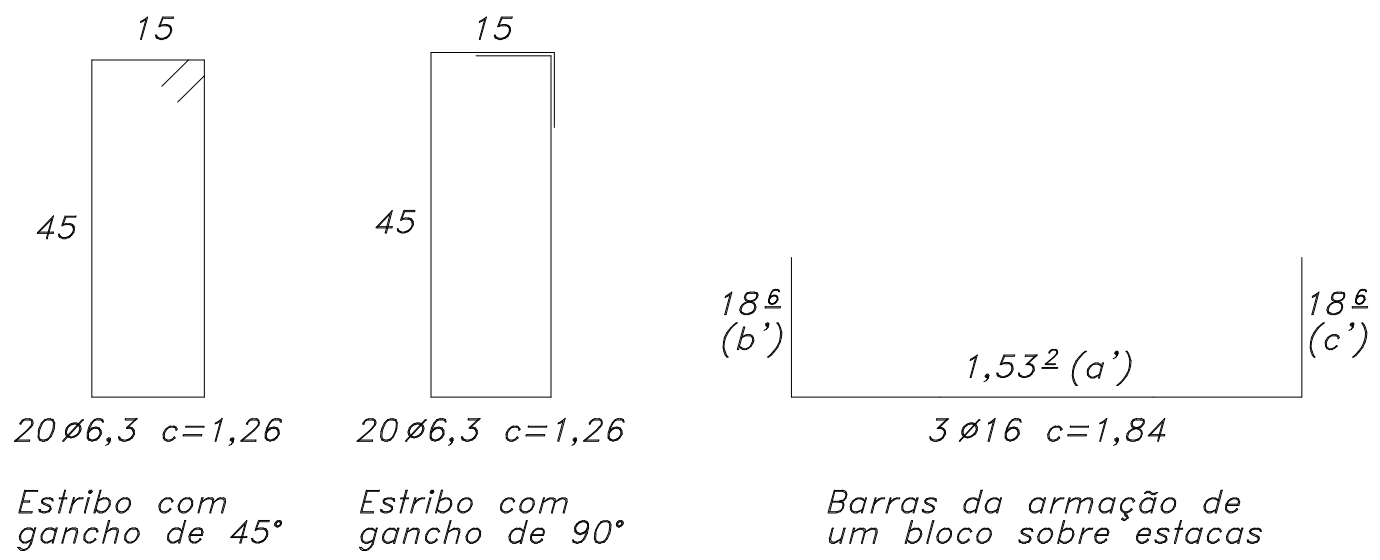

Figura B.16 - Exemplos de representação de estribos e barras no sistema simplificado.

\section{NOTAS:}

1으) Vê-se na terceira armadura (Figura B.16) que arredondar as medidas dos seus tamanhos não fornece comprimentos totais arredondados.

2으 Neste sistema é necessário fornecer tabelas para que o armador possa calcular, sem maiores dificuldades, os gabaritos dos trechos a serem dobrados.

3으 Aqui, quando não se especificarem raios ou diâmetros de dobramentos, é para se considerarem os valores mínimos especificados pela NBR 6118, item 6.3.4.1.

\section{B.4. FÓRMULAS PARA O CÁlCULO DOS COM- PRIMENTOS DOS TIPOS MAIS COMUNS DE ARMADURAS DOBRADAS}

Utilizando-se dos conceitos já expostos nos itens anteriores deste anexo, obterse-ão aqui, para cada tipo de armadura dobrada, as FÓRMULAS para o cálculo dos seus comprimentos, quando desenhados no SISTEMA SIMPLIFICADO.

Para cada tipo de armadura dobrada, apresentar-se-á uma fórmula contendo 
dois termos. Um primeiro termo será sempre a soma de todos os TAMANHOS do tipo de armadura referida na fórmula. O outro será um complemento do comprimento desta armadura, designado por $\Delta \mathrm{C}$ e denominado de CORREÇÃO DO COMPRIMENTO de uma armadura dobrada. Este complemento $\Delta \mathrm{C}$ é função da bitola, dos comprimentos dos ganchos e do tipo da armadura dobrada.

Nestas condições, todas as fórmulas para o cálculo dos comprimentos das armaduras, apresentadas neste anexo, terão as seguintes formas:

- Para os estribos retangulares ${ }^{7} \quad \mathrm{C}=\sum \mathrm{b}^{\prime}+\sum \mathrm{h}^{\prime}+\Delta \mathrm{C}$

- Para as barras dobradas $\quad \mathrm{C}=\mathrm{a}^{\prime}+\mathrm{b}^{\prime}+\ldots+\Delta \mathrm{C}$

Para melhor utilização destas fórmulas na prática, as expressões de $\Delta \mathrm{C}$ devem ser tabeladas para as bitolas mais usadas em estribos e em barras, bem como para alguns tipos de estribos e de barras mais comuns. Tabelas assim são apresentadas no final deste anexo.

\footnotetext{
${ }^{7}$ Por ser a grande maioria dos tipos de estribos mais usados, serão considerados neste trabalho apenas os estribos retangulares, ou seja, com ângulos entre lados consecutivos iguais a $90^{\circ}$, incluindo nesta definição aqueles de um só ramo.
} 


\section{B.4.1.COMPRIMENTO DOS ESTRIBOS COM $\phi \leq 10$}

B.4.1.1. Valores mínimos de $\mathbf{p}_{\alpha}, \Delta, \mathbf{C}_{\alpha}$ e $\mathbf{g}_{\alpha}$ dos ganchos e das curvas das dobras dos estribos - 6.3.4.1 da NBR 6118 (Figura B.17)

$$
\begin{aligned}
& \left.P_{90^{\circ}}=10 \varnothing\right\rceil \prod_{\varnothing} \quad \mathrm{C}_{90^{\circ}}=\frac{2 \pi(2 \phi)}{4}=\pi \phi \\
& \Delta=2,5 \varnothing+\mathrm{g}_{90^{\circ}}=\mathrm{p}_{90^{\circ}}+\mathrm{C}_{90^{\circ}}=(10+\pi) \phi \\
& \left.C_{90^{\circ}} \equiv \pi \varnothing\right\rceil \downarrow \Delta=2,5 \varnothing
\end{aligned}
$$

a) Gancho de $90^{\circ}$ (dobramento de $90^{\circ}$ )

$$
\begin{aligned}
& 2,5^{\phi} x \\
& \mathrm{C}_{45^{\circ}}=\mathrm{C}_{90^{\circ}} \cdot \frac{3}{2}=1,5 \pi \phi \\
& c_{45^{\circ}}=1,5 \pi \phi \underbrace{r=1,5 \phi}_{\Delta=2,5 \varnothing} \\
& g_{45^{\circ}}=p_{45^{\circ}}+C_{45^{\circ}}=(5+1,5 \pi) \phi
\end{aligned}
$$

b) Gancho de $45^{\circ}$ (dobramento de $135^{\circ}$ )

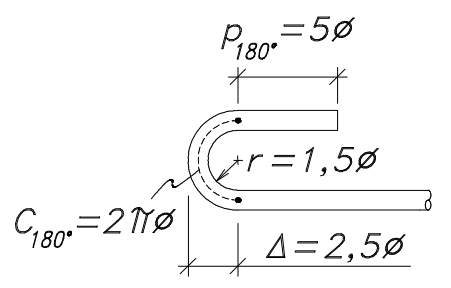

$$
\begin{aligned}
& \mathrm{C}_{180^{\circ}}=\frac{2 \pi(2 \phi)}{2}=2 \pi \phi \\
& \mathrm{g}_{180^{\circ}}=\mathrm{p}_{180^{\circ}}+\mathrm{C}_{180^{\circ}}=(5+2 \pi) \phi
\end{aligned}
$$

c) Ganchos semicirculares (dobramento de $180^{\circ}$ )

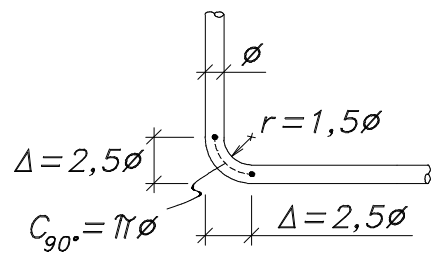

$$
\mathrm{C}_{90^{\circ}}=\frac{2 \pi(2 \phi)}{4}=\pi \phi
$$

d) Curvas das dobras (dobramento de $90^{\circ}$ )

Figura B.17 - Valores mínimos de $\mathrm{p}_{\alpha}, \Delta, \mathrm{C}_{\alpha}$ e $\mathrm{g}_{\alpha}$ dos ganchos e das curvas das dobras dos estribos. 


\section{B.4.1.2. Deduções das fórmulas dos comprimentos dos estribos mais comuns}

a) Estribos retangulares com ganchos de $45^{\circ}$

Sendo C o comprimento total ao longo do eixo dos estribos, vê-se facilmente que $\mathrm{C}=2\left(\mathrm{~b}_{\mathrm{r}}+\mathrm{h}_{\mathrm{r}}\right)+2 \mathrm{~g}_{45^{\circ}}+3 \mathrm{C}_{90^{\circ}}$ (Figura B.18).

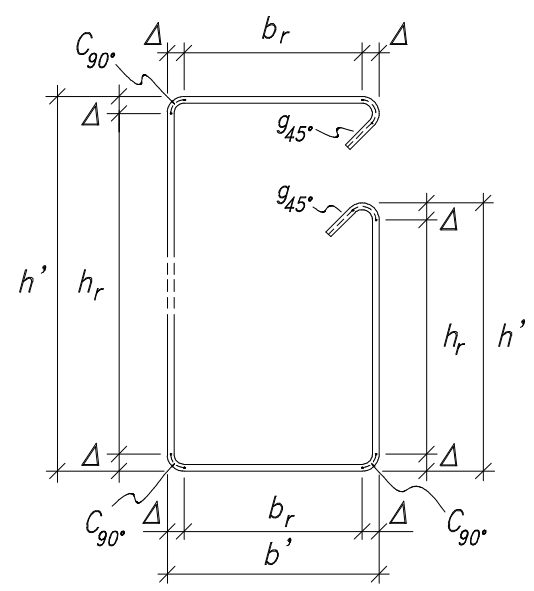

Figura B.18 - Estribo retangular com ganchos de $45^{\circ}$

Colocando tudo em função dos b', h' e de $\phi$ e utilizando a expressão do item 1.3.5 para $b_{r}$ e $h_{r}$ bem como utilizando as expressões do item anterior 4.1.1 para os valores mínimos de $\Delta, \mathrm{g}_{45^{\circ}}$ e $\mathrm{C}_{90^{\circ}}$, tem-se:

$\mathrm{C}=2\left(\mathrm{~b}^{\prime}-2 \Delta+\mathrm{h}^{\prime}-2 \Delta\right)+2(5+1,5 \pi) \phi+3 \pi \phi=2\left(\mathrm{~b}^{\prime}+\mathrm{h}^{\prime}\right)-8 \Delta+10 \phi+6 \pi \phi$

$C=2\left(b^{\prime}+h^{\prime}\right)-10 \phi+6 \pi \phi=2\left(b^{\prime}+h^{\prime}\right)+2(3 \pi-5) \phi$

Observações:

1을 Se estes estribos apresentarem larguras diferentes $\left(b_{1}^{\prime}\right.$ e $\left.b_{2}^{\prime}\right)$ ou alturas diferentes $\left(h_{1}{ }^{\prime}\right.$ e $\left.h_{2}{ }^{\prime}\right)$, porém com quatro trechos retos, a fórmula é a mesma, bastando generalizá-la (Figura B.19). 

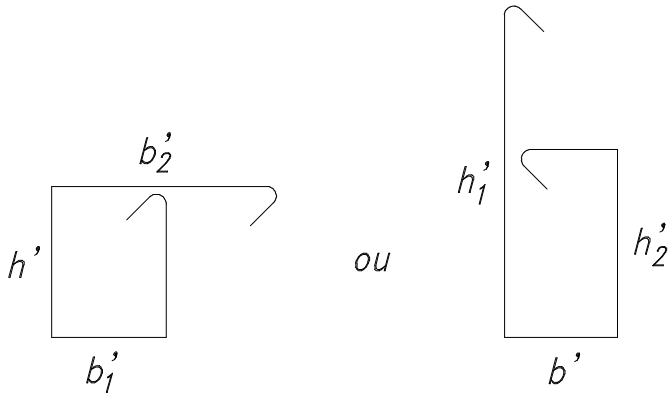

$$
\mathrm{C}=\sum \mathrm{b}^{\prime}+\sum \mathrm{h}^{\prime}+2(3 \pi-5) \phi(1)
$$

Figura B.19 - Exemplos de estribos com larguras e alturas, respectivamente, diferentes e a fórmula generalizada para o cálculo do comprimento, $\mathrm{C}$.

$2^{\mathrm{O}}$ ) Nesta fórmula o segundo termo $2(3 \pi-5) \phi$ é a parte complementar $\Delta \mathrm{C}$, já denominado no início do item 4 de CORREÇÃO DO COMPRIMENTO.

Leva em conta o comprimento dos dois ganchos de $45^{\circ}$ e das curvas das três dobras, descontando os $8 \Delta$ computados indevidamente nas somatórias de b' e h' do primeiro termo.

Para cada outro tipo de estribo, com quatro lados ou menos e/ou com ganchos diferentes, a expressão de $\Delta \mathrm{C}$ muda, chegando até a fornecer valores negativos para estribos sem ganchos. Este fato justifica por si só a acertiva na escolha do nome CORREÇÃO DO COMPRIMENTO para $\Delta \mathrm{C}$, em lugar de "COMPLEMENTO DO COMPRIMENTO", ou pior ainda, de "COMPRIMENTO DE DOIS GANCHOS".

b) Estribos em forma de "U" com ganchos de $45^{\circ}$ (Figura B.20)

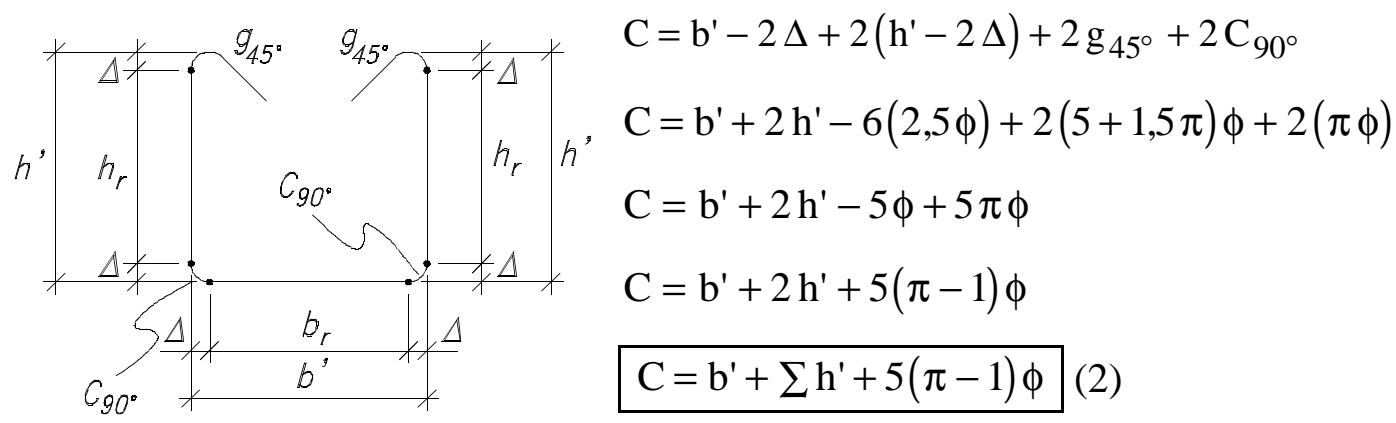

Figura B.20 - Estribo em forma de "U" com ganchos de $45^{\circ}$ e o cálculo de seu comprimento, C. 
c) Estribos de um ramo só com ganchos de $45^{\circ}$ (Figura B.21)

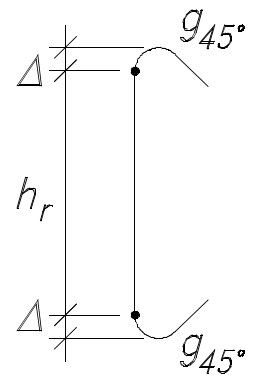

$$
\begin{aligned}
& \mathrm{C}=\mathrm{h}^{\prime}-2 \Delta+2 \mathrm{~g}_{45^{\circ}} \\
& \mathrm{C}=\mathrm{h}^{\prime}-2(2,5 \phi)+2(1,5 \pi+5) \phi \quad \therefore \\
& \mathrm{C}=\mathrm{h}^{\prime}+(3 \pi+5) \phi
\end{aligned}
$$

Figura B.21 - Estribo de um só ramo com ganchos de $45^{\circ}$ e o cálculo de seu comprimento, C.

d) Estribos retangulares com ganchos de $90^{\circ}$ (Figura B.22)

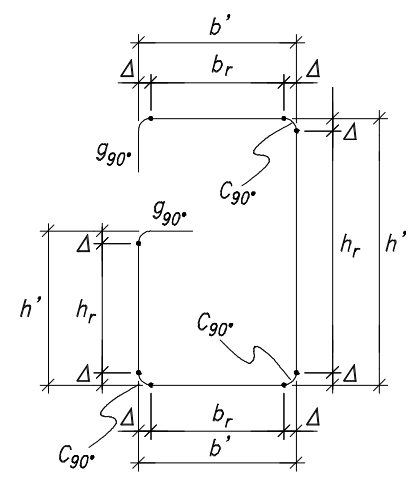

$$
\begin{aligned}
& \mathrm{C}=\left(\mathrm{b}^{\prime}-2 \Delta+\mathrm{h}^{\prime}-2 \Delta\right)+2 \mathrm{~g}_{90^{\circ}}+3 \mathrm{C}_{90^{\circ}} \\
& \mathrm{C}=2\left(\mathrm{~b}^{\prime}+\mathrm{h}^{\prime}\right)-8(2,5 \phi)+2(10+\pi) \phi+3 \pi \phi \\
& \mathrm{C}=2\left(\mathrm{~b}^{\prime}+\mathrm{h}^{\prime}\right)+5 \pi \phi \text { e generalizando } \\
& \mathrm{C}=\sum \mathrm{b}^{\prime}+\sum \mathrm{h}^{\prime}+5 \pi \phi
\end{aligned}
$$

Figura B.22 - Estribo retangular com ganchos de $90^{\circ}$ e o cálculo de seu comprimento, C.

e) Estribos em forma de "U" com ganchos de $90^{\circ}$ (Figura B.23)

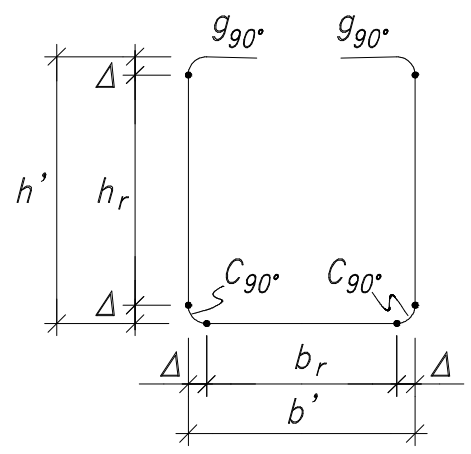

$$
\begin{aligned}
& \mathrm{C}=\mathrm{b}^{\prime}-2 \Delta+2\left(\mathrm{~h}^{\prime}-2 \Delta\right)+2 \mathrm{C}_{90^{\circ}}+2 \mathrm{~g}_{90^{\circ}} \\
& \mathrm{C}=\mathrm{b}^{\prime}+2 \mathrm{~h}^{\prime}-6(2,5 \phi)+2 \pi \phi+2(\pi+10) \phi \\
& \mathrm{C}=\mathrm{b}^{\prime}+2 \mathrm{~h}^{\prime}+(4 \pi+5) \phi \quad \text { e genericamente } \\
& \mathrm{C}=\mathrm{b}^{\prime}+\sum \mathrm{h}^{\prime}+(4 \pi+5) \phi(5)
\end{aligned}
$$

Figura B.23 - Estribo em forma de "U” com ganchos de $90^{\circ}$ e o cálculo de seu comprimento, C. 
f) Estribos de um só ramo com ganchos de $90^{\circ}$ (Figura B.24)

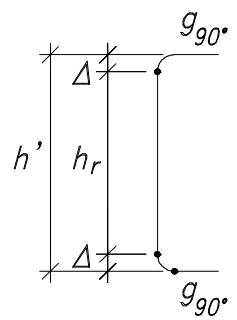

$$
\begin{aligned}
& \mathrm{C}=\mathrm{h}^{\prime}-2 \Delta+2 \mathrm{~g}_{90^{\circ}} \\
& \mathrm{C}=\mathrm{h}^{\prime}-2(2,5 \phi)+2(\pi+10) \phi \\
& \mathrm{C}=\mathrm{h}^{\prime}+(2 \pi+15) \phi(6)
\end{aligned}
$$

Figura B.24 - Estribo de um só ramo com ganchos de $90^{\circ}$ e o cálculo de seu comprimento, C.

g) Estribos retangulares com ganchos semicirculares (Figura B.25)

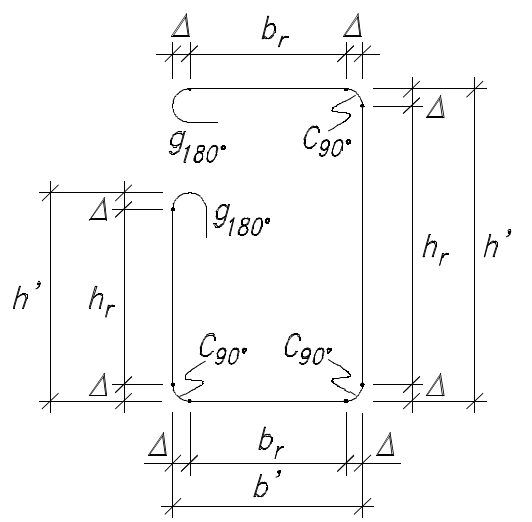

$$
\begin{aligned}
& \mathrm{C}=2\left(\mathrm{~b}^{\prime}-2 \Delta+\mathrm{h}^{\prime}-2 \Delta\right)+3 \mathrm{C}_{90^{\circ}}+2 \mathrm{~g}_{180^{\circ}} \\
& \mathrm{C}=2\left(\mathrm{~b}^{\prime}+\mathrm{h}^{\prime}\right)-8(2,5 \phi)+3 \pi \phi+2(2 \pi+5) \phi \\
& \mathrm{C}=2\left(\mathrm{~b}^{\prime}+\mathrm{h}^{\prime}\right)+(7 \pi-10) \phi \text { e genericamente } \\
& \mathrm{C}=\sum \mathrm{b}^{\prime}+\sum \mathrm{h}^{\prime}+(7 \pi-10) \phi(7)
\end{aligned}
$$

Figura B.25 - Estribo retangular com ganchos semicirculares e o cálculo de seu comprimento, C.

h) Estribos em "U" com ganchos semicirculares (Figura B.26)

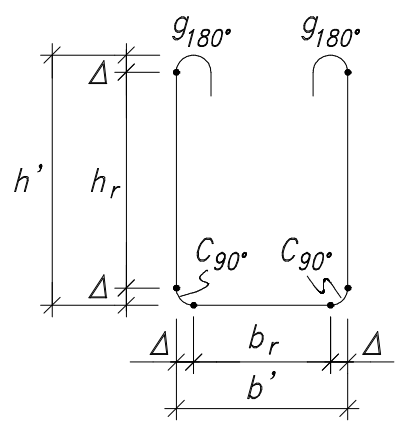

$$
\begin{aligned}
& \mathrm{C}=\mathrm{b}^{\prime}-2 \Delta+2\left(\mathrm{~h}^{\prime}-2 \Delta\right)+2 \mathrm{C}_{90^{\circ}}+2 \mathrm{~g}_{180^{\circ}} \\
& \mathrm{C}=\mathrm{b}^{\prime}+2 \mathrm{~h}^{\prime}-6(2,5 \phi)+2 \pi \phi+2(2 \pi+5) \phi \\
& \mathrm{C}=\mathrm{b}^{\prime}+2 \mathrm{~h}^{\prime}+(6 \pi-5) \phi \text { e genericamente } \\
& \mathrm{C}=\mathrm{b}^{\prime}+\sum \mathrm{h}^{\prime}+(6 \pi-5) \phi
\end{aligned}
$$

Figura B.26 - Estribo em forma de "U" com ganchos semicirculares e o cálculo de seu comprimento, C.

i) Estribos de um só ramo com ganchos semicirculares (Figura B.27)

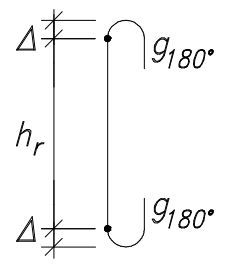

$$
\begin{aligned}
& \mathrm{C}=\mathrm{h}^{\prime}-2 \Delta+2 \mathrm{~g}_{180^{\circ}} \\
& \mathrm{C}=\mathrm{h}^{\prime}-2(2,5 \phi)+2(2 \pi+5) \phi \\
& \mathrm{C}=\mathrm{h}^{\prime}+(4 \pi+5) \phi
\end{aligned}
$$

Figura B.27 - Estribo se um só ramo com ganchos semicirculares e o cálculo de seu comprimento, C. 
j) Estribos de quatro lados com ganchos de $45^{\circ}$ e $90^{\circ}$ (Figura B.28)
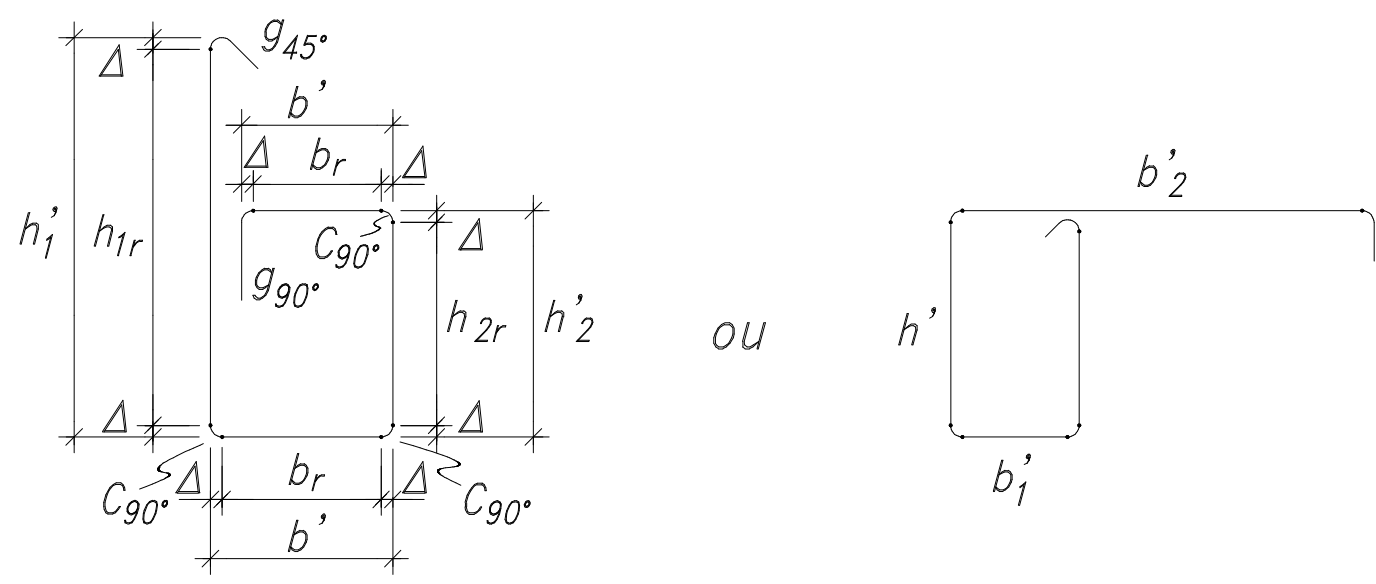

$$
\begin{aligned}
& \mathrm{C}=2\left(\mathrm{~b}^{\prime}-2 \Delta\right)+\mathrm{h}_{1}{ }^{\prime}-2 \Delta+\mathrm{h}_{2}{ }^{\prime}-2 \Delta+3 \mathrm{C}_{90^{\circ}}+\mathrm{g}_{45^{\circ}}+\mathrm{g}_{90^{\circ}} \\
& \mathrm{C}=2 \mathrm{~b}^{\prime}+\mathrm{h}_{1}{ }^{\prime}+\mathrm{h}_{2}{ }^{\prime}-8(2,5 \phi)+3 \pi \phi+(1,5 \pi+5) \phi+(\pi+10) \phi \\
& \mathrm{C}=2 \mathrm{~b}^{\prime}+\mathrm{h}_{1}{ }^{\prime}+\mathrm{h}_{2}{ }^{\prime}+(5,5 \pi-5) \phi \text { e generalizando }
\end{aligned}
$$$$
\mathrm{C}=\sum \mathrm{b}^{\prime}+\sum \mathrm{h}^{\prime}+(5,5 \pi-5) \phi
$$

Figura B.28 - Estribos de quatro lados com ganchos de $45^{\circ}$ e $90^{\circ}$ e o cálculo de seu comprimento, C.

k) "Estribos" em forma de "U" sem ganchos (Figura B.29)

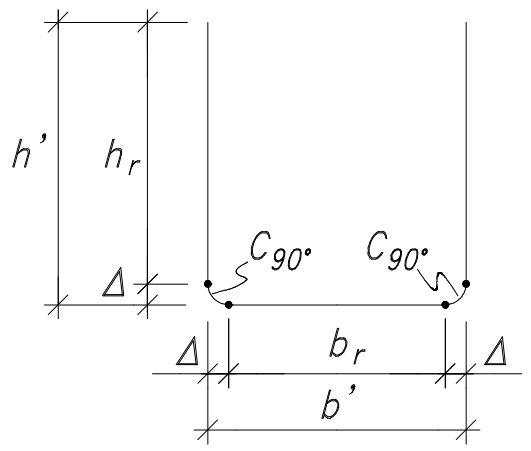

$$
\begin{aligned}
& \mathrm{C}=\mathrm{b}^{\prime}+2 \mathrm{~h}^{\prime}-4 \Delta+2 \mathrm{C}_{90^{\circ}} \\
& \mathrm{C}=\mathrm{b}^{\prime}+2 \mathrm{~h}^{\prime}-4(2,5 \phi)+2 \pi \phi \\
& \mathrm{C}=\mathrm{b}^{\prime}+2 \mathrm{~h}^{\prime}+2(\pi-5) \phi \text { e generalizando } \\
& \mathrm{C}=\mathrm{b}^{\prime}+\sum \mathrm{h}^{\prime}+2(\pi-5) \phi
\end{aligned}
$$

Figura B.29 - "Estribo" em forma de "U” sem ganchos e o cálculo de seu comprimento, C.

Obs. Como neste caso a armadura não tem gancho, o termo $2(\pi-5) \phi \approx-7 \phi$ desempenha tão somente o papel de correção do comprimento, uma vez que, retira os $4 \Delta$ computados indevidamente nos termos b' e $2 \mathrm{~h}^{\prime}$ e adiciona o comprimento $\mathrm{C}_{90^{\circ}}$ das curvas das duas dobras. 


\section{B.4.2. COMPRIMENTOS DAS BARRAS DOBRADAS}

B.4.2.1. Valores mínimos de $p_{\alpha}, \Delta, \mathbf{C}_{\alpha}$ e $\mathbf{g}_{\alpha}$ dos ganchos e das curvas das dobras das barras - 6.3.4.1 e 6.3.4.2 da NBR 6118 (Figura B.30)

para $\phi \leq 16: \quad \quad$ para $\phi \geq 20$ :

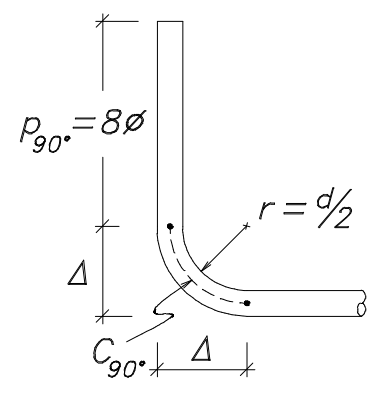

$$
\begin{array}{ll}
\mathrm{r}=2,5 \phi & \mathrm{r}=4 \phi \\
\Delta=\mathrm{r}+\phi=3,5 \phi & \Delta=\mathrm{r}+\phi=5 \phi \\
\mathrm{C}_{90^{\circ}}=\frac{2 \pi(3 \phi)}{4}=1,5 \pi \phi & \mathrm{C}_{90^{\circ}}=\frac{2 \pi(4,5 \phi)}{4}=2,25 \pi \phi \\
\mathrm{g}_{90^{\circ}}=(1,5 \pi+8) \phi & \mathrm{g}_{90^{\circ}}=(1,5 \pi+8) \phi
\end{array}
$$

a) Gancho de $90^{\circ}$ (dobramento de $90^{\circ}$ )

$$
\begin{array}{ll}
\text { para } \phi \leq 16: & \text { para } \phi \geq 20: \\
\mathrm{r}=2,5 \phi & \mathrm{r}=4 \phi \\
\Delta=\mathrm{r}+\phi=3,5 \phi & \Delta=\mathrm{r}+\phi=5 \phi \\
\mathrm{C}_{45^{\circ}}=\frac{3}{2} \cdot \mathrm{C}_{90^{\circ}}=2,25 \pi \phi & \mathrm{C}_{90^{\circ}}=\frac{3}{2} \cdot \mathrm{C}_{90^{\circ}}=3,375 \pi \phi \\
\mathrm{g}_{45^{\circ}}=(2,25 \pi+4) \phi & \mathrm{g}_{45^{\circ}}=(3,375 \pi+4) \phi
\end{array}
$$

b) Gancho de $45^{\circ}$ (dobramento de $135^{\circ}$ )

$$
\text { para } \phi \leq 16: \quad \quad \text { para } \phi \geq 20 \text { : }
$$

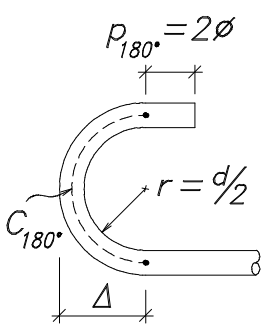

$$
\begin{array}{ll}
\mathrm{r}=2,5 \phi & \mathrm{r}=4 \phi \\
\Delta=\mathrm{r}+\phi=3,5 \phi & \Delta=\mathrm{r}+\phi=5 \phi \\
\mathrm{C}_{180^{\circ}}=2 \mathrm{C}_{90^{\circ}}=3 \pi \phi & \mathrm{C}_{180^{\circ}}=2 \mathrm{C}_{90^{\circ}}=4,5 \pi \phi \\
\mathrm{g}_{180^{\circ}}=(3 \pi+2) \phi & \mathrm{g}_{180^{\circ}}=(4,5 \pi+2) \phi
\end{array}
$$

c) Gancho semicircular (dobramento de $180^{\circ}$ ) 


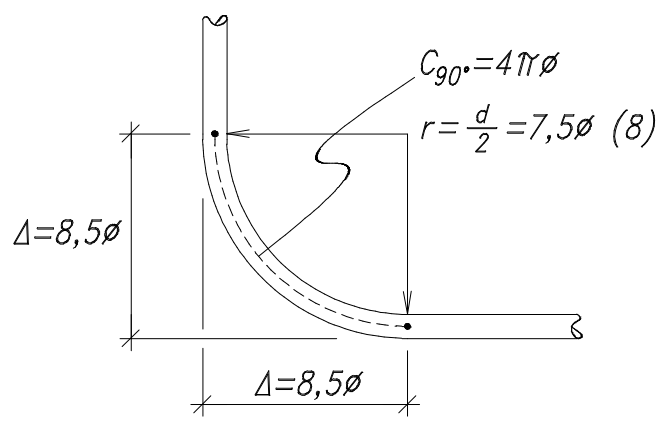

$\left.\mathrm{d}^{8}\right)$ Barras dobradas ${ }^{10}$ com trações altas

$\phi \leq 16$ :

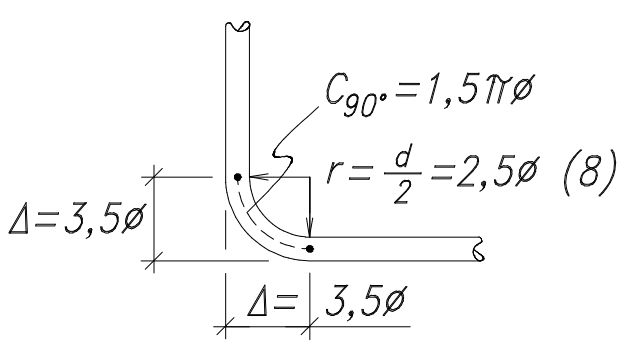

$\phi \geq 20$ :

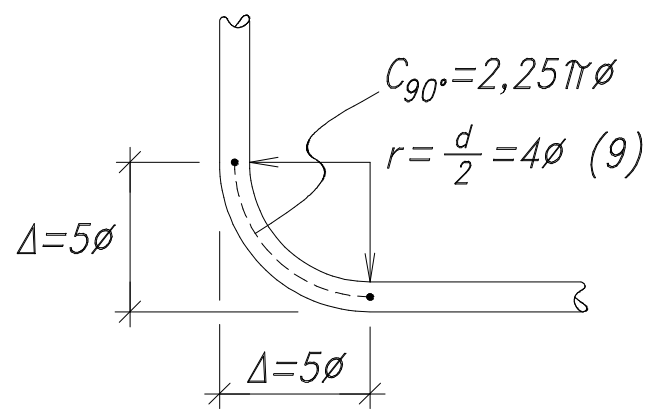

$\left.\mathrm{e}^{8}\right)$ Barras dobradas ${ }^{10}$ com raios de ganchos ${ }^{9}$

Figura B.30 - Valores mínimos de $\mathrm{p}_{\alpha}, \Delta, \mathrm{C}_{\alpha}$ e $\mathrm{g}_{\alpha}$ dos ganchos e das curvas das dobras das barras.

${ }_{10}^{8}$ Por razões didáticas e práticas, considerar-se-á aqui e no item (e) seguinte, apenas dobras de $90^{\circ}$.

9 O item 6.3.4.2 da NBR 6118 especifica para as barras dobradas com tensões altas $\left(\sigma_{\mathrm{s}}=\mathrm{f}_{\mathrm{yd}}\right) \mathrm{um}$ raio mínimo para as curvas dos dobramentos igual à $7,5 \phi\left(\mathrm{d}_{\text {mín }}=15 \phi\right)$. Por outro lado, ele especifica também que para tensões menores pode-se reduzir proporcionalmente estes valores mínimos, mas nunca a valores inferiores aos exigidos para os ganchos.

Assim sendo, pode-se escrever que $2,5(4) \phi \leq \mathrm{r} \leq \frac{\sigma_{\mathrm{s}}}{\mathrm{f}_{\mathrm{yd}}} \cdot 7,5 \phi$.

${ }^{10}$ Também neste item estas barras são denominadas de BARRAS CURVADAS, numa alusão ao seu "enorme" raio de curvatura. Semântica à parte, preferiu-se aqui a denominação genérica de BARRAS DOBRADAS, visando um ganho didático maior mesmo porque, para $\phi \leq 10$ com alguns cuidados, está-se usando raios de ganchos mesmo para tensões altas. 


\section{B.4.2.2. Fórmulas dos comprimentos das barras dobradas mais comuns}

a) Barra reta com um gancho de $90^{\circ}$ (Figura B.31)

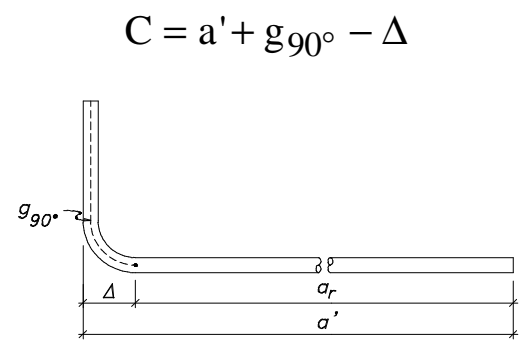

$$
\begin{aligned}
& \phi \leq 16: \\
& C=a^{\prime}+(1,5 \pi+8) \phi-3,5 \phi \\
& C=a^{\prime}+(1,5 \pi+4,5) \phi \\
& \phi \geq 20: \\
& C=a^{\prime}+(2,25 \pi+8) \phi-5 \phi \\
& C=a^{\prime}+(2,25 \pi+3) \phi
\end{aligned}
$$

Figura B.31 - Barra reta com um gancho de $90^{\circ}$ e o cálculo de seu comprimento, C.

b) Barra reta com dois ganchos de $90^{\circ}$ (Figura B.32)

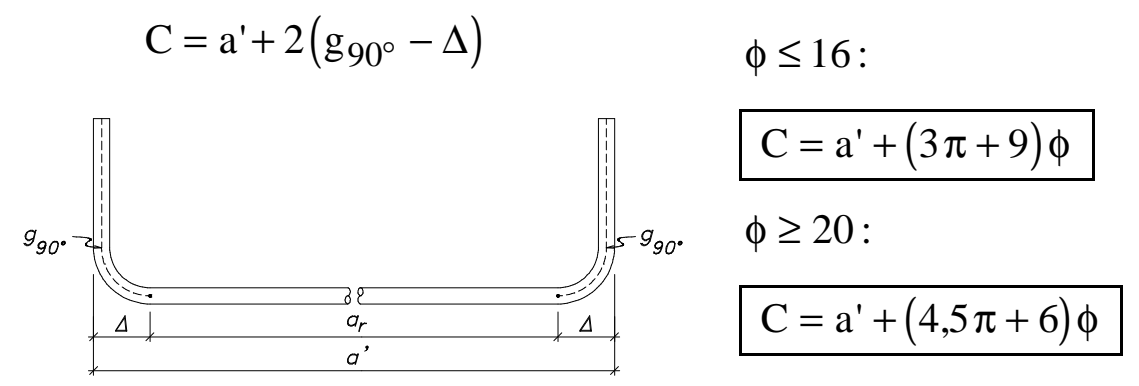

Figura B.32 - Barra reta com dois ganchos de $90^{\circ}$ e o cálculo de seu comprimento, C.

c) Barra reta com um gancho de $45^{\circ}$ (Figura B.33)

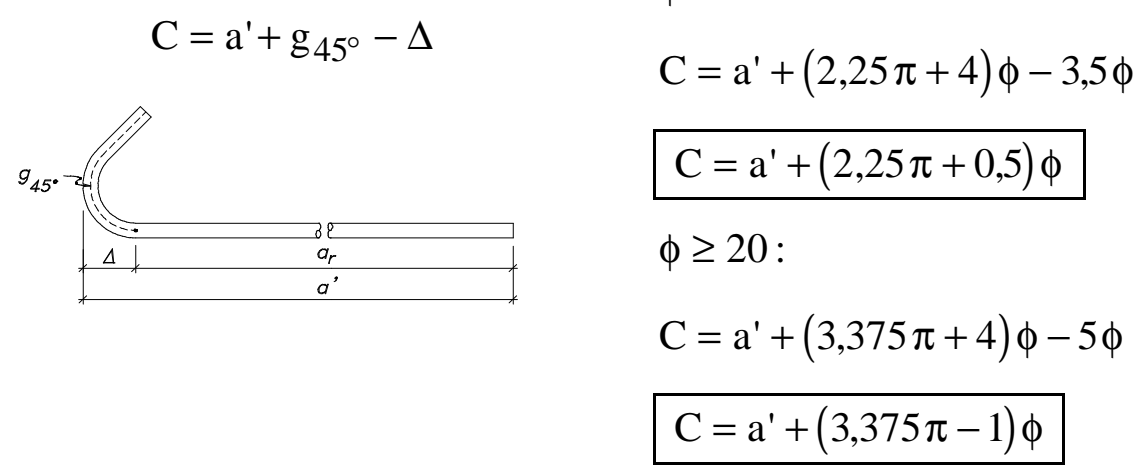

Figura B.33 - Barra reta com um gancho de $45^{\circ}$ e o cálculo de seu comprimento, C. 
d) Barra reta com dois ganchos de $45^{\circ}$ (Figura B.34)

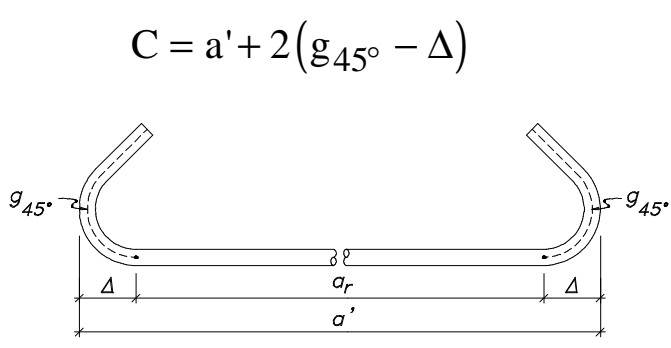

$$
\begin{aligned}
& \phi \leq 16: \\
& C=a^{\prime}+(4,5 \pi+1) \phi \\
& \phi \geq 20: \\
& C=a^{\prime}+(6,75 \pi-2) \phi
\end{aligned}
$$

Figura B.34 - Barra reta com dois ganchos de $45^{\circ}$ e o cálculo de seu comprimento, C.

e) Barra reta com um gancho semicircular (Figura B.35)

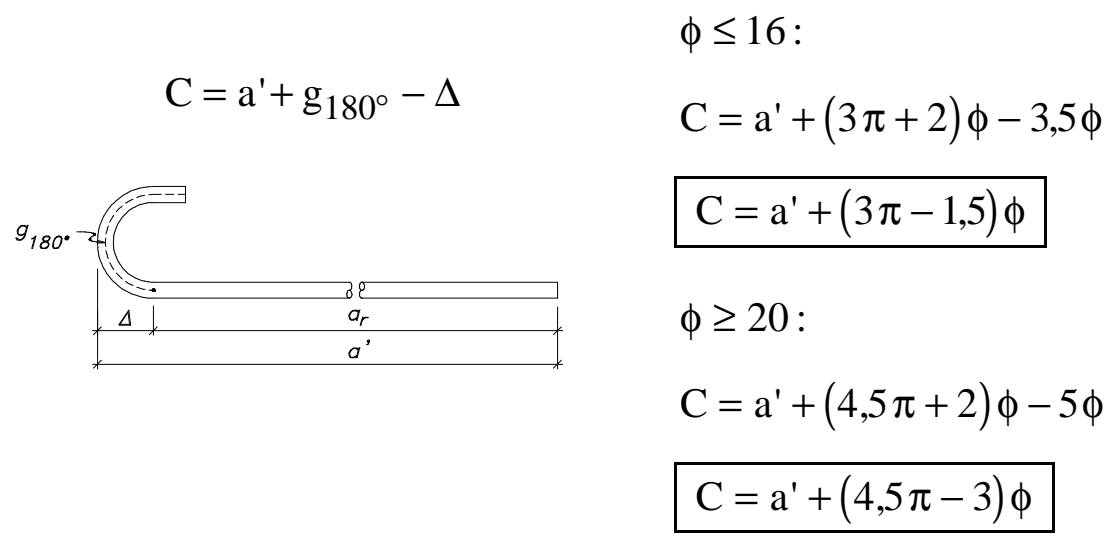

Figura B.35 - Barra reta com um gancho semicircular e o cálculo de seu comprimento, C.

f) Barra reta com dois ganchos semicirculares (Figura B.36)

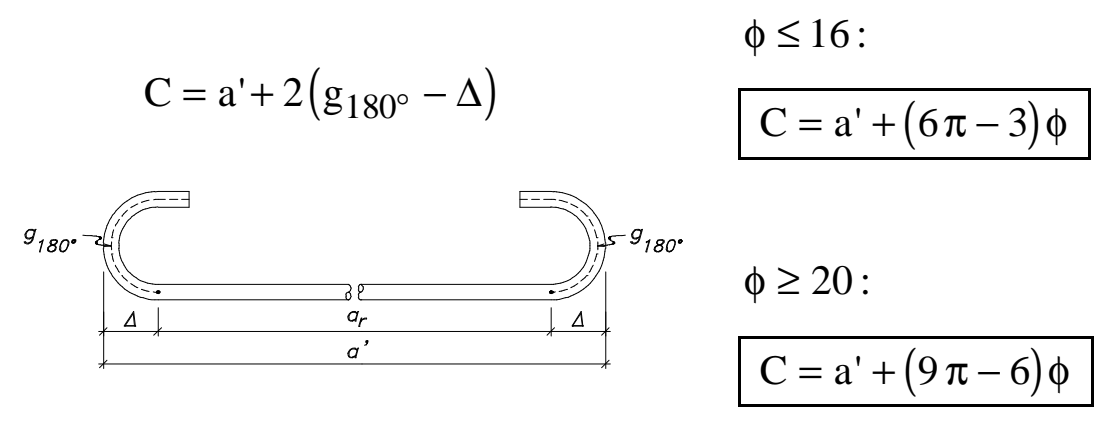

Figura B.36 - Barra reta com dois ganchos semicirculares e o cálculo de seu comprimento, C. 
g) Barra sem gancho com uma dobra (Figura B.37)

$\mathrm{C}=\mathrm{a}^{\prime}+\mathrm{b}^{\prime}+\mathrm{C}_{90^{\circ}}-2 \Delta$

$\phi \leq 16$ :

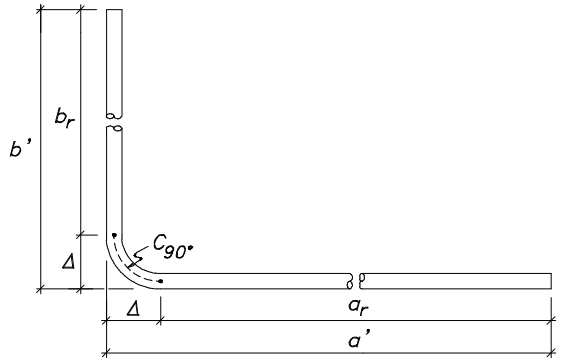

$$
\mathrm{C}=\mathrm{a}^{\prime}+\mathrm{b}^{\prime}+1,5 \pi \phi-2(3,5 \phi)
$$$$
\mathrm{C}=\mathrm{a}^{\prime}+\mathrm{b}^{\prime}+(1,5 \pi-7) \phi
$$

$\phi \geq 20$ :

$\mathrm{C}=\mathrm{a}^{\prime}+\mathrm{b}^{\prime}+2,25 \pi \phi-2(5 \phi)$

$\mathrm{C}=\mathrm{a}^{\prime}+\mathrm{b}^{\prime}+(2,25 \pi-10) \phi$

Figura B.37 - Barra sem gancho com uma dobra e o cálculo de seu comprimento, C.

h) Barra sem gancho com duas dobras (Figura B.38)

$\mathrm{C}=\mathrm{a}^{\prime}+\mathrm{b}^{\prime}+\mathrm{c}^{\prime}+2\left(\mathrm{C}_{90^{\circ}}-2 \Delta\right)$

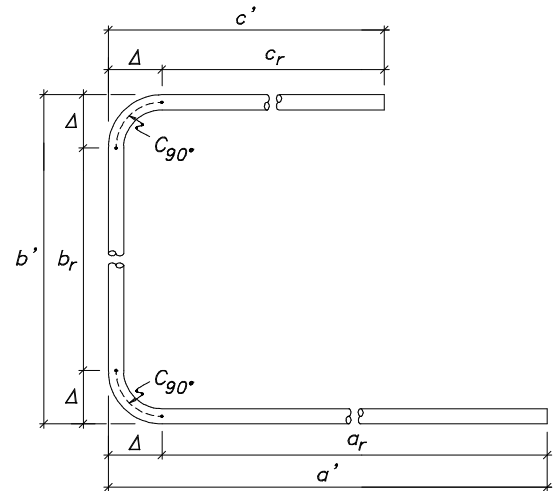

$$
\begin{aligned}
& \phi \leq 16: \\
& C=a^{\prime}+b^{\prime}+c^{\prime}+(3 \pi-14) \phi
\end{aligned}
$$

$\phi \geq 20$ :

$$
\mathrm{C}=\mathrm{a}^{\prime}+\mathrm{b}^{\prime}+\mathrm{c}^{\prime}+(4,5 \pi-20) \phi
$$

Figura B.38 - Barra sem gancho com duas dobras e o cálculo de seu comprimento, C.

\section{i) Barras sem gancho com três dobras (Figura B.39)}

$C=a^{\prime}+b^{\prime}+c^{\prime}+d^{\prime}+3\left(C_{90^{\circ}}-2 \Delta\right)$

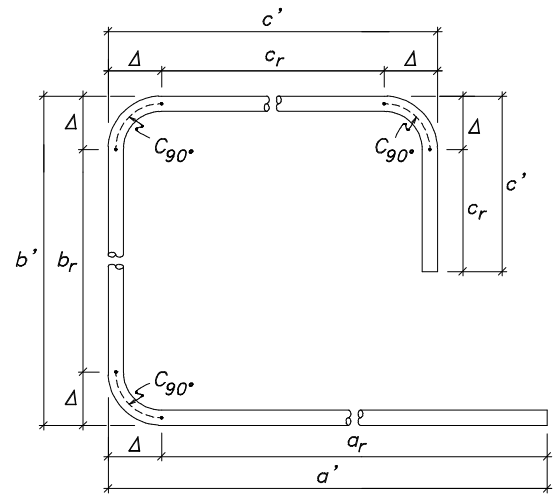

$$
\phi \leq 16:
$$

$$
C=a^{\prime}+b^{\prime}+c^{\prime}+d^{\prime}+(4,5 \pi-21) \phi
$$

$\phi \geq 20$ :

$$
C=a^{\prime}+b^{\prime}+c^{\prime}+d^{\prime}+(6,75 \pi-30) \phi
$$

Figura B.39 - Barras sem gancho com três dobras e o cálculo de seu comprimento, C. 
j) Barra com uma dobra e um gancho a $45^{\circ}$ (Figura B.40)

$\mathrm{C}=\mathrm{a}^{\prime}+\mathrm{b}^{\prime}+\mathrm{g}_{45^{\circ}}+\mathrm{C}_{90^{\circ}}-3 \Delta \quad \phi \leq 16:$

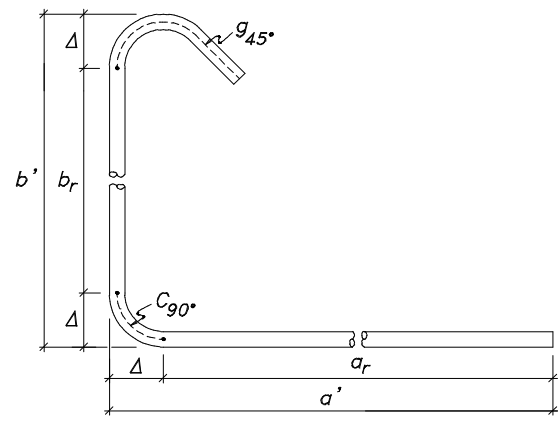

$\mathrm{C}=\mathrm{a}^{\prime}+\mathrm{b}^{\prime}+(2,25 \pi+4) \phi+1,5 \pi \phi-3(3,5 \phi)$

$\mathrm{C}=\mathrm{a}^{\prime}+\mathrm{b}^{\prime}+(3,75 \pi-6,5) \phi$

$\phi \geq 20$ :

$\mathrm{C}=\mathrm{a}^{\prime}+\mathrm{b}^{\prime}+(3,375 \pi+4) \phi+2,25 \pi \phi-3(5 \phi)$

$\mathrm{C}=\mathrm{a}^{\prime}+\mathrm{b}^{\prime}+(5,625 \pi-11) \phi$

Figura B.40 - Barra com uma dobra e um gancho a $45^{\circ}$ e o cálculo de seu comprimento, C.

k) Barras com duas dobras e dois ganchos a $45^{\circ}$ (Figura B.41)

$\mathrm{C}=\mathrm{a}^{\prime}+\mathrm{b}^{\prime}+\mathrm{c}^{\prime}+2\left(\mathrm{~g}_{45^{\circ}}+\mathrm{C}_{90^{\circ}}-3 \Delta\right)$

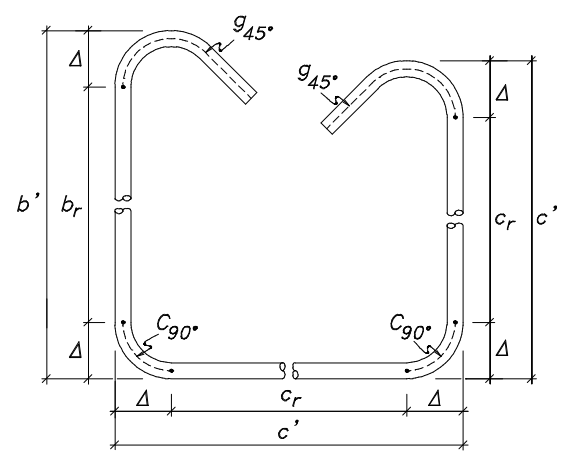

$$
\begin{aligned}
& \phi \leq 16: \\
& C=a^{\prime}+b^{\prime}+c^{\prime}+(7,5 \pi-13) \phi \\
& \phi \geq 20: \\
& C=a^{\prime}+b^{\prime}+c^{\prime}+(11,25 \pi-22) \phi
\end{aligned}
$$

Figura B.41 - Barras com duas dobras e dois ganchos a $45^{\circ}$ e o cálculo de seu comprimento, C. 


\section{B.5. TABELAS AUXILIARES PARA CALCULISTAS E ARMADORES}

TABELA B.1: Bitolas, áreas e pesos

\begin{tabular}{|c|c|c|c|}
\hline \multicolumn{3}{|c|}{ CA-50A e B } & ou CA-60B \\
\hline \multicolumn{2}{|c|}{ Bitolas $(\varnothing)$} & \multicolumn{2}{c|}{ Valores } \\
\hline $\begin{array}{c}\text { Fios } \\
(\mathrm{mm})\end{array}$ & $\begin{array}{c}\text { Barras } \\
(\mathrm{mm})\end{array}$ & $\begin{array}{c}\text { Area } \\
\left(\mathrm{cm}^{2}\right)\end{array}$ & $\begin{array}{c}\text { Peso linear } \\
(\mathrm{kg} / \mathrm{m})\end{array}$ \\
\hline \hline 3,2 & - & 0,08 & 0,063 \\
\hline 4 & - & 0,125 & 0,10 \\
\hline 5 & 5 & 0,20 & 0,16 \\
\hline 6,3 & 6,3 & 0,315 & 0,25 \\
\hline 8 & 8 & 0,50 & 0,40 \\
\hline 10 & 10 & 0,80 & 0,63 \\
\hline- & 12,5 & 1,25 & 1,00 \\
\hline- & 16 & 2,00 & 1,60 \\
\hline- & 20 & 3,15 & 2,50 \\
\hline- & 25 & 5,00 & 4,00 \\
\hline- & 32 & 8,00 & 6,30 \\
\hline
\end{tabular}

Ganchos das barras:
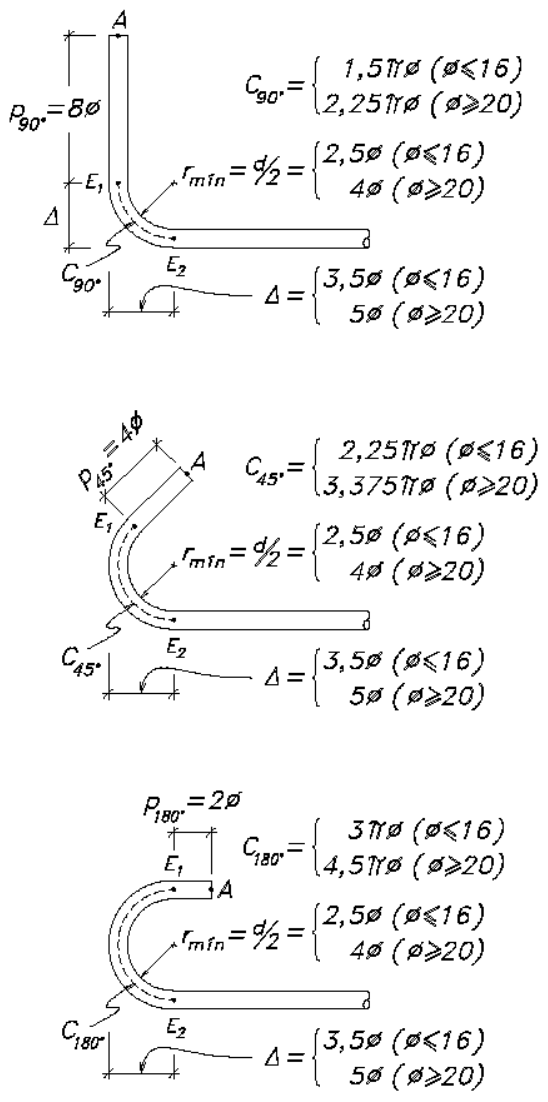

Ganchos dos estribos e suas representações nos desenhos:
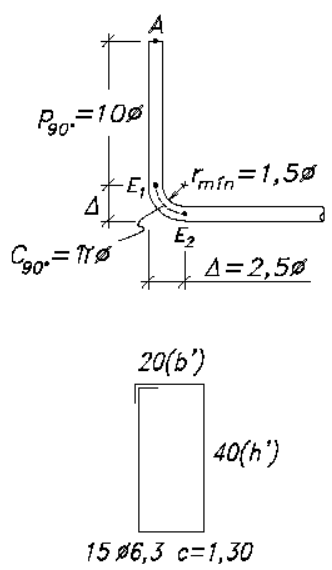
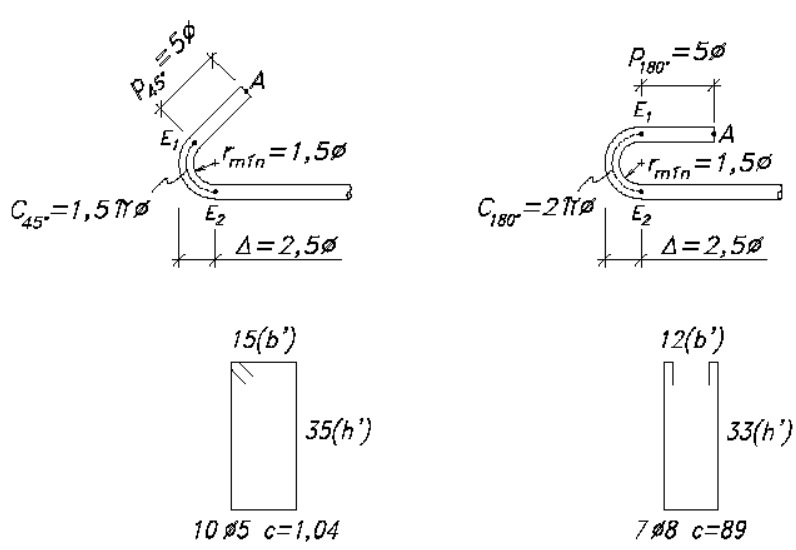
TABELA B.2: Valores de $\Delta \mathbf{C}(\mathrm{cm})$ para ESTRIBOS $\quad \mathbf{C}=\boldsymbol{\Sigma} \mathbf{b}^{\mathbf{}}+\boldsymbol{\Sigma} \mathbf{h}^{\mathbf{1}}+\boldsymbol{\Delta C}$

\begin{tabular}{|c|c|c|c|c|c|c|c|}
\hline \multirow{2}{*}{$\begin{array}{c}\text { CA-50 } \\
\text { ou } \\
\text { CA-60 }\end{array}$} & \multirow{2}{*}{\begin{tabular}{|c|} 
ganchos de $90^{\circ}$ \\
$h^{.}{ }_{b^{\prime}}$ \\
\end{tabular}} & \multicolumn{3}{|c|}{ ganchos de $45^{\circ}$} & \multicolumn{2}{|c|}{ ganchos de $180^{\circ}$} & \multirow{2}{*}{$\left.h^{\prime}\right|_{b^{\prime}} ^{\mid}$} \\
\hline & & $h^{\prime}$ & $\left.h^{\prime}\right|_{b^{\prime}}$ & $h^{\prime}$ & $\left.h^{\prime}\right|_{b^{\prime}} ^{\Gamma}$ & $h^{\prime}$ & \\
\hline $\begin{array}{c}\text { fórmulas } \\
\text { de } \Delta C \text { para } \\
r_{\text {min }}=1,5 \varnothing\end{array}$ & $5 \pi \varnothing$ & $(6 \pi-10) \varnothing$ & $(5 \pi-5) \varnothing$ & $(3 \pi+5) \varnothing$ & $(6 \pi-5) \varnothing$ & $(4 \pi \uparrow+5) \varnothing$ & $(2 \pi-10) \varnothing$ \\
\hline$\varnothing 5$ & 8 & 4 & 5 & 7 & 7 & 9 & -2 \\
\hline$\varnothing 6,3$ & 10 & 6 & 7 & 9 & 9 & 11 & -2 \\
\hline$\varnothing 8$ & 13 & 7 & 9 & 12 & 11 & 14 & -3 \\
\hline$\varnothing 10$ & 16 & 9 & 11 & 14 & 14 & 18 & -4 \\
\hline
\end{tabular}

TABELA B.3: Valores de $\boldsymbol{\Delta C}(\mathrm{cm})$ para BARRAS

\begin{tabular}{|c|c|c|c|c|c|c|c|c|c|c|}
\hline \multirow{3}{*}{ CA-50 } & \multicolumn{2}{|c|}{ ganchos de $90^{\circ}$} & \multicolumn{4}{|c|}{ ganchos de $45^{\circ}$} & \multicolumn{2}{|c|}{ ganchos de $180^{\circ}$} & \multicolumn{2}{|c|}{ sem ganchos } \\
\hline & 8 & $\therefore$ & 0 & 0 & $\therefore$ & $\therefore$ & & . & 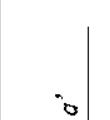 & $\therefore$ \\
\hline & & & & & $\therefore$ & $\therefore$ & & & $\therefore$ & is \\
\hline $\begin{array}{c}\text { fórmulas } \\
\text { de } \Delta C \text { para } \\
r_{\text {min }}=2,5 \varnothing\end{array}$ & $5^{x^{x^{2+x^{6}}}}$ & (3) & & 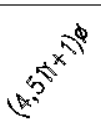 & $50^{\circ}$ & 5 & (5) & $60^{33^{9}}$ & $5^{x^{9}}$ & (s) \\
\hline$\varnothing 8$ & 7 & 15 & 6 & 12 & 4 & 8 & 6 & 13 & -2 & -4 \\
\hline$\varnothing 10$ & 9 & 18 & 8 & 15 & 5 & 11 & 8 & 16 & -2 & -5 \\
\hline$\varnothing 12,5$ & 12 & 23 & 9 & 19 & 7 & 13 & 10 & 20 & -3 & -6 \\
\hline$\varnothing 16$ & 15 & 29 & 12 & 24 & 8 & 17 & 13 & 25 & -4 & -7 \\
\hline $\begin{array}{c}\text { fórmulas } \\
\text { de } \Delta C \text { para } \\
r_{\text {min }}=4 \varnothing\end{array}$ & $2^{3^{x^{3}}}$ & $55^{30^{60^{6}}}$ & $3^{5}$ & & & 5 & $5^{33^{3}}$ & 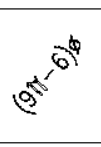 & $2^{x^{10^{9}}}$ & 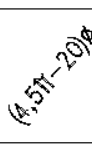 \\
\hline$\varnothing 20$ & 20 & 40 & 19 & 38 & 13 & 27 & 22 & 45 & -6 & -12 \\
\hline$\varnothing 25$ & 25 & 50 & 24 & 48 & 17 & 33 & 28 & 56 & -7 & -15 \\
\hline
\end{tabular}


TABELA B.4: Valores de $r_{\min }, \mathbf{p}_{\alpha}, \mathbf{C}_{\boldsymbol{\alpha}}$ e $\boldsymbol{\Delta}(\mathrm{em} \mathrm{cm})$ para DOBRAR ESTRIBOS

\begin{tabular}{|c|c|c|c|c|c|c|c|}
\hline \multirow{2}{*}{$\begin{array}{c}\text { CA-50 } \\
\text { ou } \\
\text { CA-60 }\end{array}$} & \multirow{2}{*}{\begin{tabular}{|c|} 
RAIO DE \\
DOBRAMENTO \\
$r_{\text {min }}=\frac{d}{2}$ \\
\end{tabular}} & \multicolumn{2}{|c|}{ PONTA RETA $p_{\alpha}$} & \multicolumn{3}{|c|}{ CURVA $\mathrm{C}_{\alpha}$} & \multirow{2}{*}{$\frac{\text { DESCONTO }}{\Delta}$} \\
\hline & & $P_{90^{\circ}}$ & $P_{45^{\circ} \text { e } 180^{\circ}}$ & $C_{90^{\circ}}$ & $C_{45^{\circ}}$ & $C_{180^{\circ}}$ & \\
\hline$f(\varnothing)$ & $1,5 \varnothing$ & $10 \varnothing$ & $5 \varnothing$ & $\pi \varnothing$ & $1,5 \pi \varnothing$ & $2 \pi \varnothing$ & $2,5 \varnothing$ \\
\hline$\varnothing 5$ & 0,75 & 5 & 2,5 & 1,6 & 2,4 & 3,1 & 1,3 \\
\hline$\varnothing 6,3$ & 0,95 & 6,3 & 3,2 & 2,0 & 3,0 & 4,0 & 1,6 \\
\hline$\varnothing 8$ & 1,2 & 8 & 4 & 2,5 & 3,8 & 5,0 & 2,0 \\
\hline$\varnothing 10$ & 1,5 & 10 & 5 & 3,1 & 4,7 & 6,3 & 2,5 \\
\hline
\end{tabular}

a) Fórmulas dos gabaritos para estribos retangulares com ganchos de $90^{\circ}, 45^{\circ}$ e $180^{\circ}$

$$
\begin{aligned}
& g_{d} a b g_{a}=p_{a}+C_{a} \\
& g_{d} a b b^{\prime}=b^{\prime}-\Delta+C_{90^{\circ}} \\
& g_{e} a b\left(h^{\prime}+b^{\prime}\right)=h^{\prime}+b^{\prime}-3 \Delta+C_{90^{\circ}} \\
& g_{e} a b h^{\prime}=h^{\prime}-\Delta
\end{aligned}
$$

c) Estribo dobrado

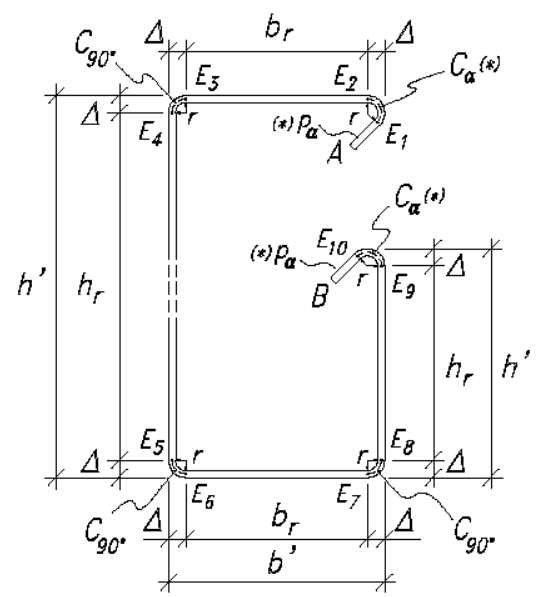

b) Seqüência dos dobramentos

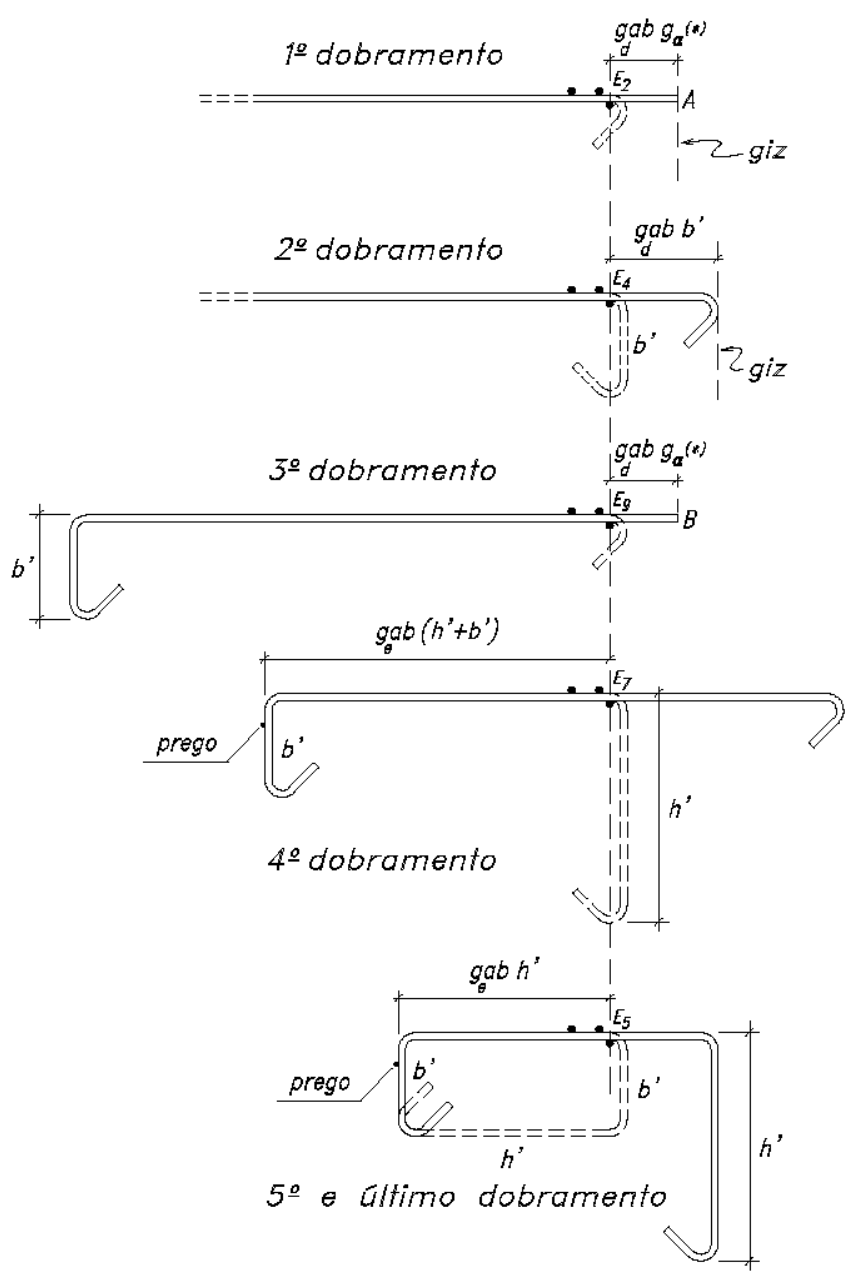

(*) Neste exemplo, $p_{\alpha}=p_{45^{\circ}}$ e $C_{\alpha}=C_{45^{\circ}}$. 
TABELA B.5: Valores de $\mathbf{r}_{\mathbf{m}^{\prime} n}, \mathbf{p}_{\boldsymbol{\alpha}}, \mathbf{C}_{\boldsymbol{\alpha}}$ e $\Delta$ (em cm) para DOBRAR BARRAS

\begin{tabular}{|c|c|c|c|c|c|c|c|c|}
\hline \multirow{2}{*}{ CA-50 } & \multirow{2}{*}{\begin{tabular}{|c} 
RAIO DE \\
DOBRAMENTO \\
$r_{\text {mín }}=\frac{d}{2}$
\end{tabular}} & \multicolumn{3}{|c|}{ PONTA RETA $p_{\alpha}$} & \multicolumn{3}{|c|}{ CURVA $C_{\alpha}$} & \multirow{2}{*}{$\frac{\text { DESCONTO }}{\Delta}$} \\
\hline & & $P_{90^{\circ}}$ & $P_{45^{\circ}}$ & $P_{180^{*}}$ & $C_{90^{\circ}}$ & $C_{45^{\circ}}$ & $C_{180^{\circ}}$ & \\
\hline$f(\varnothing)$ & $2,5 \varnothing$ & $8 \varnothing$ & 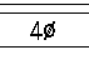 & $2 \varnothing$ & $1,5 \pi \rrbracket$ & $2,25 \pi \varnothing$ & $3 \pi \varnothing$ & $3,5 \varnothing$ \\
\hline$\varnothing 8$ & 2 & 6,4 & 3,2 & 1,6 & 3,8 & 5,7 & 7,5 & 2,8 \\
\hline$\varnothing 10$ & 2,5 & 8 & 4 & 2 & 4,7 & 7,1 & 9,4 & 3,5 \\
\hline$\varnothing 12,5$ & 3,1 & 10 & 5 & 2,5 & 5,9 & 8,8 & 11,7 & 4,4 \\
\hline$\varnothing 16$ & 4 & 12,8 & 6,4 & 3,2 & 7,5 & 11,3 & 15,1 & 5,6 \\
\hline$f(\phi)$ & $4 \phi$ & $8 \varnothing$ & $4 \varnothing$ & $2 \not x$ & $2,25 \pi \nsim$ & $3,375 \pi \phi$ & $4,5 \pi 6$ & $5 \varnothing$ \\
\hline$\varnothing 20$ & 8 & 16 & 8 & 4 & 14,1 & 21,2 & 28,3 & 31,4 \\
\hline$\varnothing 25$ & 10 & 20 & 10 & 5 & 17,7 & 26,5 & 35,3 & 39,3 \\
\hline
\end{tabular}

a) Aspectos importantes de um dobramento

- Definir em quantas etapas cada curva deve ser dobrada, marcando na bancada, se necessário, os gabaritos radiais $\left(90^{\circ}, 45^{\circ}, 30^{\circ}\right.$, etc.);

- Escolher a melhor seqüência para os dobramentos das curvas;

- A chave é sempre colocada $\frac{C_{a}}{a}$ a direita do pino de dobramento, sendo n o námero de etapas em que se dobra uma curva.

b) Fórmulas dos gabaritos para os dobramentos de barras

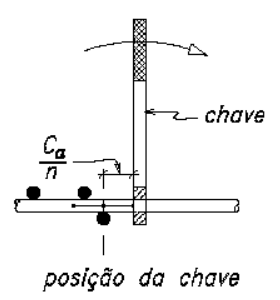

$b_{i}$-Com os dois trechos retos grandes

- Com dobramento em uma só etapa:

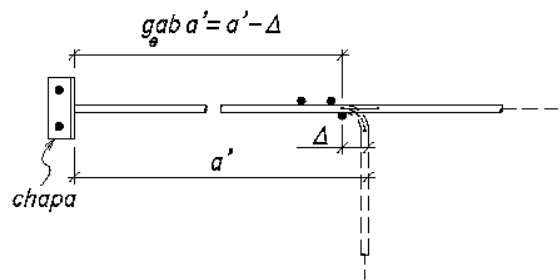

- Com dobramento em $n$ etapas:

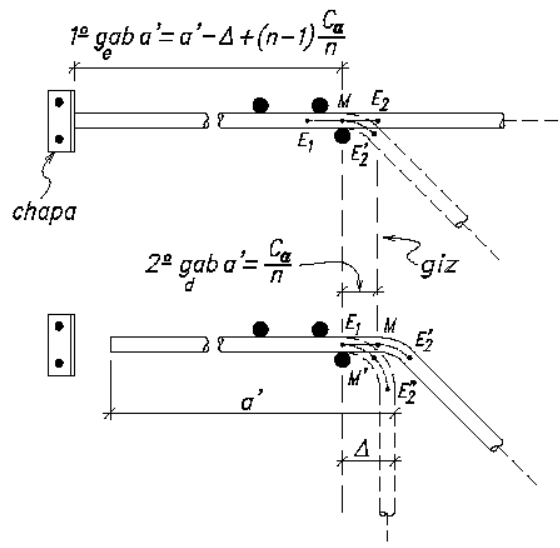

$b_{2}$ - Com um trecho reto pequeno ou com gancho

- Com dobramento em uma só etapa:

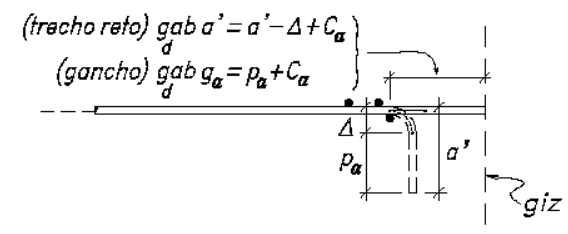

- Com dobramento em n etopas:

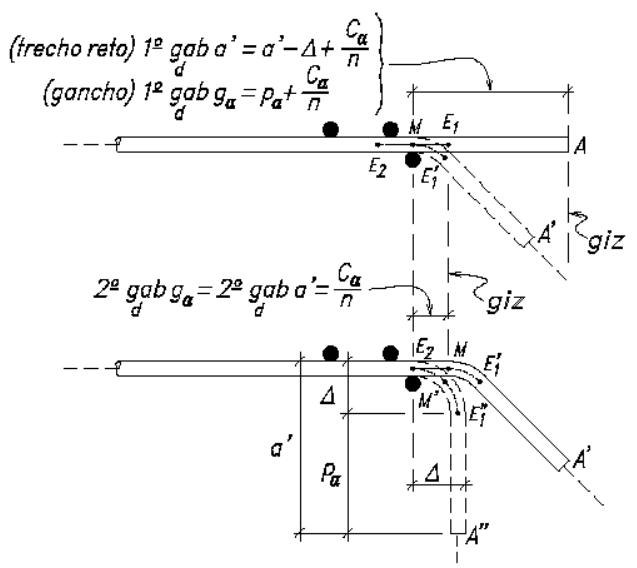




\section{REFERÊNCIAS BIBLIOGRÁFICAS}

ASSOCIAÇÃO BRASILEIRA DE NORMAS TÉCNICAS (1987). NBR 6123 Forças devidas ao vento em edificações. Rio de Janeiro.

ASSOCIAÇÃO BRASILEIRA DE NORMAS TÉCNICAS (1978). NBR 6122 Projeto e execução de fundações. Rio de Janeiro.

ASSOCIAÇÃO BRASILEIRA DE NORMAS TÉCNICAS (1978). NBR 6118 -

Projeto e execução de obras de concreto armado. Rio de Janeiro.

ASSOCIAÇÃO BRASILEIRA DE NORMAS TÉCNICAS (1983). NBR 8681 Ações e segurança nas estruturas. Rio de Janeiro.

ASSOCIAÇÃO BRASILEIRA DE NORMAS TÉCNICAS (1990). NBR 12190 -

Seleção da impermeabilização. Rio de Janeiro.

BAIKOV, V. N. et al. (1978). Reinforced Concrete Structures. Moscow. Mir Publishers.

BAREŠ, R. (1970). Tablas para el calculo de placas y vigas pared. Barcelona. Gustavo Gili.

BOWLES, J. E. (1982). Foundation Analysis and Design. Tokyo. McGraw-Hill Kogakusha.

BURMAN, I. (1991). Fissuração no Concreto Armado: Natureza do Fenômeno e sua Interferência no Comportamento e Durabilidade das Estruturas. São Paulo. Dissertação (mestrado) - Escola Politécnica, Universidade de São Paulo.

CARMONA FILHO, A.; HELENE, P.R.L. (1986). Fissuração das Peças de Concreto Armado e Corrosão das Armaduras. In: SEMINÁRIO NACIONAL DE CORROSÃO NA CONSTRUÇÃO CIVIL, 2., Rio de Janeiro, set. 1986. Anais. Rio de Janeiro, ABRACO. p.172-95.

FRANZ, G. (1971). Tratado del Hormigón Armado. Barcelona. Gustavo Gili. $2 \mathrm{v}$. 
FUSCO, P. B. (1995). Técnica de armar as estruturas de concreto. São Paulo. Pini.

GUERRIN, A.; LAVAUR, R.C. Tratado de concreto armado. São Paulo. Hemus. v.5.

HANAI, J.B. (1977). Reservatórios com parede ondulada. São Carlos. 250 p. Dissertação (mestrado) - Escola de Engenharia de São Carlos, Universidade de São Paulo.

LEONHARDT, F.; MÖNNING, E. (1978). Construções de concreto. Rio de Janeiro. Interciência. v.2 e 3.

MACSA. - MALLAS DE ACERO PARA LA CONSTRUCCIÓN, S.A. (1969). Muros de apoyo y sostenimiento. Madrid, n.6, 50p.

MONTOYA, P.J.; MESEGUER, A.G.; CABRE, F.M. (1976). Hormigón Armado. Barcelona. Gustavo Gili. v.1.

NAVFAC DM-7 Design Manual (1971). Soil mechanics, foudations and earth structures.

NILSON, I.H.E.; LOSBERG, A. ( ） Reinforced Concrete Corners and Joints Subjected to Bending Moment. Journal of the Structural Division.

OLIVEIRA, P.S.F. (1991). Proteção e Manutenção das Estruturas de Concreto. Engenharia, n.485, p.11-26, nov. dez.

PARK, R.; PAULAY, T. (1975) Reinforced Concrete Structures. New York: John Wiley \& Sons. Cap. 13.

TSCHEBOTARIOFF, G.P. (1973). Fundations, Retaining and Earth Structures. New York. McGraw-Hill Book Company.

VAN LANGENDONCK, T. H. M. (1959). Cálculo de Concreto Armado. ABCP. 3.ed. Rio de Janeiro, Editora Científica. v.1, §95, p.179, v.2, §212, p.7-17.

WÖELFER, K.H. (1969). Vigas flotantes en medio elástico. Barcelona. Gustavo Gili. 